\title{
Site ${\mathrm{M} 0028^{1}}^{1}$
}

\author{
Expedition 313 Scientists $^{2}$
}

\section{Chapter contents}

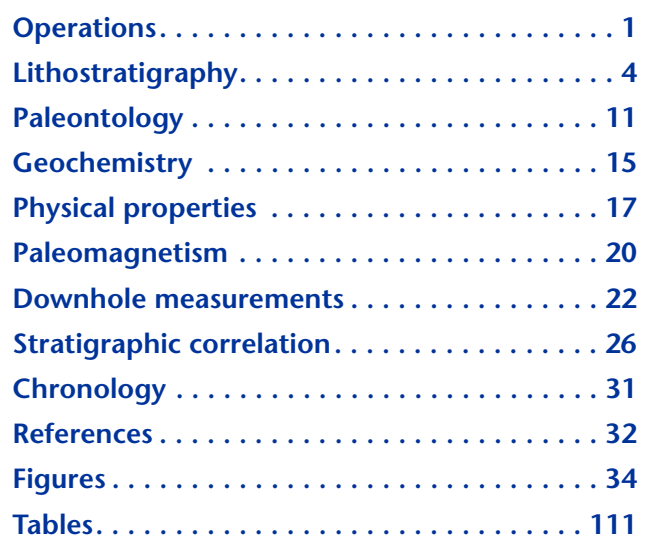

${ }^{1}$ Expedition 313 Scientists, 2010. Site M0028. In Mountain, G., Proust, J.-N., McInroy, D., Cotterill, C., and the Expedition 313 Scientists, Proc. IODP, 313: Tokyo (Integrated Ocean Drilling Program Management International, Inc.). doi:10.2204/iodp.proc.313.104.2010 'Expedition 313 Scientists' addresses.

\section{Operations}

\section{Transit to Hole M0028A}

Preparations for transit to Integrated Ocean Drilling Program (IODP) Hole M0028A commenced at $2100 \mathrm{~h}$ Universal Time Coordinated (UTC) on 22 May 2009. The jack-down procedure began at $2315 \mathrm{~h}$, and the $L / B$ Kayd moved off IODP Hole M0027A at $2335 \mathrm{~h}$, arriving at Hole M0028A at $0100 \mathrm{~h}$ on 23 May. The legs were lowered to the seafloor by $0120 \mathrm{~h}$, when the preloading procedure began. The drilling floor was opened up to operations personnel at $1100 \mathrm{~h}$ to begin setting up generators, powering up containers, and preparing the drilling floor.

\section{Hole M0028A}

The casing plan for Hole M0028A was to run the casing as deep in the hole as possible. The casing operation began after midday and continued overnight (Table T1). Progress was very slow because of the ground conditions. Just before $0600 \mathrm{~h}$ on 24 May 2009, the casing twisted off at the crossover sub 1-2 $\mathrm{m}$ above the seabed. A remotely operated vehicle (ROV) inspection confirmed that casing was protruding from the seabed and lengths of casing pipe were lying on the seabed, which would require a salvage operation to remove.

The decision was made to try to restart the hole at the same location. The new casing string was prepared and run into the seabed, and, rather than case to a great depth, it was decided to run in open hole using the PQ string to the target depth of $215 \mathrm{~m}$ drilling depth below seafloor (DSF) and then continuously core the middle and lower sections of the hole to $750 \mathrm{~m} \mathrm{DSF}$, as this was the primary objective. By the end of 24 May, $80 \mathrm{~m}$ had been drilled with the noncoring inner barrel inserted.

At $0030 \mathrm{~h}$ on 25 May, recovery of the noncoring barrel (to flush the pipe) began. However, the drill pipe became stuck at $102 \mathrm{~m}$ DSF. The jam was cleared by $0830 \mathrm{~h}$, and open-hole drilling resumed, reaching $157 \mathrm{~m}$ DSF by $1450 \mathrm{~h}$. Drilling stopped at this point to lower the casing further into the seabed using the $L / B$ Kayd before restarting. Just before $1800 \mathrm{~h}$, a clay formation was encountered at $178 \mathrm{~m}$ DSF. The core barrel was inserted, but the drill pipe was sticking, so the base of the borehole was reamed out. This proved unsuccessful. Sticking points had been encountered higher up in the hole (probably due to swelling clays), so a 
much more substantial reaming operation began in order to condition the hole before the start of continuous coring operations. The pipe was tripped back to $98 \mathrm{~m} \mathrm{DSF}$, and a mud mix that would help inhibit the swelling clays was pumped into the hole.

The reaming operation continued overnight and for most of the following morning. The hole was openhole drilled to $220 \mathrm{~m}$ DSF by $1230 \mathrm{~h}$ on 26 May, and coring began using the standard rotary corer (ALN) drill string. Backpressure was encountered during coring on the first and second runs. After that, backpressure diminished. A zone of high backpressure was encountered in Hole M0027A at a similar depth interval. Coring and reaming continued until midnight, with core recovery $100 \%$ or greater on all runs, reaching $246 \mathrm{~m}$ DSF. Overnight, core recovery became more variable as sandy formations were encountered, and there were problems with the drill pipe sticking, which required more hole conditioning. At $0820 \mathrm{~h}$ on 27 May at $264 \mathrm{~m}$ DSF, the core barrel did not latch in when lowered. It could not be retrieved, and there was no flush. The only solution was to trip the pipe and recover the barrel. The pipe was tripped by $1330 \mathrm{~h}$, and the bottom of the bottom-hole assembly (BHA) was found to be blocked with sand. As the drill pipe had been tripped, this was an opportunity to try to deepen the casing beneath the seabed to improve its stability. The casing operation continued until midnight.

On 28 May, casing continued to be run, interrupted for a few hours by mechanical problems with the drilling rig. An ROV inspection at $0900 \mathrm{~h}$ showed that the casing had entered the seabed close to the previously abandoned casing and clear of any casing pipe debris. The operation was completed at $1945 \mathrm{~h}$, by which time the foot of the casing was at $22.39 \mathrm{~m}$ DSF and occupying the hole from which the PQ pipe and casing had been previously tripped. The operation to lower the PQ drill pipe back to $264 \mathrm{~m}$ DSF and to clean and ream the hole continued overnight and was completed by $1945 \mathrm{~h}$ on 29 May.

The first cores of this new run were very sandy with poor recovery. There were also problems getting the core barrel to latch in because of sand entering the BHA. This required removal of some pipes to raise the bit from the bottom of the hole and pumping mud to clear the BHA. Once flushed clear, the core barrel was lowered and latched in, and then the drill pipe was lowered to the base of the hole to begin coring again at $2310 \mathrm{~h}$. Backpressure due to artesian water was also noted in this zone.

By midnight on 29 May, the base of the hole had advanced to $270 \mathrm{~m}$ DSF. Coring continued throughout 30 May with the ALN core barrel, and by midnight, the hole had advanced to $317.62 \mathrm{~m}$ DSF. There were some problems with recovery and blocked core barrels due mainly to alternating beds of lithified sandstones and unlithified silty sands and clays. Zones of high backpressure were also encountered at 274 and $305 \mathrm{~m}$ DSF, but there was no evidence for gas being the cause.

From $\sim 0800 \mathrm{~h}$ on 31 May, recovery dropped significantly as a coarse, sandy formation was encountered. By $1200 \mathrm{~h}$ the bottom of the hole had advanced to $339 \mathrm{~m}$ DSF. At this time the drill pipe (probably the BHA) got stuck in the hole following a cave-in. After some effort, the drill pipe was freed, but it was apparent that there was a problem with the bit on the BHA. There was little further penetration, and on retrieval, the inner barrel showed signs of damage and scoring. The drill pipe was tripped, and the BHA was on deck at $1740 \mathrm{~h}$. The bit and reaming shell were missing, having probably been sheared off while freeing the drill pipe. Rather than attempt to restart drilling immediately with a new BHA, it was decided to fish for the missing parts, as they could impede further progress in the hole. The Bowen spear was made ready, and the fishing operation began at 2020 h.

The fishing operation proceeded very slowly throughout the night. At $0600 \mathrm{~h}$ on 1 June, the tool was at $198 \mathrm{~m}$ DSF and was encountering bridges that were difficult to wash away. Around $1200 \mathrm{~h}$, the tool encountered a zone of swelling clays that was known to extend to $240 \mathrm{~m}$ DSF. Progress was halted by the clays, torque on the string was very high, and the drill string was not advancing. At $1230 \mathrm{~h}$ the decision was made to abandon the fishing operation, as there was little chance of further progress downhole and there was danger that the tool would also be lost. The tool was tripped and was back on deck at $1430 \mathrm{~h}$. A new BHA was prepared with a diamond impregnated drill bit, capable of drilling through or pushing aside the missing bit and reaming shell. By midnight on 1 June, washing and reaming down had advanced the drill string to $143 \mathrm{~m}$ DSF, and by midnight on 2 June, it was at $326.77 \mathrm{~m}$ DSF.

Coring started at 0215 on 3 June and continued until midnight. The cored material was very variable for several core runs, from solid sandstone to running sand, with thin clay layers. The loose sand caused caving and slowed the progress for $\sim 15 \mathrm{~m}$, with several cores incorporating infill.

On 4 June, coring from 360 m DSF became easier, although core recovery was variable. Small cavings occasionally slowed progress through alternating soft and firm formations. From $1750 \mathrm{~h}$ onward, sandy formations forced shorter core runs and caving sands required additional reaming. 
At $\sim 0100 \mathrm{~h}$ on 5 June, a bridge formed above the BHA that caused the drill string to become stuck. Several hours were spent trying to pull the BHA past the bridge and circulate mud. This was unsuccessful, and the decision was made at $0900 \mathrm{~h}$ to continue coring using the HQ drill string through the PQ drill string, effectively using the PQ string as casing set at $404 \mathrm{~m}$ DSF. Before the HQ string was run into the hole, a through-pipe gamma ray wireline log was taken from $390 \mathrm{~m}$ DSF to the surface, which was completed by $1530 \mathrm{~h}$. A total of $10 \mathrm{~m}$ of infill material in the PQ pipe had to be reamed out before HQ coring could begin.

At $0330 \mathrm{~h}$ on 6 June, coring using the HQ Tight Tolerance (HQTT) core barrel commenced. After four core runs, a hole collapse due to fine caving sands risked the HQ string becoming stuck, so the HQ string was pulled back into the PQ casing (0830$1320 \mathrm{~h})$. Attempts were then made to ream back down, but the hole pressurized and four additional pipes had to be removed. A second attempt at reaming back down was successful, and coring started again at $1620 \mathrm{~h}$. However, on the fifth HQTT core run, the drill string became stuck again for an hour. Amendments were subsequently made to the mud mixture.

The first few hours of 7 June were spent circulating and advancing the HQ string to the base of the PQ casing. While advancing the HQ string, the driller noted little penetration and thought there was an obstruction. The HQ string was pulled back to the surface and the BHA checked. The bit was still attached but was severely worn; it was replaced with a similar but harder matrix-impregnated bit. Upon running the HQ string down the hole, $67 \mathrm{~m}$ of sand was encountered inside the PQ string. The remainder of the day and the beginning of Monday, 8 June, was spent reaming out this material. A core of infill was taken from material believed to represent $\sim 403.79$ $411.86 \mathrm{~m}$ DSF.

At $0745 \mathrm{~h}$ on 8 June, normal coring commenced, with nine good cores collected. The improvement in coring progress continued into Tuesday, 9 June. Coring was suspended from 1055 to $1225 \mathrm{~h}$ because of an electrical storm.

Coring continued to progress well until $1200 \mathrm{~h}$ on 10 June, with eight core runs and $18.5 \mathrm{~m}$ penetration, reaching 533.85 m DSF. However, a decreasing penetration rate caused concern, with the view that the inside cutting diameter of the core bit had worn out and thus the bit was cutting an oversized core. It was decided to pull the HQ string to check the bit. This decision coincided with the detection of $\mathrm{H}_{2} \mathrm{~S}$ in the last core run returned to the deck $(\sim 1100 \mathrm{~h})$. Precautions were taken, including venting the core prior to curation, and the borehole was monitored. The HQ string was pulled and the bit inspected. Although the bit showed considerable wear, it still did not account for the poor penetration. At $1725 \mathrm{~h}$, the HQ string was run back into the hole with a polycrystalline diamond (PCD) bit attached. The hole appeared to be stable, and $\sim 1.2 \mathrm{~m}$ of cavings was cleared. After reaming, the core barrel was retrieved for an $\mathrm{H}_{2} \mathrm{~S}$ test (to $2400 \mathrm{~h}$ ).

From 0035 to $0515 \mathrm{~h}$ on 11 June, there was a smell of $\mathrm{H}_{2} \mathrm{~S}$ on the drill floor, although nothing registered on the gas monitors. The first core of the day smelled of $\mathrm{H}_{2} \mathrm{~S}$ and registered $4.3 \mathrm{ppm}$ on the gas monitor, which soon dissipated. Drilling continued with regular checks for $\mathrm{H}_{2} \mathrm{~S}$ returning with the mud. The second and third cores also smelled of $\mathrm{H}_{2} \mathrm{~S}$ but did not register on the gas monitor. Several more core runs were made, resulting in near $100 \%$ recovery, but failed to penetrate the full length of the $3 \mathrm{~m}$ core run because of a harder lithology. As the lithology changed to looser material, full core runs were recovered.

An electrical storm briefly halted operations from 0255 to $0330 \mathrm{~h}$ on 12 June. Penetration rates slowed in comparison to previous days, but with no discernible change in the lithology.

Early on 13 June, the drill string was pulled, and it was found that the outer cutting edge of the bit had worn away. At $0555 \mathrm{~h}$, the HQ string was run back down with a new bit and stabilizer ring. At $326 \mathrm{~m}$ DSF, very high mud backpressure indicated a blocked bit. It was not possible to latch the core barrel with the overshot. A second HQ trip was made, and sand was found behind the core barrel, blocking its release. On running the HQ string back in, it was found that the PQ string had filled up with sand to $250 \mathrm{~m}$ DSF, and flushing was required. At $\sim 439 \mathrm{~m}$ DSF, the drill string easily dropped into the hole.

The HQ string reached the base of the hole at $0530 \mathrm{~h}$ on 14 June, and coring recommenced with the HQTT barrel. Core recovery varied throughout the day but improved slightly on 15 June, when coring entered stiff, swelling clays.

At $0225 \mathrm{~h}$ on 16 June, the end of coring in Hole M0028A was declared (base of last core; $669 \mathrm{~m} \mathrm{DSF).}$ At $0240 \mathrm{~h}$, the final core was curated. The last 10 double rods $(61 \mathrm{~m})$ were lifted to ream out the bottom of the hole in readiness for logging. The wireline and vertical seismic profile (VSP) logging winches were set up on either side of the drill rig. At $1140 \mathrm{~h}$, through-pipe spectral gamma ray logging began and was completed by $1650 \mathrm{~h}$. A marine mammal watch began at $1730 \mathrm{~h}$ prior to the through-pipe VSP logging commencing at $1800 \mathrm{~h}$. 
The VSP tool was returned to the deck by $0030 \mathrm{~h}$ on 17 June. At $0130 \mathrm{~h}$, mud circulation began, and the HQ string pulled to a clay layer $\sim 30 \mathrm{~m}$ below the PQ string at $425 \mathrm{~m}$ DSF, keeping it below the running sand that caused earlier coring and reaming problems. Between 0450 and $2100 \mathrm{~h}$, wireline logging and VSP of the lower open-hole interval from 669 to $425 \mathrm{~m}$ DSF was conducted with no problems. The air guns were left in the water, test firing until the next VSP run (through PQ pipe), which started at $\sim 0200 \mathrm{~h}$ on 18 June. The marine mammal observation continued throughout this period.

At midnight on 18 June, the HQ string was pulled slowly out of Hole M0028A. The cautious approach was to prevent the hole from backfilling with sand, and this was confirmed when logging tools passed safely to the base of the PQ string. After successfully completing the VSP run at $0805 \mathrm{~h}$, resistivity and acoustic sondes were run in the open-hole interval directly below the PQ string (396-425 m DSF). Various attempts were then made to lift the PQ string, which was found to be stuck fast and likely to be held higher up in the hole. Attempts were made to cut the PQ pipe at 387 and $351 \mathrm{~m}$ DSF using a cutting tool, which finally succeeded at $286 \mathrm{~m}$ DSF before the HQ string and cutter also became stuck.

The HQ rods were worked through the night into 19 June in an effort to free the string. Meanwhile, a spare cutter was ordered from the shore. Other methods to free the HQ string were explored: a heavy tool was manufactured that was intended to break the tool joint connecting the cutter to the string, and a pinch bar was attached to the wireline and repeatedly hammered, through freefall, onto the top of the cutter. Neither method worked, although an increase in water flow, partial rotation, and slow pull-up of the HQ pipe was achieved. After further working of the rods, the HQ pipe was finally released and tripped with the cutter and box end missing.

While waiting for the spare cutter to arrive, a Bowen spear was deployed to try to pull the PQ. This was unsuccessful. Throughout the rest of the day, various attempts were made to free the PQ. Backing off was also attempted, but only resulted in disconnecting close to the drill floor and not below the seabed. The PQ rods continued to be worked overnight into 20 June. At $0600 \mathrm{~h}$, the spare cutter arrived, and shortly after $0900 \mathrm{~h}$, the PQ had been successfully cut just inside the casing and the HQ string and cutter were returned to deck. By $0930 \mathrm{~h}$, what was left of the PQ string was recovered onto deck.

To free the stuck casing, the $65 \%$ inch casing cutter was modified by removing the centralizing ball bearings so that it was able to fit inside the buttress casing. The casing was successfully cut, allowing the team to recover the casing and rig down in anticipation of sailing to the next hole.

\section{Lithostratigraphy}

Figure F1 provides a key to colors and symbols used for figures in this section.

Hole M0028A was drilled in the shallow shelf to sample the thick early Miocene succession, as well as the late and middle Miocene. Seven lithostratigraphic units are defined (Table T2). Figure F2 illustrates the position of the lithostratigraphic units on the seismic section.

The oldest stratigraphic unit in Hole M0028A (Unit VII; 668.66-662.98 meters below seafloor [mbsf]; ?Aquitanian) comprises dark brown siltstone with thin-walled articulated shells deposited in a deep offshore environment. Unit VI (622.98-611.19 mbsf; Aquitanian to early Burdigalian) is a pale brown clayey silt with intercalated very fine and fine sand beds deposited in a river-dominated offshore (prodelta) environment. The contact with the overlying Unit V (611.19-525.52 mbsf; middle early Miocene [early-middle Burdigalian]) is abrupt and bioturbated. Unit V is divided into three coarse-grained subunits that are all interpreted as deposits of sediment gravity flows supplied from remobilization of updip sediment. Subunits VB and VC have characteristics of debrites, whereas Subunit VA shows more evidence for turbidites. The poorly sorted coarse sediments of Subunit VA are interpreted as deposits from high-concentration flows of coarse sediment deposited at the toe of a degraded clinotherm. Unit IV (525.52-512.29 mbsf; middle early Miocene [middle Burdigalian]) consists of sediment gravity flows, possibly from river flood events, deposited in an offshore environment. Unit III (512.29-335.37 mbsf; middle-late Burdigalian) is divided into four subunits that, overall, mark the shallowing uphole and outbuilding of a storm-dominated and river-influenced delta. Unit II (335.37-223.33 mbsf; middle Miocene) is also divided into four subunits. Subunit IID is poorly sorted and dominantly coarse grained, with a mix of mud, coarse sand, and gravel that is low in mica and organics and deficient in silt to medium sand grain sizes and which may have been deposited at the clinoform rollover. Subunits IIC-IIA represent a series of transgressive and shoreface to offshore and regressive offshore to shoreface sedimentary cycles. Unit I was not cored at Site M0028A.

Figure F3 summarizes Units I-VII, and their constituent subunits are described in more detail below. Lithologic descriptions are given according to the order of core numbering, from the top to the base of each lithostratigraphic unit or subunit, whereas interpre- 
tations are given in chronologic order, from the base of each unit or subunit uphole. Table T3 describes thin sections that aided in core descriptions.

\section{Unit I}

No core was recovered in this hole, but this unit is correlated with Unit I in Holes M0027A and M0029A based on similar well log character and seismic facies.

\section{Unit II}

Interval: 313-M0028A-2R-1, $0 \mathrm{~cm}$, to 49R-2, $58 \mathrm{~cm}$ Depth: 223.33-335.37 mbsf

Age: middle Miocene (Langhian)

\section{Subunit IIA}

Interval: $313-\mathrm{M} 0028 \mathrm{~A}-2 \mathrm{R}-1,0 \mathrm{~cm}$, to $12 \mathrm{R}-1,40 \mathrm{~cm}$ Depth: 223.33-254.23 mbsf

Sections 313-M0028A-2R-1 through 8R-2 (223.33242.13 mbsf) comprise gray-yellow-brown colorbanded clay, with Chondrites and pyritic and silty laminae in the upper $15 \mathrm{~m}$ (e.g., Section 3R-3, $18 \mathrm{~cm}$; $229.38 \mathrm{mbsf}$ ). Small-scale (centimeters) folds and faults indicate deformation of cohesive sediment in the lower $4 \mathrm{~m}$ of the clay. An abrupt boundary is observed between clay and underlying bioturbated fine sand containing moderately sorted medium sand with glauconite and thick-walled shells (interval 313-M0028A-8R-2, 100-103 cm; 242.12-242.15 mbsf). Bored cemented sand nodules with glauconitized rims (intervals 313-M0028A-9R-1, 48-53 cm [243.16-243.21 mbsf] and 9R-1, 97-110 cm [243.65$243.78 \mathrm{mbsf}$ ) (Fig. F4) are found in poorly sorted fine and medium sand with glauconite, mica (both $2 \%$ ), and benthic foraminifers. A further abrupt burrowed boundary with poorly sorted very coarse sand above silty clay is observed in Section 313-M0028A$10 \mathrm{R}-1$ at $7 \mathrm{~cm}$ (245.80 mbsf). The coarse sand contains granules that also infill Thalassinoides down to $25 \mathrm{~cm}$ below the contact. The underlying brown silty clay is intercalated with rare beds of very fine sand with scour-based, ripple cross-laminae. Plant debris and scattered shells are common, with burrows filled with coarse sand and gravel near the base of Subunit IIA (Section 313-M0028A-12R-1, $40 \mathrm{~cm} ; 252.23$ mbsf).

\section{Interpretation}

Offshore silts with rare storm-event beds are cut by an erosion surface at 245.80 mbsf near the base of Subunit IIA. This is overlain by coarse to fine sand with bored nodules and glauconite grains, indicative of condensed deposition and subsequent erosion and exhumation. The environment of sand deposi- tion is possibly shoreface, based on siliciclastic grain size. Reworking of the top of the sand may have taken place in shoreface-offshore transition zone and offshore settings. An abrupt deepening and change to dysoxic offshore environment is marked by clay deposition. Color banding in clays is from discrete depositional events that are interpreted as low-density turbidity currents triggered by storm events. Deformation of cohesive sediment indicates a component of downslope transport, and a clastic sill near the base of the clays may relate to overpressure in underlying sands.

\section{Subunit IIB}

Interval: 313-M0028A-12R-1, $40 \mathrm{~cm}$, to $25 \mathrm{R}-1,14$ $\mathrm{cm}$

Depth: 254.23-286.92 m

The top of Subunit IIB is marked by an abrupt coarsening downhole across a surface separating clayey silt above from poorly sorted coarse sand with granules below. There is a core gap (Core 313-M0028A13R) above well to moderately sorted quartz-rich coarse sand (Section 14R-1; 254.88 mbsf) that fines downhole to medium sand (Section 16R-1; 260.98 mbsf) and then, abruptly, to micaceous silty fine sand (Section 19R-1; 268.82 mbsf). Shell fragments and plant debris are common throughout, and glauconite grains are rare. In Section 313-M0028A-20R-1, $49 \mathrm{~cm}$ (272.36 mbsf), there is an abrupt contact surface between silty sand and silty sandstone. From this level, there is a coarsening downhole to weakly graded and bioturbated gravel-rich sandstone containing complete benthic foraminifers (Section 313M0028A-21R-1; 274.52 mbsf). In Section 313M0028A-21R-2, $56 \mathrm{~cm}$ (276.58 mbsf), there is a change to glauconitic (30\%) sandstone, but the contact is not preserved in the core because of drilling disturbance. The glauconitic muddy sand and muddy sandstone is thoroughly mixed, containing mud-filled burrows, scattered pyrite grains, and rare subangular quartz granules (Fig. F5). There are no shells, but molds are present. Cores 313-M0028A23R and 24R (281.02-285.44 mbsf) are glauconite coarse sand (up to 40\%) (Fig. F6) with clay laminae and beds (e.g., interval 313-M0028A-24R-1, 67-78 $\mathrm{cm}$; 284.74-284.85 mbsf) along with indurated and cemented units.

\section{Interpretation}

The muddy glauconitic sand and glauconite sandstone at the base of Subunit IIB are interpreted as offshore deposits with glauconite grains forming in situ and a background sedimentation of clay. The presence of isolated quartz granules and pebbles remains enigmatic but implies a component of downslope 
transport. The clay in the middle of the glauconite sandstone (interval 313-M0028A-24R-1, 67-78 cm; $284.74-284.85 \mathrm{mbsf}$ ) is firm but not indurated and is bioturbated on top. It is interpreted as the deepest water facies of this glauconite-rich package. The contact with the overlying graded quartzose gravelly sandstone at $\sim 273 \mathrm{mbsf}$ is not preserved in core. However, these poorly sorted sediments containing well-preserved benthic foraminifers are interpreted as high concentration sediment gravity flow deposits (debrites) close to or within a channelized environment in a clinoform rollover position. The overlying succession fines abruptly (Section 313-M0028A-19R1; $268.82 \mathrm{mbsf}$ ) to a silty sand, which is interpreted as a shoreface-offshore transition environment. Above this, grain size coarsens uphole, which is interpreted to indicate a shallowing in the environment of deposition through a shoreface-offshore transition zone to a storm-dominated shoreface.

\section{Subunit IIC}

Interval: 313-M0028A-25R-1, $14 \mathrm{~cm}$, to 34R-2, 55 $\mathrm{cm}$

Depth: 286.92-310.53 mbsf

The top of the section is medium and fine sand with plant debris, concentrically filled burrows (?Cylindrichnus), and bivalve and gastropod (Turritella) shells and shell fragments, which are locally concentrated into layers. The succession gradually fines downhole to silty clay containing thin-walled shells and benthic foraminifers, as well as dispersed plant debris in Section 313-M0028A-34R-1 (308.47 mbsf).

\section{Interpretation}

The clay that overlies an abrupt surface (Section 313M0028A-34R-2, $55 \mathrm{~cm} ; 310.53 \mathrm{mbsf}$ ) is interpreted to indicate deepening, with coarse sediment starvation during transgression. This is itself overlain by a fining-upward package interpreted as a shoreface-offshore transition to offshore environment, with shell beds and graded sand beds indicating storm activity. The overlying succession gradually coarsens uphole from clay and silt to medium sand and is interpreted as a shallowing-upward trend from an offshore setting to a river-influenced shoreface-offshore transition zone.

\section{Subunit IID}

Interval: 313-M0028A-34R-2, $55 \mathrm{~cm}$, to 49R-2, 58 $\mathrm{cm}$

Depth: 310.53-335.37 mbsf

During coring, the drill string needed to be pulled out just before the base of Subunit IID. When reinserting the drill string, the bit deviated from the orig- inal hole, and core recovery began just above Subunit IID. As a result, most of Subunit IID was cored twice. Through sedimentary logging of both sections, it has been established that Sections 313M0028A-38R-2, $104 \mathrm{~cm}$, to 42R-1, $10 \mathrm{~cm}$, are repeated by Sections $45 \mathrm{R}-2,62 \mathrm{~cm}$, to $48 \mathrm{R}-3,40 \mathrm{~cm}$, with the rest of Core $42 \mathrm{R}$ and all of Cores $43 \mathrm{R}$ and $44 \mathrm{R}$ containing drilling slurry and cavings. Here, a synthesis description and interpretation is provided.

Below Section 313-M0028A-34R-2, 55 cm (310.53 mbsf), sediment coarsens downhole over $40 \mathrm{~cm}$ to a rugose surface in Section 34R-2, $95 \mathrm{~cm}$ (310.92 mbsf). An underlying $2.5 \mathrm{~m}$ thick package of very fine sand with common benthic foraminifers and minor glauconite grains (3\%) coarsens down to a poorly sorted medium sand with granules resting abruptly on silty clay in Section 313-M0028A-35R-2, $48 \mathrm{~cm}$ (313.50 mbsf). The succession grades down to clay with scattered benthic foraminifer and gastropod shells, which abruptly overlies a bioturbated contact (Section 313-M0028A-37R-2, $142 \mathrm{~cm} ; 320.52$ mbsf). The underlying very fine sand with silt contains concentrically filled burrows (?Cylindrichnus).

Sediments encountered in Sections 313-M0028A38R-2, $104 \mathrm{~cm}$ (overlap with Section 45R-2, $62 \mathrm{~cm}$ ), to $49 \mathrm{R}-2,58 \mathrm{~cm}$ (335.37 mbsf), are generally poorly sorted, muddy, glauconitic (up to $40 \%$ ) coarse sand with common quartz and lithic granules and pebbles. The shapes of pebbles and granules range from well rounded to angular but are commonly subangular. Common mud- and glauconite-filled burrows indicate high levels of bioturbation. Beds with weak normal grading (e.g., Section 313-M0028A-40R-2, overlap with Section 47R-2) and 1-4 cm thick gravel layers (the same one is encountered in Section 40R$1,64 \mathrm{~cm}$, and in the overlap in Section 47R-1, $78 \mathrm{~cm}$; $327.97 \mathrm{mbsf}$ ) preserve the original stratification. Section 313-M0028A-41R-1 (overlap with Section 48R1) has more bioturbated muddy units, along with rounded mud clasts that contain a bioturbated fabric (e.g., 41R-1, 69 cm; $330.51 \mathrm{mbsf}$ ) (Fig. F7). Shell molds are observed (Section 313-M0028A-47R-1; 327.19-328.71 mbsf). The number of matrix-supported granules and pebbles increases from Section 313-M0028A-48R-1, $110 \mathrm{~cm}$, at 331.34 mbsf (overlap with Section $41 \mathrm{R}-1,100 \mathrm{~cm}$ ), to $2 \%-3 \%$ to $5 \%-10 \%$ and locally $>20 \%$ of the total sediment volume in Section 48R-2, $68 \mathrm{~cm}$, at 332.42 mbsf (overlap with Section 41R-2, $70 \mathrm{~cm}$ ). Beds of subangular to subrounded gravelly sediment show weak normal grading. Granules and pebbles are dominantly quartz but include quartzite and metasedimentary clasts. The base of the succession is poorly sorted, with a mix of mud, coarse sand, and gravel. It is quartz rich (glauconite $=\sim 5 \%-10 \%$ ), with pyritized and mud-filled 
burrows (Section 313-M0028A-49R-1, 58 cm; 333.87 mbsf).

\section{Interpretation}

Subunit IID is poorly sorted and dominantly coarse grained, with a mix of mud, coarse sand, and gravel. Generally, sediment is low in mica and organic matter and deficient in silt to medium sand grain sizes compared to the surrounding stratigraphy. Overall, the succession becomes more glauconitic (up to $40 \%$ ) and increasingly stratified uphole, with highly bioturbated mud-rich units with gravel layers or weakly graded beds (0.1-0.2 m thick). Rounded clay clasts that have a bioturbated fabric are interpreted as intraclasts entrained from the substrate. The poorly sorted sand with mud and gravel, with shell molds and rip-up clasts, indicates erosion and reworking in a marine setting. The weak grading of some deposits supports waning sediment gravity flows. Possible interpretations of these deposits at the clinoform rollover include gully-fills and/or outbuilding of small deltas with steep fronts that formed during periods of lowered relative sea level. The lack of plant debris and mica and the low proportion of very fine to medium sand compared to the surrounding stratigraphy suggest that these components may have been transported downdip, with the coarser material and muds from eroded surrounding substrate preferentially retained. The extent of the drainage basin that fed the deltas/gullies is not clear. However, the source for the coarse extrabasinal material need not be tied directly to the hinterland and may have been from older deposits. The environment of deposition above Section 313M0028A-38R-2, $104 \mathrm{~cm}$ (323.21 mbsf), is interpreted to deepen abruptly to an offshore setting, which was organic poor (distal to terrigenous source) before being overlain by very fine sand interpreted as shoreface-offshore transition deposits.

\section{Unit III}

Interval: 313-M0028A-49R-2, $58 \mathrm{~cm}$, to $110 \mathrm{R}-2$, $110 \mathrm{~cm}$

Depth: 335.37-512.29 mbsf

Age: early middle to late early Miocene (early Langhian to late Burdigalian)

\section{Subunit IIIA}

Interval: 313-M0028A-49R-2, $58 \mathrm{~cm}$, to $67 \mathrm{R}-2,42$ $\mathrm{cm}$

Depth: $335.37-391.38 \mathrm{~m}$

This subunit is poorly recovered, with most cores retaining small amounts of heavily disturbed material that is water saturated. This succession is distin- guished because it is a coarse quartz sand to sandstone with glauconite.

Cores 313-M0028A-49R through 54R (335.37-352.97 mbsf) contain poorly sorted, bioturbated silty sandstone with $15 \%-20 \%$ glauconite. Shell fragments are common. In Section 313-M0028A-52R-2, $60 \mathrm{~cm}$ (350.59 mbsf), there is an apparent scoured surface. Cores 313-M0028A-54R through 57R (335.37-362.55 m) comprise moderately sorted coarse quartz sand with $\sim 2 \%$ glauconite. At the base, Cores 313M0028A-58R through 67R (365.3-391.38 mbsf) are mostly medium sand with $1 \%-2 \%$ glauconite. The cores are all highly disturbed, and primary sedimentary fabrics cannot be recognized. Core 313M0028A-67R (389.46-391.38 mbsf) is more cemented, and a strongly bioturbated fabric is evident.

\section{Interpretation}

Poor recovery prevents detailed environmental analysis. Grain size and sorting in the recovered sediment indicate either downslope reworking of a clinoform topset or a shoreface and shoreface-offshore transition setting. Seismic reflection geometries support the latter interpretation.

\section{Subunit IIIB}

Interval: 313-M0028A-67R-2, $42 \mathrm{~cm}$, to $79 \mathrm{R}-2,70$ $\mathrm{cm}$

$$
\text { Depth: 391.38-414.67 m }
$$

Subunit IIIB is characterized as being quartz sand containing little or no glauconite. The unit was poorly recovered. The top of the section (Cores 313M0028A-68R through 73R; 391.38-400.30 mbsf) consists of loose poorly sorted medium-coarse and fine sand with scattered granules. Shell hash in wellsorted medium sand is found from Core 313M0028A-73R (400.07 mbsf) downhole. The shells show evidence of strong in situ dissolution, and the resulting material mimics carbonate crust. Section 313-M0028A-74R-CC (402.48-402.61 mbsf) contains one oyster shell, which is pristine. Cores 313M0028A-76R through 78R (398.11-408.24 mbsf) are likely disturbed, as the hole was reentered and some overlapping sections exist. The cores preserve a crude fining-downward succession (supported by acoustic image logs).

\section{Interpretation}

The base of the succession (Section 313-M0028A79R-2, $70 \mathrm{~cm}$, through Core 73R; 414.67-400.07 mbsf) is a shoreface-offshore transition that coarsens uphole. The upper part of the succession (Core 313M0028A-73R through Section 67R-2; 400.07-391.38 mbsf) is interpreted as reflecting a change in the en- 
vironment from the lower to upper part of a wavedominated shoreface.

\section{Subunit IIIC}

Interval: 313-M0028A-79R-2, $70 \mathrm{~cm}$, to 98R-2, 64 $\mathrm{cm}$

Depth: 414.67-475.22 mbsf

Beginning in Core 313-M0028A-79R (412.47 mbsf), more competent and finer grained cores continue the fining-downward trend. There is also a marked increase in the amount of mica and plant debris present. Moderate bioturbation is present throughout, including simple vertical burrows. Cores 313M0028A-80R through 88R (416.32-445.80 mbsf) record fining downhole with predominantly fine to very fine sand at the top and silt common at the base (Fig. F8). Most of the cores are dominated by subparallel and subhorizontal laminations and thin beds. Core 313-M0028-80R (416.32-419.38 mbsf) picks up hints of lamination and sand beds that generally increase in frequency and thickness downhole. There are many distinctive two-part sand beds showing slight grain-size change at a lamina scale (Fig. F9). These beds have sharp bases overlain by clean quartz sand (no silt or mica); above is silty sand with subparallel low-angle lamination (Fig. F9). Some of these beds have current ripple lamination and possible symmetrical/aggradational ripples at the top. Shells and plant debris are concentrated near the tops of beds (Fig. F9). Bed tops are typically bioturbated to a range of intensity.

Cores 313-M0028A-89R through 98R (445.82-476.35 mbsf) are clay-rich silt with sand. The succession of sediments is largely monotonous from top to bottom. The lower cores have somewhat more clay-rich microlaminated beds that show a greater contrast with the intercalated fine sand beds. Burrowing is intense in sand beds but absent in the clay. Teichichnus is a recognizable burrow.

\section{Interpretation}

Subunit IIIC is interpreted to record an initial uphole fining and deepening followed by coarsening and shallowing from a river-influenced offshore to a river-influenced shoreface-offshore transition back to a river-influenced offshore environment with the change in trend around 445 mbsf. Cores 313M0028A-98R through 89R (476.35-445.82 mbsf) were deposited in an offshore marine environment. The scarcity of shells and abundance of lamination suggest bottom waters were poorly oxygenated, except during deposition of sand (Fig. F10). Sand-sized sediment is interpreted to have been delivered to the seafloor by storm-induced density or geostrophic currents in a river-influenced offshore setting.
The abundance of mica and plant debris in Cores 313-M0028A-88R through 80R (445.80-416.32 mbsf) suggests sediment supply had a strong fluvial influence. The two-part sand beds are interpreted as combined-flow storm deposits. The lower clean and slightly coarser quartz sand is interpreted as having been deposited from geostrophic (unidirectional) currents that transported sediment entrained from the coeval shoreface to deeper water. The upper sediment was locally agitated, and deposits from (orbital) currents set up by storm waves formed low-amplitude hummocks, current ripples, and late-stage symmetrical (wave) ripples before organisms could start to mix the sediment again. The succession is interpreted as having been deposited in the shorefaceoffshore transition zone in a river-influenced setting.

\section{Subunit IIID}

Interval: 313-M0028A-98R-2, $64 \mathrm{~cm}$, to 110R-2, $110 \mathrm{~cm}$

Depth: 475.22-512.29 mbsf

The top of the section (Cores 313-M0028A-99R through 100R; 476.32-482.47 mbsf) documents a minor fining-downward succession from fine sand to sandy silt. Silty very fine sand and very fine sandy silt continue downhole (Core 313-M0028A-101R to Section 105R, 32 cm; 482.42-494.94 mbsf) (Fig. F11). Interval 313-M0028A-105R-1, 32-54 cm (494.94495.16 mbsf), contains a sharp-based sand bed with a brecciated contact with fractures filled by sand (not drillers mud). Another sharp-based bed of normally graded sand is found between Section 313-M0028A105R-2, $100 \mathrm{~cm}$ (497.16 mbsf), and the base of Section 105R-2 (497.67 mbsf). Silty very fine sand and sandy silt continues in Cores 313-M0028A-106R through 108R (497.67-505.94 mbsf). There is a small amount of sand at the base of Core 313-M0028A108R (505.94-506.00 mbsf). Beginning in Core 313M0028A-109R (506.825 mbsf), bioturbated poorly sorted silty fine and medium sand contains rare bivalves, scattered pebbles, and granules. This lithology grades to fine sand with scattered pebbles and granules and plant debris down to a bioturbated contact with underlying clayey silt in Section 313M0028A-110R-2, $110 \mathrm{~cm}$ (512.29 mbsf).

\section{Interpretation}

The bioturbated poorly sorted sand with granules that lies above the well-marked surface defining the base of the subunit accumulated at the toe of a clinoform slope as sediment gravity flow deposits. Average grain size increases toward the top of Core 313M0028A-109R (506.82 mbsf). From 505.94 mbsf uphole, the succession fines, and the two prominent sand beds in Core 313-M0028A-105R (494.94-497.67 
mbsf) may represent storm deposits or wave-modified turbidites in an offshore toe-of-slope setting. The brecciated basal contact of the upper bed has evidence of hydraulic fracturing and remobilization of sandy sediment into fractures due to pore water overpressure. Cores 313-M0028A-104R and 103R (494.53-488.52 mbsf) are low in sand, shell fragments, and plant debris, indicating an offshore environment. Cores 313-M0028A-99R and 100R (477$482 \mathrm{mbsf}$ ) have interbedded bioturbated and laminated sand beds, indicating the influence of storm events and/or river flood events in what is interpreted as a river-influenced shoreface-offshore transition environment.

\section{Unit IV}

Interval: 313-M0028A-110R-2, $110 \mathrm{~cm}$, to 115R-1, $101 \mathrm{~cm}$

Depth: 512.29-525.52 mbsf

Age: middle early Miocene (middle Burdigalian)

Subunit IV is thin $(13.23 \mathrm{~m})$. The upper part of the unit is bioturbated silty clay with thin beds of sand that either coarsen or fine uphole. Plant and shell debris are concentrated in laminae. Downhole, scattered glauconite grains ( 2\%) appear first in Section 313-M0028A-112R-1, $62 \mathrm{~cm}$ (516.59 mbsf), in fine and medium sand. The proportion of glauconite increases downhole to $\sim 40 \%$ at a sharp and burrowed surface in Section 313-M0028-113R-1, 68 cm (519.70 $\mathrm{cm}$ ) (Fig. F12). Burrows are filled with glauconitic medium sand. Below this level is a return to silt and clay, with downhole increasing glauconite sand $(<50 \%)$ and quartz sand content. Clay clasts and clay-lined burrows are present in Section 313M0028A-114R-2 (523.57-524.65 mbsf).

\section{Interpretation}

The lower part of the unit is interpreted as a mix of sediment gravity flow deposits that entrained clay clasts and background hemipelagic deposits. The decreases in glauconite and grain size uphole to a prominent burrowed surface in Section 313-M0028A113R-1, $68 \mathrm{~cm}$ (519.70 mbsf), indicate a reduction in downdip sediment supply. The burrowed surface itself could have originated from sediment starvation and/or the onset of predominantly erosive sedimentladen flows and is a candidate unconformity. The overlying sandy sediment fines uphole; mica and plant debris support the presence of a river-influenced sediment source. Bioturbation obscures evidence for the physical depositional processes; however, the graded boundaries of some sand beds supports interpretation of river flood events, probably with storm influence.

\section{Unit V}

Interval: 313-M0028A-115R-1, $101 \mathrm{~cm}$, to 152R-1, $76 \mathrm{~cm}$

Depth: 525.52-611.28 m

Age: middle early Miocene (early-middle Burdigalian)

\section{Subunit VA}

Interval: 313-M0028A-115R-1, $101 \mathrm{~cm}$, to 120R-1, $63 \mathrm{~cm}$

Depth: 525.52-533.59

Core 313-M0028A-115R and those below are predominantly composed of glauconite (40\%-60\%) sand with scattered granules. Locally, $80 \%$ glauconite is reported in Section 313-M0028A-116R-1 (525.65 mbsf). Sediment is poorly sorted, with a muddy matrix in Cores 313-M0028A-115R and 116R. However, in Core 313-M0028A-117R to Section 119R-1, $140 \mathrm{~cm}$ (527.5-532.62 mbsf), beds of medium glauconite-quartz sand are inclined up to $\sim 15^{\circ}$ (apparent dip) (Fig. F13). The cross-stratification is delineated by common muddy laminae, which are crosscut by clay-filled Chrondrites. Cross bedsets are on the order of $100 \mathrm{~cm}$ thick. Normal grading from gravel to medium sand is well preserved in a bed in interval 313-M0028A-118-2, 60-70 cm (530.38 mbsf) (Fig. F14).

\section{Interpretation}

Subunit VA is interpreted as comprising a series of turbidites because of the normally graded beds, the well to moderately sorted sediment, and the relatively steep angle of bedding. Turbidites built dunescale migrating bedforms on the toe-of-clinoform slope. Burrows and clay laminae show that the dunescale bedforms migrated episodically, rather than from sustained flows, possibly in a channelized context. Poorly sorted deposits with floating granules and no evidence for bioturbation are interpreted as intercalated sandy debrite sourced from glauconiterich deposits higher on the clinothem.

\section{Subunit VB}

Interval: 313-M0028A-120R-1, $63 \mathrm{~cm}$, to $147 \mathrm{R}-\mathrm{CC}$, $10 \mathrm{~cm}$

Depth: 533.59-600.31 m (66.72 m thick)

This section (Cores 313-M0028A-122R through 126R) starts in indurated, poorly to moderately sorted, muddy glauconitic sandstone with common quartz granules and rare pebbles. Granule and pebble grains tend to be less rounded than sand-grade grains. There are remnants of the original physical structures (subhorizontal lamination and normal grading) and stratification (muddy beds) that have been 
largely obscured by bioturbation. Shells, mica, and plant debris are rare to absent throughout the succession. Below a coring gap, there is a change downhole at the top of Section 313-M0028A-127R-1 (546.47 mbsf) to unlithified coarse glauconitic sand. The amount of glauconite decreases from 30\% in Section 313M0028A-127R-1 (546.47 mbsf) to 5\%-10\% in Section 132R-1 (563.26 mbsf). Overall, the lithology remains medium to coarse sand, with dispersed quartz granules, concentrations of pebbles (up to 15\%), and common weak normal grading in beds. In Sections 313-M0028A-133R-1 through 135R-2 (564.77-573.48 mbsf), there is poorly sorted medium to coarse sand with variations in the proportion of glauconite $(7 \%-$ $20 \%$ ) and granules (1\%-5\%). Poorly sorted medium to coarse glauconitic sand with granules is interbedded with silt in Section 313-M0028A-136R-1 (573.92 mbsf) and a siltstone in Section 137R-1 (576.02 mbsf). From Section 313-M0028A-141R-1 (583.07 mbsf), moderately to poorly sorted medium to coarse sand is less glauconitic $(2 \%-3 \%)$, with steeply dipping silty beds (apparent dip up to $20^{\circ}$ ). In Section 313-M0028A-144R-1 (590.25 mbsf), well-sorted medium sand overlies a rare thin $(5 \mathrm{~cm})$ silty clay layer. Below the silty clay is a return to coarse sand with granules. Section 313-M0028A-145R-1 (592.22 mbsf) fines downhole to medium sand with a silty matrix, and in Section 145R-3, $82 \mathrm{~cm}$ (594.67 mbsf), there is a gradational change to coarse sand with granules.

\section{Interpretation}

Subunit VB is dominated by moderately to poorly sorted coarse sand-prone sediment with dispersed granules and pebbles and local concentrations of gravel. Poorly sorted coarse sediments are interpreted as deposits from high-concentration flows of coarse material eroded from updip positions that was deposited at the toe of a clinoform in an apron setting. Weak normal grading supports the partial transformation of debris flows into turbidity currents. The general poor sorting can be attributed to mixing through bioturbation and/or cohesive debris flow deposition. The overall succession of cores is coarsening uphole, with more silty layers and medium sand at the base that provide stratification, to largely unstratified, moderately sorted, coarser sand at the top, with greater amounts of granules and glauconite grains.

\section{Subunit VC}

Interval: 313-M0028A-147-CC, $10 \mathrm{~cm}$, to 152R-1, $76 \mathrm{~cm}$

Depth: 600.31-611.28 mbsf
Cores 313-M00028A-149R through 151R consist of medium and fine sand with mica, plant debris, and shell fragments and foraminifers, which is a significant compositional difference from Subunit VB. Other changes include some granules in Core 313M0028A-150R and glauconitic medium quartz sand in Section 152R-1, $0 \mathrm{~cm}$ (610.52 mbsf), becoming increasingly glauconitic down to a deeply $(60 \mathrm{~cm})$ and intensely burrowed (Thalassinoides and Ophiomorpha) surface in Section 313-M0028A-152R-1, $76 \mathrm{~cm}$ (611.60 mbsf), below which is a slightly silty nannofossil-bearing clay (Fig. F15).

\section{Interpretation}

The deeply bioturbated basal surface of Subunit VC in Section 313-M0028A-152R, 76 cm (611.28 mbsf), marks a major increase in grain size and is interpreted as a sequence boundary separating Units $\mathrm{V}$ and VI. The sand in Subunit VC is evidence of sediment remobilization downslope into a toe-of-clinoform-slope apron derived from different sediment source areas compared to Subunit VB, perhaps eroding from different clinothem top successions.

\section{Unit VI}

Interval: 313-M0028A-152R-1, $76 \mathrm{~cm}$, to $169 \mathrm{R}-1$, $61 \mathrm{~cm}$

Depth: 611.28-662.98 m

Age: middle early Miocene (late Aquitanian to early Burdigalian)

Below the major lithologic change in Section 313M0028A-152R-1, $76 \mathrm{~cm}$ (611.28 mbsf), across a deeply burrowed surface (Fig. F15), the cores contain a thick succession of pale brown nannofossil-bearing silty clay and clayey silt with common sand and silt lamination (Fig. F16). Also present are postdepositional, and commonly precompactional, concretions. There is parallel and ripple lamination, and sandier beds are commonly normally graded and locally inversely graded at their base. Burrows are predominantly simple meniscate backfilled forms identified as Taenidium (Fig. F17). Pyrite replacement of burrow fills is common, and pyrite shapes along the burrow margin suggest fecal pellets (?Ophiomorpha). Overall, the amount of pyrite and the number of nodules decreases downhole. In places, laminated intervals alternate with intensely bioturbated intervals. Mica and plant debris are typically found in very fine sand beds, but shell fragments or molds are absent from the succession (Fig. F18). At the base of the succession is a $\sim 2.5 \mathrm{~m}$ thick glauconite sand that coarsens down from very fine to medium-coarse sand grade. This bed or bedset abruptly overlies a sandy siltstone, with glauconite-filled burrows reaching $87 \mathrm{~cm}$ beneath the contact. 


\section{Interpretation}

The fining-upward glauconite sand at the base of this unit is interpreted as turbidity current deposits or river flood-related graded beds, with the abrupt increase in grain size across a deeply burrowed surface indicating a sequence boundary. The abundance of plant debris and mica indicates a fluvial source, and the environment of deposition is interpreted as a river-dominated deep offshore (prodelta) setting. There is no evidence of hummocks or other indicators of storm influence in the laminated beds, and this is taken as evidence of river-dominated deposition rather than reworking by storms. This inference is supported by the very fine sand beds with gradational upper and lower boundaries. Unlike other similar facies in this hole and in Holes M0027A and M0029A, this unit seems to lack abundant colloidal organic matter. This relatively quiet water environment was periodically subject to dysoxic bottom waters that excluded burrowing fauna. At times of better oxygenation, the infauna was dominated by horizontally mining deposit feeding organisms.

\section{Unit VII}

Interval: 313-M0028A-169R-1, $61 \mathrm{~cm}$, to 171R-CC, $19 \mathrm{~cm}$

Depth: 662.98-668.66 m

Age: middle early Miocene (late Aquitanian to early Burgidalian)

This unit comprises dark brown siltstone with abundant plant debris, mica, and beds concentrated with shell fragments (Fig. F19).

\section{Interpretation}

The brown siltstone is interpreted as a river-influenced deep offshore environment.

\section{Computed tomography}

A total of 86 whole-core samples from Hole M0028A were analyzed with the computed tomography (CT) scanner in order to acquire two-dimensional (2-D) and three-dimensional (3-D) images. CT scan images were acquired along two perpendicular axes of the whole core (see "Lithostratigraphy" in the "Methods" chapter) to evaluate the dip angle of laminae and the intensity and character of bioturbation (Fig. F20).

\section{Conclusion}

The 674.34 mbsf deep Hole M0028A washed through the upper $223 \mathrm{~m}$ of stratigraphy (no core in Unit I). Silt- and clay-prone Units VI and VII are interpreted as river-influenced deep offshore (prodelta) successions (Fig. F21). The overlying stratigraphy (Units V and IV) is interpreted as deposits remobilized from a heavily degraded clinothem that led to the development of a composite and progradational apron system dominated by debrites, with turbidites forming a toe-of-clinoform-slope toeset. Unit III is a thick clinothem that is interpreted to mark the progradation and aggradation of a mixed storm-river delta body. Basal toe-of-clinoform-slope apron coarse sand, which is interpreted to be related to the degradation of a clinothem, is overlain by offshore silts through shoreface-offshore transition interbedded sand and silt to poorly recovered sand interpreted as shoreface deposits. Deposits of the overlying Unit II form an aggradational stack of topsets close to the clinoform rollover position that preserve multiple truncated offshore to shoreface (regressive) and shoreface to offshore (transgressive) packages and poorly sorted glauconite-rich coarse sand. These shallow-water deposits underlie a clay, which is the youngest core recovered.

\section{Paleontology}

Middle and lower Miocene sections were identified from calcareous nannofossils, planktonic foraminifers, and dinocysts (Fig. F22) and integrated with $\mathrm{Sr}$ isotope stratigraphy to establish a chronostratigraphic framework for Hole M0028A (Fig. F23). Calcareous microfossil occurrences ranged from absent to abundant, and preservation ranged from poor to excellent, with the best preserved, most abundant specimens and most diverse assemblages often occurring in finer grained sediments. In general, organic microfossils were abundant and well preserved in fine-grained sediments. Abundant reworking of Paleogene material made assigning ages to some intervals difficult, but there is generally good agreement between the planktonic microfossil groups and ages based on $\mathrm{Sr}$ isotopes. As in Hole M0027A, barren intervals coincided with coarse-grained sediments, diminishing biostratigraphic age control within intervals of the lower Miocene.

Paleobathymetry and paleoenvironments were determined from benthic foraminifers, dinocysts, and terrigenous palynomorphs. Paleodepths varied through these sections, ranging from inner to middle neritic (0-100 mbsf). In several sequences, paleobathymetric fluctuations indicated shallowing-upward successions that occurred within a sequence stratigraphic framework. In general, good correlation was found between lithostratigraphic units and benthic foraminifer biofacies. Similarly, benthic foraminifer water depth estimates and palynological esti- 
mates of proximity to shoreline were consistent. Palynological data support previous reconstructions of the warm, humid early Neogene climate.

\section{Biostratigraphy}

\section{Calcareous nannofossils}

A total of 56 samples from Hole M0028A were examined for calcareous nannofossil biostratigraphy. Sample spacing was generally one sample every three cores (approximately every $10 \mathrm{~m}$ ), with fewer samples taken from sandy or disturbed intervals. The total abundance of calcareous nannofossils within samples ranged from barren to abundant. Preservation varied significantly throughout the hole, ranging from poor to good. Most samples contained moderately to moderately well preserved calcareous nannofossils, with rare horizons of poor preservation. Members of the Noelaerhabdaceae family dominate the assemblages throughout the hole. Reworked Paleogene material is also prevalent, particularly in Cores 313-M0028A-79R through 113R (414.66-519.96 mbsf).

Horizons recovered in Hole M0028A contain middle and lower Miocene assemblages (Table T4; Fig. F24). Two samples from the uppermost cores in this hole (Samples 313-M0028A-2R-1, $120 \mathrm{~cm}$, and 5R-1, 43 $\mathrm{cm}$; 224.53-232.91 mbsf) contain common numbers of calcareous nannofossils typical of Miocene sediments but no biostratigraphic marker taxa. The questionable presence of Helicosphaera walbersdorfensis could suggest Martini's (1971) Zone NN7 (11.3-11.8 $\mathrm{Ma})$ or somewhat older; however, the range of this species is not well dated in the literature. A questionable specimen of Calcidiscus premacintyrei, whose last occurrence (LO) is dated to $12.65 \mathrm{Ma}$, within Zone NN6, was found in Sample 313-M0028A-8R-1, $45 \mathrm{~cm}$ ( $243.08 \mathrm{mbsf}$ ). Because there is no evidence of a significant hiatus between Cores 313-M0028A-5R and 8R (232.91-243.08 mbsf), the uppermost part of the hole is likely assignable to Zone NN6.

The LO of Sphenolithus heteromorphus is found in Sample 313-M0028A-9R-1, 145.5 cm (246.135 mbsf), although this may not be the actual extinction (13.6 $\mathrm{Ma}$ ) of this species, suggesting that these sediments are somewhat older than 13.6 Ma. The interval from this sample to Sample 313-M0028A-27R-2, $43.5 \mathrm{~cm}$ (292.105 mbsf), is assigned to Zone NN5 (13.6-15.6 Ma). S. heteromorphus is only sporadically present throughout this section; however, calcareous nannofossils were not as abundant in these horizons because of the presence of coarser grained sediment.

The LO of Helicosphaera ampliaperta (15.6 Ma) occurs in Sample 313-M0028A-30R-1, 24 cm (297.37 mbsf). There is no obvious evidence of a hiatus above this sample, so this may represent the extinction of $H$. ampliaperta. The interval from Core 313-M0028A30R to Sample 313-M0028A-113R-1, 94 cm (297.37$519.96 \mathrm{mbsf})$, is assigned to Zone NN4 (15.6-18.3 $\mathrm{Ma})$ based on the co-occurrence of $H$. ampliaperta and $S$. heteromorphus and the absence of Sphenolithus belemnos. Within this zone, the last common occurrence (LcO) of Discoaster deflandrei $(\sim 16.21 \mathrm{Ma})$ is found in Sample 313-M0028A-58R-1, $95 \mathrm{~cm}$ (364.74 mbsf). This biohorizon is below a package of coarser grained material that was not sampled, so this datum may be somewhat depressed in this hole.

A zone barren of nannofossils occurs in Cores 313M0028A-118R through 144R (530.84-590.88 mbsf), making it impossible to assign an age to these horizons. The first fossiliferous sample below this zone (Sample 313-M0028A-152R-1, $4 \mathrm{~cm}$; $610.56 \mathrm{mbsf}$ ) contains an abundant but poorly preserved lower Miocene assemblage. Because this sample is from the base of a coarser grained unit, the calcareous nannofossil assemblage is likely reworked from below. A presumed in-place assemblage occurs in fine-grained sediment in the next section (Sample 313-M0028A$152 \mathrm{R}-2,17 \mathrm{~cm} ; 612.20 \mathrm{mbsf})$. The assemblage in this sample is older than the first occurrences (FOs) of $S$. heteromorphus (18.2 Ma) and H. ampliaperta ( 21.0 $\mathrm{Ma})$. Triquetrorhabdulus carinatus, the LO of which marks the base of Zone NN3 (19.6 Ma), is questionably present in this sample. Furthermore, the assemblage must be above the LcO of T . carinatus (22.9 $\mathrm{Ma})$, which is near the base of Zone NN2. This section is also above a secondary event, the crossover in abundance of Helicosphaera euphratis with Helicosphaera carteri, which is tentatively dated to $21.5 \mathrm{Ma}$. Thus, samples from Cores 313-M0028A-152R through 154R (610.56-618.64 mbsf) are assigned to Zone NN2 and most likely the middle part of the zone, at $\sim 21-21.5 \mathrm{Ma}$.

The next sample examined (Sample 313-M0028A156R-1, $19 \mathrm{~cm}$; $622.91 \mathrm{mbsf})$ contains frequent poorly preserved calcareous nannofossils. Cores 313M0028A-158R through 168R (629.82-660.63 mbsf) are barren of calcareous nannofossils. The overlying fossiliferous and barren intervals are assigned to lithologic Unit VI, which consists of pale brown silty clay and clayey silts. The only obvious change from the top of this unit within Core 313-M0028A-152R (611.60 mbsf) to the zone barren of nannofossils beginning in Core 158R (629.82 mbsf) is a progressive decrease in the amount of pyrite and concretions (see "Lithostratigraphy"). The presence of carbonate in samples from the barren interval suggests that calcareous nannoplankton were living in the overlying water column during deposition of these sediments, but diagenetic processes significantly altered the assemblage after deposition. Calcareous nannofossils are again present in sediments from the bot- 
tom of the hole (Samples 313-M0028A-169R-1, 130.5 $\mathrm{cm}$, and 170R-4, $37 \mathrm{~cm}$; 663.675-668.47 mbsf), and the assemblage is very similar to that found in the overlying Zone NN2 horizons. Thus, these sediments are also assigned to mid?-Zone NN2.

\section{Planktonic foraminifers}

A total of 49 samples were studied for planktonic foraminifers (Fig. F25; Table T5). Of these, 31 were barren; however, planktonic foraminifers were well preserved in the remaining 18 samples. Planktonic foraminifer biostratigraphy indicates that Hole M0028A spans the lower to middle Miocene (Burdigalian-Serravalian), although sediment below Sample 313M0028A-116R-CC, 0-4 cm (527.46 mbsf), was mostly barren of planktonic foraminifers. The absence of key marker taxa (e.g., Fohsella peripheroacuta, Praeorbulina sicana, Orbulina spp., Praeorbulina glomerosa, Catapsydrax dissimilis, and Globigerinatella insueta) made identification of Miocene planktonic foraminifer zones difficult, resulting in intervals assigned to undifferentiated zones.

The first biostratigraphically useful taxa are found in Sample 313-M0028A-4R-CC (232.80 mbsf) and include Paragloborotalia mayeri (LO 11.4 Ma), a questionable Globorotalia archeomenardii (LO 13.9 Ma), and Globorotalia praemenardii (FO $14.2 \mathrm{Ma}$ ). The cooccurrence of the latter two species yields a middle Miocene (Serravalian) age of 13.9-14.2 Ma (Zone M7/N10) for this sample. The interval between Samples 313-M0028A-6R-CC and 27R-CC (238.98-293.50 mbsf) contains an assemblage consisting of Globigerinoides sacculifer, Globoquadrina baroemoenensis, Globoquadrina venezuelana, Globorotalia bella, G. archeomenardii, and $P$. mayeri. The absence of $G$. praemenardii (FO 14.2 Ma) and Catapysdrax stainforthi (LO 16.4 Ma) suggests a middle Miocene undifferentiated Zone M5-M7/N8-N10 (Langhian-Serravallian) for these sediments, although because of the absence of key taxa, this zonal assignment is based on the background assemblage, making it tentative.

C. stainforthi occurs in Sample 313-M0028A-29R-CC, $14-16 \mathrm{~cm}$ (299.72 mbsf). Although this species is not a primary marker taxon, Bolli et al. (1985) indicate that it ranges from $\mathrm{M} 2 / \mathrm{N} 5$ to $\mathrm{M} 4 / \mathrm{N} 7$, suggesting this sample is lower Miocene (upper Burdigalian) and older than 16.4 Ma. The interval from this sample to Sample 313-M0028A-38R-CC, 0-2 cm (323.92 mbsf), also contains Globorotalia praescitula, the FO of which falls within Zone M3/N6 at $18.5 \mathrm{Ma}$. Thus, this interval can be assigned to undifferentiated Zone M3-M4/N6-N7. Samples between Cores 313M0028A-40R and 79R (329.80-415.65 mbsf) were barren of planktonic foraminifers and are not zoned.
Globorotalia semivera occurs in Sample 313-M0028A82R-CC, 4-6 cm (426.74 mbsf). This species has a LO of $17.3 \mathrm{Ma}$, which approximates the base of Zone M4/N7. The interval from this sample to Sample 313-M0028A-116R-CC, 0-4 cm (527.46 mbsf), also contains G. praescitula (FO $18.5 \mathrm{Ma}$ ), as well as a general assemblage including Globigerinoides altiapertura and Globigerinoides primordius. Thus, this interval (426.74-527.46 mbsf) is assigned to lower Miocene (mid-Burdigalian) Zone M3/N6. Samples below Core 313-M0028A-116R (527.46 mbsf) were either barren or contained a sparse assemblage with no biostratigraphically useful taxa. Therefore, the interval below this sample to the base of the hole in Sample 313M0028A-170R-CC, 6-8 cm (668.63 mbsf), is not zoned.

\section{Dinocysts}

Following the zonation of de Verteuil and Norris (1996), Samples 313-M0028A-9R-CC, 12-14 cm, to 11R-CC, $10-12 \mathrm{~cm}$ (246.98-254.18 mbsf), are assigned to upper Serravalian dinocyst Zone DN7 based on the presence of Habibacysta tectata together with Erymnodinium delectabile, Cannosphaeropsis passio, Selenopemphix dionaeacysta, and Cyclopsiella granosa. Because the FO of E. delectabile has been demonstrated to occur in older sediments from the North Sea, a more conservative assignment of Zones DN6DN7 is recommended (Fig. F26; Table T6). Sample 313-M0028A-27R-CC (293.50 mbsf) is assigned to Zone DN5 because of the presence of Batiacasphaera sphaerica, Labyrinthodinium truncatum modicum, Trinovatedinium papulum, Cerebrocysta poulsenii, Heteraulacacysta campanula, and Systematophora placantha. The presence of $\mathrm{H}$. tectata and absence of Apteodinium tectatum suggest a maximum age of $14.2 \mathrm{Ma}$ for this sample, restricting it to the early Serravalian.

The occurrence of A. tectatum, Cousteaudinium aubryae, Lingulodinium multivirgatum, and L. truncatum modicum constrains the age of Samples 313-M0028A29R-CC and 30R-CC (299.74-299.21 mbsf) to Zone DN4 (latest Burdigalian-Langhian; 16.8-15.2 Ma). Sample 313-M0028A-34R-CC (311.43 mbsf) contains only relatively long ranging taxa, but Samples 37RCC through 94R-CC (320.69-464.10 mbsf) are assigned to undifferentiated Zones DN2-DN3 (late Aquitanian-Burdigalian; 22.2-16.8 Ma) based on the occurrence of $L$. multivirgatum with Apteodinium spiridoides, Distatodinium paradosum, A. tectatum, and C. aubryae. Sample 313-M0028A-97R-CC, 9-11 cm (473.35 mbsf), can be assigned to Zone DN3 based on the co-occurrence of L. multivirgatum and Sumatradinium druggii, thus constraining the age of the overlying samples (up to $311.52 \mathrm{mbsf}$ ) to the Burdigalian. 
Sample 313-M0028A-100R-CC, 6-8 cm (482.53 mbsf), contains only relatively long ranging taxa, and reworking is pervasive in Sample 102R-CC (487.68 mbsf), making age assignment difficult. Samples 313-M0028A-104R-CC to 169R-CC, $16-18 \mathrm{~cm}$ (494.53-664.50 mbsf), are assigned to Zone DN2, which spans 22.2-19.1 Ma (late Aquitanian-early Burdigalian) based on the common presence of dinocysts typical of the lower Miocene (e.g., Sumatradinium hamulatum, Tityrosphaeridium cantharellum, Cribroperidinium tenuitabulatum, and Cerebrocysta satchelliae). Substantial reworking of Paleogene cysts is also noted in Samples 313-M0028A-167R-CC, 13-15 cm (659.49 mbsf), and 169R-CC, 16-18 cm (664.50 mbsf), so age assignment relied only on FOs. Sample 313-M0028A-170R-CC, 6-8 cm (668.63 mbsf), is very rich in amorphous organic matter, suggesting a distal depositional environment, but it also contains a very sparse dinocyst flora and cannot confidently be assigned an age.

\section{Paleoenvironment}

\section{Benthic foraminifers}

Core catcher (CC) samples and samples from within cores were examined for benthic foraminifers from Samples 313-M0028A-2R-3, 30-32 cm (226.63 mbsf), through 170R-CC (668.63 mbsf) (Fig. F27; Table T7). Benthic foraminifer abundances range from absent to abundant, and preservation ranges from poor to excellent. Poorly preserved specimens likely were reworked and were not used in paleodepth estimates. Barren intervals occur throughout the section and may indicate nearshore/nonmarine environments, substantial downslope transport, or dissolution. It should be noted that the low-resolution sampling interval did not bracket all lithologic changes or unconformities. Within the sample resolution used here, benthic foraminifer biofacies groupings correlate well with lithostratigraphic units. Preliminary results presented here suggest that benthic foraminifer biofacies changes in Hole M0028A indicate that paleobathymetric fluctuations occur within a sequence stratigraphic framework, with several sequences showing a shallowing-upward succession. Detailed, higher resolution postcruise studies will elaborate on this.

Benthic foraminifer faunas in Samples 313-M0028A2R-3, 30-32 (226.63 mbsf), to 38R-CC, 0-2 cm (323.92 mbsf), indicate that paleowater depths varied within the inner to middle neritic zones $(0-100$ $\mathrm{m})$, although several samples yielded no foraminifers (Fig. F27). Assemblages within this section indicate water depths that ranged from 10-25 $\mathrm{m}$ (dominated by Hanzawaia concentrica/Hanzawaia hughesi) to 25$50 \mathrm{~m}$ (dominated by Nonionella pizarrensis/Nonionella miocenica stella) to 50-75 m (characterized by elevated abundances of Buliminella gracilis), to as deep as $100 \mathrm{~m}$ (indicated by increases in Uvigerina juncea). Samples containing more abundant $B$. gracilis indicate slightly shallower paleodepths $(50-80 \mathrm{~m})$ than samples containing more abundant $U$. juncea (75$100 \mathrm{~m}$ ), based on faunal studies from New Jersey (USA) coastal plain boreholes (Miller et al., 1997). Other rare to common species found in this section include Buliminella-Uvigerina-dominated faunas, typically including Bolivina spp., Buliminella elegantissima, Cancris sagra, Cassidulinoides spp., Cibicidoides spp., Dentalina spp., Fissurina spp., H. concentrica/H. hughesi, Lenticulina americana, Lenticulina spp., Nonion sp., Pararotalia sp., Plectofrondicularia spp., Rectuvigerina lamelata, Stilostomella spp., Textularia spp., and agglutinated foraminifers.

Samples 313-M0028A-40R-CC (329.80 mbsf) to 91RCC, 9-11 cm (453.89 mbsf), were barren or contained only one or two specimens of foraminifers, with one exception; no paleodepth could be determined for these samples (Fig. F27). Based on rare but well-preserved foraminifers (primarily B. gracilis), the paleodepth for Sample 313-M0028A-82R-CC, 4-6 cm (426.74 mbsf), is estimated at $50-75 \mathrm{~m}$.

Samples 313-M0028A-94R-CC, 0-2 cm (464.10 mbsf), through 107R-CC, 0-3 cm (503.78 mbsf), contain benthic foraminifer faunas that indicate paleowater depths in the inner to middle neritic zones (0$100 \mathrm{~m}$ ), although several samples yielded no foraminifers (Fig. F27). This interval is underlain by another that is mostly barren of benthic foraminifers from Samples 313-M0028A-110R-CC, 0-2 cm (512.72 mbsf), to 167R-CC, $13-15 \mathrm{~cm}$ (659.49 mbsf). Foraminifers in Sample 313-M0028A-152R-CC, 151$153 \mathrm{~cm}$ (613.54 mbsf), indicate a possible paleodepth of 10-25 m, but specimens are too sparse to determine this with certainty. The lowermost two samples examined, Samples 313-M0028A-169R-CC, 16-18 $\mathrm{cm}$ (664.50 mbsf), and 170R-CC, 6-8 cm (668.63 mbsf), contain B. gracilis and a few $U$. juncea, indicating a $\sim 50-80 \mathrm{~m}$ paleodepth.

\section{Terrestrial palynomorphs and palynofacies}

Sediments from 23 samples spanning the interval between Sample 313-M0028A-2R-3, 30-32 cm (226.63 mbsf), and 170R-CC, 6-8 cm (668.63 mbsf), were analyzed for palynomorphs (Tables T6, T8; Fig. F28). All samples contain numerous well-preserved pollen grains and other palynomorphs. Palynomorph identification was frequently hampered by accumulations of pyrite grains inside the palynomorphs. Nevertheless, pollen could generally be assigned to major groups: arboreal/herbal nonsaccate, grass/ sedge, and bisaccate pollen. Furthermore, frequent 
pollen types (e.g., oak, hickory, and linden pollen) were identified to genus level to distinguish dominant vegetation types. In the following, the total content of nonsaccate pollen and pollen with small sacci is used as the reference sum (thus, combined small saccate and nonsaccate pollen are always $100 \%$ ), and percentages of other palynomorphs are related to this sum. Ages mentioned are in accordance with the preliminary age model based on organic-walled dinoflagellate cysts (see "Dinocysts").

\section{Serravallian and late Burdigalian ( 225 to $\sim 320$ mbsf)}

Eight samples from the Serravallian to uppermost Budigalian were examined between Samples 313M0028A-2R-3, 30-32 cm, and 37R-CC (226.63$320.69 \mathrm{mbsf})$. All samples show high percentages of nonsaccate arboreal pollen (mainly oak and hickory). The early Serravallian obviously witnessed a spreading of hickories, as indicated by pollen percentages $>20 \%$ (Fig. F28), taking into account that hickory pollen is generally underrepresented compared to oak and other arboreal pollen. This indicates that the climate was probably humid and warm. No samples between Samples 313-M0028A37R-CC and 81R-CC, 9-11 cm (320.69-423.08 mbsf), were analyzed during the Onshore Science Party (OSP).

\section{Early Burdigalian-late Burdigalian transition ( 423 to $\sim 513$ mbsf)}

The presumed transition from the lower to upper Burdigalian is reflected in 10 palynologically analyzed samples from Cores 313-M0028A-81R through 110R (423.08-512.72 mbsf). This interval is characterized by higher percentages of bisaccates in Core 313-M0028A-97R (473.35 mbsf) and above and lower percentages below that (i.e., Core $100 \mathrm{R}$ and below; 482.53-512.72 mbsf) (Fig. F28). A similar signal is also present in the foraminifer test lining percentages, with generally higher percentages between 423.08 and $473.35 \mathrm{mbsf}$ and lower percentages $(<5 \%)$ between 482.53 and 523.72 mbsf. Dinocyst percentages increase uphole over the entire interval. This indicates that Hole M0028A was probably closer to the shoreline during the late early Burdigalian. The position of Hole M0028A presumably became more distal until the early late Burdigalian; however, fluctuations in the foraminifer test linings indicate that this overall trend was interrupted by several shorter term sea level changes. In general, this interval was climatically stable, but slight shifts in the hickory/oak ratio indicate minor changes in humidity. Samples between Cores 313-M0028A-110R and 152R (512.72-613.54 mbsf) could not be analyzed during the OSP.
Late Aquitanian to early Burdigalian ( 615 to $\sim 670$ mbsf)

Two samples (Samples 313-M0028A-152R-CC, 151$153 \mathrm{~cm}$, and 155R-CC, 11-13 cm; 613.54-622.86 mbsf) are characterized by very high percentages of bisaccate pollen $(>100 \%)$. Preliminary results from the comparison of different pine taxa indicate that these high percentages are at least partly caused by an increased distance between Hole M0028A and the shoreline, rather than by shifts in climate conditions. This hypothesis is also supported by relatively high amounts of dinocysts (>20\%) and foraminifer test linings (5\%-20\%) in these samples (Fig. F28). Slight changes in climate conditions are indicated by high amounts of pollen from western and eastern hemlock (Tsuga) species, which, with one exception, are not found in other samples from Hole M0028A. The presence of western hemlock species in combination with lower amounts of hickory pollen points to especially moist conditions during this interval (Fig. F29).

Three samples between Samples 313-M0028A-167RCC, $13-15 \mathrm{~cm}$, and 170R-CC, 6-8 cm (659.49-668.63 mbsf), reflect the probable transition between the upper Aquitanian and the lowermost Burdigalian. This interval probably witnessed a change to warmer and dryer conditions, as indicated by a strong increase in hickory pollen between $\sim 670$ and $\sim 660$ mbsf, where pollen of other trees (e.g., oaks) decreased (Fig. F28). The hinterland was probably inhabited by hickory-oak forests, with hickory as the dominant taxon (Fig. F29). This is different from the late Burdigalian, where oaks were probably dominant in the hickory-oak forests (Fig. F29).

\section{Geochemistry}

\section{Interstitial water}

As in Hole M0027A, the pore water chemistry of Hole M0028A is dominated by the alternation of relatively fresh and salty layers (Table T9; Fig. F30). Although we have no samples from above $225 \mathrm{mbsf}$, we presume that multiple freshwater layers are present there as well, as our shallowest sample has a chloride concentration of $72 \mathrm{mM}$, only $14 \%$ of that found in present-day bottom seawater in the hole $(524 \mathrm{mM})$. This is also the freshest water we sampled from Hole M0028A, and it is not nearly as fresh as its counterpart from Hole M0027A at 331 mbsf, which had only $41 \mathrm{mM} \mathrm{Cl}$. The average pore water we sampled from Hole M0028A is also not as fresh: over the sampled interval of $439 \mathrm{~m}$, from 225 to $664 \mathrm{mbsf}$, the average chloride concentration, weighted by depth interval, is $353 \mathrm{mM}, 67 \%$ of that in bottom 
seawater, implying that about a third of the water is fresh, compared with half in Hole M0027A. The lower value for Hole M0028A is biased by the absence of samples from 0 to $225 \mathrm{mbsf}$; also, if the brine at the bottom of the hole is excluded, the freshwater fraction rises to $41 \%$. Although the water from Hole M0028A may not be as fresh overall, we found significantly freshened water at a greater depth than in Hole M0027A: $214 \mathrm{mM} \mathrm{Cl} \mathrm{(41 \%} \mathrm{of}$ that in seawater) at $536 \mathrm{mbsf}, 117 \mathrm{~m}$ deeper than the deepest fresh(er) water layer in Hole M0027A. We sampled three major freshwater layers (and several minor ones) in Hole M0028A, at <225-252, 270-324, and $517-536$ mbsf. These were separated by relatively salty layers at 261-266, 335-407, and 551-664 mbsf (to the bottom of the hole). Although none of these layers could be readily correlated with those in Hole M0027A, either by depth, age, or lithologic facies, some similarities in the shape of the pore water profiles, especially for sulfate, suggest that some of the fresh and salty layers are laterally continuous between Holes M0027A and M0028A, $10 \mathrm{~km}$ apart, albeit with large changes in relative thickness. The minimum chloride content of each of the fresh layers increases with depth. The maximum chloride concentration measured, from 407 mbsf within the second of the three salty zones, which is complex and multilayered, is $607 \mathrm{mM}$, significantly higher than seawater and nearly identical to the $608 \mathrm{mM}$ measured in the deepest sample. This value and the steady increase in chloride over $50 \mathrm{~m}$ to the bottom of the hole indicate that we encountered brines here for the first time during IODP Expedition 313 and that there is probably no more freshwater in this hole below that found at 536 mbsf. Brines with up to twice the salinity of seawater are a major feature of pore waters sampled at Ocean Drilling Program (ODP) Sites 902-906 on the outer shelf and upper to mid-slope off New Jersey during Leg 150 (Mountain, Miller, Blum, et al., 1994).

As in Hole M0027A, most major and minor ions in the seawater mimic the depth profile for chloride quite closely (Fig. F30), indicating that the interlayering of freshwater and seawater dominates the chemical profiles, rather than reaction with sediment. These ions again include $\mathrm{Br}, \mathrm{Na}, \mathrm{Mg}, \mathrm{Ca}$, and Sr. $\mathrm{K}$ is similar except for the lower $80 \mathrm{~m}$, from 584 to 664 mbsf, over which $\mathrm{K}$ decreases and chloride increases. This trend is emphasized in the plot of $\mathrm{K} / \mathrm{Cl}$ (Fig. F30) and is similar to that in Hole M0027A. Na also decreases relative to chloride over this deep interval as the waters become briny near the bottom of the hole, whereas $\mathrm{Ca}, \mathrm{Sr}, \mathrm{Br}$, and $\mathrm{Ba}$ increase. In contrast to Hole M0027A, Mg, Li, and B are relatively trendless.
The sulfate profile resembles that for chloride except that microbial sulfate reduction has gone nearly to completion $(<1 \mathrm{mM}$ sulfate) within all layers of relatively freshwater below 250 mbsf (i.e., within the entire interval that was cored), as well as within the saltiest water near the bottom of the hole. The same is true for Hole M0027A below 220 mbsf. Within the salty layers, in sharp contrast (except for the deepest, briny layer), sulfate and sulfate/chloride remain at seawater values; microbes have apparently been much more successful in oxidizing organic matter by reducing sulfate within the freshwater layers than within the shallower salty layers in both holes. Microbial activity appears to be especially intense within the deepest freshwater layer at 529 mbsf, which has the highest alkalinity and ammonium in the hole and still has some remaining sulfate (3.5 $\mathrm{mM})$. At the base of this fresh layer $7 \mathrm{~m}$ deeper, at $536 \mathrm{mbsf}$, where sulfate is even lower at $0.4 \mathrm{mM}, \mathrm{H}_{2} \mathrm{~S}$ was detected for the only time in cores from Hole M0028A. As expected, alkalinity and ammonium are high wherever sulfate is low, as carbonate alkalinity and ammonium are the major products of organic matter oxidation. The exception is the deep briny layer near the bottom of the hole where, as in Hole M0027A, carbonate alkalinity is consumed by precipitation of $\mathrm{CaCO}_{3}$ in response to increasing $\mathrm{Ca}, \mathrm{Ca} /$ $\mathrm{Cl}$, and salinity with depth as the water becomes briny. As expected for pore waters saturated with barite, Ba behaves inversely to sulfate in both fresh and salty layers. In Hole M0028A, pH varies inversely with alkalinity, which was not the case in Hole M0027A.

As in Hole M0027A, the major fresh and saltwater layers appear to have distinct chemistries. The uppermost freshwater layer at $<225-252 \mathrm{mbsf}$, for example, has exceptionally high $\mathrm{Na} / \mathrm{Cl}$ and $\mathrm{B}$ values, whereas the lowermost layer at 517-536 mbsf has very high $\mathrm{K} / \mathrm{Cl}$ and the middle layer at 270-324 mbsf actually has lower $\mathrm{K} / \mathrm{Cl}$ than in seawater. These distinct chemistries, along with the shape of the sulfate profiles, suggest that it may be possible to correlate some of these layers laterally by their composition. A preliminary test of this hypothesis works well for the thickest freshwater layer from Hole M0027A, at 183$341 \mathrm{mbsf}$, which appears to correlate with the middle layer in Hole M0028A, at 270-324 mbsf. Freshwater from these layers has similarly high ratios to chloride for $\mathrm{Br}, \mathrm{Li}, \mathrm{Na}, \mathrm{B}, \mathrm{Ca}$, and Sr. The two waters share high alkalinity, ammonium, and $\mathrm{P}$ and low $\mathrm{pH}$, $\mathrm{Mg} / \mathrm{Cl}$, and sulfate. They are not identical, but they certainly are similar. Whether they are sufficiently dissimilar from the other freshwater layers above and below to correlate them uniquely requires addi- 
tional analysis. If this interpretation is correct, then the salty layer immediately above in Hole M0028A, from 261 to $266 \mathrm{mbsf}$, would correlate with the much thicker layer in Hole M0027A at 96-167 mbsf. Both of these layers have a small salty "shoulder" on their lower edge in both the chloride and sulfate profiles (Figs. F30, F31). The salty layer immediately below in Hole M0028A, at 335-407 mbsf, would correlate with a similar layer at 351-410 mbsf in Hole M0027A. Each of these salty layers displays multiple peaks for many elements and contains within it the largest chemical anomaly in each hole, a sharp peak defined by greatly elevated $\mathrm{Mn}, \mathrm{Fe}, \mathrm{Si}, \mathrm{B}, \mathrm{Li}, \mathrm{K}, \mathrm{Ca}$, and Sr, at 394 mbsf in Hole M0027A and 407 mbsf in Hole M0028A. Below these salty layers lie the deepest freshwater layer in each hole, at $517-536 \mathrm{mbsf}$ in Hole M0028A and 419 mbsf in Hole M0027A. Deeper still, Hole M0028A has a thick layer at 543610 mbsf within which sulfate reaches the seawater concentration, which would correlate with the several lesser peaks in sulfate in Hole M0027A between 493 and 593 mbsf. If these correlations are accurate, the various layers would cross several sequence boundaries identified in seismic reflection profiles, indicating that hydraulic connectivity would be independent of these boundaries to some extent.

The multipeaked salty layer at 335-407 mbsf in Hole M0028A with the large chemical anomaly does not display the simple pattern of elevated ammonium and phosphorus seen at 351-410 mbsf in Hole M0027A that we attributed to microbial activity, but it does contain elevated concentrations of both of these chemical species. The large chemical anomaly at 407 mbsf in Hole M0028A is nearly identical to that located at 394 mbsf in Hole M0027A, except that here it is defined by three samples from 407 to $419 \mathrm{mbsf}$ rather than by a single sample. It is even more extreme: it has the highest concentrations in the hole for $\mathrm{Mn}, \mathrm{Fe}, \mathrm{Si}, \mathrm{K}, \mathrm{Li}$, and $\mathrm{Ca}$ and nearly so for $\mathrm{B}$ and Sr. As in Hole M0027A, it has the lowest $\mathrm{Na} / \mathrm{Cl}$ ratio measured. Unlike Hole M0027A, it also has the highest $\mathrm{P}$ and the lowest $\mathrm{pH}$ measured. Its origin is presently unknown. Profiles for $\mathrm{Mn}$ and Fe are simpler in Hole M0028A than in Hole M0027A, with far fewer peaks, largely because we did not core the upper 220 mbsf. The only other depth in Hole M0028A at which both $\mathrm{Mn}$ and Fe are elevated is 600 mbsf.

\section{Sediment chemistry and mineralogy}

Sediment samples were analyzed for total carbon (TC), total organic carbon (TOC), and total sulfur (TS) concentrations. Total inorganic carbon (TIC) was calculated as the difference between TC and TOC (Table T10). Bulk sample X-ray diffraction
(XRD) data were produced for the same samples (Table T11).

The patterns seen in Hole M0027A of high concentrations of TOC and TS in the quartz-poor freshwater layers and low concentrations in the quartz-rich salty layers are present in Hole M0028A (Figs. F32, F33, F34) but are not as obvious, in large part because sampling was sparser, but the clear distinction between fresh and salty water is not as obvious in Hole M0028A, either. The three salty layers sampled are generally quartz rich and clearly have lower TOC and TS, but the pattern for the freshwater layers is more complicated. The uppermost freshwater layer is clay rich and has high TOC and TS, but mainly along its upper and lower boundaries, suggesting a role for chemical reaction. Concentrations of TOC and TS are lower overall in Hole M0028A than they are in Hole M0027A, with maximum concentrations of 2.9 and $3.1 \mathrm{wt} \%$, respectively.

As in Hole M0027, TS correlates very well with pyrite as measured by XRD (Fig. F32). The near absence of both TS and pyrite below $\sim 620 \mathrm{mbsf}$, in the deeper part of Hole M0028A that is occupied by sulfate-free brine, indicates that this brine lost its sulfate somewhere else. It may well have ascended from greater depth, as suggested for the similar brine in Hole M0029A. As expected from the depth profiles for alkalinity and dissolved $\mathrm{Ca}$, TIC is relatively high $(0.7$ $\mathrm{wt} \%$ ) within the brine because of precipitation of $\mathrm{CaCO}_{3}$.

Quartz and kaolinite dominate the mineralogy of Hole M0028A even more than they did in Hole M0027A. Quartz accounts for $24 \%$ to $81 \%$ (mean $64 \%$ ) of the total XRD signal for a given sample, and kaolinite for $0 \%-54 \%$ (mean $8.9 \%$ ) (Table T11). The only other minerals with a maximum signal above $6 \%$ are chlorite and goethite.

\section{Physical properties}

The focus of this section is to provide a description of the petrophysical data sets collected on cores from Hole M0028A and their significant characteristics and variations, as well as concentrating in more detail on a number of interesting aspects. Some measurements display variation primarily associated with depositional sedimentary changes, whereas other measurements are controlled more by postdepositional factors such as the degree of cementation and the type of interstitial water. In addition, combined integration of the core and logging petrophysical data sets allows calibration of core data with in situ borehole properties and provides an assessment of the precise depth from which core was collected in the borehole. 
Whole-core measurements were acquired on a multisensor core logger (MSCL): gamma ray attenuation density (here referred to as gamma density), $P$-wave velocity, noncontact electrical resistivity, and magnetic susceptibility. Thermal conductivity and natural gamma radiation (NGR) measurements were taken on whole cores prior to the commencement of the OSP (see "Physical properties" the "Methods" chapter). Density, porosity, and $P$-wave velocity were measured and calculated from, on average, one discrete sample in every core section. Figure F35 provides an overview of the data. A synthesis of downhole and physical property data can be found at the end of "Downhole measurements" (Fig. F36).

\section{Density and porosity}

\section{Gamma density and wet bulk density}

Gamma density in Hole M0028A varies more than in Hole M0027A. Only values between 1.5 and $2.9 \mathrm{~g} /$ $\mathrm{cm}^{3}$ are considered below (Fig. F37). Wet bulk density calculated from wet and dry weight and dry volume of samples from cores varies between 1.65 and $2.57 \mathrm{~g} / \mathrm{cm}^{3}$. Repeated measurements with resaturation of sediment before measurement indicate that the density of samples may be overestimated by up to $5 \%$. Despite this uncertainty, there is a fair correspondence between gamma density and wet bulk density. Wet bulk density estimates tend to be lower than those in Hole M0027A (Fig. F38).

Density varies downhole with intervals of lower densities $\left(\sim 1.85 \mathrm{~g} / \mathrm{cm}^{3}\right)$ and higher densities $\left(\sim 2.1 \mathrm{~g} / \mathrm{cm}^{3}\right)$ (Fig. F37). These variations broadly correspond to lithology: respectively, clay- to silt-rich intervals and sand, glauconite, or cemented intervals. This correspondence to lithology is particularly clear when investigated in combination with porosity (see below).

\section{Calculated porosity}

Calculated porosity, here referred to as porosity, is calculated from the difference between wet and dry weights and the dry volume of selected sediment samples (see "Physical properties" the "Methods" chapter). Some core liners had little drill fluid in them. As a result, sediments with high permeability may have been drained of water during storage and handling. Porosity may therefore be underestimated, particularly that of sands. Based on repeated measurements, we estimate that the porosity of sands may be underestimated by $1 \%-10 \%$ and perhaps up to $19 \%$. Clays and silt with low permeability are not expected to have drained as much. Calculated porosity values vary from $20 \%$ to $61 \%$.

Stratigraphically, porosity varies with intervals of low porosity ( 40\%) and high porosity ( 50\%-60\%).
This variation corresponds to lithology variation (Fig. F37). Clay- to silt-rich sediments in general have high porosities, and sand, glauconitic, or cemented sediments have low porosities.

The porosity of clay and silt intervals decreases with depth. The same tendency is observable for sand-rich intervals. Porosity reductions broadly follow the exponential decrease in porosity of sands, silts, and clays that have been observed from a number of passive margins and derived analytically (Sclater and Christi, 1980; Bahr et al., 2001).

\section{Combined density and porosity as a stratigraphic tool}

As in Hole M0027A, there is significant inverse variation between porosity and density of samples (Fig. F39). The different lithologies of Hole M0028A fall close to a mixing line between rock (zero porosity and density of $2.7 \mathrm{~g} / \mathrm{cm}^{3}$ ) and saltwater (100\% porosity and density of $1.024 \mathrm{~g} / \mathrm{cm}^{3}$ ). Sand sediments and the majority of clay and silt samples plot close to the mixing line between rock and saltwater. Glauconite clearly plots above the mixing line with higher densities because mature glauconite has a density of 2.9 $\mathrm{g} / \mathrm{cm}^{3}$ as opposed to $\sim 2.65 \mathrm{~g} / \mathrm{cm}^{3}$ for quartz. A significant portion of silt and clay samples plot below the line and have relatively reduced densities.

Downhole, there are significant differences between gamma density and density measured on samples. Gamma density corresponds to the main lithology variations (Fig. F40A, F40B, F40C). There is little separation between density and porosity curves. In this context, it is worth noting that at these shallow depths, porosities of clay and silt are still relatively higher than that of sands (cf. Bahr et al., 2001). As a result, the separation of the porosity and density curves is not fully expressed, as in deeply buried shale and sand successions (Rider, 2006).

A number of packages of gradual overall uphole increasing density and decreasing porosity can be delineated based on the average "log motif" of gamma density and sample-based density and porosity (Fig. F40A, F40B, F40C). The packages are, in general, separated by abrupt density decreases and porosity increases. These packages correspond to large-scale coarsening-upward successions ending in abrupt fining (horizontal arrows; Fig. F40A, F40B, F40C) (see "Paleontology"). Sometimes the top of the packages and the following abrupt density decrease is masked by large fluctuations in density and porosity caused by glauconite and cemented sections (Fig. F40C). Significant boundaries based on the averaged log motif are identified at $\sim 254,323,340,388,495,610$, and 636 mbsf. (see Table T12 for all key physical 
property boundaries). A boundary is also present at 553 or $538 \mathrm{mbsf}$ but is difficult to pick because high glauconite content and cementation mask the log motif. A significant proportion of the identified boundaries correspond to flooding surfaces or other important sequence stratigraphic surfaces, as determined by sedimentology and stratigraphic correlators (see "Lithostratigraphy" and "Stratigraphic correlation"). Intervals with abundant phytoclasts show reduced densities.

\section{P-wave velocity}

In most of Hole M0028A, velocity measurements on whole cores do not always correlate well with density measurements (Fig. F36). There is considerable scatter and some offsets in the data are due to the variable liner fill and saturation of cores. No downhole sonic log was obtained in Hole M0028A, so this data cannot be used for comparison with the core measurements.

Discrete samples were measured for velocity from 220 mbsf, where coring began, to the base of the hole. Between 220 and 320 mbsf (Fig. F41), velocities are $<2000 \mathrm{~m} / \mathrm{s}$ and are relatively constant, with a slight increase between 290 and 320 mbsf (Subunits IIA-IIC). These trends are matched by MSCL data. At $\sim 323$ mbsf (Subunits IIC into IID), velocities observed in both discrete samples and the whole core despite some scatter increase in some cemented sandstone horizons and glauconitic sandstone. Between $\sim 272$ and 282 mbsf, MSCL velocities increase in an interval of cemented sandstones, but velocities from discrete samples remain similar to the units above; this is thought to be due to sampling the less indurated parts of sections in this interval. In the sandier units below, only a few discrete samples could be measured. Here, MSCL velocities are low but increase again (with scatter) between 285 and 293 mbsf where sandstone is present.

Throughout Units II and III there is, on average, a slight increase in velocity with depth. At the Subunit IIIA/IIIB boundary, both MSCL velocity and density increase significantly in a carbonate-cemented medium-grained sandstone. In Subunit IIID (513 mbsf), both MSCL velocity and density increase as glauconite appears in the sands. Discrete velocities do not increase significantly in this unit. In Unit V (Section 313-M0028A-129R-2), a sandstone bed is identified by an increase in velocity (also clearly picked out by a change in density, the acoustic image, and conductivity). In the lower part of Subunit VB ( 581-599 mbsf), some higher velocities display some correlation with MSCL conductivity, and discrete velocities increase again from $\sim 610$ mbsf in the tan-colored silty clays of Unit VI.

\section{Magnetic susceptibility}

Magnetic susceptibility was measured at $1 \mathrm{~cm}$ intervals and illustrates changes in lithology associated with variations in the nature of magnetic minerals and/or their sizes. Core measurements and log measurements correlate extremely well, although absolute values are different. From 223 to 350 mbsf (Unit II and the top of Unit III), the magnetic susceptibility signal fluctuates from high values to intervals of low values. High-value intervals are described below. From 350 mbsf downhole, the magnetic susceptibility signal is very flat to $516 \mathrm{mbsf}$, where it increases drastically. This high-value interval extends over 34 $\mathrm{m}$ to the base of the glauconitic-rich/-poor sand transition at 550 mbsf. Slight variations then occur in the rest of Unit V to $\sim 610$ mbsf. Below this depth, Unit VI is characterized by a high magnetic susceptibility signal with alternating high and medium values.

From the seven main intervals of higher magnetic susceptibility observed from 220 mbsf to the base of Hole M0028A, four occur within Unit II through Subunit IIIA, followed by generally low magnetic susceptibility until Subunit IIID, where glauconite reappears in the sediments. The first interval of high magnetic susceptibility occurs in Subunit IIA, with a maximum at $\sim 235$ mbsf. In this interval, there are some glauconitic sand, glauconitized burrows, and also some sulfide (possibly the magnetic sulfide mineral, greigite). This unit may be similar to the clays of Unit II in Hole M0027A. Around 275 mbsf and again at 325 mbsf (Subunits IIIB and IIID), increased magnetic susceptibility is clearly related to increased glauconite in the sediments. A smaller peak is evident in Subunit IIIA, again due to glauconite. At $\sim 515$ mbsf, magnetic susceptibility is again high and the sediment glauconite rich. Susceptibilities decrease slightly below the glauconite layer. A large broad peak in susceptibility around 615-660 mbsf (Unit VI) is not related to glauconite. Figure F42 shows the relationship between $\mathrm{K}, \mathrm{K} / \mathrm{Th}$ ratios, and magnetic susceptibility, along with the glauconite content estimated by the sedimentologists.

There is a linear correlation between density and magnetic susceptibility in several intervals (Fig. F43). Glauconite was identified in all of these intervals. Linear correlations probably represent a mixing line between sediment rich in mature glauconite with high density $\left(2.9 \mathrm{~g} / \mathrm{cm}^{3}\right)$ on the one hand and high magnetic susceptibility ( 120 SI) and with siliciclastic sediment with a lower density $\left(2.5 \mathrm{~g} / \mathrm{cm}^{3}\right)$ and very low magnetic susceptibility (a few SI) on the other. Glauconite's influence on density is also seen in the density-porosity crosscorrelation (above and in Hole M0027A). 


\section{Electrical resistivity}

Resistivity is affected by a number of variables, including lithology, pore fluid and salinity, and core liner saturation. In general, there appears to be a decrease in the amount of drill fluid saturation of the core liner down a recovered core. As a result, the last section of every core has very high resistivity. Therefore, all Section 3s (generally short sections) were removed from the analysis below. Most very short sections have low core liner fluid saturation. High-pass filtering attempts to remove this effect (Figs. F37, F40).

Resistivity is highly variable from low values of $\sim 0.3$ $\Omega \mathrm{m}$ to high values of $6 \Omega \mathrm{m}$. High resistivity is encountered at a number of levels that are cemented. Low resistivity $(\sim 0.7 \Omega \mathrm{m})$ is registered between 220 and 414 mbsf, with brief intervals of higher resistivity. From 415 mbsf downhole, background resistivity gradually increases from $\sim 1.2$ to $1.6 \Omega \mathrm{m}$. This interval also has frequent brief increases in resistivity. The overall variability is greater below 415 mbsf than above.

Overall, the correspondence between resistivity measured on cores and the chlorinity of formation waters or lithology is not as clear as in Hole M0027A (see "Downhole measurements").

\section{Digital linescans and color reflectance}

All cores from Hole M0028A were measured using an X-ray fluorescence (XRF) digital linescan system. Data were recorded at a resolution of $0.068 \mathrm{~mm}$ as both images and as red-green-blue (RGB) values down the core centerline. All suitable cores were also scanned for color reflectance with the Minolta logger. Color reflectance data may reflect changes in such factors as glauconite or iron content by analysis of a specific wavelength or $\mathrm{a}^{*} / \mathrm{b}^{*}$ ratios. The scatter in the data set brought into question the suitability of the core section for this measurement (see "Physical properties" the "Methods" chapter). Efforts were made to compare the changes of color reflectance as measured by the Minolta logger with other measurements and observation, but results still need improvements.

\section{Thermal conductivity}

Thermal conductivity measurements are scattered down to $300 \mathrm{mbsf}$, with lower values around $1.4 \mathrm{~W} /$ $(\mathrm{m} \cdot \mathrm{K})$. Scattering does not allow easy interpretation of the variation. Below $300 \mathrm{mbsf}$, thermal conductivity to a first order is related to the chlorinity of interstitial waters. From 315 to 420 mbsf, high thermal conductivity fits with high electrical conductivity and salty interstitial waters (Fig. F41). Thermal con- ductivity decreases to $1.4 \mathrm{~W} /(\mathrm{m} \cdot \mathrm{K})$ at $460 \mathrm{mbsf}$, following the decrease in chlorinity of the interstitial waters. Electrical conductivity does not follow this trend. Below 520 mbsf, high thermal conductivity values again fit with the variation of both chlorinity and electrical conductivity. The low spatial resolution of thermal conductivity precludes identification of detailed chlorinity spikes. Comparison with downhole conductivity measurements and chlorinity is discussed further in "Downhole measurements."

\section{Natural gamma radiation and core-log correlation}

NGR was measured on all cores, primarily for core$\log$ correlation. Data collected are equivalent to the total gamma ray (TGR) downhole log, although absolute values are different. Gamma ray trends are described in "Downhole measurements" In general, correlation between the core and log data sets is excellent, with only minor $(<1 \mathrm{~m}$ and often $<0.4)$ adjustments required in some intervals toward the top of the cored section (see "Stratigraphic correlation"). Correlations show a most straightforward match where there are both good core recovery and distinctive peaks in downhole and core/MSCL data sets.

The correlation between core depths and logging data was verified using other petrophysical data sets, like magnetic susceptibility.

\section{Petrophysical surfaces and intervals}

Important surfaces and intervals can be identified based on pronounced or sharp changes in trends in one or more of the petrophysical measurements. Many of the abrupt shifts correspond to surfaces or intervals with trend changes in wireline logs. A preliminary summary of the most important surfaces or intervals are given in Table T12. Some surfaces and intervals correspond to important surfaces, as determined from sedimentology and/or seismic data (see "Lithostratigraphy" and "Stratigraphic correlation").

A synthesis of petrophysical data and downhole logs and derived quantities of each lithostratigraphic unit are presented at the end of "Downhole measurements."

\section{Paleomagnetism}

\section{Discrete sample measurements}

A total of 457 samples from Hole M0028A were measured in the pass-through magnetometer. In addition 
to the standard one sample per section, Cores 313M0028A-2R through 11R, 27R through 37R, and $152 \mathrm{R}$ through $171 \mathrm{R}$ were sampled at a denser resolution ranging from one sample every $50 \mathrm{~cm}$ to one sample every $20 \mathrm{~cm}$. The natural remanent magnetization (NRM) as well as the remanence after sequential alternating-field (AF) demagnetization up to 15 , 30 , or $60 \mathrm{mT}$ was measured for all samples.

\section{Remanent magnetization}

Similar to Hole M0027A, the primary magnetization in Hole M0028A is mostly carried by a low-coercivity component, and again demagnetization also indicates the presence of a high-coercivity magnetic mineral. The initial NRM moment of the sediments is typically weak, on the order of $10^{-10}$ to $10^{-8} \mathrm{Am}^{2}$, except for two clay-rich horizons in Cores 313M0028A-7R and 8R ( 239-245 mbsf) and 155R through 167R ( 620-660 mbsf), which exhibit stronger magnetic moments on the order of $10^{-8}$ to $10^{-6}$ $\mathrm{Am}^{2}$, accompanied by peaks in magnetic susceptibility (Fig. F44).

The coarser grained sequences that dominate Hole M0028A very rarely exhibit a stable NRM component after AF demagnetization. The fine-grained sediments (silt and clay) from Cores 313-M0028A-27R through 37R ( 290-321 mbsf) are also very weakly magnetized. As in Hole M0027A, inclination data show prevailing normal polarity, suggesting a viscous overprint. All cores were recovered using the ALN, which, according to our observations in Hole M0027A, could induce weak and unstable NRM magnetization magnetic grain rotation and/or structural deformation. In general, data are too noisy to distinguish any polarity zones except for Cores 313M0028A-2R through 11R (223.33-253.83 mbsf) and 152R through 171R ( 612-669 mbsf) (Fig. F45).

For the lower part of Hole M0028A, we decided to limit the demagnetization procedure to a maximum alternating field of $15 \mathrm{mT}$ in order to preserve the signal for more detailed and careful treatment after the OSP. This decision was made after looking in detail at the Hole M0027A results.

In Cores 313-M0028A-7R and 8R between 239 and 245 mbsf, inclination data show frequent reversals carried by stable components (with the maximum angular deviation typically around $3^{\circ}-5^{\circ}$ ). However, interpreting all of these intervals as real polarity chrons is not compatible with the general age-depth constraints given by $\mathrm{Sr}$ ages and biostratigraphic time zones. Instead, we suspect that either the normal or the reversed parts of this interval could be caused by a chemical remanent magnetization (CRM) overprint and more analyses are required to determine this.
As in Hole M0027A, we could only isolate a stable characteristic remnant magnetization (ChRM) within intervals with high magnetic susceptibility, implying to some degree dissolution of the primary magnetic carriers within intervals with low magnetic susceptibility. In thin sections, iron sulfide and iron carbonate are commonly observed as diagenetic phases in the sediment matrix (Fig. F46).

\section{Magnetostratigraphy}

Because of the generally weak and unstable NRM of the sediments, we were only able to establish a polarity magnetostratigraphy for Cores 313-M0028A-2R through 12R ( 223-255 mbsf) (Fig. F47) and 152R through 171R ( 610-669 mbsf) (Fig. F45). Preliminary magnetostratigraphic age-depth tie points are given in Table T13. For Cores 313-M0028A-2R through 11R ( 223-254 mbsf), polarity interpretations are based partly on principal component analysis (PCA) (red line in Fig. F47) and inclination after $20 \mathrm{mT}$ AF demagnetization. Samples from Cores 313M0028A-152R through 171R ( 610-669 mbsf) were only AF demagnetized up to $15 \mathrm{mT}$, and polarity interpretations are therefore based on the inclination after $15 \mathrm{mT}$ AF demagnetization in addition to studies of NRM components using orthogonal Zijderveld plots.

As in Hole M0027A, the magnetostratigraphic interpretation of inclination data from Cores 313M0028A-2R through 12R ( 223-255 mbsf) is dependent on the placement of the m4.1 surface (currently placed at 236 mbsf), which, according to the seismic study, could represent an unconformity in Hole M0028A. In this chapter, we present two alternative interpretations (Table T13) for each reversal boundary based on the constraints given by $\mathrm{Sr}$ isotope ages and biohorizons (Figs. F45, F47).

For Cores 313-M0028A-2R through 11R ( 223-254 mbsf), the first reversal boundary (from normal to reversed polarity $[\mathrm{N} / \mathrm{R}]$ ) between 242.59 and 242.30 mbsf is identified as the onset of either Chron $\mathrm{C} 5 \mathrm{ABr}$ or $\mathrm{C} 5 \mathrm{ACr}$. The next reversal boundary $(\mathrm{R} / \mathrm{N})$ between 226.53 and $226.23 \mathrm{mbsf}$ is identified as the onset of Chron C5AAn or C5ABn.

For Cores 313-M0028A-152R through 171R (610-669 $\mathrm{mbsf})$, the first reversal boundary (N/R) between 666.41 and $665.91 \mathrm{mbsf}$ is identified as the onset of Chron C6Ar. The reversal boundary $(\mathrm{R} / \mathrm{N})$ between 656.34 and $655.92 \mathrm{mbsf}$ is identified as the onset of Chron C6An.2n. The reversal boundary (N/R) between 622.90 and $622.65 \mathrm{mbsf}$ is identified as the onset of Chron C6An.1r, and the last reversal boundary $(\mathrm{R} / \mathrm{N})$ between 617.02 and $616.52 \mathrm{mbsf}$ is identified as the onset of Chron C6An.1n. 


\section{Downhole measurements}

The focus in this section is to provide a description of the downhole data sets collected in Hole M0028A and their significant characteristics and variations. A few examples are given of log trends and boundaries. Some measurements display variation primarily with lithology, whereas others are controlled more by postdepositional factors such as the degree of cementation and diagenesis and the type of interstitial formation water. Integration of the core and logging petrophysical data sets allow calibration of core data with in situ borehole properties and provides an assessment of the precise depth from which core was collected. These correlations are described briefly in "Physical properties" At the end of the section, a synthesis of petrophysical data, downhole logs, and derived quantities are presented for each lithostratigraphic unit.

\section{Downhole measurements in Hole M0028A}

In Hole M0028A, $1379.67 \mathrm{~m}$ of wireline logging data was acquired, in addition to VSP measurements (see Tables T7 and T8 in the "Methods" chapter). Spectral gamma ray logs were acquired through the steel drill pipe down to $670.27 \mathrm{~m}$ wireline log depth below seafloor (WSF).

Two overlapping sections of open hole were logged in Hole M0028A, from 426.3 to $657.7 \mathrm{~m}$ WSF (lower section) and from 396 to $429.2 \mathrm{~m}$ WSF (middle section). In the lower interval in open hole, acoustic, conductivity, and magnetic susceptibility logs were run. In the middle interval, acoustic and conductivity logs were acquired over a $\sim 30 \mathrm{~m}$ interval in open hole. Acoustic logs in this interval were the highest resolution and quality of all boreholes (see description below). VSP measurements were acquired at 404-656 m WSF in open hole and 0-668 m WSF through pipe (see Table T8 in the "Methods" chapter). Figure $\mathbf{F 4 8}$ provides an overview of the downhole measurements for Hole M0028A.

In all figures, downhole geophysical data and images are plotted in meters below present-day seafloor based on the wireline scale (WSF) and, where appropriate, boundaries between lithostratigraphic units (I-VII) are indicated to facilitate comparison with other chapters.

\section{Spectral gamma ray logs}

Spectral gamma ray logs allow continuous characterization of the entire borehole and are influenced primarily by lithology. The TGR signal from the downhole probe and the NGR measurement run on whole cores correlate very well and in some cases allow ac- curate repositioning of core depth below seafloor (see "Stratigraphic correlation"). In general, trends in TGR, K, Th, and $\mathrm{U}$ curves are relatively similar in the upper $500 \mathrm{~m}$ of Hole M0028A and illustrate alternating coarse-grained intervals with clay-rich intervals (Fig. F48). Total counts in the upper $220 \mathrm{~m}$ WSF are generally low. TGR values below 50 cps correspond to dominantly coarse-grained sand intervals (21-53, 90-114, 126-179, and 189-218 m WSF), whereas higher values ( $>100 \mathrm{cps}$ ) correspond to clayrich levels and stable $\mathrm{Th} / \mathrm{K}$ and $\mathrm{U} / \mathrm{K}$ ratios $(\sim 0.1)$. The top of Unit II is also dominated by clays as evidenced by TGR values $>150 \mathrm{cps}$ down to $256 \mathrm{~m}$ WSF. The TGR signal then decreases drastically in the sands below, with values $<30$ cps down to $270 \mathrm{~m}$ WSF. The lower part of Unit II is dominated by clays except at the base, where TGR increases slightly down to 324 $\mathrm{m}$ WSF (with few incursions of low counts) with a decrease in total counts over the lowest $11 \mathrm{~m}$ of the unit, when entering sands. In Unit III, TGR values are relatively low $(<80 \mathrm{cps})$, with the smallest counts encountered between 391.5 and $412 \mathrm{~m}$ WSF, which ties with intervals of poor core recovery. From 412 to $495 \mathrm{~m}$ WSF, the signal is relatively constant, with a step around $475.8 \mathrm{~m}$ WSF. A peak at $498 \mathrm{~m}$ WSF is related to an increase in Th content, whereas the highvalue interval covering Unit IV and the upper part of Unit V (519-545 m WSF) is related to high K content, reflecting the presence of glauconite within dominantly coarse-grained sediment (see "Lithostratigraphy"). TGR values decrease in the lower part of Unit V, with higher $\mathrm{K}$ content between 562 and $575 \mathrm{~m}$ WSF. Between 592 and $612 \mathrm{~m}$ WSF, TGR gradually rises because of a progressive increase in $\mathrm{Th}$ content. Unit $\mathrm{V}$ is rich in Th with a constant TGR signal around $200 \mathrm{cps}$, except at the lower limit, where an increased TGR count is associated with increased $\mathrm{K}$ content and decreased Th content, reflecting the presence of glauconite in the sediment. TGR then gradually decreases in Unit VII.

Gamma ray logs recorded in Hole M0028A can be interpreted using the same guidelines as in Hole M0027A (see "Downhole measurements" in the "Site M0027" chapter), based on TGR counts and the concentration of the spectral elements $\mathrm{K}, \mathrm{U}$, and $\mathrm{Th}$ and their ratios (Figs. F48, F49). In the upper $220 \mathrm{~m}$ of Hole M0028A, no core was recovered, and the only basis for lithological inference is the gamma ray log collected through pipe and drilling observations or assumed correlations with units recovered elsewhere. The proportion of clay versus sand in a given sedimentary body can be evaluated by the change in TGR when $\mathrm{Th} / \mathrm{K}$ ratio is stable. The occurrence of glauconite can be assessed by $\mathrm{U} / \mathrm{K}$ and $\mathrm{Th} / \mathrm{K}$ ratios (here, $<0.05$ is assumed to indicate glauconite). In- 
creasing contents of marine organic matter can possibly be assessed by a $\mathrm{U} / \mathrm{K}$ ratio higher than the Th/K ratio.

Using these guidelines, the interpretation of the gamma ray logs is generally consistent with the sedimentological observations on cores (see "Lithostratigraphy"), with a few exceptions:

- From 311 to $314 \mathrm{~m}$ WSF is the only interval where glauconite was identified in cores but not in gamma ray measurements.

- From 340 to $392 \mathrm{~m}$ WSF (top of Unit III), U/K and $\mathrm{Th} / \mathrm{K}$ ratios suggest that the glauconitic content in sands slightly decreases progressively downhole, as evidenced by a gradual decrease in $\mathrm{K}$ content and increase in $\mathrm{Th} / \mathrm{K}$ ratio.

- From 410 to $515 \mathrm{~m}$ WSF, the $\mathrm{Th} / \mathrm{K}$ ratio is very stable. The $476 \mathrm{~m}$ WSF boundary does not correspond to a change in sediment mineralogy but instead to a sudden change in the clay/sand ratio together with higher U/K ratio, possibly indicating an increase in marine organic matter that decreases progressively downhole to $492 \mathrm{~m}$ WSF. Two gamma ray spikes at 495 and $507 \mathrm{~m}$ WSF can also be related to high marine organic matter content.

- From 515 to $605 \mathrm{~m}$ WSF, glauconitic sands exhibit higher $\mathrm{U} / \mathrm{K}$ than $\mathrm{Th} / \mathrm{K}$ ratios, possibly suggesting that this unit is rich in organic matter.

- In contrast, sands from 605 to $612 \mathrm{~m}$ WSF and the underlying claystones are depleted in U compared to Th. The K content appears very low in this unit, suggesting either diagenetic $\mathrm{K}$ washout or different dominant clay mineralogy.

Based on these guidelines, it is possible to propose a lithological interpretation of the upper part of the hole (0-220 mbsf), where no cores were retrieved (Fig. F50). This section is interpreted to be dominated by sands (often caved below 136 mbsf), with potentially some glauconitic and silty successions and some clays. At $220 \mathrm{~m}$ WSF, coring started in an abruptly coarsening-upward clayey unit. Above this, there appears to be a change to sands at $214 \mathrm{~m} \mathrm{WSF}$, possibly similar to the uphole coarsening observed in offshore to shoreface-offshore transition successions from 440 to $400 \mathrm{~m}$ WSF lower in Hole M0028A or from 440 to $380 \mathrm{~m}$ WSF in Hole M0027A.

Another noteworthy feature is the $3 \mathrm{~m}$ thick clay layer (133-136 m WSF) with upper and lower boundaries underlined by strong $U$ depletion, suggesting chemical reaction at the sand/clay boundaries, possibly related to redox changes.

\section{Magnetic susceptibility logs}

Commonly, magnetic susceptibility is a clear indicator of lithological variations. In all holes, magnetic susceptibility signals from wireline measurements (EM51 probe) and the MSCL on whole cores correlate well, allowing, in some cases, accurate repositioning of core depth below seafloor. As the magnetic susceptibility wireline log in Hole M0028A begins at $\sim 425 \mathrm{~m}$ WSF in Subunit IIIC, a more extensive analysis of magnetic susceptibility can be found in "Physical properties."

\section{Acoustic image logs}

The ABI40 was run at two different resolutions in Hole M0028A, the lower resolution (72 ppt) in the lower open-hole section and the higher resolution (288 ppt) between 396 and $426 \mathrm{~m}$ WSF. Acoustic amplitude and traveltime images provide an estimate of the induration and texture of the borehole walls.

In Hole M0028A, the high-resolution interval in Unit III enables detailed features to be viewed in the borehole wall, in several places supporting sedimentological observations. In this region, the succession grades downhole from coarser grained sandier sediments to finer grained sediments. The acoustic image indicates hardening over this interval by a general increase in amplitudes and faster traveltimes. The clearest change is at $\sim 414.6 \mathrm{~m}$ WSF, where amplitude increases and the acoustic caliper changes from variable to a smaller constant diameter when encountering siltier sediments. This change correlates the Subunit IIIB/IIIC boundary. Smaller packets of high- to low-amplitude intervals evident on the images below $415 \mathrm{~m}$ WSF are consistent with normal graded storm beds identified in the cores (Fig. F51; see "Lithostratigraphy"). The mottled texture observed on the images from this interval is interpreted as possible burrows, in agreement with observations from core descriptions. Burrows are generally either harder if cemented or otherwise softer than the surrounding formation and would be expected to show up on a high-resolution acoustic log. In Section 313M0028A-79R-1, a large shell was identified in the archive half of the core but was not present in the working half. On the acoustic image, several lowand high-traveltime "patches" could indicate the location of shells. Below $426 \mathrm{~m}$ WSF, the ABI40 was run at a lower resolution (image color changes at this depth are thus artificial). In this interval, it was not possible to get good tool centralization, affecting the image quality and accuracy of the acoustic caliper. However, a generally large and variable diameter borehole is indicated in softer intervals and a more consistent smaller diameter in more indurated zones. A major change in image impedance is clearly observed around $550.2 \mathrm{~m}$ WSF, corresponding with the appearance of glauconitic-free sands. 


\section{Sonic velocity logs}

The sonic tool was not run in Hole M0028A (see "Downhole measurements" in the "Methods" chapter). Velocity measurements from whole cores and discrete samples are described in "Physical properties."

\section{Conductivity logs}

Conductivity in the borehole is influenced by a variety of aspects, including lithology, pore water content, and salinity. In Hole M0028A, the conductivity signal shows high variability (Fig. F48). The highest values are observed in Unit III between 395 and 411 $\mathrm{m}$ WSF in an interval of poor core recovery that corresponds to poorly sorted unconsolidated medium sands (e.g., Core 313-M0028A-70R). Below $411 \mathrm{~m}$ WSF, conductivity decreases abruptly in more competent and finer gained sediments containing clayey silt. This facies transition is also clearly seen on the spectral natural gamma probe (ASGR) curve and ABI40 images (Fig. F48). Conductivity then increases relatively progressively downhole to $475 \mathrm{~m}$ WSF, where it shows a low. Below this depth, conductivity is relatively constant until $497.9 \mathrm{~m}$ WSF, where it displays a significant low that correlates with a U- and Th-rich interval located just below the m5.4 boundary (see "Stratigraphic correlation"). Below this boundary, conductivity generally increases downhole to $\sim 610 \mathrm{~m}$ WSF, with numerous excursions to much lower values. In this interval, conductivity lows often tie to cemented horizons described in the cores (e.g., calcite cemented at $526 \mathrm{~m}$ WSF [top 35 $\mathrm{cm}$ of Section 313-M0028A-116R-1] and coarsegrained sandstones at $554.45 \mathrm{~m}$ WSF [lower part of Sections 129R-1 and 129R-2]). A sharp decrease in conductivity is observed at $610 \mathrm{~m}$ WSF, associated with a major change in facies from sands to the silty Th-rich clays of Unit VI. In this unit, conductivity slightly increases to $648.7 \mathrm{~m}$ WSF.

As in Hole M0027A, variations in the electrical conductivity curve fit relatively well with chlorinity changes in interstitial waters (Fig. F41; see "Geochemistry"), with the exception of the 430-470 m WSF interval, where electrical conductivity increases downhole and chlorinity slightly decreases. This exception fits with a downhole decrease in density measured in both MSCL and discrete samples and an increase in porosity over this interval. This suggests that the increased conductivity may reflect either an increase in surface conductivity related to changes in the clay fraction and/or a higher volume of pore water stored in the sediment.

\section{Vertical seismic profiling}

VSP data were acquired through pipe from $668 \mathrm{~m}$ WSF to the seafloor (Fig. F52). Downgoing waves were picked and time-depth relationships calculated. The resultant time-depth curve can be used to calibrate the time to depth of the seismic reflection profile.

\section{Example of multi-log interpretation}

Petrophysical and downhole measurements can provide evidence for sequence stratigraphic boundaries. Figure F53 is a compilation of several parameters around the m5.8 boundary (see "Stratigraphic correlation") located at the interface between lithologic Units VI and VII. It marks the abrupt transition between brown sandy siltstone with glauconite-filled burrows below and glauconitic silty medium sand above. This boundary was located at $662.98 \mathrm{mbsf}$ in the core by the sedimentologists (see "Lithostratigraphy"). In Figure F53, core and data measured on the whole core match the wireline signal relatively well, and no core depth shift was required. The m5.8 boundary is marked on the petrophysical data by a clear decrease in $P$-wave velocity and resistivity and by slight changes in density when passing from siltstone to sands. The magnetic susceptibility signal also increases significantly at this boundary, reflecting the presence of glauconite in the sand. These sands, which extend from 662.98 to $660.7 \mathrm{~m} \mathrm{WSF}$, are characterized by low TGR counts (with low Th content). TGR counts decrease toward the top of the sands, with a minimum at $661 \mathrm{~m}$ WSF, fitting with a peak in magnetic susceptibility and a slight increase in density. The top of the sands is described in the core as an abrupt but transitional change to dark sandy clays, becoming tan colored moving uphole. This transition is marked by a progressive increase in TGR counts and Th content, a slight increase in resistivity, and a decrease in magnetic susceptibility and density. The tan-colored sandy clays above show low total counts, high Th content, and high magnetic susceptibility not related to glauconite, as testified by the low K content in these deposits.

\section{Downhole log and physical property interpretation}

This section combines results of the logging and physical property measurements with the main characteristics of the lithostratigraphic units. A brief summary shows the links between key petrophysical intervals (Table T12) and stratigraphic surfaces (Fig. F36A, F36B, F36C, F36D, F36E). Lithostratigraphy depths are given in meters below seafloor and ignore 
small differences that may exist between core (mbsf) and $\log$ (m WSF) depths. More details can be found in "Physical properties" or elsewhere in this chapter. Numerical data are accessible online; see "Publisher's notes" for links to the database.

\section{Lithostratigraphic Unit VII}

Unit VII is only $7 \mathrm{~m}$ thick. From $669 \mathrm{mbsf}$ to the top of the unit, gamma ray, magnetic susceptibility, and density increase, the latter peaking at the Unit VII/VI boundary (surface m5.8). These changes reflect increasing glauconite content.

The transition to Unit VI shows a significant peak in TGR, a porosity low, and a density peak that corresponds to a sandy siltstone. The drop in amplitude of all parameters above corresponds to a change in lithology to glauconite sand.

\section{Lithostratigraphic Unit VI}

Unit IV TGR data show a flat serrated shape in high values corresponding to clay and siltstone sediments. Magnetic susceptibility displays a bow shape in the middle part of the unit that does not correlate to any change in $\mathrm{K}$ content or to glauconite content. However, as the mineralogy here is again fine grained (as in the high-magnetic susceptibility clays of Holes M0027A and M0028A in Unit II), the signal may correlate with fine-grained silt and clay glauconite. This hypothesis is supported by two XRD measurements on samples on both sides of this interval indicative of a high glauconite content. The boundary with Unit $\mathrm{V}$ shows a sharp decrease in TGR and an increase in conductivity.

\section{Lithostratigraphic Unit V}

The Unit V TGR curve shows a complex pattern with a large bow-shaped trend overlain by three irregular bell-shaped trends in low to high values. This, together with parallel variations in $\mathrm{K}$ and low $\mathrm{Th} / \mathrm{K}$ ratios, corresponds to a change in glauconite content in an overall sandy material. Large variations in conductivity values appear to relate to changing chlorinity (see "Thermal conductivity") bounded by highdensity/low-conductivity horizons in numerous cemented intervals. Most often, sediments in this unit contain some glauconite, with a general increase through the unit. This is shown by a slight increase in magnetic susceptibility from the base of the unit to 246 mbsf (surface m5.6), where there is a step increase at a marked increase in glauconite content. There appears to be an interval anomalous to this trend from 546 to $565 \mathrm{mbsf}$, where magnetic susceptibility (and the K content) is slightly lower but the glauconite content remains high.
At the boundary with Unit IV, TGR values show a distinct kick with an increase, a sharp decrease at the boundary, and then an immediate increase above the boundary. Density shows a peak and conductivity a low at this boundary.

\section{Lithostratigraphic Unit IV}

Unit IV is a thin unit that shows considerable variations in gamma ray and conductivity values. Magnetic susceptibility decreases throughout this unit, mirrored by decreasing density, which corresponds to a glauconite decrease.

The boundary with Unit III is characterized by an abrupt but gradational decrease in $\mathrm{K}$ content (and increase in $\mathrm{Th} / \mathrm{K}$ ratio) from below the boundary with a sharp step decrease at the boundary. This is accompanied by a low in MSCL velocity and porosity.

\section{Lithostratigraphic Unit III}

The Unit III TGR curve shows high values with a monotonous serrated shape at the base overlain by low values in a series of boxcar-shaped trends becoming more serrated with higher values uphole. This corresponds to the overall superposition of clayey silts with sand interbeds overlain by clean sand with possibly some glauconite. In detail, however, gamma ray values are variable, with a large peak at 498 mbsf just below the m5.4 surface. This kick is mirrored by a peak in density and a low in conductivity. In Subunit IIC, conductivity shows a gradual decrease, whereas chloride content increases, which contrasts with the trends in the remainder of the unit that follow chlorinity (see "Thermal conductivity"). The more variable gamma values in the upper subunit reflect the presence of glauconite. Magnetic susceptibility throughout this unit is low to 336 mbsf in Subunit IIA (correlating with $\mathrm{K}$ content), where glauconite appears in the formation.

The boundary with Unit II (surface m5.3) is characterized by an increase in gamma ray, which corresponds to an increase in glauconite content across the boundary. Density decreases toward the boundary to a low just below the boundary, and then, as with gamma ray values, increasing values respond to glauconite.

\section{Lithostratigraphic Unit II}

The TGR curve in Unit II shows the superposition, from base to top, of high values with a serratedshaped curve (335-295 mbsf), alternations of intermediate and low values with funnel and boxcarshaped trends (295-255 mbsf), and high values with a serrated-shape trend $(255-225 \mathrm{~m})$. These trends correspond, respectively, to clayey sediments over- 
lain by sand/silty clay alternations ending with a thick sand package capped by a fining-upward succession from silt/sand to clays. The thick sand with a boxcar character shows high Th values that may relate to the presence of glauconite despite very low magnetic susceptibility. The unit shows three highs in magnetic susceptibility (336-320, 276-284, and 232-244 mbsf). The lower two correspond to high densities and as such indicate the presence of probable fine-grained glauconite together with magnetite, as demonstrated by XRD analyses. The upper one, with low density and a low $\mathrm{Th} / \mathrm{K}$ ratio, does not correspond to glauconite but rather to ferrimagnetic mineral in the sediment. Four specific levels at 316, 288,272 , and 246 mbsf exhibit high density and low conductivity and may correspond to permeability barriers for the diffusion of fresh and salty waters in the sedimentary column. The upper two and the lower one correlate, respectively, with unconformities recognized both in cores and in the seismic data: $\mathrm{m} 5, \mathrm{~m} 5.45$, and $\mathrm{m} 5.2$. The boundary with Unit I is characterized by an abrupt decrease in TGR, from high values below to low and constant values above, reflecting an abrupt increase in grain size from silty clays to clean sands. However, the maximum decrease in TGR occurs at 217 mbsf, a few meters above the boundary. This difference in interpretation is probably due to the pick in the first recovered core by the sedimentologists.

\section{Lithostratigraphic Unit I}

The TGR curve in Unit I shows alternation of $\sim 10 \mathrm{~m}$ thick low values, boxcar trends and meter scale high values in a stack of serrated-, bow-, bell, and funnelshaped patterns. These characters correspond to alternation of shallow shelf and shoreface clean sands and coastal plain silts and clays. The $\mathrm{Th} / \mathrm{K}$ ratio shows a number of peaks from 225 to $110 \mathrm{mbsf}$; these tend to disappear in the upper part of the unit. The lack of cores and MSCL logs in this unit prevent, however, any further interpretation of these changes in $\mathrm{K}$ content.

Table T12 summarizes the key petrophysical surfaces and intervals defined in this chapter. Many of these relate to stratigraphic surfaces (last column of Table T12). An exception to this are the m5.3 sequence boundary, not picked by petrophysical characters, and a candidate for an unconformity (600-604 mbsf). Possibly, a minor peak in the $\mathrm{Th} / \mathrm{K}$ ratio and a slight decrease in density may justify the lithostratigraphic peak of the surface. Other changes of the petrophysical characteristics not recorded in the lithostratigraphy section correspond to cemented horizons or minor facies variations in the units.

\section{Stratigraphic surfaces and correlation with petrophysical intervals}

Table T12 lists the key petrophysical surfaces and intervals defined. Many of these relate to stratigraphic surfaces (see penultimate right-hand column on Table T12), although typically there is a small difference in depth that can be attributed to the precise location of the surface (i.e., at the start of an increase in a parameter value or at the peak of the change). Petrophysical surfaces and intervals are defined using the full suite of logs and petrophysical parameters, generally chosen where more than one property displays a significant change. For Site M0028, almost all stratigraphic surfaces are also characterized by a change in petrophysical parameters at or adjacent to the surface. There are apparent exceptions to this, as the m5.2 and m5.3 sequence boundaries along with the possible sequence boundary identified at 600.3-604.42 mbsf (see "Stratigraphic correlation") do not correlate with a key surface identified from petrophysical logs. However, there is a minor impedance contrast at the m5.2 boundary and a minor $\mathrm{K} / \mathrm{Th}$ peak at the m5.3 surface, along with a density decrease just below, but these were not considered significant in relation to larger variations above and below. Again at this site, several of the petrophysical surfaces/intervals that are identified do not clearly correlate with stratigraphic surfaces or lithological units/subunits. Some of these relate to cemented horizons (see notes in last column of Table T12), whereas some reflect minor sedimentological changes rather than changes on a unit/subunit scale.

\section{Stratigraphic correlation Seismic sequence identifications}

Three generations of seismic data guided the site selection of Hole M0028A. These include the Ewing 9009 (Ew9009) at $\sim 15 \mathrm{~m}$ vertical resolution and the Oceanus 270 (Oc270) and Cape Hatteras 0698 (CH0698) at $\sim 5 \mathrm{~m}$ vertical resolution. The higher resolution Oc270 and CH0698 imaged several seismic sequence boundaries not previously noted on Ew9009 and older, lower resolution data (see Table T10 in the "Methods" chapter).

Hole M0028A lies within a CH0698 grid of closely spaced lines at the crossing of dip profile 207 common depth point (CDP) 11390 and strike profile 218 CDP 4274 (Fig. F7 in the "Expedition 313 summary" chapter). CH0698 line 207 coincides with the regional Oc270 line 529. Hole M0028A is at CDP 5062 on Oc270 line 529 (Fig. F47). Time-depth correla- 
tions for this hole were based on semblance velocity data from Oc270 like they were for other Expedition 313 holes (see "Stratigraphic correlation" the "Methods" chapter).

Holes M0027A-M0029A were designed to sample different locations along the same transect of seismic sequences. Site M0028A samples features downdip from those sampled in Hole M0027A and updip from equivalents in Hole M0029A. Pleistocene through lower Miocene seismic surfaces were targeted in Hole M0028A. Pleistocene and middle Miocene surfaces comprised the first series of seismic boundaries intersected in Hole M0028A. Sheridan et al. (2000) used Geopulse data to identify Pleistocene surfaces that were named marine isotope chron (MIC) 3a, MIC3c, and MIC4. However, these reflectors were not cored, as recovery proved difficult in similar materials in Hole M0027A. Likewise, Miocene seismic sequence boundaries $\mathrm{m} 1, \mathrm{~m} 3$, and $\mathrm{m} 4$ were rotary drilled without collecting samples. The seismic facies comprising $\mathrm{m} 1, \mathrm{~m} 3$, and $\mathrm{m} 4$ contains low to moderate amplitudes and chaotic reflectors. This facies complicates tracking these surfaces through the long distances required to predict corresponding depths in Hole M0028A. Two new surfaces named m4.1 and m4.5 were traced into Hole M0028A from reflectors farther offshore. Surface m4.1 is a high-amplitude continuous reflector representing three merged surfaces as it tracks into this location. It directly overlies seismic surface $\mathrm{m} 4.5$, also a high-amplitude continuous reflector at the drill site. No previous drilling supplied chronological information regarding these two surfaces.

Strong seismic definition of lower and middle Miocene seismic surfaces continues in Hole M0028A (Figs. F54, F55). Surfaces $\mathrm{m} 5, \mathrm{~m} 5.2$, and $\mathrm{m} 5.3$ are moderate- to high-amplitude continuous sigmoidal reflectors. Hole M0028A lies proximal to their clinoform rollover positions. Clinoform rollover positions are at CDPs 4848,4860 , and 4857 on Oc270 profile 529 for $\mathrm{m} 5, \mathrm{~m} 5.2$, and $\mathrm{m} 5.3$, respectively. The seismic facies between surfaces $\mathrm{m} 4.5$ and $\mathrm{m} 5$ is uniformly transparent. Below surface $\mathrm{m} 5$, the seismic facies remains relatively transparent, with the addition of two to three high-amplitude reflectors displaying toplap against surface m5. Several moderate- to highamplitude reflectors with both toplap and downlap terminations occur within a transparent seismic facies between surfaces $\mathrm{m} 5.2$ and $\mathrm{m} 5.3$ and a newly defined surface m5.32. A surface marking a series of well-defined downlapping reflectors between CDPs 5411 and 4934 on Oc270 profile 529 across Hole M0028A marks surface m5.32 before it begins to steepen and merges with overlying surface m5.3.

Below surface m5.32, the seismic facies becomes low to moderate amplitude, discontinuous, and subpar- allel to a new surface named m5.33 (Figs. F54, F55). This surface is moderate amplitude and discontinuous on Oc270 profile 529. It appears as a moderateto high-amplitude continuous reflector on strike lines within the CH0698 200 hazard grid as well as strike line $\mathrm{CH} 0698$ profile 24 . Surface m5.33 merges with surface $\mathrm{m} 5.4$ at its clinoform rollover position at CDP 5767 on Oc270 profile 529 and downlaps onto surface m5.4 at CDP 4389 on Oc270 profile 529. Below surface m5.33, the seismic facies is low to moderate, discontinuous, and hummocky to subparallel, with hints of onlap onto a moderate-amplitude continuous reflector at $533 \mathrm{~ms}$ in Hole M0028A. This surface marks a downhole change in seismic facies of moderate-amplitude subparallel inclined seaward reflectors. They display both onlap and downlap against the underlying m5.4 surface, here a moderate- to high-amplitude sigmoidal reflector. Hole M0028A intersects sigmoidal surface m5.4 seaward of its change back to a gentle seaward-dipping slope.

Three closely spaced seismic surfaces, m5.45, m5.47, and m5.6 in descending order, lie below surface m5.4 (Figs. F54, F55). Both m5.45 and m5.47 are moderate-amplitude continuous reflectors. Lower amplitude downlapping reflectors are imaged in the $15 \mathrm{~ms}$ space between these two surfaces. No sigmoidal clinoforms are observed on surfaces m5.45 and m5.47 on Oc270 profile 529. However, both of these surfaces track into the $\mathrm{CH} 0698$ data along strike, where they display seismic terminations characteristic of seismic sequence boundaries (Monteverde et al., 2008). Reflector m5.47 displays an incised character terminating at CDP 5398 on Oc270 profile 529, just west of Hole M0028A. It truncates the underlying m5.6 surface that emerges at CDP 5516 on Oc270 line 529. Data suggest that the original sigmoidal clinoform structure of reflector m5.6 was subsequently removed by the m5.47 surface where it displays a highly rugose pattern (CDPs 7033-5386 on Oc270 profile 529).

The next surface intersected is m5.7 (Figs. F54, F55). It is a moderate-amplitude continuous reflector east of Hole M0027A that decreases in amplitude, becoming discontinuous. Moderate-amplitude discontinuous reflectors that toplap against surface m5.47 and downlap against surface m5.7 define a seismic facies bounded by surfaces $\mathrm{m} 5.47, \mathrm{~m} 5.6$, and $\mathrm{m} 5.7$. The final surface predicted to be sampled by Hole M0028A is m5.8, a moderate-amplitude continuous reflector that displays an amplitude increase at this site.

\section{Core-seismic sequence boundary integration}

The Pleistocene to upper middle Miocene section was not cored in Hole M0028A. The uppermost re- 
flectors cored were two previously unnamed reflections, $\mathrm{m} 4.1$ and $\mathrm{m} 4.5$. The former was predicted at 231-234 mbsf. No prominent surfaces were observed in Cores 313-M0028A-2R through 7R, but a series of nodules in Sections 313-M0028A-6R-1, $61 \mathrm{~cm}, 6 \mathrm{R}-1$, $110 \mathrm{~cm}$, and 6R-2, $26 \mathrm{~cm}(236.1,236.6$, and 237.3 mbsf) cause density peaks and an impedance contrast associated with reflector m4.1 (Fig. F56). We interpret this zone as a possible maximum flooding surface (MFS), consistent with its interpretation based on core observations (see "Lithostratigraphy"). A surface in Section 313-M0028A-8R-2, 101 $\mathrm{cm}$ (244.23 mbsf), consists of homogeneous gray clay that abruptly changes downsection to medium quartz sand. No impedance contrast is associated with this surface, and it is interpreted as a flooding surface. A surface in Section 313-M0028A-9R-1, 135 $\mathrm{cm}$ (246.06 mbsf), includes bored nodules and a shell bed. The core is somewhat disturbed, but MSCL data show density peaks in this layer, which is interpreted as a transgressive surface (Fig. F57); a core magnetic susceptibility change at 236.8 mbsf may mark the top of the underlying unit. An erosional surface in Section 313-M0028A-10R-1, $5 \mathrm{~cm}$ (247.78 mbsf), is interpreted as a sequence boundary; it consists of granuliferous shoreface sand abruptly overlying offshore brown silty clay. The interpretation is consistent with its interpretation based on core observations (see "Lithostratigraphy"). Density decreases from clays to sands. The change in impedance between Cores 313-M0028A-9R and 10R is associated with reflector $\mathrm{m} 4.5$, which was predicted at 241-244 mbsf. A surface in Section 313-M0028A-12R-1, 19.5 $\mathrm{cm}$ (254.02 mbsf), consists of clayey silt over sands and is interpreted as a flooding surface.

Seismic sequence boundary $\mathrm{m} 5$ was predicted at 258-263 mbsf, placing it within a medium-coarse sand package (252-267 mbsf). Cores in this interval and immediately below (down to $275 \mathrm{mbsf}$ ) are disturbed and poorly recovered. We tentatively place reflector $\mathrm{m} 5$ in a coring gap from 266 to 269 mbsf near a major increase in downhole gamma ray values. This placement associates the m5 sequence with a seismically transparent facies interpreted as sands.

Two closely spaced surfaces associated with core density peaks occur near the level where seismic sequence m5.2 is predicted at $340-348$ mbsf. A surface in Section 313-M0028A-34R-2, 95 cm (310.92 mbsf), is a sharp erosional contact between offshore above and shoreface-offshore transition below that is interpreted as a transgressive surface. A surface in Section 313-M0028A-35R-2, $48 \mathrm{~cm}$ (313.48 mbsf), is an erosional contact with shoreface-offshore transition fine-medium sand over offshore shelly clay that is interpreted as a sequence boundary (Fig. F58). Both surfaces yield density peaks, and the seismic reflector is a composite of these surfaces. This agrees with interpretations based on core observations (see "Lithostratigraphy").

A heavily burrowed surface in Section 313-M0028A$37 \mathrm{R}-2,143 \mathrm{~cm}$ (320.61 mbsf), is a contact of clay over very fine sand interpreted as an MFS (Fig. F59).

We targeted seismic sequence m5.4 in Hole M0028A where it approaches its greatest thickness (predicted from $\sim 347$ to $497 \mathrm{mbsf}$ ). Two internal reflectors within this sequence were named $\mathrm{m} 5.32$ and $\mathrm{m} 5.33$, at 370-375 and 393 mbsf, respectively. Neither shows any prominent core expression, though recovery in this interval was not good. The lower reflector, $\mathrm{m} 5.3$, is predicted immediately below a downhole gamma log increase and may be a flooding (though not MFS) surface. Core observations suggest that this may be a candidate sequence boundary at $\sim 390 \mathrm{mbsf}$ (see "Lithostratigraphy"). A tentative MFS is identified at $\sim 462$ mbsf based on core observations. The lithologic expression of the basal unconformity predicted at $489-497$ mbsf is likely a subtle surface in Section 313-M0028A-105R-1, $58 \mathrm{~cm}$ (495.19 mbsf) (Fig. F60). This is the base of a sand bed on top of sandy silt that causes a density peak. A downhole gamma log peak occurs just below this (498 mbsf), associated with the finer grained bed below.

Seismic sequence boundary m5.45 (predicted depth of $510-517 \mathrm{mbsf}$ ) is placed in Section 313-M0028A110R-2, $110 \mathrm{~cm}$ (512.29 mbsf), at the base of toe-ofclinoform-slope apron fine poorly sorted silty sand over deep offshore shelly clayey silt (Fig. F61). A surface in Section 313-M0028A-113R-1, 68 cm (519.70 mbsf), consists of toe-of-clinoform-slope apron glauconitic sands over deep offshore claystones at a burrowed surface (Fig. F62). This is likely seismic reflector $\mathrm{m} 5.47$, which is predicted at $521-530$ mbsf. An indurated zone at the top of Core 313-M0028A-116R (525.65 mbsf) likely contributes to the impedance contrast imaged as reflector m5.47. The surface at 519.70 mbsf is interpreted as a candidate sequence boundary based on core observations.

Seismic sequence boundary m5.6 (predicted depth of $540-550 \mathrm{mbsf}$ ) is in a coring gap between Cores 313M0028A-126R and 127R (544.55-546.47 mbsf) at a prominent downhole gamma log peak. Core observations did not identify a candidate sequence boundary near 545 mbsf (see "Lithostratigraphy"), reflecting difficulty in identifying sequence boundaries in stacked amalgamated toe-of-slope apron deposits.

Core surfaces associated with seismic sequence m5.7 (predicted depth of 589-599 mbsf) are uncertain. There is a deeply burrowed surface in Section 313- 
M0028A-152R-1, $76 \mathrm{~cm}$ (611.6 mbsf), with toe-ofclinoform-slope apron glauconite sand burrowed down into clay over a contact zone in interval 313M0028A-152R-1, 77-142 cm (Fig. F63). This surface is either a sequence boundary or a MFS; such heavily burrowed MFSs have not been observed onshore in New Jersey but have been interpreted in the Miocene at Bethany Beach, Delaware (USA) (Browning et al., 1996). Sediments above the glauconite sands from Section 313-M0028A-147R-1 to the top of Core 149R are shelly quartz sands rich in plant debris that could be interpreted as delta front deposits, which are in turn overlain by clinoform apron slope deposits in Core $147 \mathrm{R}$ and above; Core $148 \mathrm{R}$ is a coring gap. Thus, the unconformity may lie in the coring gap $(600.3 / 604.42 \mathrm{mbsf})$, though the surface in Core 313-M0028A-151R is a major density contrast that contributes to if not causes reflector m5.7 in Hole M0028A.

Seismic sequence boundary m5.8 (predicted depth of $649-657 \mathrm{~m}$ ) is placed in Section 313-M0028A-169R$1,61 \mathrm{~cm}(662.98 \mathrm{mbsf})$, at a major contact of silty glauconite medium sand above and sandy siltstone below a burrowed contact that is interpreted as a core sequence boundary (see "Lithostratigraphy"). The density contrast clearly begins above the sequence in the glauconite sands at $\sim 660 \mathrm{mbsf}$.

An acoustic impedance log was computed for Hole M0028A following the OSP to aid in core-seismic integration. The impedance log was constructed using MSCL bulk densities; velocities were taken from MSCL velocity logs only because downhole sonic logs were not available. The resultant acoustic impedance logs shown on the synthesis figures (Figs. F56, F57, F58, F59, F60, F61, F62, F63, F64, F65, F66, F67, F68) allow evaluation of seismic-core correlation made by other means: (1) we first predicted depth based on the velocity-depth function (Table T14); (2) we then slightly adjusted our predicted depths based on core surfaces, downhole log, and MSCL changes. In general, the impedance log at M0028 versus the other sites is hampered by recovery and reliance on MCSL data alone. Major downhole increases in impedance are associated with levels where we placed reflectors $\mathrm{m} 4.5$ (244.23 mbsf) and m5.45 (512.29 mbsf), whereas minor downhole impedance increases are associated with reflectors m5.2 (313.48 mbsf), m5.4 (495.19 mbsf), and m5.47 (519.70 mbsf). We cannot evaluate acoustic impedance contrasts associated with reflectors $\mathrm{m} 4.1, \mathrm{~m} 5$, $\mathrm{m} 5.3, \mathrm{~m} 5.32$, m5.33, m5.6, and $\mathrm{m} 5.7$ because of coring gaps.

\section{Core-seismic-log synthesis}

Figures F56, F65, F66, and F67 summarize the ties among sequence boundaries, sedimentary facies, and chronostratigraphy developed in Hole M0028A and are discussed below, emphasizing the relations between core sequences, logs, and seismic facies within a lithostratigraphic framework. (These figures are combined in Fig. F68.) These figures illustrate the same information as those for Hole M0027A (see "Stratigraphic correlation" the "Site M0027" chapter), but bulk sediment density plots from MSCL measurements are included for this site. The MSCL plot appears discontinuous because of recovery gaps, but it shows significant changes that helps define seismic boundaries. In particular, several high-density (mineralized) intervals are found in this hole; the peaks of sediment density help correlate lithology to the impedance contrasts detected on seismic profiles.

\section{Lithostratigraphic Unit II (223.33-335.37 mbsf)}

Lithostratigraphic Subunit IIA is based by an unresolved seismic reflector correlated to a sediment surface picked in the core at 254.03 mbsf and corresponding to a flooding surface at the top of the shoreface sand of lithostratigraphic Subunit IIB, marking the transition to offshore silt and clay (Subunit IIA). This reflector is positioned at the base of a fine-grained clayey silt resting on poorly sorted coarse sand and granules (the Subunit IIA/IIB contact) and a corresponding abrupt downhole decrease in NGR and TGR values. A moderate impedance contrast is present at this depth as well. Subunit IIA is composed of two fining-upward intervals, corresponding basically to shoreface-offshore transitions in depositional environments. Several surfaces observed in the cores can be possibly correlated to the two seismic reflectors recognized within Subunit IIA: $\mathrm{m} 4.1$ and $\mathrm{m} 4.5$.

Seismic reflector m4.1 is predicted at $231-234 \mathrm{mbsf}$ and matches the MFS surface placed between 236 and 237 mbsf. In fact, three distinct density peaks observed in Sections 313-M0028A-6R-1 (61 and 110 $\mathrm{cm})$ and $6 \mathrm{R}-2(26 \mathrm{~cm})$ appear to generate the impedance contrast observed on seismic reflection (Fig. F56).

The depth range calculated on velocity for surface $\mathrm{m} 4.5$ corresponds to the surfaces detected in the sedimentary record. The surface $\mathrm{m} 4.5$ predicted interval (241-244 mbsf) covers the lithological horizon that includes the seismic boundary at 247.78 mbsf (Section 313-M0028A-10R-1, $5 \mathrm{~cm}$ ), a transgressive surface at 246.06 mbsf (Section 9R-1, $135 \mathrm{~cm}$ ), and a flooding surface at 244.23 (Section 8R-2, $103 \mathrm{~cm}$ ). The maximum for sediment density correlates with the flooding surface (carbonate nodules occurring at the condensed interval; see "Core-seismic sequence 
boundary integration"). Fairly good chronological data suggest that the base of the sequence is $\sim 14 \mathrm{Ma}$ (Sr isotope age of $13.8 \mathrm{Ma} \pm 17 \mathrm{~m}$.y.; see "Chronology").

Poor recovery does not allow precise placement of seismic sequence boundary $\mathrm{m} 5$, which is predicted between 258 and 263 mbsf. Nonetheless, it can be tentatively positioned at the base of Core 313M0028A-18R in an interval spanning from 266 to 269 mbsf. Reflector m5 also marks a change in seismic facies that passes from transparent to subparallel reflectors and a lithological transition clearly seen in TGR/NGR values (Fig. F56).

Subunit IIC is based by seismic reflector m5.2. It is predicted at 310-316 mbsf and contains two surfaces described in the cores, corresponding to two distinctive peaks in density values. The first one is interpreted as a transgressive surface and has been described at 310.92 mbsf (Section 313-M0028A-34R-2, $95 \mathrm{~cm}$ ). The second is placed at $313.48 \mathrm{mbsf}$ (Section $313-\mathrm{M} 0028 \mathrm{~A}-35 \mathrm{R}-2,48 \mathrm{~cm}$ ) and correlates to a sequence boundary described in the core as an erosional contact associated with a high impedance contrast. TGR values decrease between the two surfaces, related to the low Th concentration in finegrained sand (Fig. F56). Changing lithology corresponds to fining-upward grain size in Subunit IIC, with shelly sands at the base passing to silt containing shell debris and wood fragments, indicating a passage from shoreface-offshore transition into an offshore environment. This part of the succession coarsens uphole into Subunit IIB (river-influenced shoreface). Variations in bulk density, TGR values, and impedance contrasts are visible on the logs in this interval (between 270 and 310 ), but no seismic reflection can be identified that corresponds to these changes.

\section{Lithostratigraphic Unit III (335.37-512.29 mbsf)}

The depth range based on velocity for surface m5.3 is predicted between 340 and 348 mbsf, but an associated surface was not identified in cores from this interval. However, this predicted depth range correlates approximately with the transition between $\mathrm{a} \sim 7$ $\mathrm{m}$ coring gap and the contact between lithostratigraphic Units II and III. We place the seismic boundary associated with reflector $\mathrm{m} 5.3$ in this coring gap between 335 and 342 mbsf (Fig. F56).

Reflectors m5.3 and m5.33 bracket lithostratigraphic Subunit IIIA, which is composed of massive coarse sand with sparse glauconite, interpreted as having been deposited in a shoreface environment. The predicted depth for reflector m5.33 is at 393 mbsf, located at the transition in seismic facies from subpar- allel to weak and discontinuous reflectors. Gamma ray values show a peak at $\sim 391$ mbsf related to enrichment in $U$ content. A peak in density is also observed at $\sim 390$ mbsf (cemented sand), but sedimentary facies are poorly documented in this interval because of discontinuous recovery. Nonetheless, the density increase creates a sharp impedance contrast we conclude is the cause of reflector m5.33 (Fig. F65).

Sequence reflector m5.32 is predicted between 370 and 375 mbsf, but no sedimentary discontinuity can be detected in the cores (poorly recovered interval). Nonetheless, a clear change in seismic facies can be observed at this level, passing from subparallel-inclined reflectors to weak discontinuous reflectors downhole (Fig. F65).

Lithostratigraphic Subunit IIIB (river-influenced shoreface deposits) is a poorly recovered interval that correlates with very low gamma ray values (coarsegrained sand). Subunit IIIB represents the top of a shallowing-upward sequence that begins at seismic sequence boundary m5.4. The predicted depth for this latter reflector (489-498 mbsf) matches a surface in the core (Section 313-M0028A-105R-1, $58 \mathrm{~cm}$; 495.19 mbsf). From the m5.4 sequence boundary uphole, the coarsening-upward sedimentary succession (most of Subunit IIID and all of Subunits IIIC and IIIB) is clearly marked by blocky stepwise decreasing gamma ray values. The seismic facies associated with this sequence begins at the base as strong, continuous reflectors onlapping the m5.4 clinoform slope and changes abruptly to subparallel and discontinuous reflectors close to an interval of poor core recovery at 450 mbsf. No change in log character is apparent at this depth (Fig. F65). The $\sim 17 \mathrm{~m}$ interval between reflectors $\mathrm{m} 5.4$ and $\mathrm{m} 5.45$ (the base of lithostratigraphic Unit III) corresponds to coarse sand and gravel deposited in an apron at the toe of a clinoform and is overlain by a rapidly fining-upward package ending at surface m5.4 (Fig. F66).

\section{Lithostratigraphic Unit IV (512.29-525.52 mbsf)}

Lithostratigraphic Unit IV is separated from Unit III by seismic reflector m5.45. The predicted depth for sequence boundary m5.45 is between 510 and 517 mbsf and correlates well with the discontinuity in Section 313-M0028A-110R-2, $114 \mathrm{~cm}$ (512.33 mbsf). A decrease in gamma ray values coincides with this surface being marked by a shelly lag (Figure F66). The upper part of lithostratigraphic Unit IV lies between the m5.45 and m5.47 seismic sequence boundaries. This interval is characterized by a seismic facies showing clear parallel reflectors, possibly related to sediment lithology and consisting of alter- 
nating silt and thin sand beds deposited in a deepoffshore environment.

The predicted depth to seismic sequence boundary $\mathrm{m} 5.47$ (521-530 mbsf) is slightly deeper than the discontinuity noted in the core (519.70 mbsf). In addition, sequence m5.47 will need to be better constrained in age because the assignment to dinocyst Zone DN2 (early Miocene) appears to be too old compared to constraints on the overlying sequence (NN4; for sequence boundary m5.45, see "Chronology"). Nonetheless, it correlates well with a downhole interval to low TGR values (coarse sand bed overlying offshore clay) (Fig. F66).

\section{Lithostratigraphic Unit V (525.52-611.19 mbsf)}

Lithostratigraphic Unit $\mathrm{V}$ is mostly composed of coarse sand-bearing glauconite. An indurated zone between 530 and 545 mbsf corresponds to a K-enriched zone (glauconite). The predicted depth of reflector m5.6 closely matches the base of this interval of indurated beds. Glauconite and high-K gamma log values decrease steadily below this depth, and the remainder of lithostratigraphic Unit $\mathrm{V}$ is predominantly quartz rich, occasionally coarse-grained toe-of-slope debrites.

The calculated depth for sequence boundary m5.6 is between 540 and 550 mbsf (Fig. F66). The sedimentary discontinuity associated with this reflector is placed in a coring gap between Cores 313-M0028A126R and 127R.

Seismic sequence boundary m5.7 bounds the base of lithostratigraphic Unit V (Subunit VC) and is predicted at 589-599 mbsf, but a corresponding surface in recovered cores is not clearly defined. Three surfaces are possible: $600.3 \mathrm{mbsf}$ (base of Core 313M0028A-147R), 604.42 mbsf (top of Core 149R), and 611.6 mbsf (Section 152R-1, $108 \mathrm{~cm}$ ), as shown in Figure F66.

The possible sequences bordered by boundaries $\mathrm{m} 5.47$, m5.6, and $\mathrm{m} 5.7$ are poorly constrained in age. Between 545 and 610 mbsf, several peaks in TGR and MSCL bulk density are visible on the log (as well as significant impedance contrasts), but no additional seismic reflectors were identified. The interval is characterized by strong hummocky downlapping seismic facies (Fig. F66).

\section{Lithostratigraphic Unit VI (611.19-662.98 mbsf)}

Lithostratigraphic Unit VI is bordered by sequence boundaries $\mathrm{m} 5.7$ and $\mathrm{m} 5.8$. Both reflectors have been correlated to abrupt changes in impedance, al- though their predicted depths leave this association uncertain and in need of further analysis. The entire unit is assigned to mid-Zone NN2 and Zone DN2 (middle early Miocene).

Seismic surface m5.8 is predicted between 649 and 657 mbsf, positioned slightly shallower than the sedimentary discontinuity described in the core (Section 313-M0028A-169R-1, $61 \mathrm{~cm}$ ) where a major burrowed contact correlates with a density contrast and the beginning of a peak on the gamma ray values (increasing $\mathrm{K}$ concentration in correspondence with glauconite sand; Fig. F67).

Lithostratigraphic Unit VI is a mostly fine-grained, well-laminated interval composed of clay and silt alternations deposited in a river-influenced offshore setting. The seismic facies characterizing this interval consists of transparent-parallel reflectors, generating a moderate impedance (Fig. F67).

In summary, log data are only available from 223 mbsf in Hole M0028A, covering lithostratigraphic Units II-VII (Fig. F64). Sequence boundaries $\mathrm{m} 4.5$, m5.2 (Unit II), m5.45 (Unit III), and m5.8 (Unit VII) picked in the cores correlate perfectly with downlogging data and seismics, whereas the position of seismic reflectors m5 (Unit II), m5.32, m5.33 (Unit III), and m5.6 (Unit V) remain problematic because of core gaps. Nonetheless, sequence boundary m5.6 corresponds to a prominent peak in TGR values at the base of indurate glauconite sandstone. Thus, reflector m5.6 can be confidently correlated to the TRG peak at the passage between Cores 313M0028A-126R and 127R, despite the coring gap. Multiple seismic surfaces are possible for sequence boundary m5.7. The correlation with NGR and TGR values appears inconclusive; the unconformity may lie in a core gap. Finally, despite a prominent drop in impedance, a strong lithologic change, and a major gamma log change, the correlation of sequence boundary m5.8 to the core record remains unclear.

\section{Chronology}

The Pleistocene to upper middle Miocene section was not cored in Hole M0028A, and the hole bottomed in the lower Miocene. Chronology for the lower middle to lower Miocene in Hole M0028A was obtained by integrating on an age-depth diagram (Fig. F23) the following:

1. Biostratigraphy provided by calcareous nannofossil, planktonic foraminifer, and dinocyst data. Zonal durations are plotted using tables provided in "Paleontology" along with select datum levels (first and last occurrences). 
2. Sr isotopic ages and associated age errors.

3. Placement of sequence boundaries and other stratal surfaces (Table T14).

4. The timescale of Berggren et al. (1995; BKSA95).

Surfaces were picked as seismic sequence boundaries in two-way traveltime (Table T14) and converted to depth and tied to cores (Table T14) using a velocity function (see "Stratigraphic correlation" in the "Methods" chapter for discussion of criteria used to define seismic sequence boundaries and the derivation of the time to depth conversion of seismic data). In figures, features are presented as follows:

- If unsampled by cores, the reflector is indicated with a gray shaded zone.

- If identified in a core, the surface was plotted as a solid red line for sequence boundaries and a dashed line where uncertain or where there was more than one possible core surface for a given seismic sequence boundary (see "Stratigraphic correlation").

- A few prominent (but not all) features interpreted as MFSs identified in the cores (see "Stratigraphic correlation") are indicated with a green line.

- A visual best fit sedimentation rate line was estimated for each sequence and an age error assigned to each. The sedimentation rate is not corrected for postdepositional compaction and represents a minimum sedimentation rate.

The section above sequence boundary m4.5 (247.78 mbsf) is constrained only by one $\mathrm{Sr}$ isotope age of $13.8 \mathrm{Ma} \pm 1.17 \mathrm{~m} . \mathrm{y}$. and is assigned to calcareous nannofossil Zones ?NN6 and NN5 and planktonic foraminifer Zone M7/N10. The overlap of G. praemenardii (FO $\sim 14.2 \mathrm{Ma}$ ) and G. archeomenardii (LO 13.9 $\mathrm{Ma})$ suggests that the base of this sequence is $\sim 14$ Ma. This sequence is older than sequences $\mathrm{m} 3$ and $\mathrm{m} 4$, which correlate with the two major steps (Mi3 and Mi4) in the middle Miocene oxygen isotopic record (Miller et al., 1998).

Sequence $\mathrm{m} 5$ (246.0-268/271 mbsf) is constrained in age by one $\mathrm{Sr}$ isotope age estimate of $14.0 \mathrm{Ma} \pm 1.17$ m.y. and is assigned to dinocyst Zone DN5 and nannofossil Zone NN5. Its age is determined largely by superposition as 14-15 Ma. Sequence m5.2 (268/ 271-313.48 mbsf) is constrained in age by $\mathrm{Sr}$ isotope age estimates of $15.8 \mathrm{Ma} \pm 0.6$ m.y. and $16.1 \mathrm{Ma} \pm$ 0.6 m.y. to Zone DN4 and Zones NN5 and NN4. The NN4/NN5 zonal boundary provides a firm age constraint $(15.6 \mathrm{Ma})$ within the sequence, with a basal age of $\sim 16 \mathrm{Ma}$ obtained by assuming a high, constant sedimentation rate. Sequence m5.3 (313.48$335.5 / 342.4 \mathrm{mbsf}$ ) is constrained in age by $\mathrm{Sr}$ isotope age estimates of $16.7 \mathrm{Ma} \pm 0.6 \mathrm{~m} . \mathrm{y}$. and $16.4 \mathrm{Ma} \pm$ 0.6 m.y., Zone NN4, and Zone DN2-DN3. Its age is not well constrained $(\sim 16-17 \mathrm{Ma})$, with a possible age of 16.4-16.8 Ma. Sequence m5.4 (335.5/342.4?495.2 mbsf) is assigned to Zones NN4, M3/N6 or older, and DN3 (DN2 dinocysts are reworked into this sequence). Sr isotope ages of $16.6 \mathrm{Ma} \pm 0.6 \mathrm{~m} . \mathrm{y}$. and $17.3 \mathrm{Ma} \pm 0.6 \mathrm{~m} . \mathrm{y}$. are concordant with the biostratigraphy, but two ages of 18.8 and 18.3 Ma may suffer from reworking, as noted by the dinocysts. The basal age is 17.3-18.3 Ma, with a best estimate of $\sim 18 \mathrm{Ma}$. Sequence m5.45 (?495.2-512.3 mbsf) is assigned to Zones NN4 (<18.4 Ma) and DN2-DN3. The sole $\mathrm{Sr}$ isotopic age estimate of $18.6 \mathrm{Ma} \pm 0.6 \mathrm{~m}$.y. is consistent within errors. The sequence boundary is clearly younger than $18.4 \mathrm{Ma}$ but could be as young as $\sim 17$ Ma with a best estimate of $\sim 18.2 \mathrm{Ma}$. Sequence m5.47 (512.3-519.7 mbsf) has little age constraint other than superposition. The assignment to dinocyst Zone DN2 appears too old compared to constraints on the overlying and underlying sequence. Sequence m5.6 (519.7-544.5/546.7 mbsf) is only constrained by the presence of $G$. praescitula (FO 18.5 Ma) and the presence of Zone NN4 $(<18.4$ $\mathrm{Ma})$ at the top. Extrapolation of sedimentation rates would yield an age range of $18.6-19.6 \mathrm{Ma}$. Sequence m5.7 (544.5-600.3 mbsf) has no constraint other than superposition (18.6 to $\sim 20.5 \mathrm{Ma}$ ). Sequence m5.8 (600.3-663.0 mbsf) is assigned to midZone NN2 ( 20-21.5 Ma) and Zone DN2. Provisional magnetostratigraphy (see "Paleomagnetism") identifies a thick $(>18 \mathrm{~m})$ normal magnetozone in the lower part of this sequence, overlain by a more complicated interval that appears reversed. Given the biostratigraphic constraints $(\sim 20-21.5 \mathrm{Ma})$ that are quite consistent with regional correlations (including Hole M0027A), this normal magnetozone may be Chron C6AN.2n and the reversal below it Chron C6AN.2r, suggesting a basal age of $\sim 21.5$ Ma. Sequence $\mathrm{m} 6$ was just reached at the bottom of the hole, with an Sr isotope age of $20.7 \mathrm{Ma} \pm 0.6$ m.y.

Sedimentation rates are difficult to estimate in Hole M0028A from the preliminary age constraints. Typical sedimentation rates shown on Figure F23 are 40 $\mathrm{m} / \mathrm{m}$.y. Sedimentation rates during deposition of the m5.4 sequence in a position near its greatest thickness were higher: the $\sim 145 \mathrm{~m}$ of this sequence was deposited in 1-1.5 m.y. with sedimentation rates of $\sim 100-145 \mathrm{~m} / \mathrm{m} . \mathrm{y}$. The relatively thick sequences m5.2 and m5.8 ( 43 and $51 \mathrm{~m}$, respectively) appear to have been deposited in $<1 \mathrm{~m}$.y. with rough sedimentation rates of $\sim 50$ and $75 \mathrm{~m} / \mathrm{m}$.y., respectively.

\section{References}

Bahr, D.B., Hutton, E.W.H., Syvitski, J.P.M., and Pratson, L.F., 2001. Exponential approximations to compacted 
sediment porosity profiles. Comp. Geosci., 27(6):691700. doi:10.1016/S0098-3004(00)00140-0

Berggren, W.A., Kent, D.V., Swisher, C.C., III, and Aubry, M.-P., 1995. A revised Cenozoic geochronology and chronostratigraphy. In Berggren, W.A., Kent, D.V., Aubry, M.-P., and Hardenbol, J. (Eds.), Geochronology, Time Scales and Global Stratigraphic Correlation. Spec. Publ.-SEPM (Soc. Sediment. Geol.), 54:129-212.

Bolli, H.M., Saunders, J.B., and Perch-Nielsen, K. (Eds.), 1985. Plankton Stratigraphy: Cambridge (Cambridge Univ. Press).

Browning, J.V., Miller, K.G., and Pak, D.K., 1996. Global implications of lower to middle Eocene sequence boundaries on the New Jersey Coastal Plain-the icehouse cometh. Geology, 24(7):639-642. doi:10.1130/ 0091-7613(1996)024<0639:GIOLTM>2.3.CO;2

Cande, S.C., and Kent, D.V., 1995. Revised calibration of the geomagnetic polarity timescale for the Late Cretaceous and Cenozoic. J. Geophys. Res., [Solid Earth], 100(B4):6093-6095. doi:10.1029/94JB03098

de Verteuil, L., and Norris, G., 1996. Miocene dinoflagellate stratigraphy and systematics of Maryland and Virginia. Micropaleontology, 42(Suppl.). doi:10.2307/ 1485926

Martini, E., 1971. Standard Tertiary and Quaternary calcareous nannoplankton zonation. Proc. Int. Conf. Planktonic Microfossils, 2:739-785.

Miller, K.G., Mountain, G.S., Browning, J.V., Kominz, M., Sugarman, P.J., Christie-Blick, N., Katz, M.E., and Wright, J.D., 1998. Cenozoic global sea level, sequences, and the New Jersey transect: results from coastal plain and continental slope drilling. Rev. Geophys., 36(4):569602. doi:10.1029/98RG01624
Miller, K.G., Rufolo, S., Sugarman, P.J., Pekar, S.F., Browning, J.V., and Gwynn, D.W., 1997. Early to middle Miocene sequences, systems tracts, and benthic foraminiferal biofacies, New Jersey coastal plain. In Miller, K.G., and Snyder, S.W. (Eds.), Proc. ODP, Sci. Results, 150X: College Station, TX (Ocean Drilling Program), 169-186. doi:10.2973/ odp.proc.sr.150X.313.1997

Monteverde, D.H., Mountain, G.S., and Miller, K.G., 2008. Early Miocene sequence development across the New Jersey margin. Basin Res., 20(2):249-267. doi:10.1111/ j.1365-2117.2008.00351.x

Mountain, G.S., Miller, K.G., Blum, P., et al., 1994. Proc. ODP, Init. Repts., 150: College Station, TX (Ocean Drilling Program). doi:10.2973/odp.proc.ir.150.1994

Rider, M., 2006. The Geological Interpretation of Well Logs (2nd ed.): Sutherland, Scotland (Whittles).

Sclater, J.G., and Christie, P.A.F., 1980. Continental stretching: an explanation of the post-mid-Cretaceous subsidence of the central North Sea basin. J. Geophys. Res., [Solid Earth], 85(B7):3711-3739. doi:10.1029/ JB085iB07p03711

Sheridan, R.E., Ashley, G.M., Miller, K.G., Waldner, J.S., Hall, D.W., and Uptegrove, J., 2000. Offshore-onshore correlation of upper Pleistocene strata, New Jersey coastal plain to continental shelf and slope. Sediment. Geol., 134(1-2):197-207. doi:10.1016/ S0037-0738(00)00020-8

Publication: 4 December 2010 MS 313-104 
Figure F1. Symbols and colors used in "Lithostratigraphy" and "Stratigraphic correlation" figures for Hole M0028A.

$\begin{array}{llll}\text { Silt } & \text { Sand } & \text { Bioclastic horizon } \\ \text { Very fine/fine sand } & \text { Glauconite }(>25 \%) & X \quad X \text { Indurated/nodule }\end{array}$

\begin{tabular}{|c|c|c|c|c|c|}
\hline$\triangle$ & Fining-upward interval & $\mathrm{p}$ & Pyrite & $\infty$ & Echinoids \\
\hline$\nabla$ & Coarsening-upward interval & g & Glauconite & Q & Shell fragments \\
\hline$\uparrow$ & Normal grading & $\pi$ & Cross laminae & $\triangle$ & Shell debris \\
\hline$\downarrow$ & Reverse grading & $\geqq$ & Wedge-planar laminae & (2) & Articulated shell \\
\hline 6 & Burrow & $m$ & Scour & 8 & Foraminifers \\
\hline क & $\begin{array}{l}\text { Hummocky cross } \\
\text { stratification }\end{array}$ & $=$ & Horizontal lamination & छీ & Gastropods \\
\hline $\mathscr{E}$ & $\begin{array}{l}\text { Swaley cross } \\
\text { stratification }\end{array}$ & 2 & $\begin{array}{l}\text { Convoluted bedding } \\
\text { Bioturbation }\end{array}$ & C.D. & $\begin{array}{l}\text { Organic matter } \\
\text { Core disturbance }\end{array}$ \\
\hline
\end{tabular}

\begin{tabular}{ll} 
S.5.4 & Predicted depth range for seismic reflection \\
\hline S.3 Surface boundary & Surface based on log data \\
\hline
\end{tabular}

$\mathrm{SF}=$ shoreface $\mathrm{OFF}=$ offshore $\mathrm{dOFF}=$ distal offshore $\mathrm{SOT}=$ shoreface-offshore transition 
Figure F2. Location of Hole M0028A on seismic line 529, showing lithostratigraphic units in color on a background with seismic reflectors. CDP = common depth point.

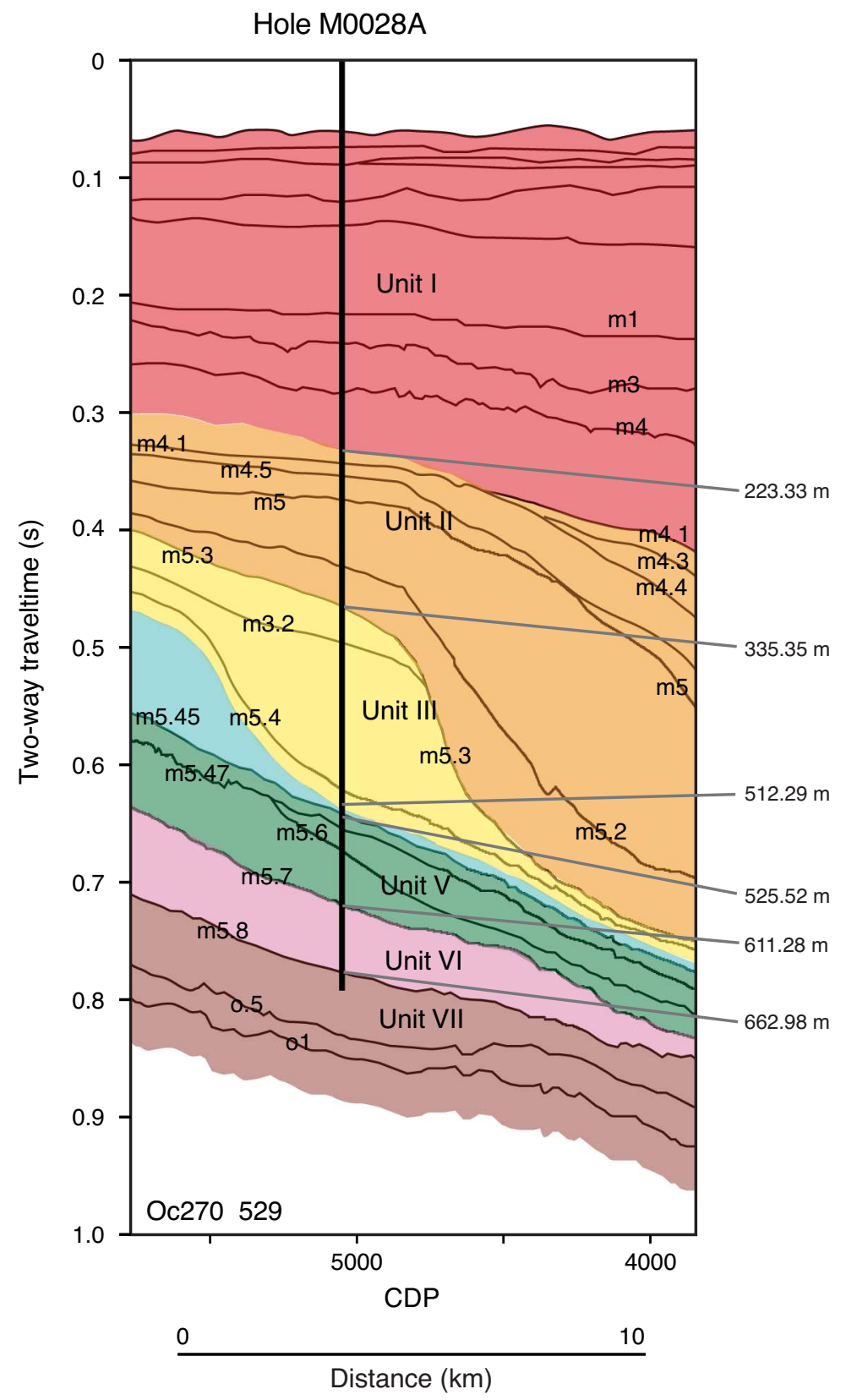




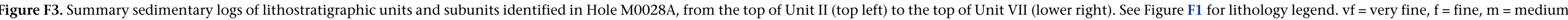
= coarse
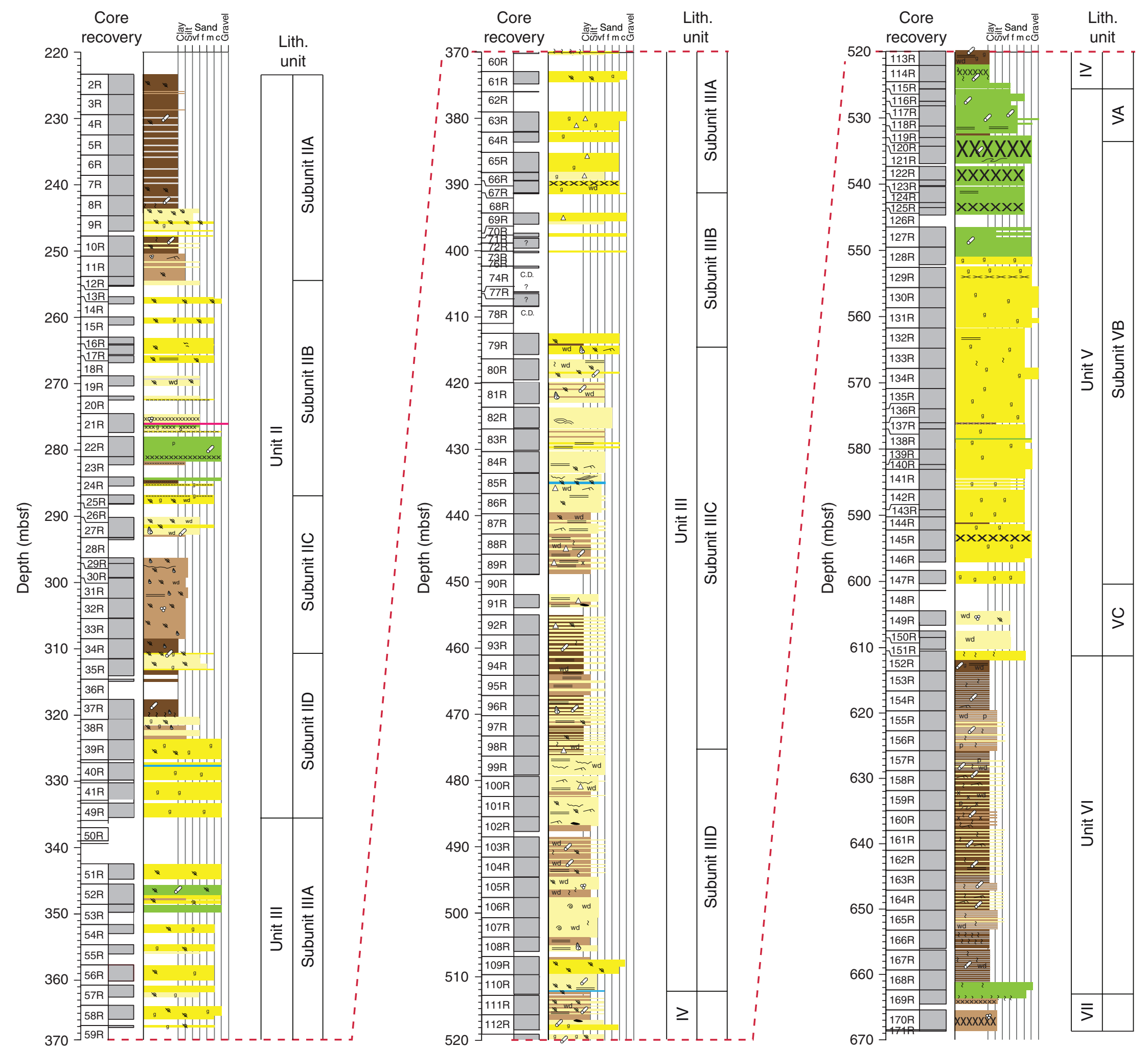
Figure F4. Core photograph of very fine grained sand with carbonate-cemented nodules showing glauconitized rims and borings (interval 313-M0028A-9R-1, 96-134 cm). Shell bed at $130 \mathrm{~cm}$ with medium sand matrix. Shells are mostly gastropods and few bivalves.

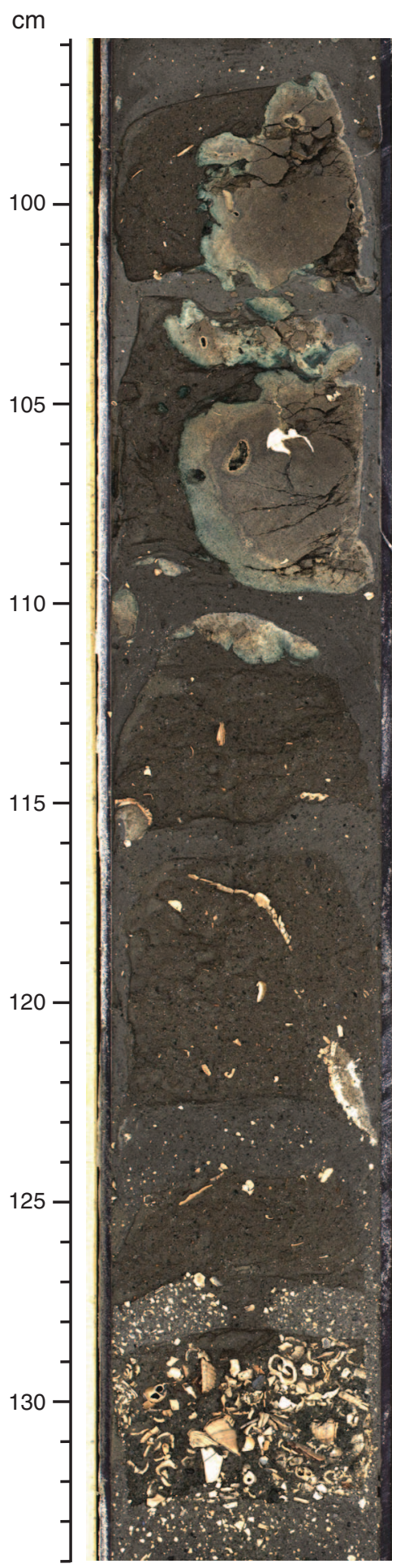


Figure F5. Core photograph of silty, glauconitic (30\%) medium sand with scattered quartz granules and mudfilled burrows (interval 313-M0028A-22R-1, 13-30 cm).

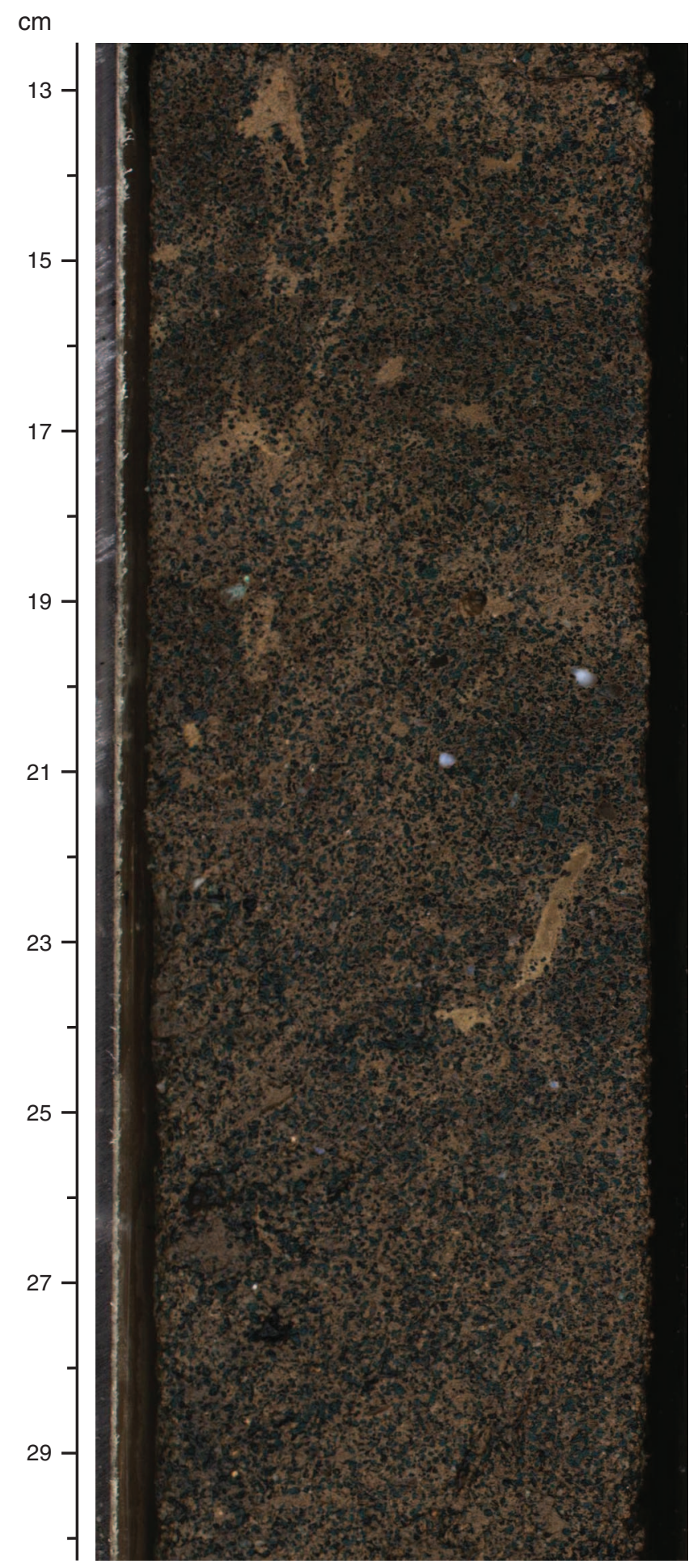


Figure F6. Photomicrograph of calcite-cemented glauconitic silty medium sandstone under cross-polarized light (Sample 313-M0028A-25R-1, 5-10 cm). Quartz grains are subrounded to subangular, with some surfaces rimmed by glauconite. Calcite cement occurs as microspar. Opaque grains are scattered within the cement and concentrated along the fringe of and within glauconite grains. Large dark green glauconite grain on right shows irregular lobate morphology. Pale green glauconite grain on left has irregular shape and is surrounded by sparry calcite. Field of view $=0.7 \mathrm{~mm}$.

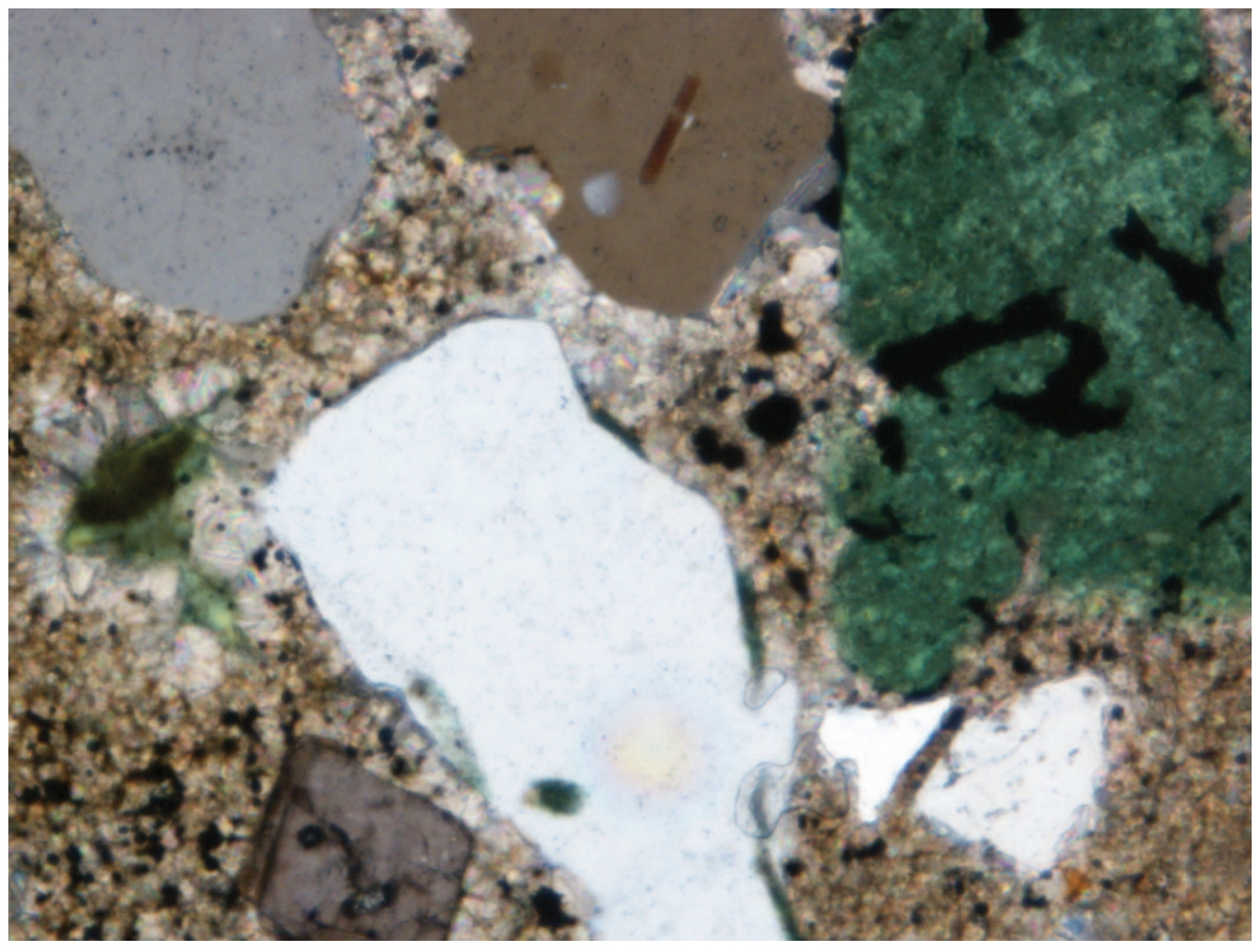


Figure F7. Core photograph of poorly sorted glauconitic (30\%) coarse sandstone with numerous dispersed subangular quartz and lithic granules $(2 \%-3 \%)$, rounded clay clasts $(68-70 \mathrm{~cm})$, and heavily bioturbated fabric (interval 313-M0028A-41R-1, 50-96 cm).

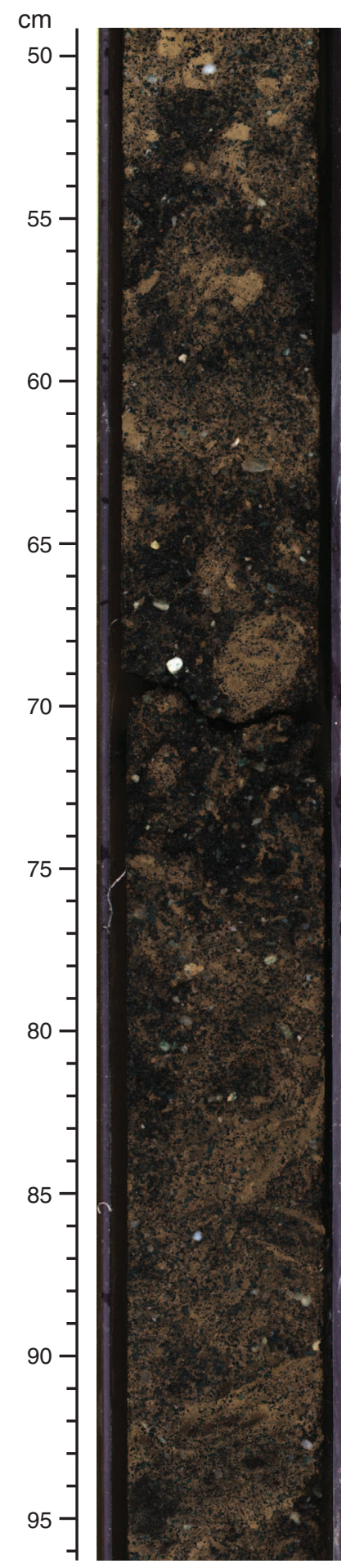


Figure F8. Smear slide photomicrograph of silty very fine sand with fragments of microfossils such as diatoms, sponge spicules, silicoflagellates (middle left), and foraminifers (upper right), together with a small amount of mica, framboidal pyrite, and some opaque minerals (Sample 313-M0028A-83R-1, $15 \mathrm{~cm}$ ). Field of view =0.7 $\mathrm{mm}$.

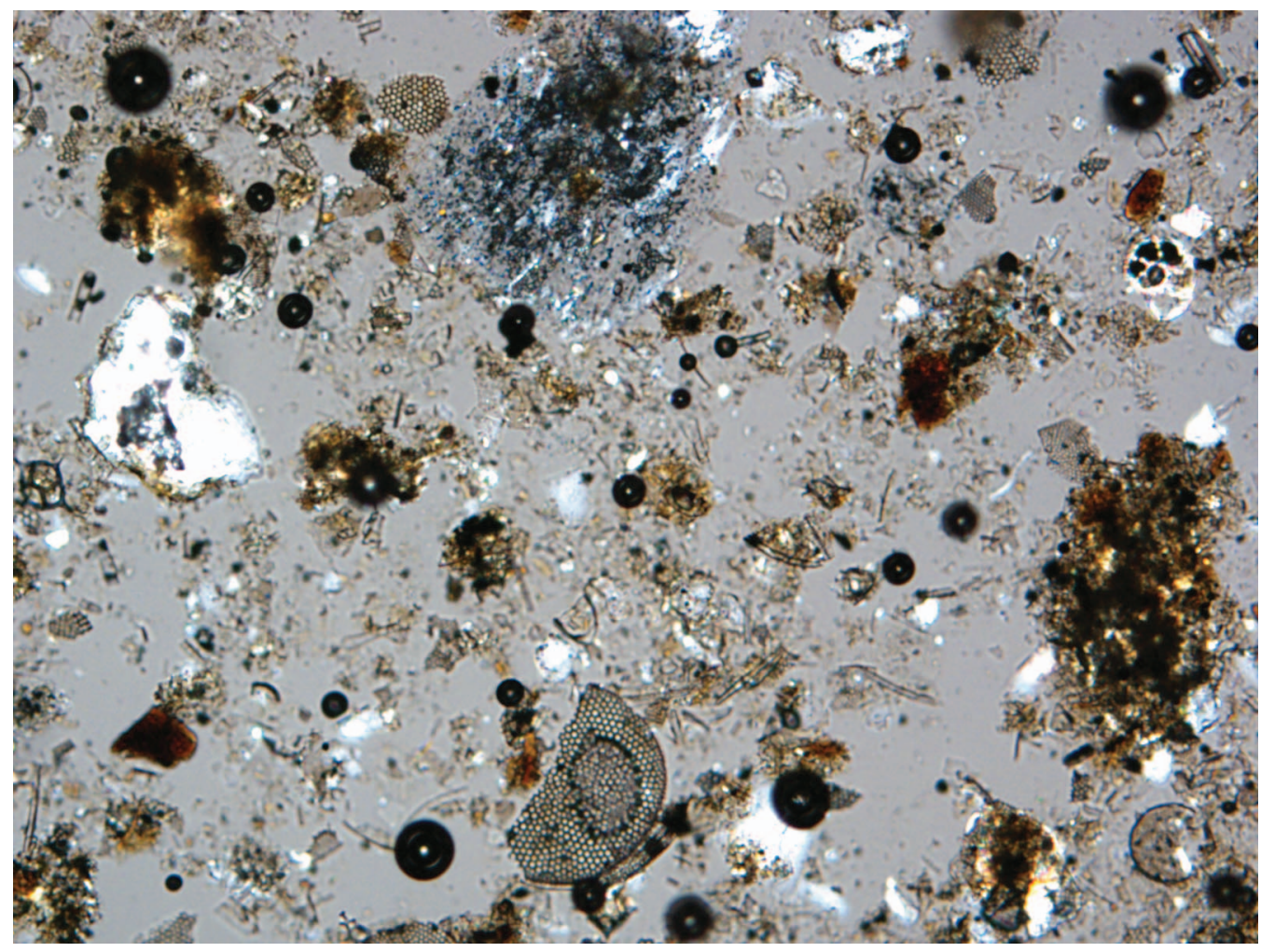


Figure F9. Core photograph of sharp-based two-part sand bed with lower clean sand division $(64-59 \mathrm{~cm})$ with shell fragments concentrated at the top and no bioturbation and upper silty sand division $(59-54 \mathrm{~cm})$ with lowangle laminations, clay, and no bioturbation (interval 313-M0028A-80R-2, 43-67 cm). Above $54 \mathrm{~cm}$ is muddy and bioturbated fine sand. These two-part beds are interpreted as combined flow deposits under the influence of geostrophic (lower division) and storm wave (upper division) generated currents.

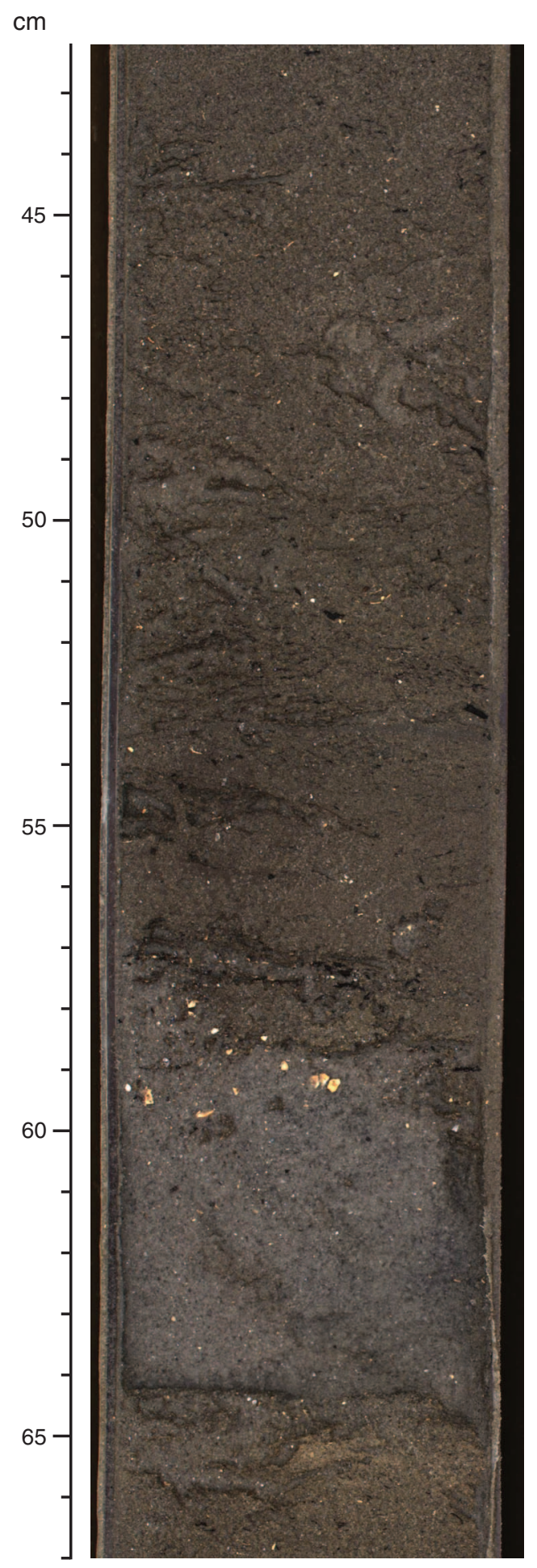


Figure F10. Core photograph of interbedded clayey silt (55-51 and 45-40 cm) and very fine grained sand with sharp bases that have locally been flushed during core splitting $(50-45 \mathrm{~cm})$ and low-angle subparallel lamination (interval 313-M0028A-92R-2, 35-55 cm). The environment of deposition is interpreted as a storm-influenced shoreface-offshore transition zone.

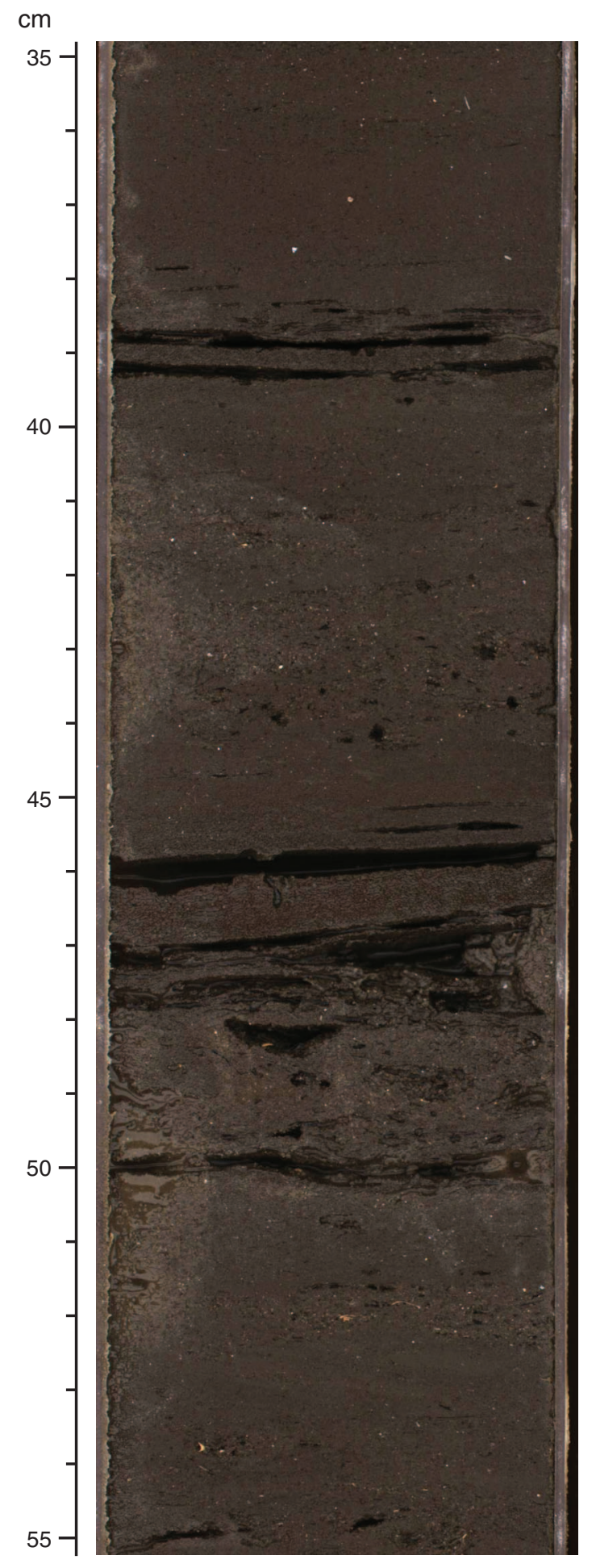


Figure F11. Smear slide photomicrograph of silt with abundant diatom fragments and sponge spicules, along with sand, mica, framboidal pyrite, and some other opaque minerals (Sample 313-M0028A-101R-2, $116 \mathrm{~cm}$ ). Field of view $=0.7 \mathrm{~mm}$.

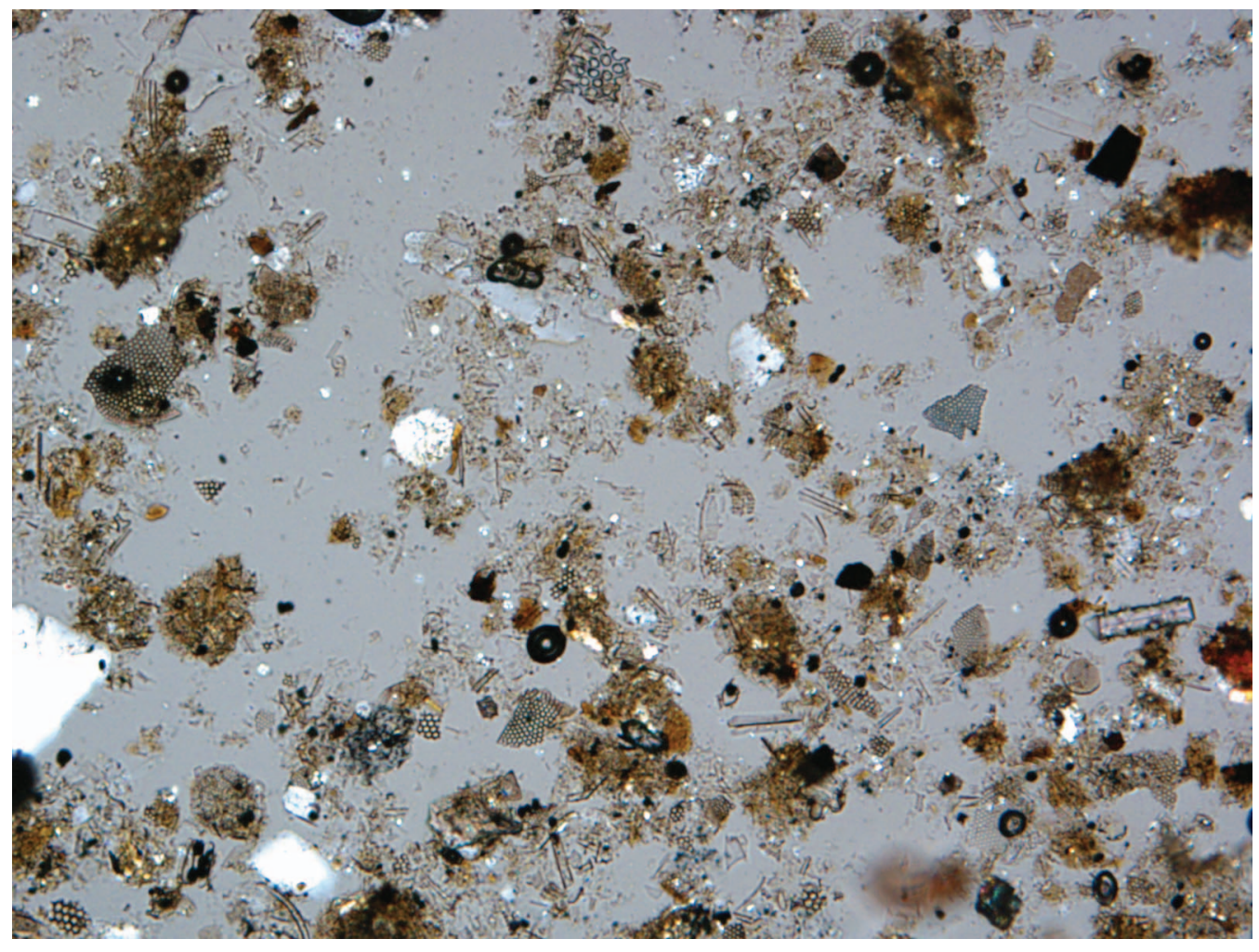


Figure F12. Core photograph of poorly sorted fine glauconite sand (40\%). Sand is bounded below by a sharp surface at $68 \mathrm{~cm}$ above a claystone with burrows filled from the glauconite sand above (from 68 to $88 \mathrm{~cm}$ ) (interval 313-M0028A-113R-1, 49-91 cm). Firmground required some time to be formed before sand deposition.

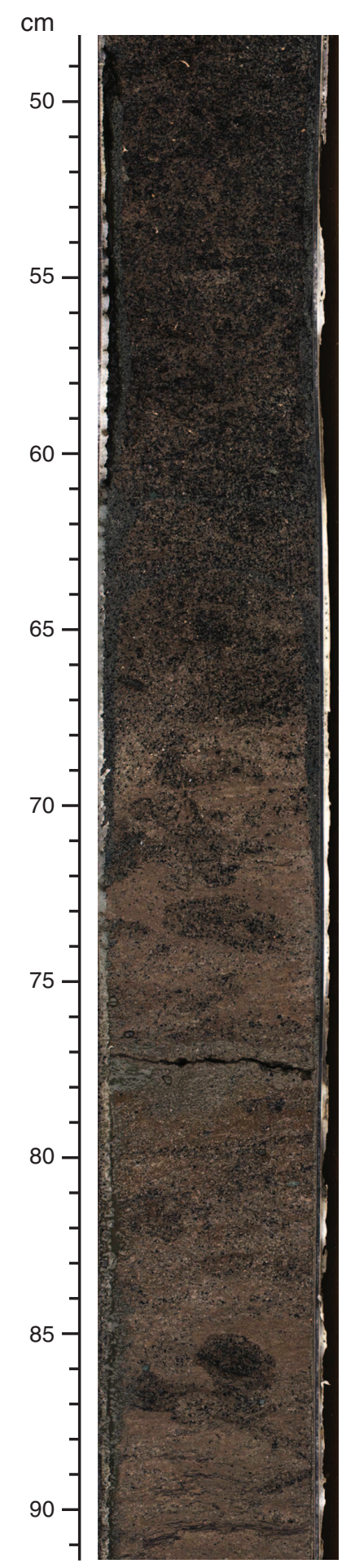


Figure F13. Core photograph of moderately sorted glauconitic medium sand cross-beds with clay-rich interlamination (interval 313-M0028A-118R-1, 45-85 cm). Note apparent steepening-upward trend in dip of crossbeds interpreted as characteristic of the original dune-scale bedform.

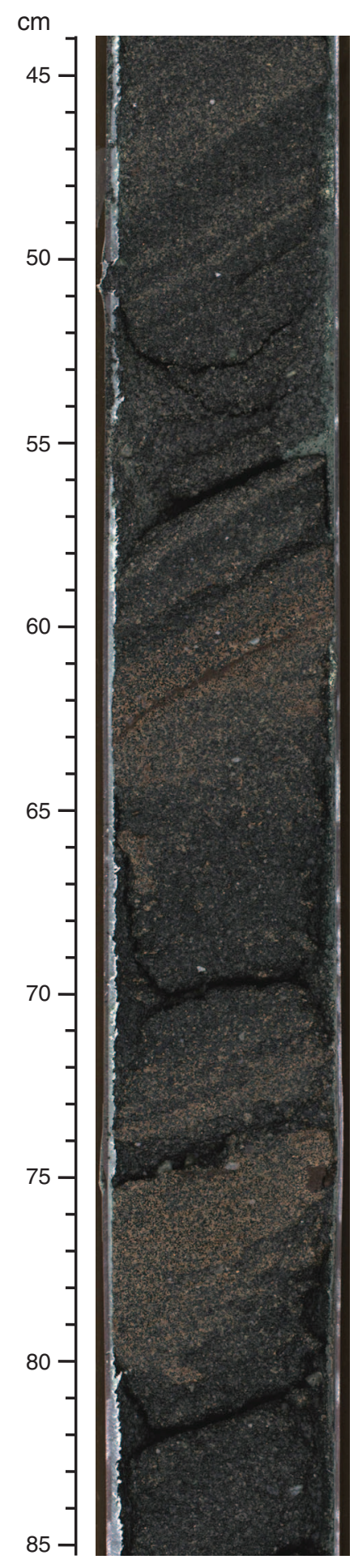


Figure F14. Core photograph of normal grading in very coarse to fine glauconite sand bed (interval 313M0028A-118R-2, 45-76 cm). Bed with normal grading from 65 to $55 \mathrm{~cm}$ is interpreted as turbidite.

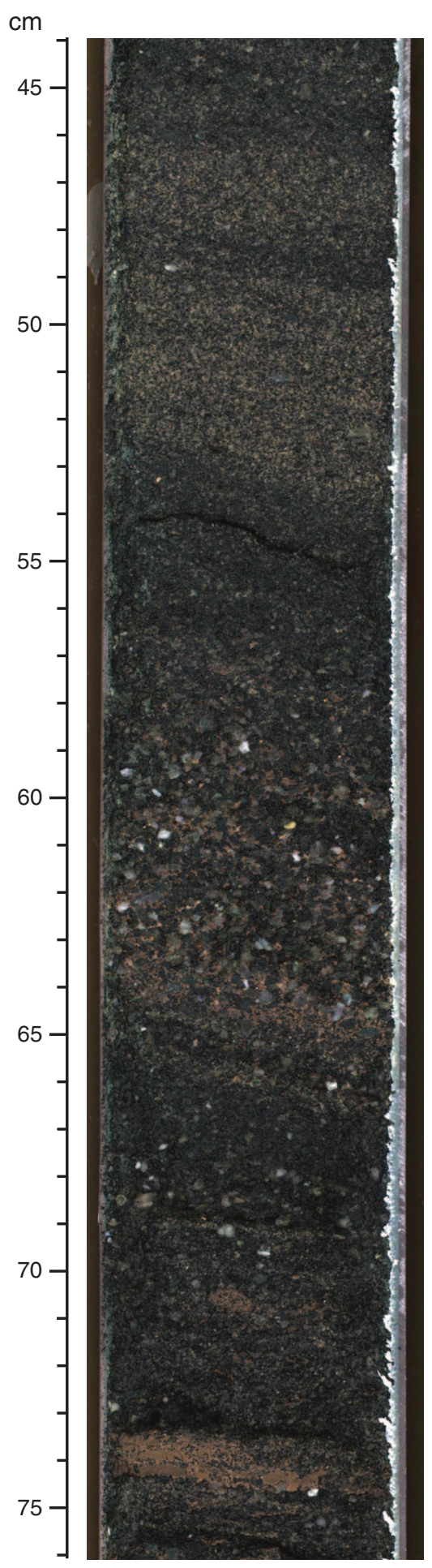


Figure F15. Core photograph of bioturbated contact between Units V and VI (interval 313-M0028A-152R-1, $65-143 \mathrm{~cm})$. The overlying medium sand $(65-76 \mathrm{~cm})$ increases in the proportion of glauconite downhole $(2 \%-$ $20 \%$ ) to an intensely bioturbated contact (at $76 \mathrm{~cm}$ ) with silty clay. Burrows in clay are filled with glauconite sand, including large vertical burrow with sharp scalloped margins and multiple branches identified as Thalassinoides and Ophiomorpha.

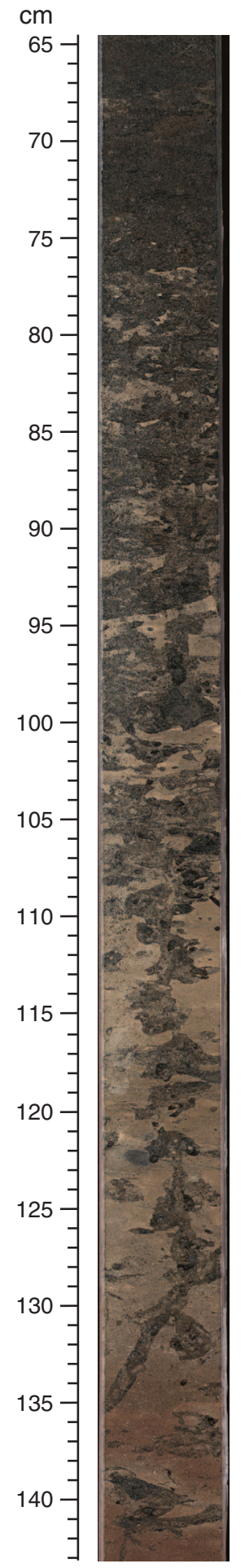


Figure F16. Smear slide photomicrographs of calcareous silty clay with quartz, mica, framboidal pyrite, and nannofossils (Sample 313-M0028A-163R-2, $106 \mathrm{~cm}$ ). Field of view $=0.7 \mathrm{~mm}$. A. Plane-polarized light. (Continued on next page.)

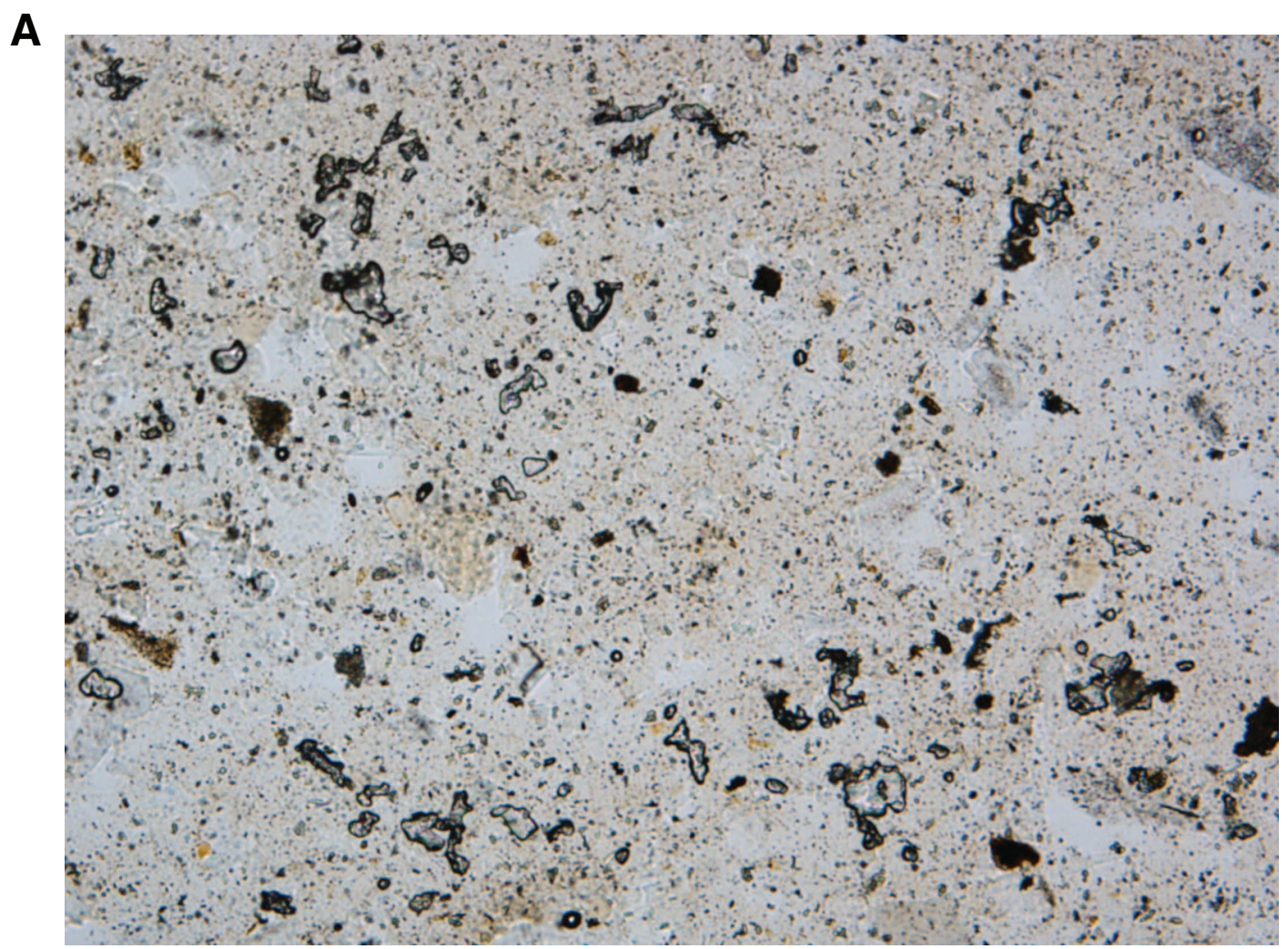


Figure F16 (continued). B. Cross-polarized light.

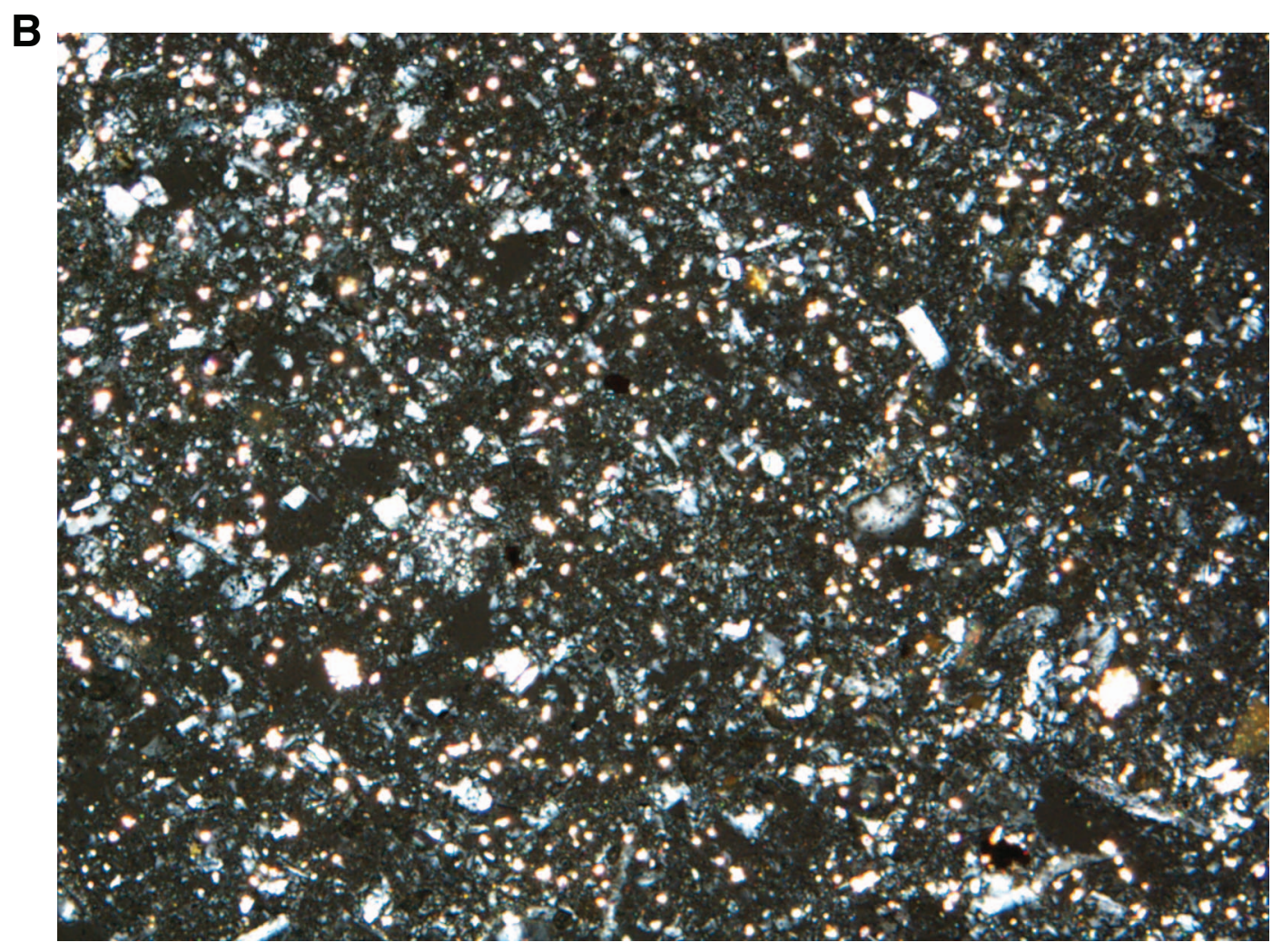


Figure F17. Core photograph of a bed-parallel meniscate backfilled burrow $(90-91 \mathrm{~cm})$ in interbeds of clay, silt, and very fine grained sand in Unit VI (interval 313-M0028A-154R-1, 87-95 cm). Burrow is identified as Taenidium.

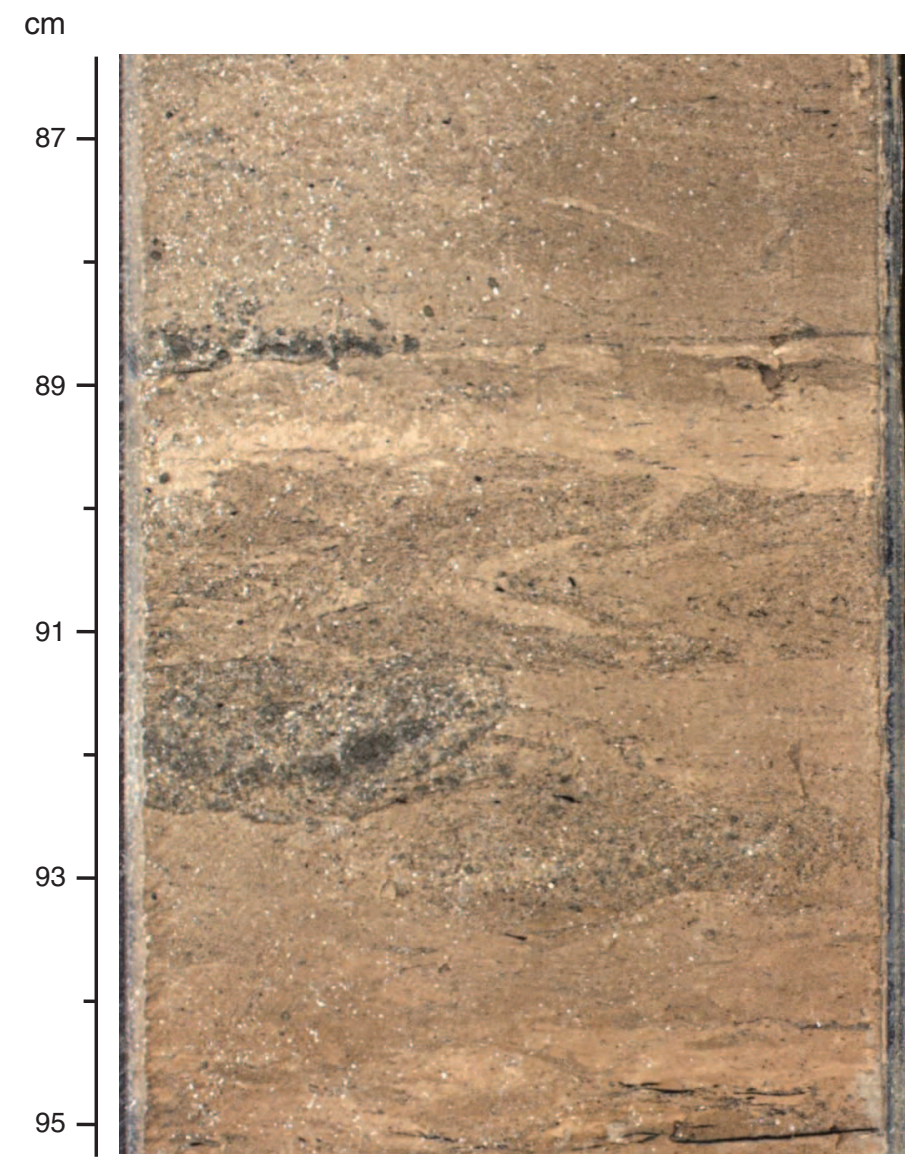


Figure F18. Core photograph of alternating laminated and bioturbated horizons that characterize Unit VI (Taenidium at $80 \mathrm{~cm}$ ) (interval 313-M0028A-166R-2, 77-108 cm). Interlaminated clay and silt includes normally graded very fine sand rich in terrestrial organic matter and mica, interpreted as having been deposited in an offshore or prodeltaic environment. Small carbonate concretions are present at 82, 84, and $91 \mathrm{~cm}$.

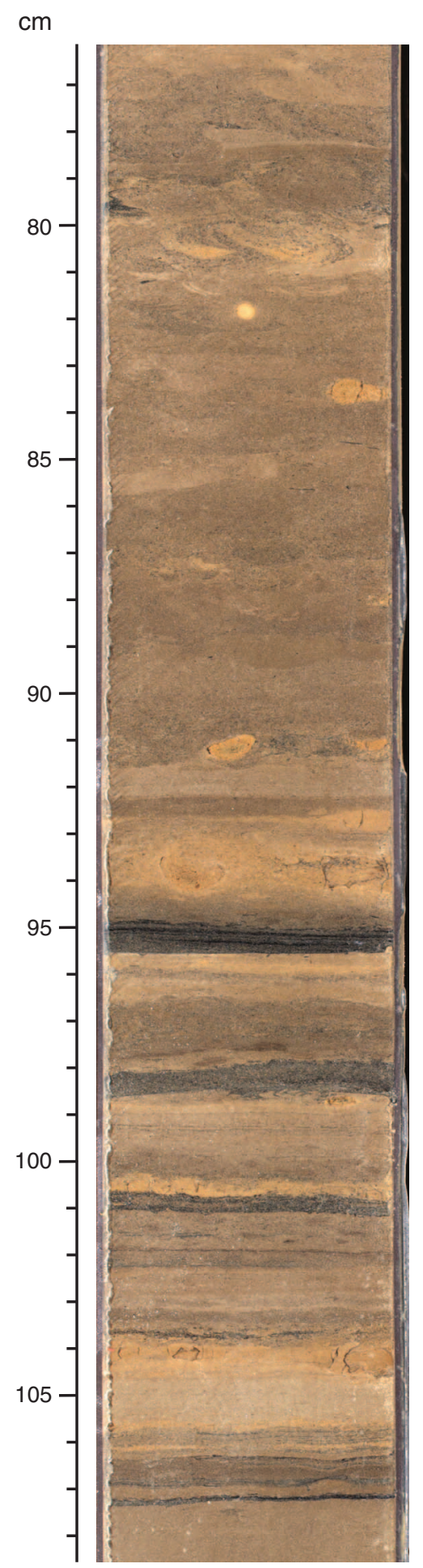


Figure F19. Photomicrograph of sandy silt with glauconite, mica, sponge spicules, diatom fragments, and framboidal pyrite (Sample 313-M0028A-169R-1, $142 \mathrm{~cm}$ ). Field of view $=0.7 \mathrm{~mm}$.

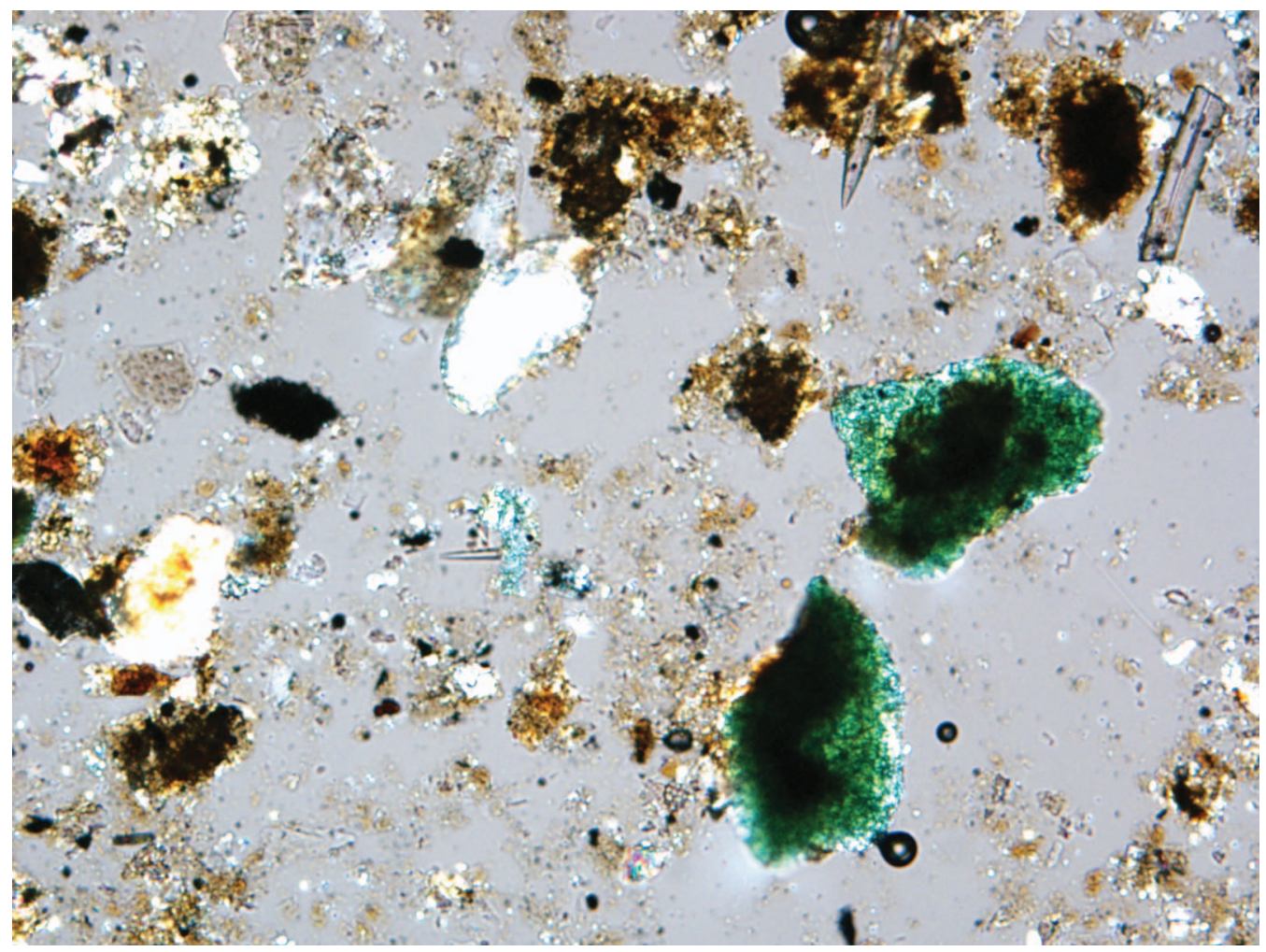


Figure F20. Archive-half line scan image, magnetic susceptibility (red), and density (blue) (from multisensor core logger [MSCL] measurements), with 2-D computed tomography (CT) scans of whole-core and borehole acoustic impedance images (Section 313-M0028A-97R-1). H = horizontal scan, V = vertical scan (see "Lithostratigraphy" in the "Methods" chapter). Subunit IIIC (Section 313-M0028A-97R-1) consists of very fine sandy silt and clay, very fine sand, and fine sand, in laminated and bioturbated interbeds. Plant debris is common; shell fragments are rare. Density and magnetic susceptibility from MSCL measurements show no significant oscillations, and the acoustic image appears homogeneous (slightly darker in intensely laminated areas). Visual description of core enabled the identification of alternating silt and sand layers. The thickest sandy beds are in agreement with visual core descriptions, whereas the millimeter-scale thin beds are only clearly distinguished on the CT digital images and not on visual core description. At least seven intervals between discrete sand beds can be identified. Each interval contains an 11-25 cm thick bed of fine-/very fine grained sand and slightly bioturbated laminae. Discrete accumulation of high-density (heavy?) minerals may correspond to the lightest gray laminae and individual white grains at 50,88 , and $132 \mathrm{~cm}$. The presence of wood fragments, a low-density material, is evidenced by dark spots (see the dark laminae at $93 \mathrm{~cm}$ and the clast at $133 \mathrm{~cm}$ ). (Figure shown on next page.) 
Figure F20 (continued). (Caption shown on previous page.)

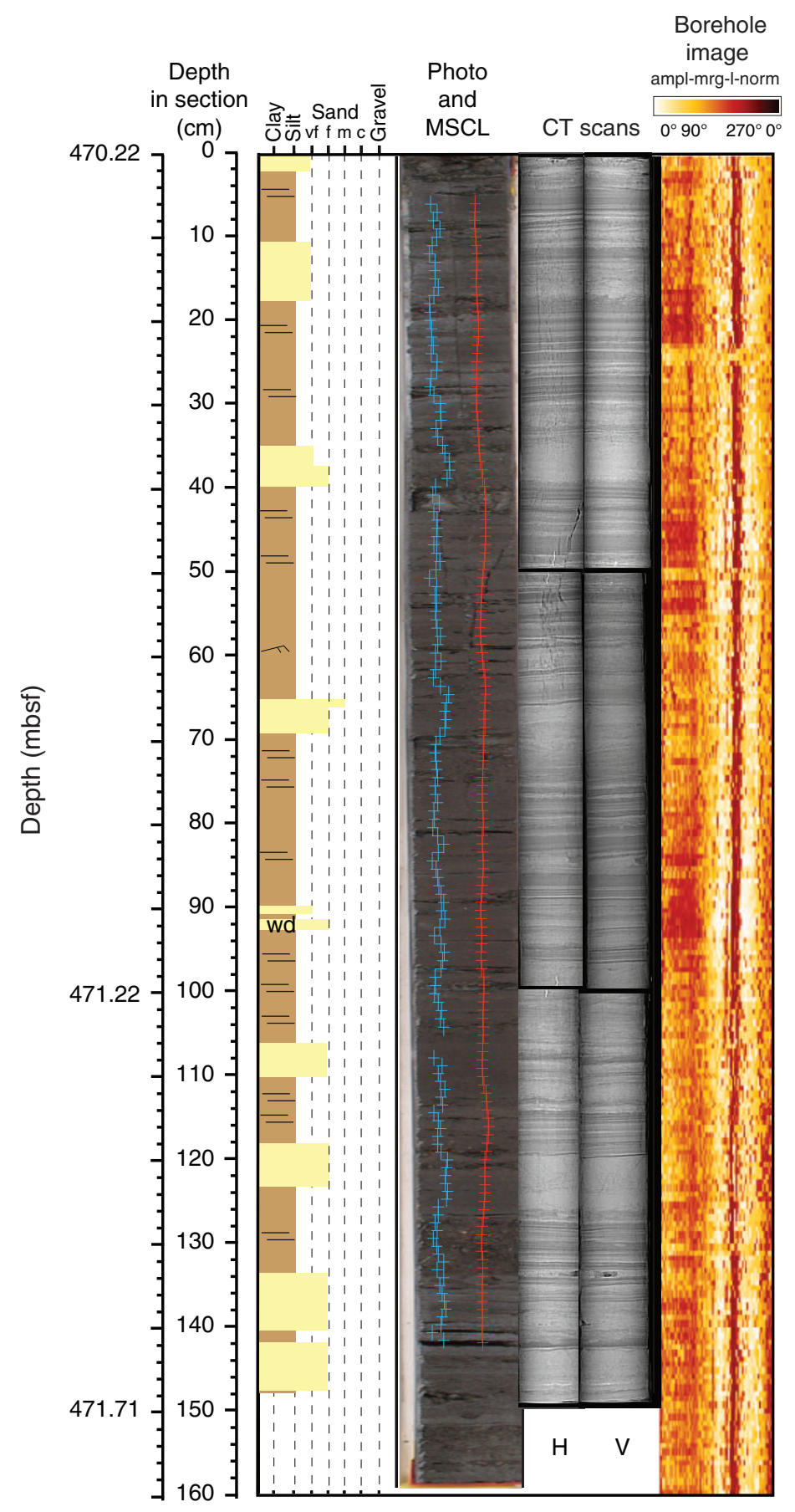


Figure F21. Percentages of sand, silt, and clay based on estimates from smear slides from Hole M0028A. See "Lithostratigraphy" in the "Site M0027A" chapter and "Lithostratigraphy" in the "Methods" chapter for more information.

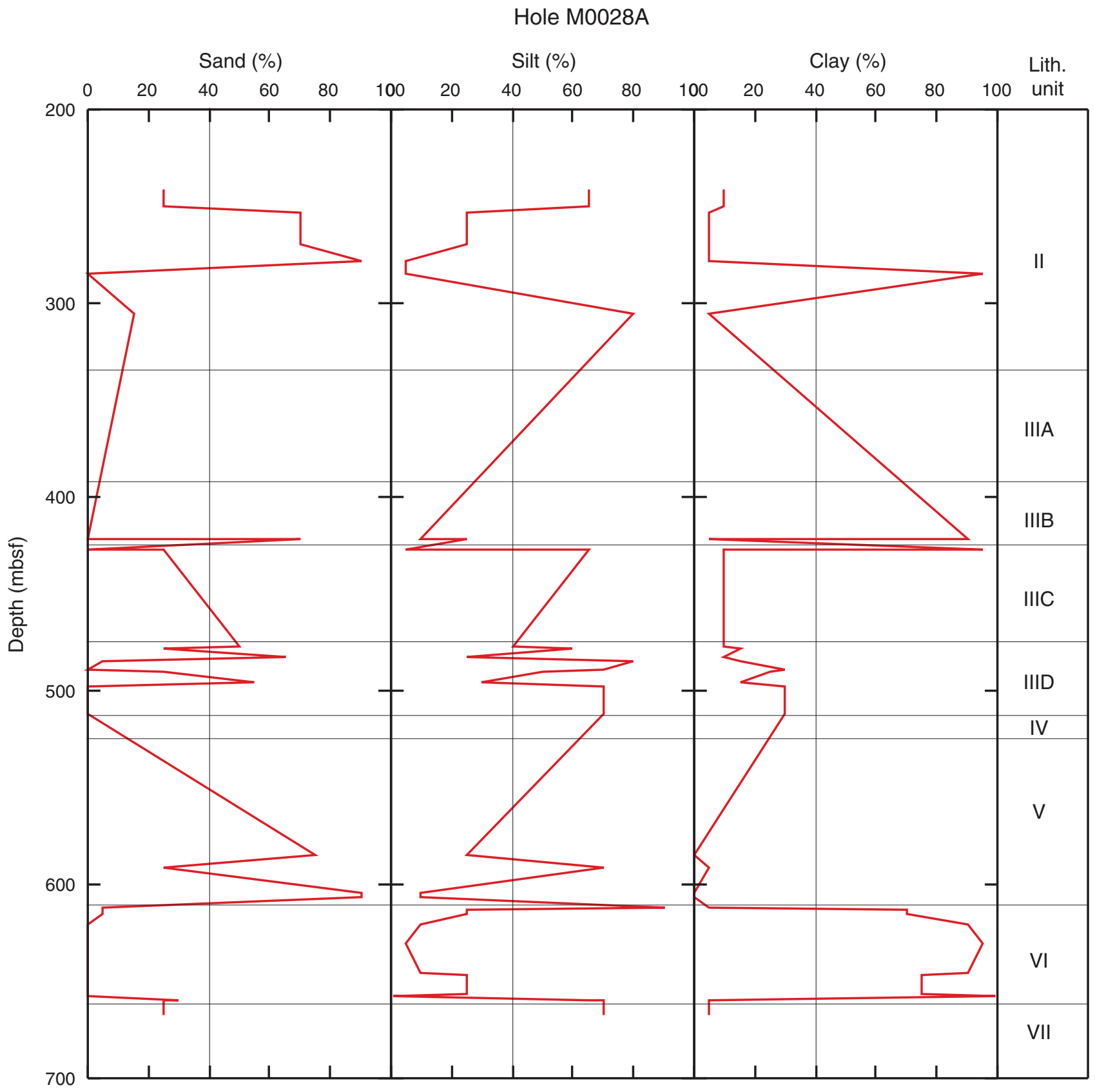


Figure F22. Biostratigraphic summary interpreted from calcareous nannofossils, planktonic foraminifers, and dinocysts, showing Miocene stages in Hole M0028A. See Figure F12 in the "Methods" chapter for an explanation of the datums used. Zone boundaries are drawn diagonally to indicate uncertainty in zonation between samples because of either the absence of sampling between points or the absence of age-diagnostic taxa. Zonal boundaries are correlated to the geologic timescale. Dashed lines indicate some uncertainty in age assignments. The geologic timescale is that of Berggren et al. (1995), based on the geomagnetic polarity timescale of Cande and Kent (1995). See Figure F4 in the "Methods" chapter for lithology legend.

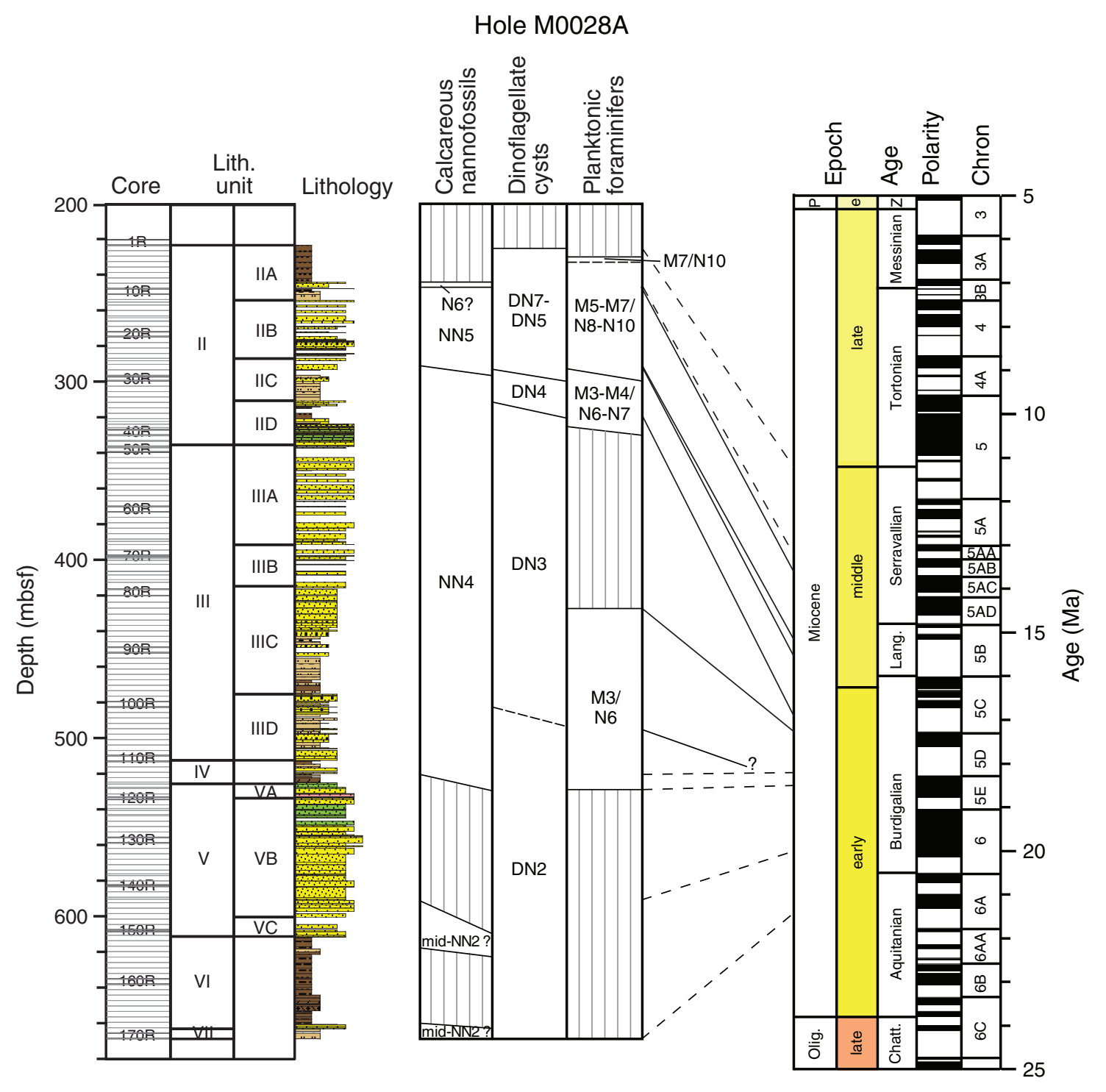


Figure F23. Age-depth plot showing cores (every fifth core shaded) in Hole M0028A, the timescale of Berggren et al. (1995), calcareous nannoplankton zones (light blue bars), planktonic foraminifer zones (dark blue bars), and dinocyst zones (green bars). Sr isotopic ages are shown as circles with errors of $\pm 0.6 \mathrm{~m} . \mathrm{y}$. (older than 15.2 $\mathrm{Ma}$ ) and $\pm 1.17 \mathrm{~m} . \mathrm{y}$. (younger than $15.2 \mathrm{Ma}$ ). Boxes are ages from magnetochronology. Horizontal lines for sequence boundaries (red) and tentative sequence boundaries (dashed red) lines are labeled with their corresponding depths. Green lines = flooding surfaces, blue lines = transgressive surfaces. Planktonic foraminifer $\mathrm{M}$, PL, and Pt zones are from Berggren et al. (1995); nannofossil zones are from Martini (1971); and dinocyst zones are from de Verteuil and Norris (1996). Geomagnetic polarity timescale is from Cande and Kent (1995). LcO = last common occurrence.

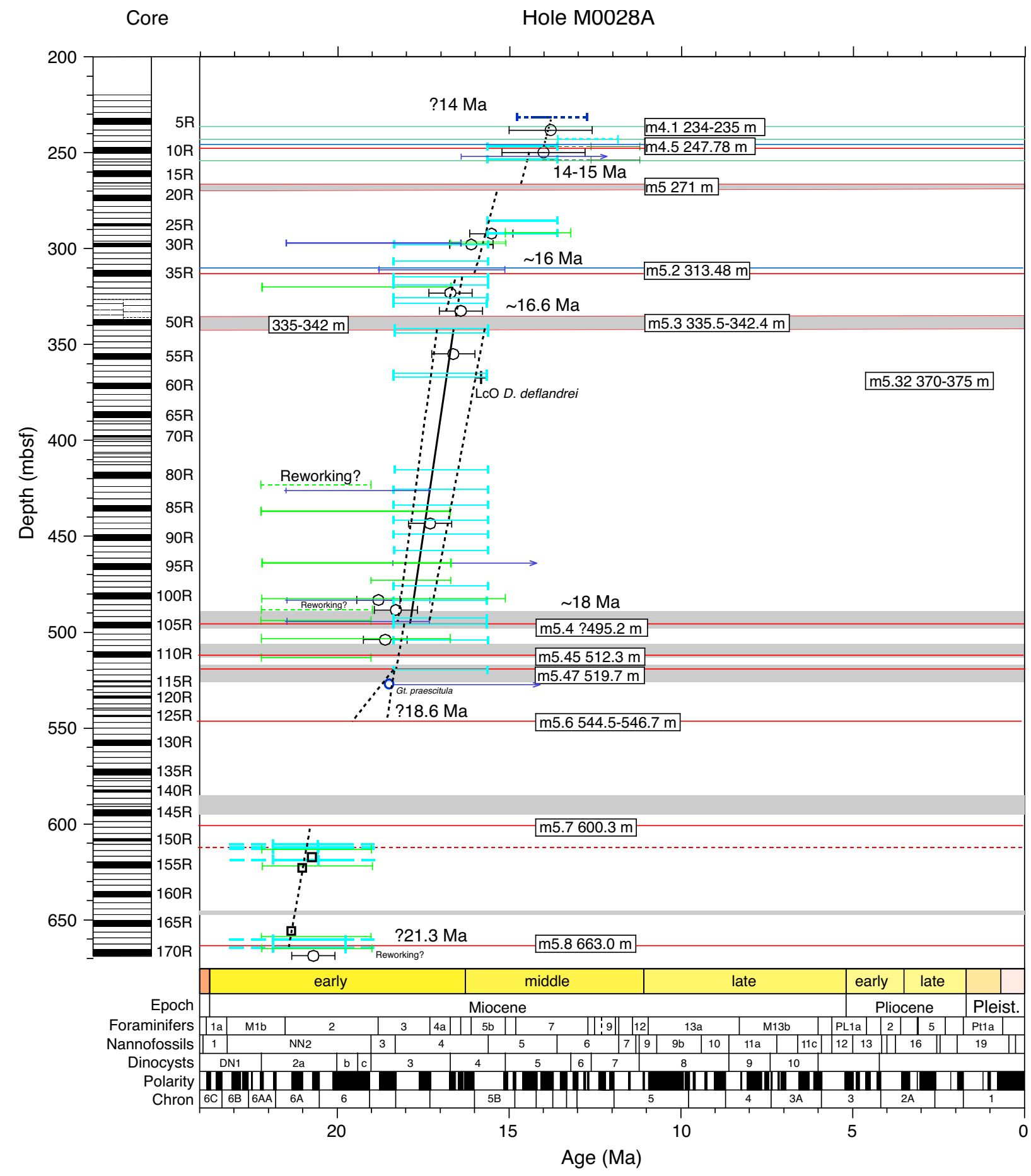


Figure F24. Distribution of biostratigraphically important calcareous nannofossil taxa in Hole M0028A. Thickness of distribution line indicates relative abundance of species. Zonal assignments (Martini, 1971) are given, with approximate age indicated. A $>$ or $<$ in front of the age indicates when part of a zone is presumed to be missing because of an unconformity or nonrecovery of nannofossil-rich facies. Red lines = sequence boundaries, green lines $=$ major flooding surfaces, blue lines $=$ transgressive surfaces. See Figure F4 in the "Methods" chapter for lithology legend.

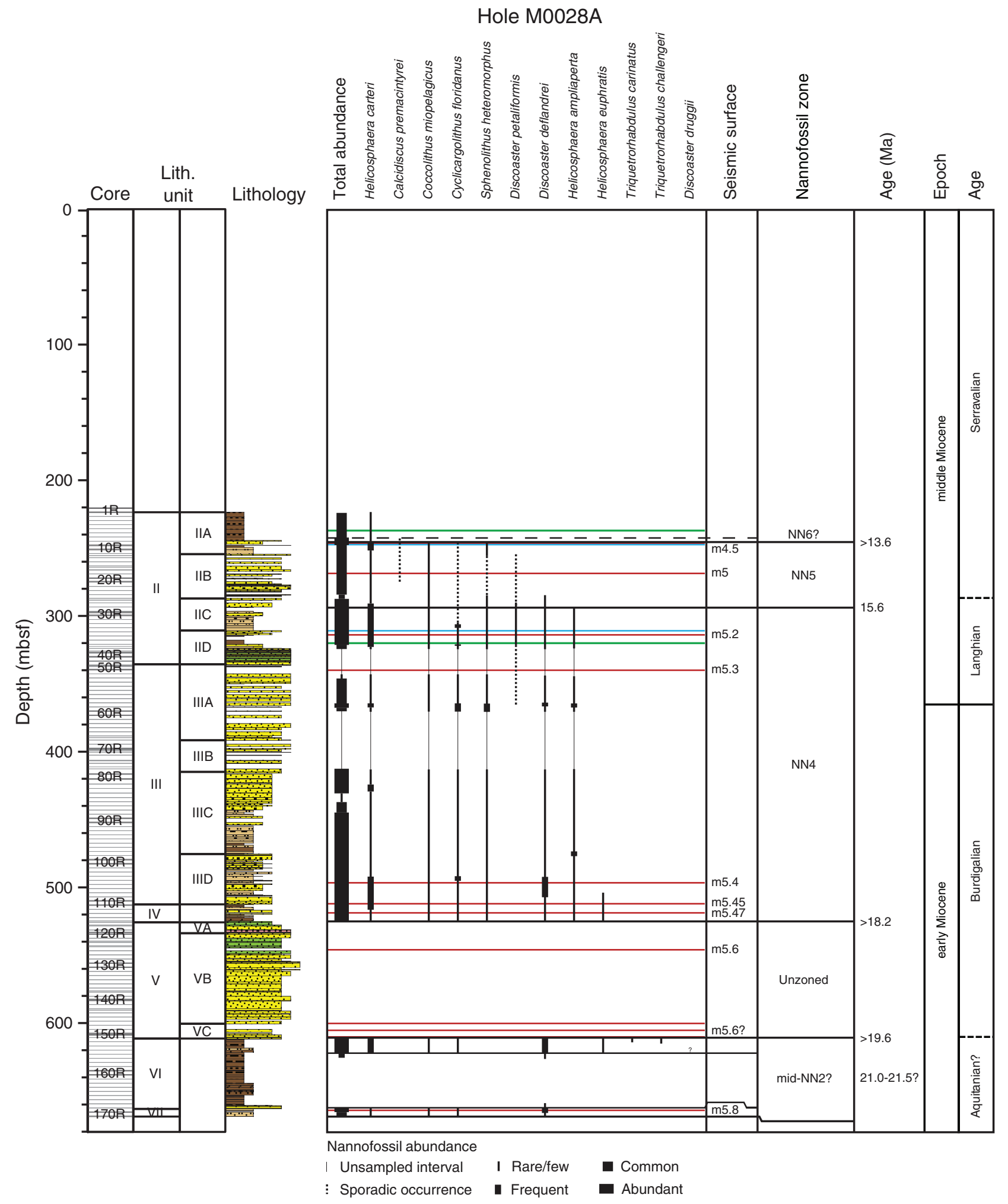


Figure F25. Planktonic foraminifer stratigraphic distributions in Hole M0028A. See Figure F4 in the "Methods" chapter for lithology legend.

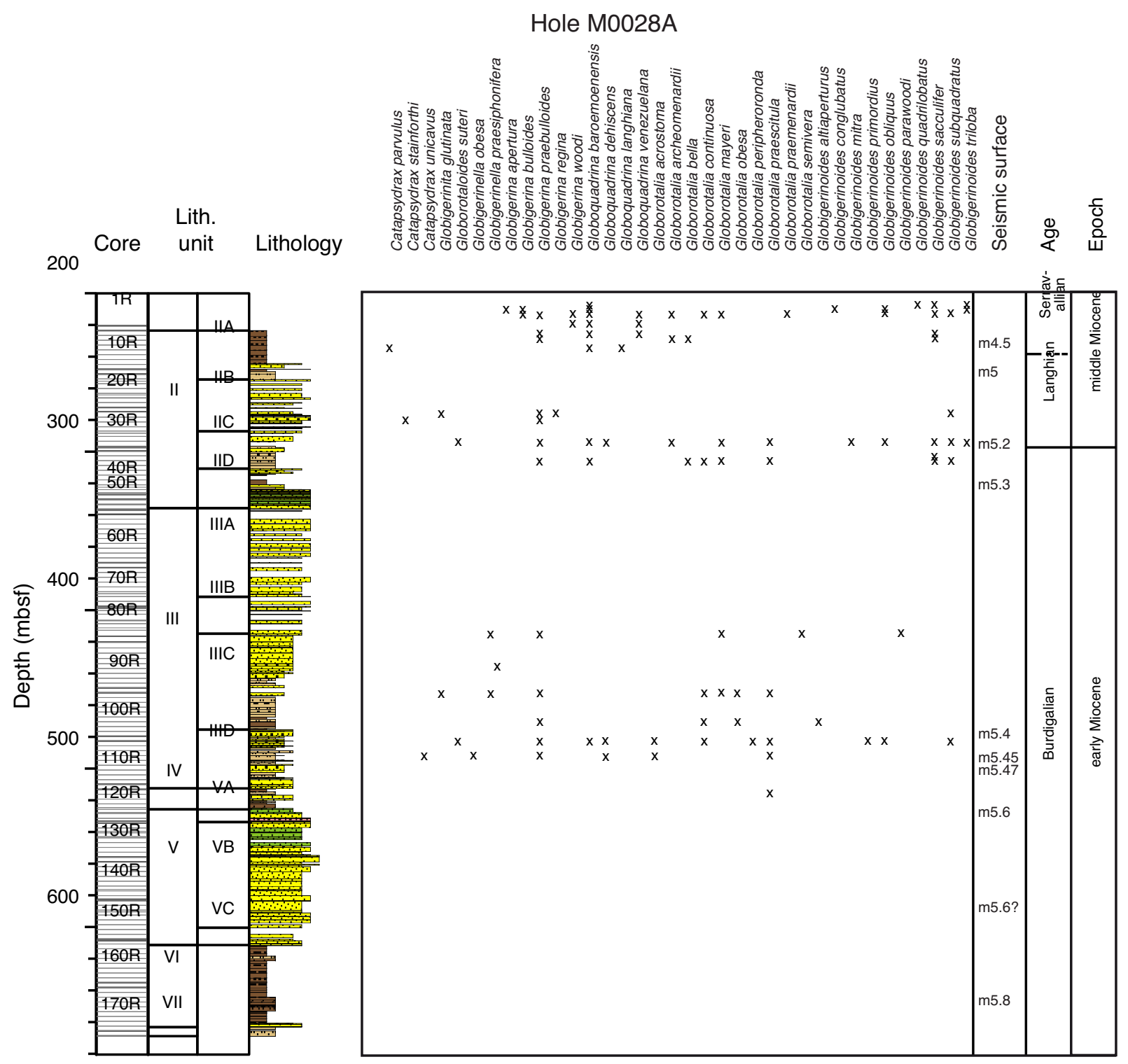


Figure F26. Stratigraphic distribution of age-diagnostic dinocyst taxa in Hole M0028A, with the Miocene zoned following de Verteuil and Norris (1996). Zone boundaries are drawn diagonally to indicate uncertainty in zonation between samples, because of either the absence of sampling between points or of age-diagnostic taxa. Red lines $=$ sequence boundaries, green lines $=$ major flooding surfaces, blue lines $=$ transgressive surfaces. See Figure F4 in the "Methods" chapter for lithology legend.

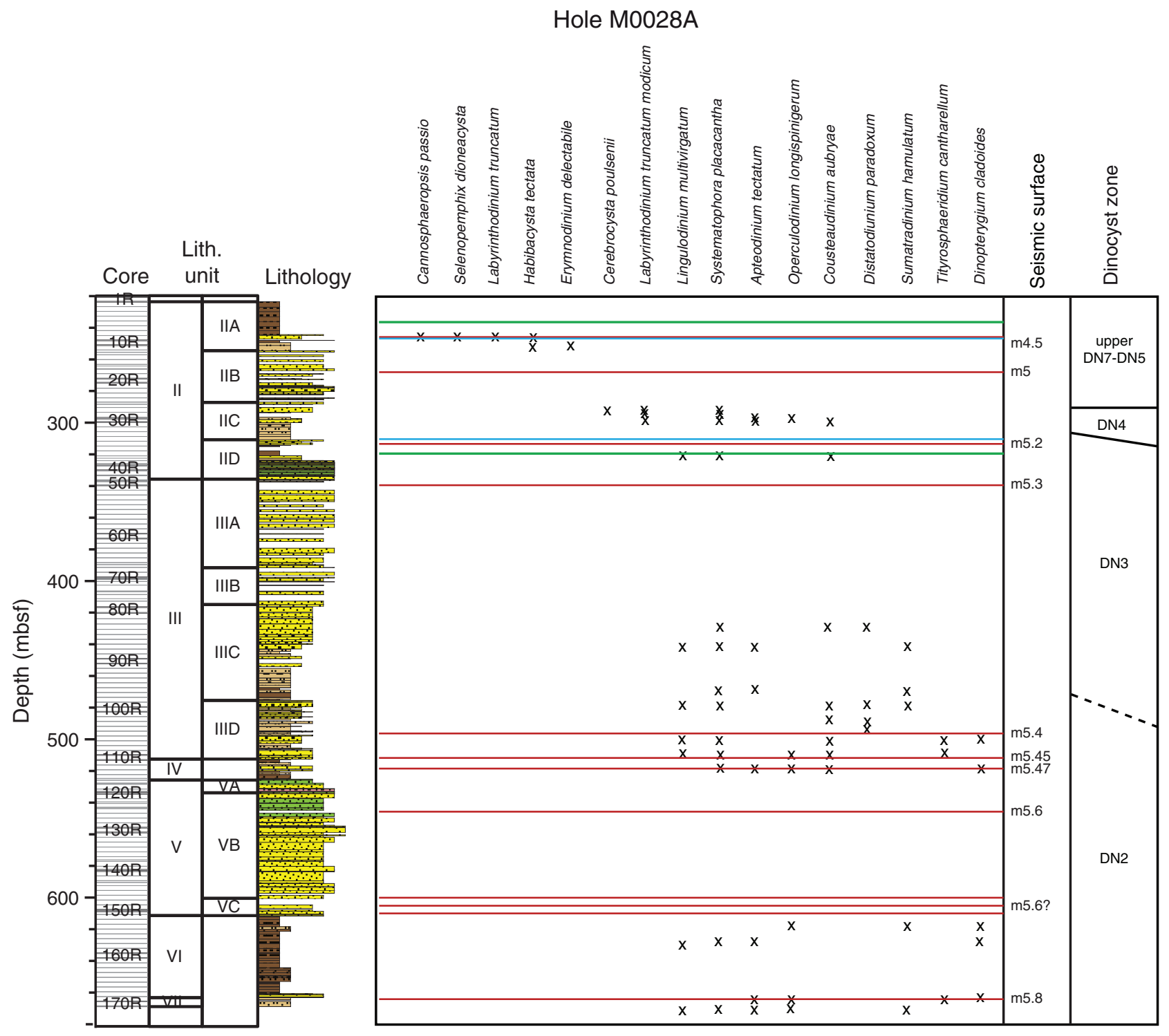


Figure F27. Benthic foraminifer paleobathymetric estimates for Hole M0028A. ? = barren samples or samples with too few specimens to determine a paleodepth. Arrows = depths deeper than $100 \mathrm{~m}$ (mostly likely shallower than $\sim 200 \mathrm{~m}$ ). Red lines $=$ sequence boundaries, green lines $=$ major flooding surfaces, blue lines $=$ transgressive surfaces. See Figure F4 in the "Methods" chapter for lithology legend.

\section{Hole M0028A}

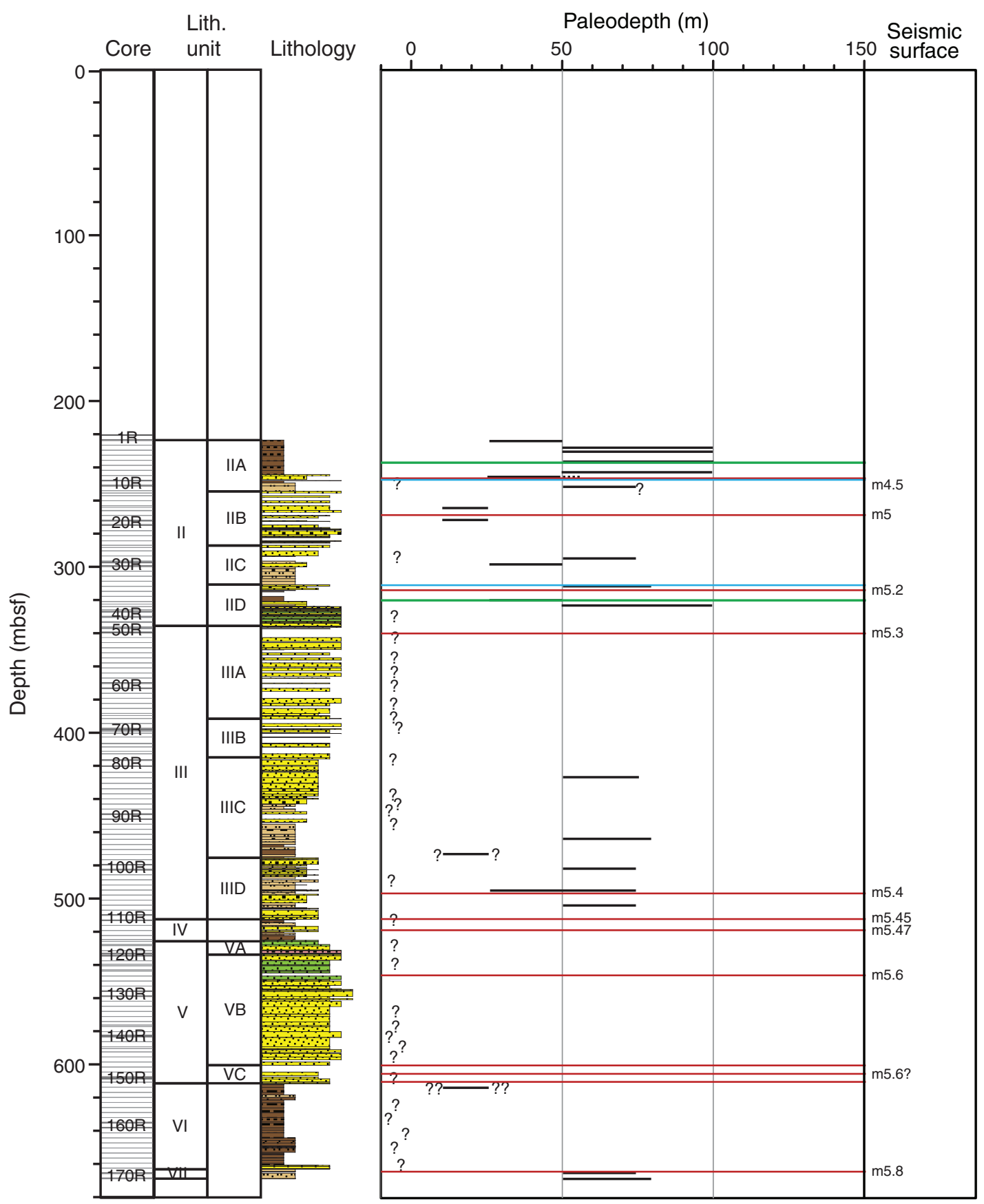


Figure F28. Palynomorph distribution, Hole M0028A. Reference sum for percentages is total amount of nonsaccate pollen and pollen with small sacci (Tsuga, nonsaccate herb, arboreal, sedge, and grass pollen, as well as unidentified nonsaccate pollen).

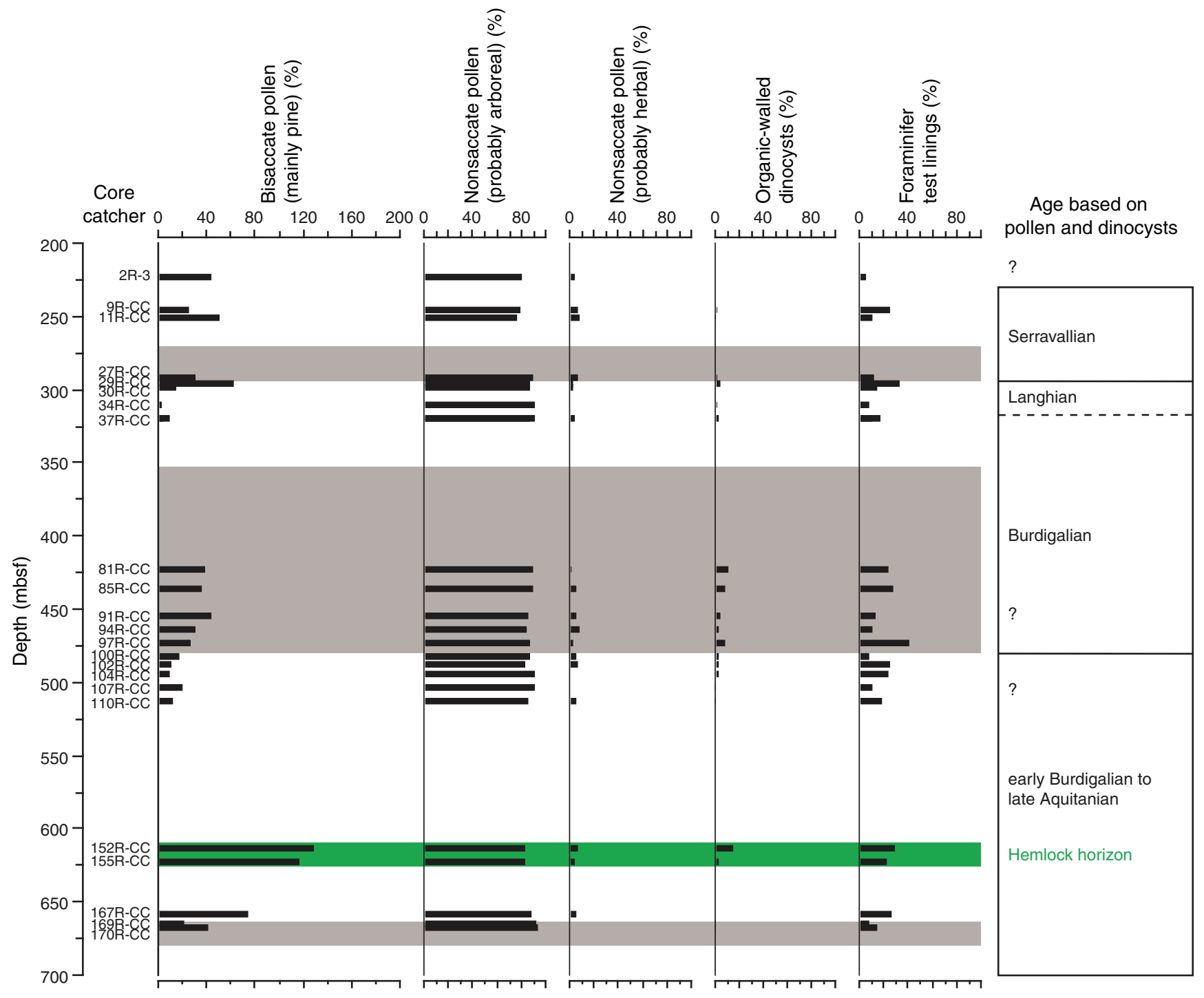


Figure F29. Simplified sketches based on terrestrial palynomorph sample analyses for Hole M0028A, showing hinterland and coastal ecology for the late Burdigalian to late Aquitanian. Gray trees = pines producing bisaccate pollen, green trees $=$ trees producing nonsaccate pollen or pollen with small sacci. Blue-green conifers $=$ hemlock, light green trees $=$ hickory, dark green trees $=$ other trees (mainly oak). Gray triangles $=$ bisaccate pollen transport potential, green triangles $=$ nonsaccate pollen transport potential. Blue-green triangle $=$ transport potential of hemlock pollen (pollen with small sacci). Red flowers = herbs producing nonsaccate pollen, excluding monoporate pollen; yellow tussocks = grasses. Spirals = foraminifer test linings, cyan symbols = dinocysts. Size of yellow sun is proportional to estimated temperatures, size of rain cloud = moisture availability. Percentages of palynomorphs are displayed on the right. Reference sum is the total amount of nonsaccate pollen. Light green bars = hickory pollen, blue-green bars = hemlock pollen, dark green bars = pollen probably related to oaks and other broad-leaved trees, yellow bars = pollen of grasses (Poacea), red bars = herbal pollen. Gaps between green, red, and yellow bars = nonsaccate pollen that could not be assigned to the three main groups (pollen grains of aquatic plants, pollen filled with pyrite, and pollen of families containing both herbal and arboreal taxa).

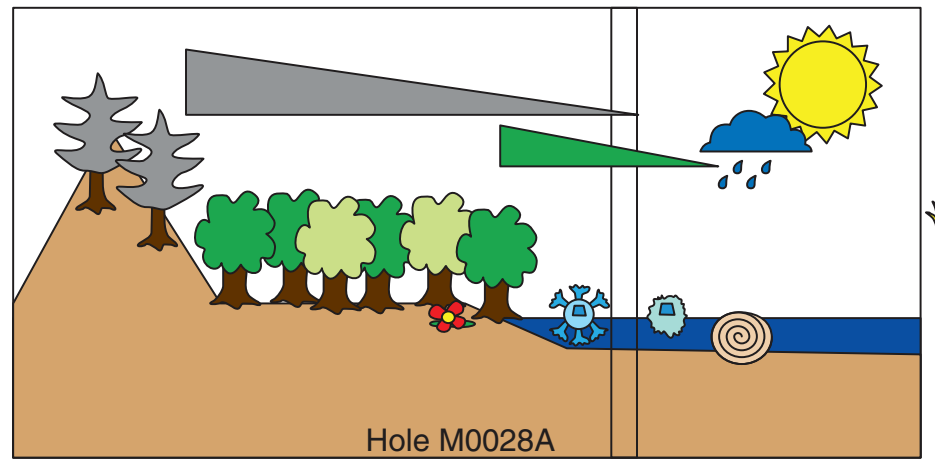

late Burdigalian ( 450 mbsf)
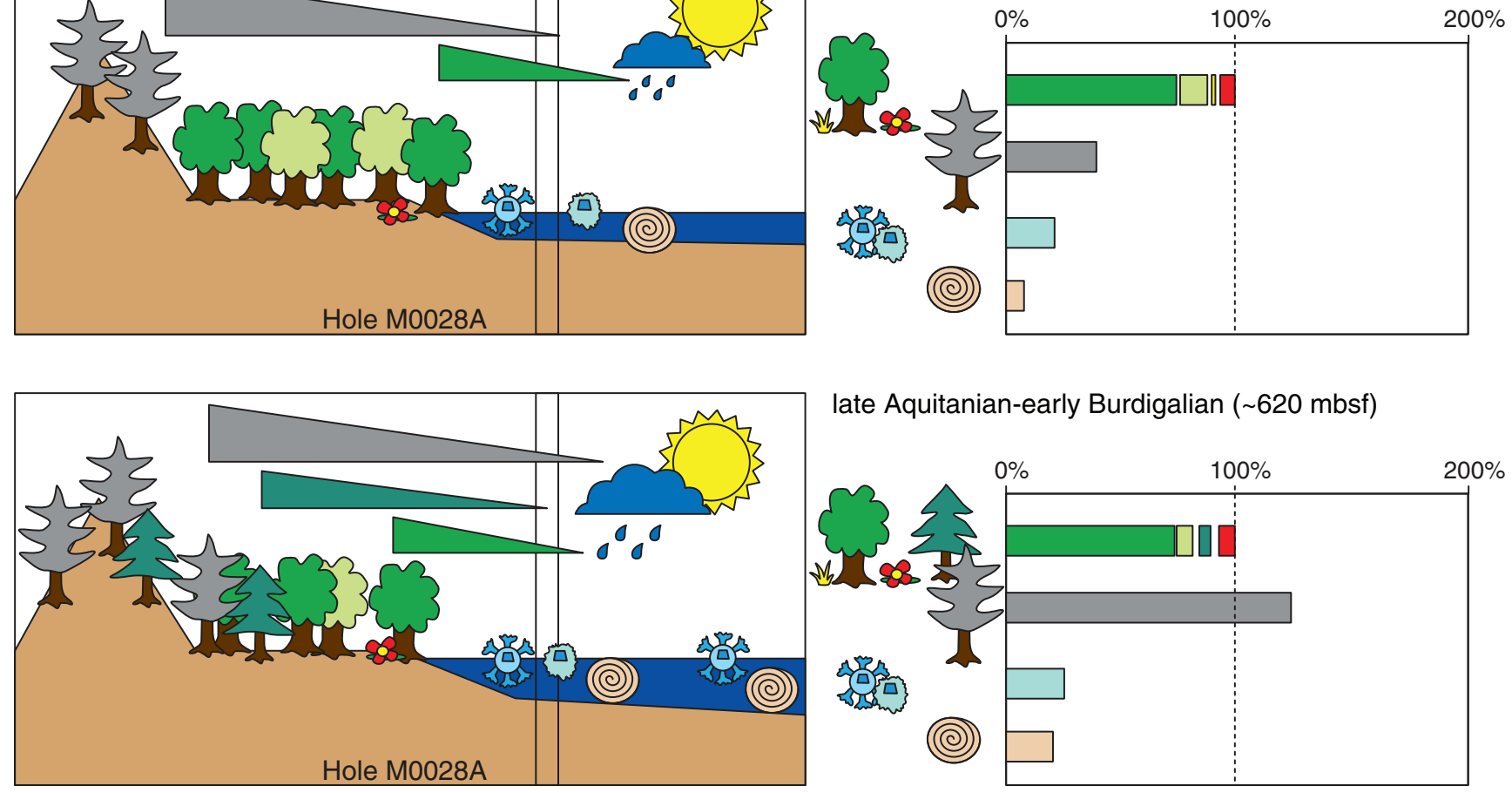

late Aquitanian-early Burdigalian ( 620 mbsf)
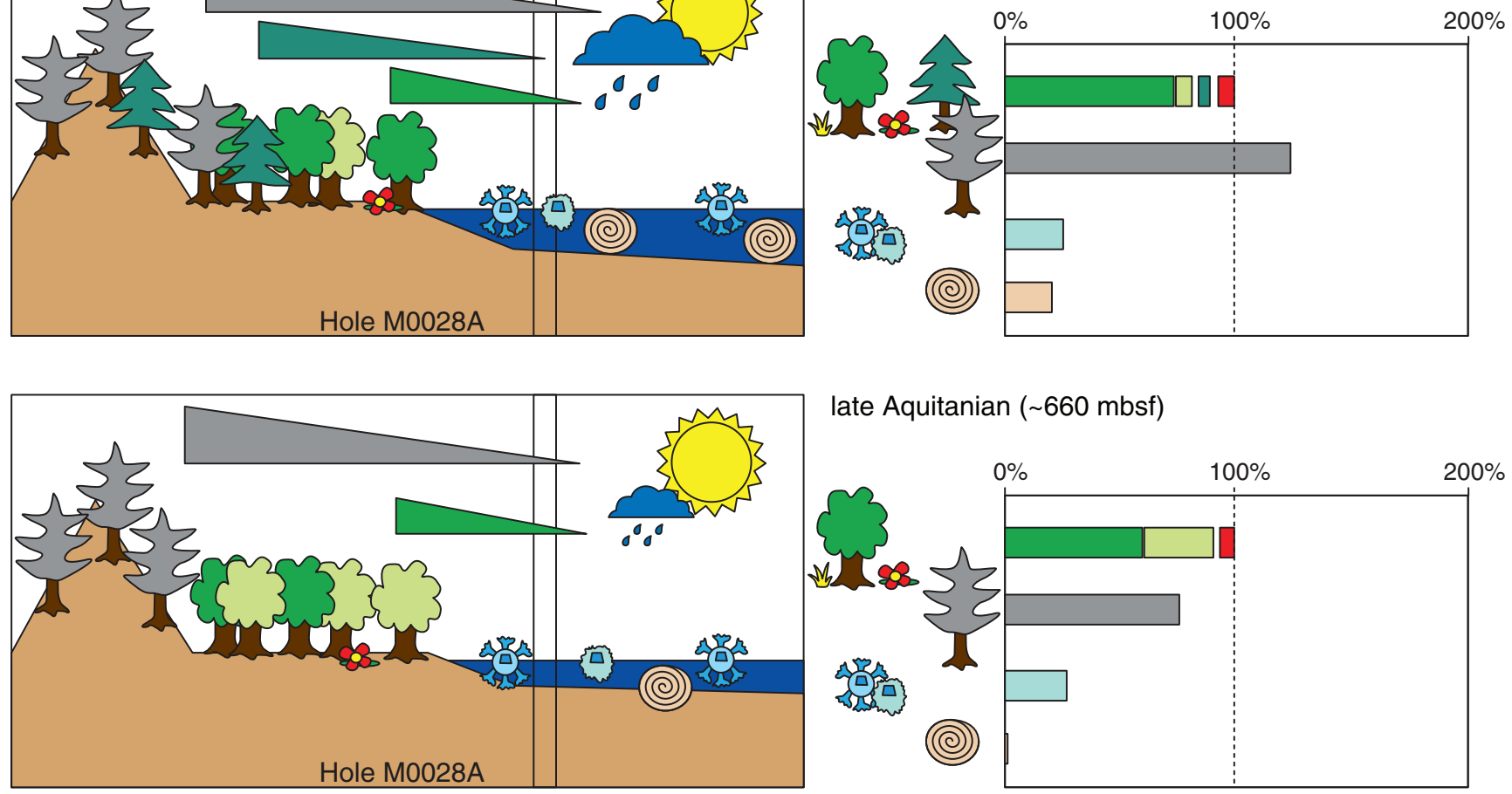

late Aquitanian ( 660 mbsf)

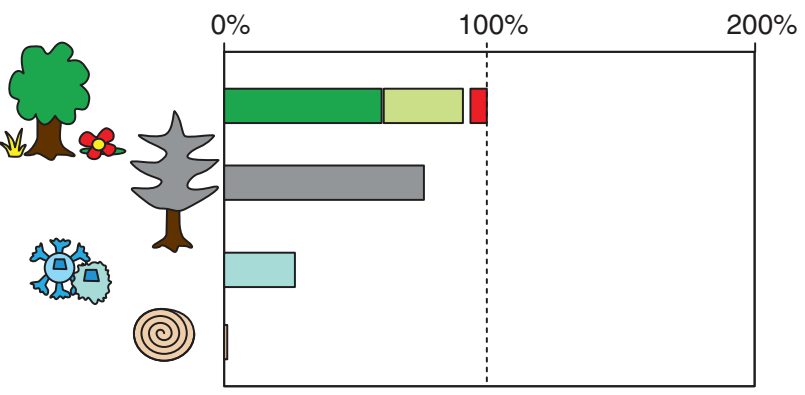


Figure F30. Composition-depth profiles of interstitial water, Hole M0028A. Vertical lines designate value calculated for present-day bottom seawater, which has a chloride concentration of $\sim 524 \mathrm{mM}$. Horizontal color bands denote discrete freshwater (blue) and salty (pink) layers of interstitial water.

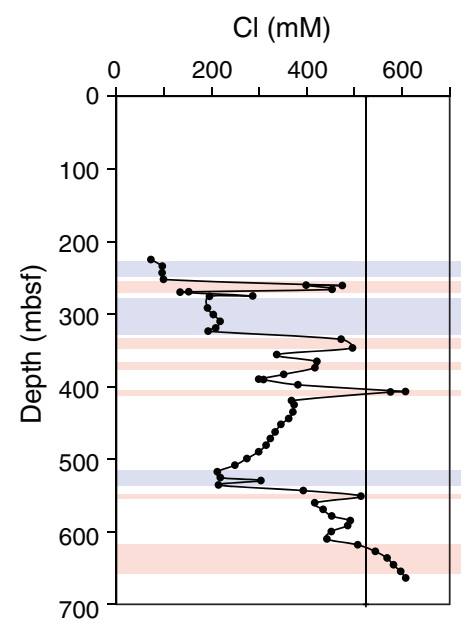

$\mathrm{Br} / \mathrm{Cl} \times 1000$ (molar)

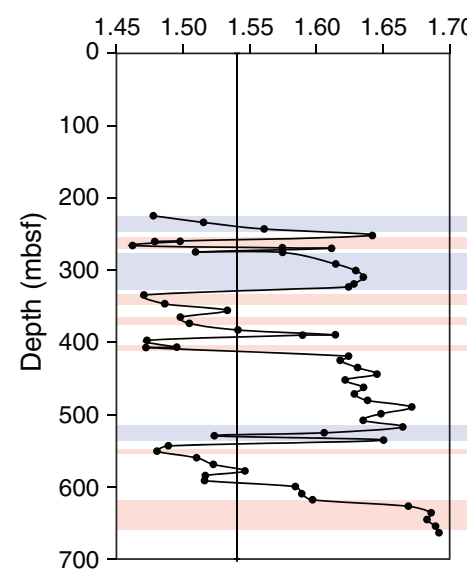

$\mathrm{Mg}(\mathrm{mM})$

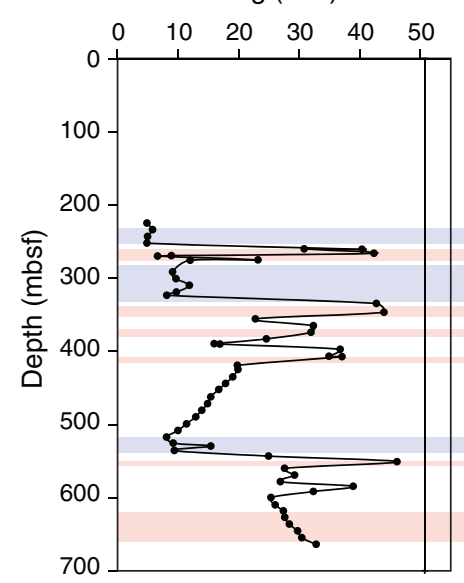

$\mathrm{Br}(\mu \mathrm{M})$

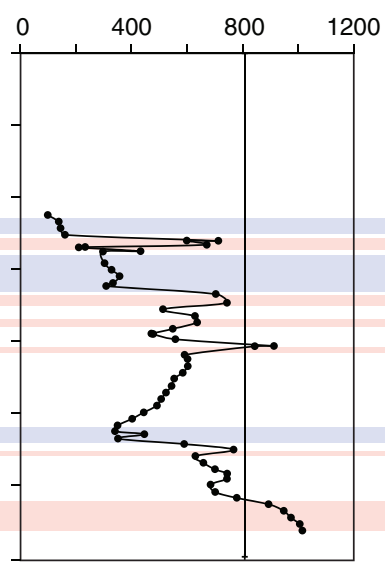

$\mathrm{Li}(\mu \mathrm{M})$

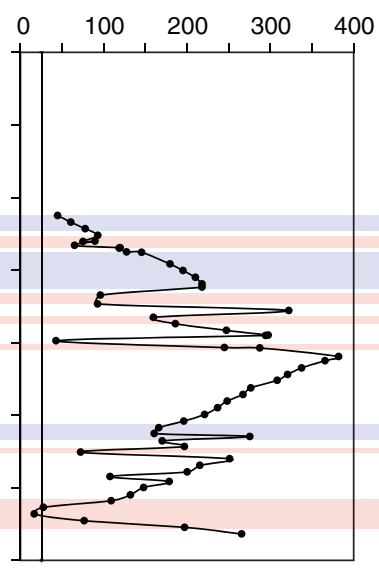

$\mathrm{Mg} / \mathrm{Cl}$ (molar)

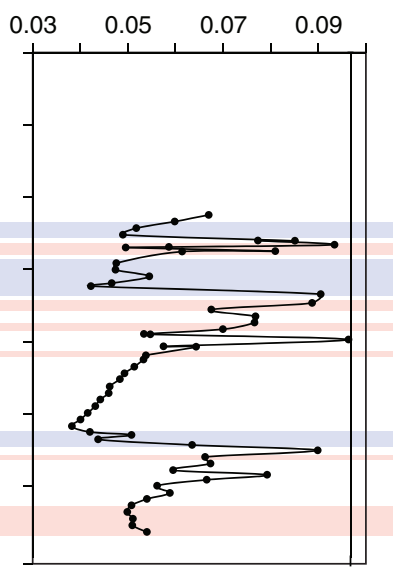

$\mathrm{Na}(\mathrm{mM})$

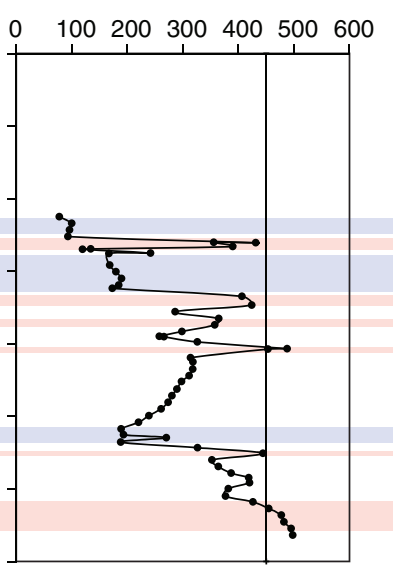

$\mathrm{K}(\mathrm{mM})$

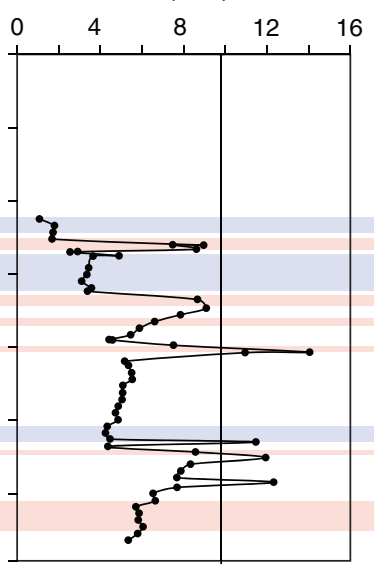

$\mathrm{Ca}(\mathrm{mM})$

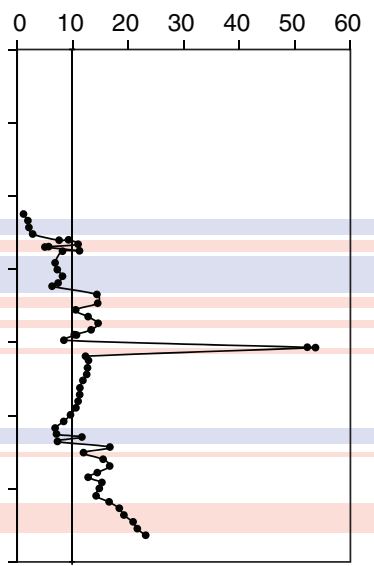

$\mathrm{Na} / \mathrm{Cl}$ (molar)

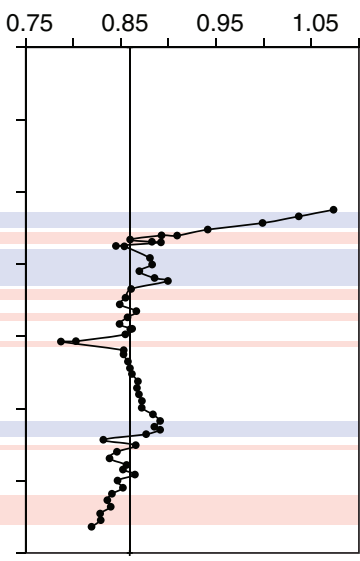

$\mathrm{K} / \mathrm{Cl}$ (molar)

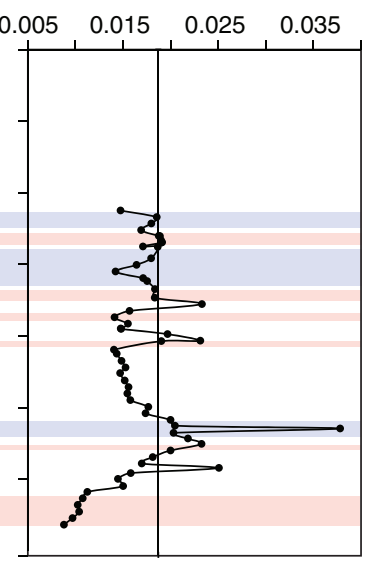

$\mathrm{Ca} / \mathrm{Cl}$ (molar)

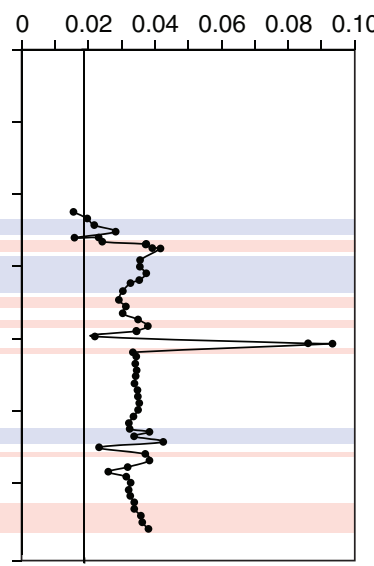


Figure F31. Composition-depth profiles of interstitial water, Hole M0028A. Vertical lines designate value calculated for present-day bottom seawater, which has a chloride concentration of $\sim 524 \mathrm{mM}$. Horizontal color bands denote discrete freshwater (blue) and salty (pink) layers of interstitial water.

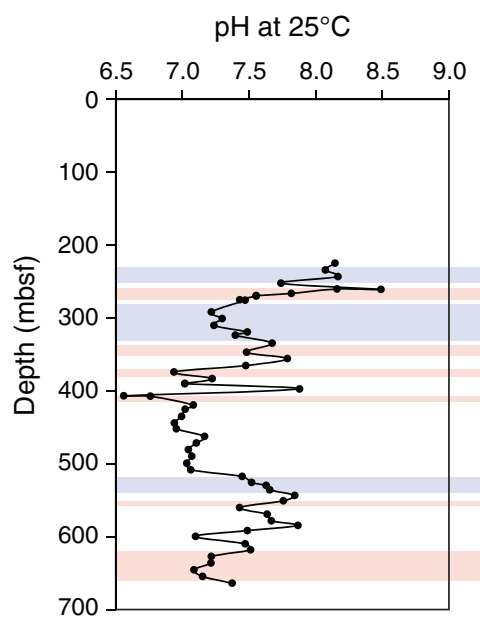

$\mathrm{Mn}(\mu \mathrm{M})$
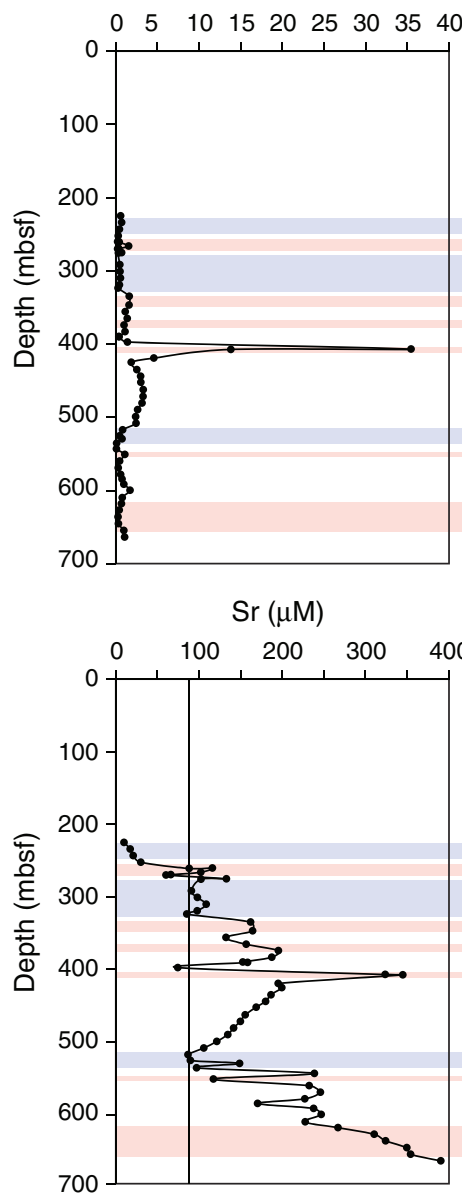

Alkalinity (meq/L)

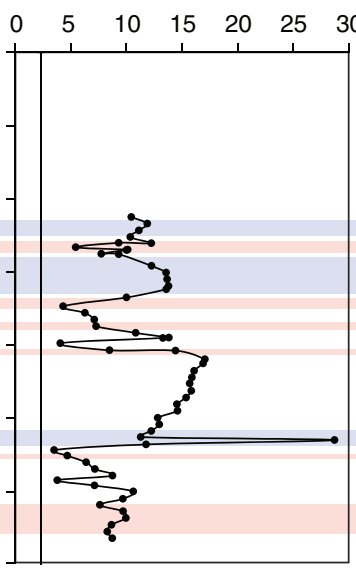

$\mathrm{Fe}(\mu \mathrm{M})$

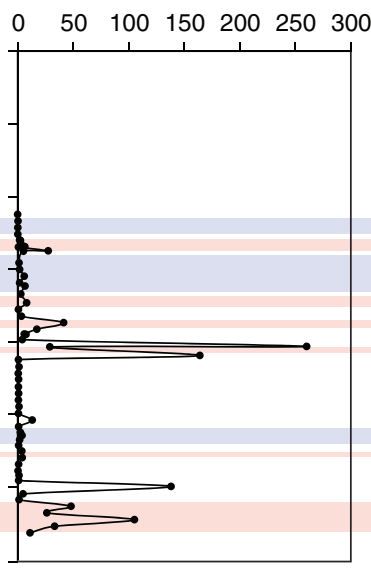

$\mathrm{Ba}(\mu \mathrm{M})$
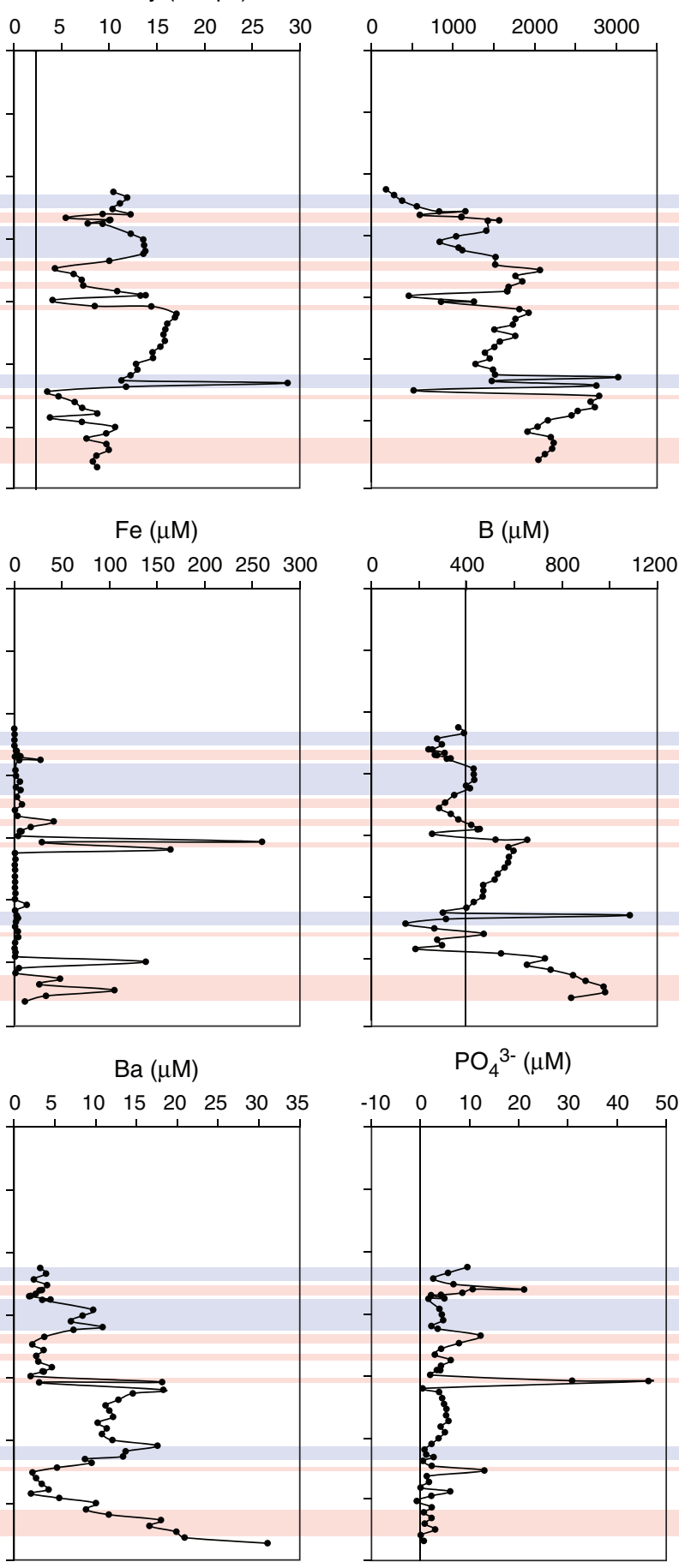

$\mathrm{B}(\mu \mathrm{M})$

$\mathrm{PO}_{4}{ }^{3-}(\mu \mathrm{M})$
$\mathrm{SO}_{4}{ }^{2-}(\mathrm{mM})$
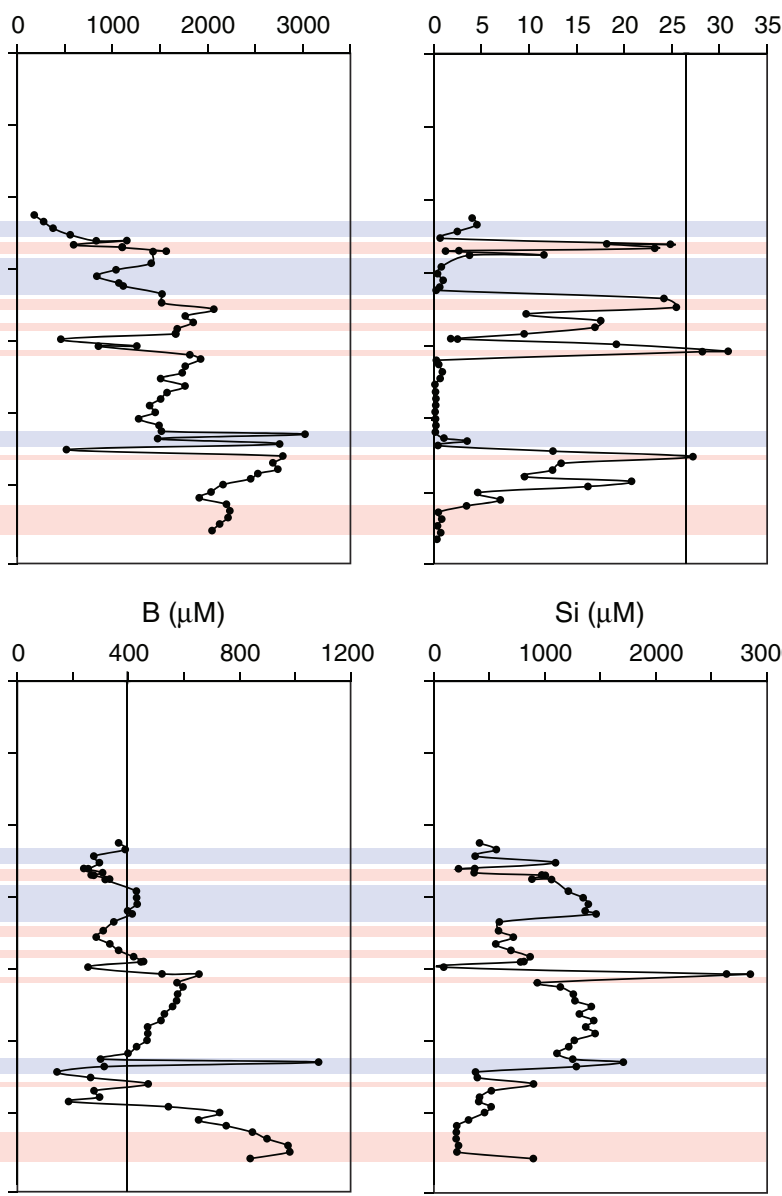

$\mathrm{Si}(\mu \mathrm{M})$

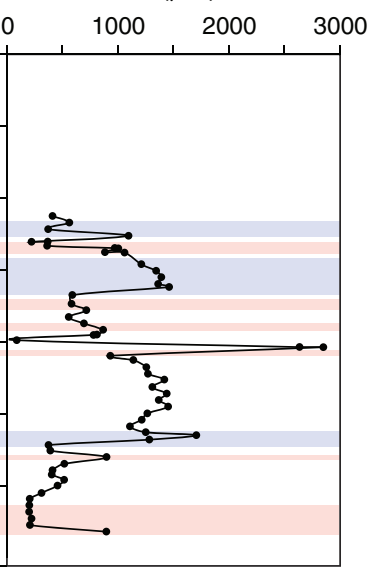

$\mathrm{Al}(\mu \mathrm{M})$

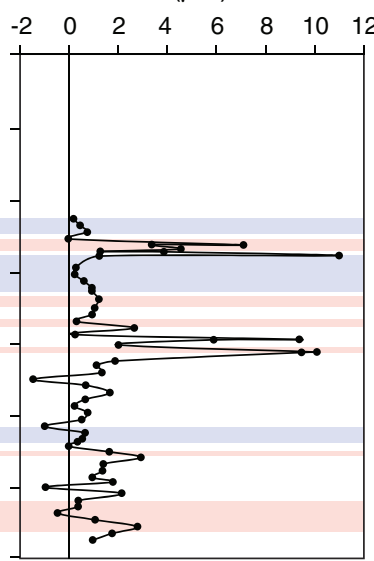


Figure F32. Composition-depth profiles of sediment chemistry and mineralogy compared with interstitial water chemistry, Hole M0028A. Upper row: total carbon (TC), total organic carbon (TOC), total inorganic (carbonate) carbon (TIC), and total sulfur (TS) concentrations in sediment. Lower row: sulfate/chloride and total phosphorus in interstitial water and concentrations of apatite and pyrite from XRD. Horizontal color bands denote discrete freshwater (blue) and salty (pink) layers of interstitial water.
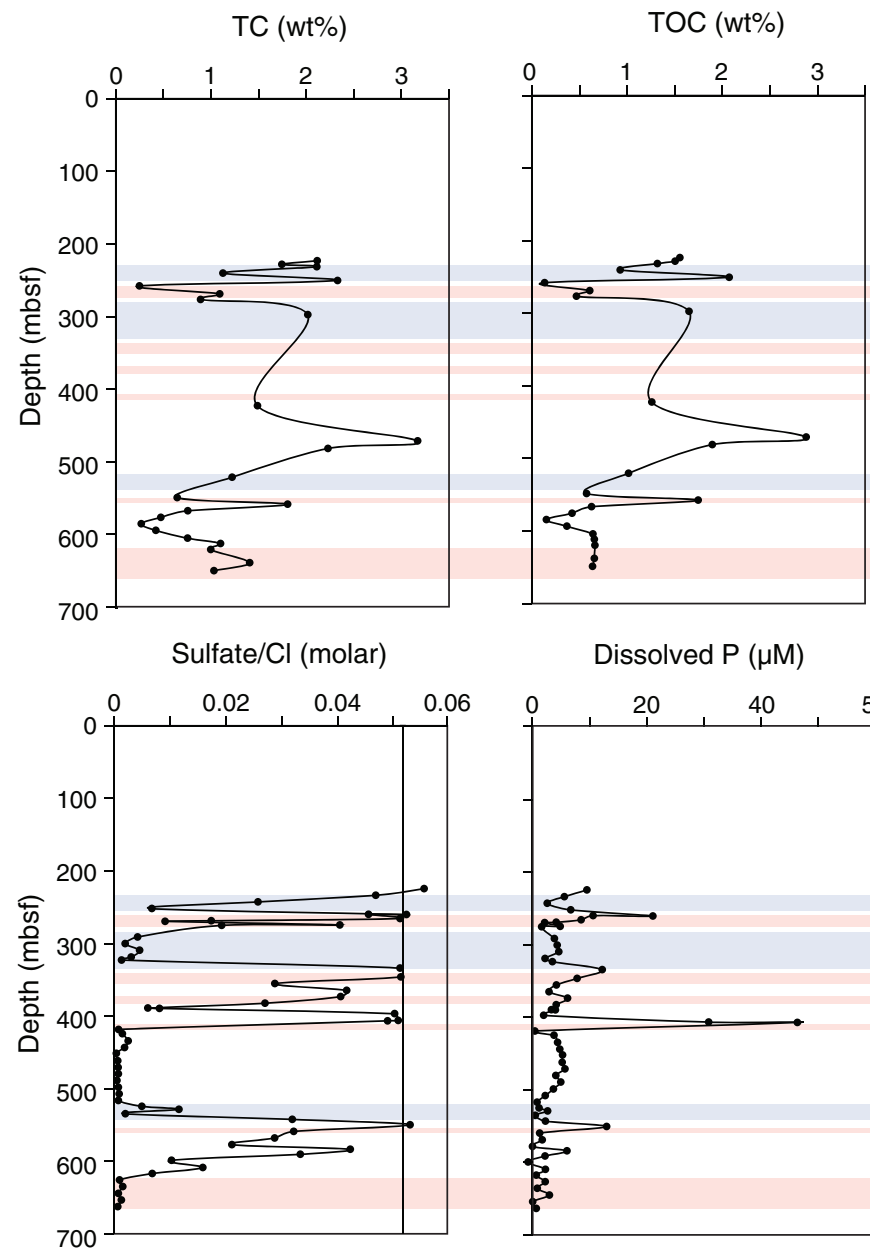

Dissolved P $(\mu \mathrm{M})$

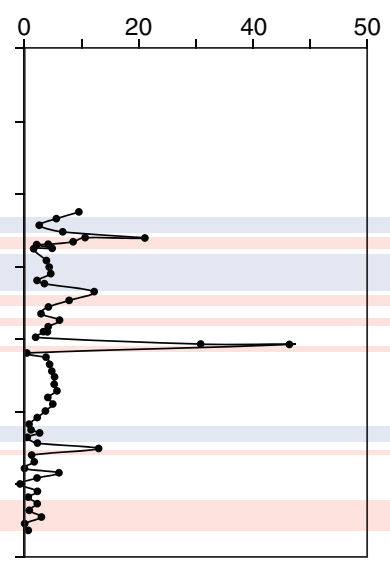

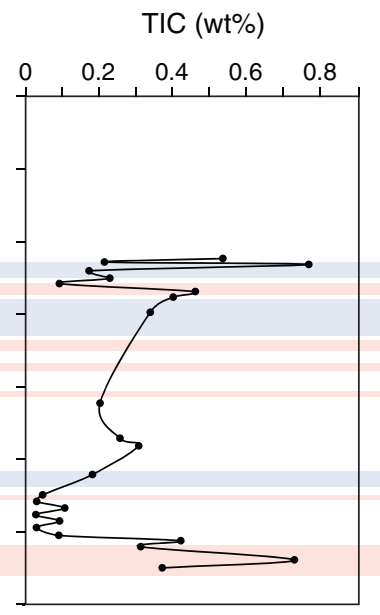

Apatite $2.801 \AA$

TS (wt\%)

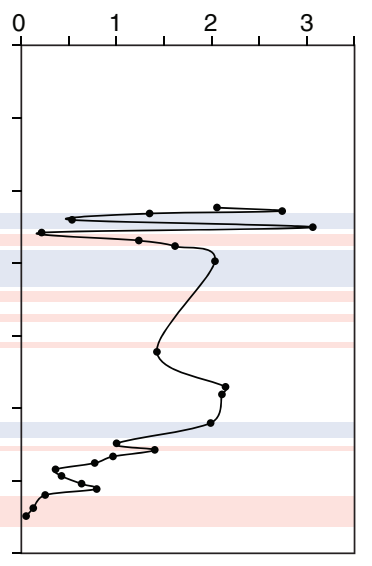

Pyrite $2.17 \AA$
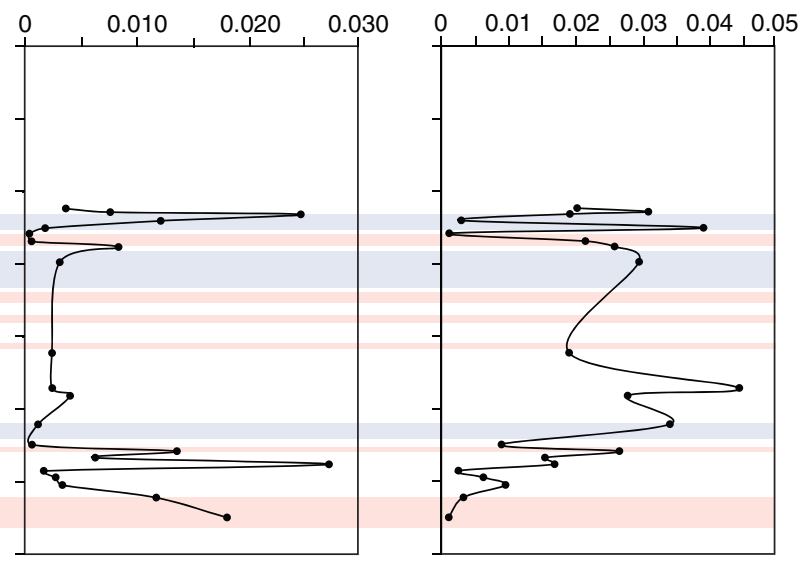
Figure F33. Composition-depth profiles of mineral content in sediment, Hole M0028A, as the ratio of intensity of the specified XRD peak(s) to total intensity of all peaks. Horizontal color bands denote discrete freshwater (blue) and salty (pink) layers of interstitial water.

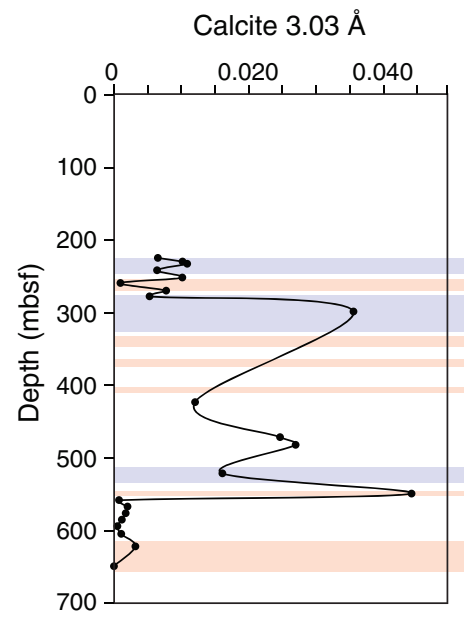

Plagioclase 3.22-3.15 ̊
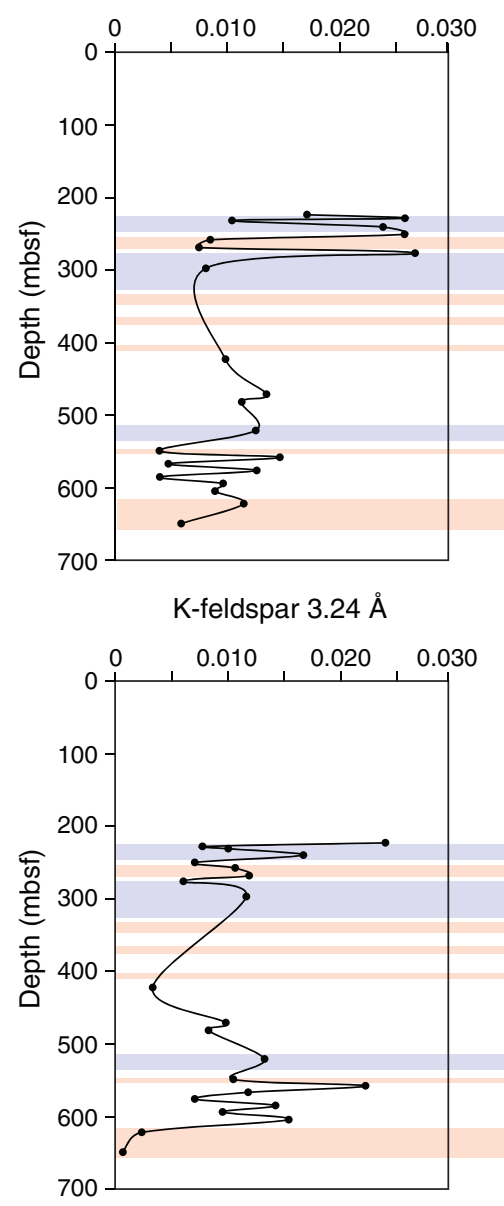

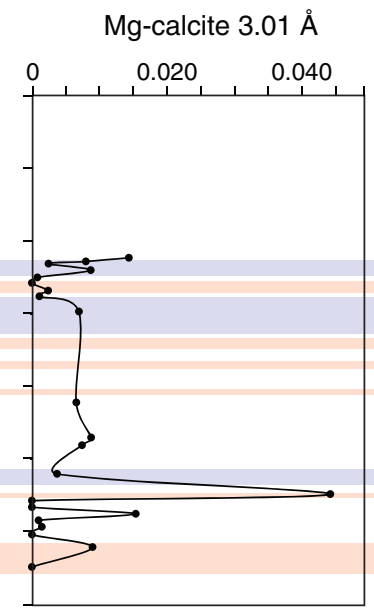

Pyroxene 2.99-2.91 A

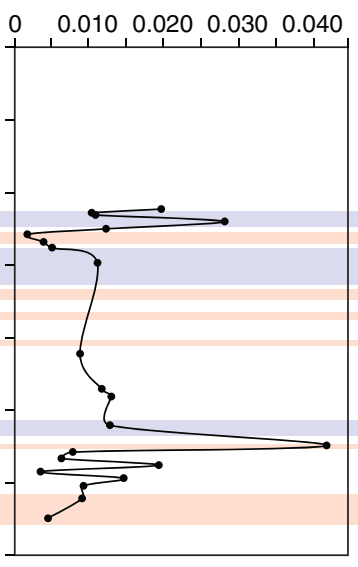

Zeolite 8.8-9.2 Å

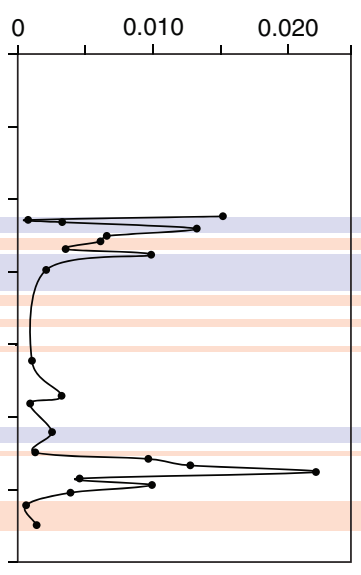

Aragonite $3.4 \AA$

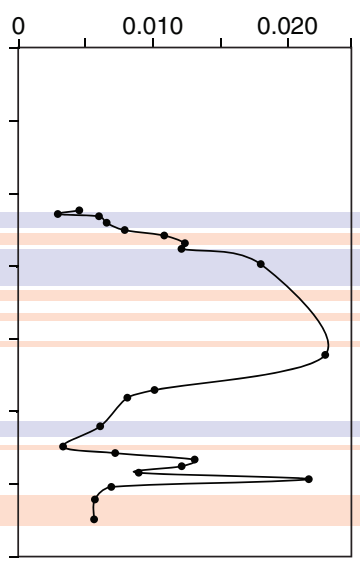

Epidote 2.68-2.66 ̊̊

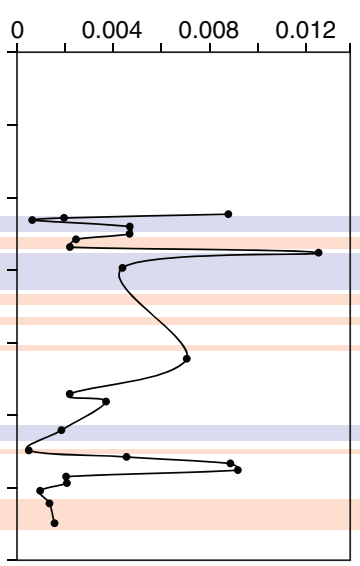

Siderite $2.79 \AA$

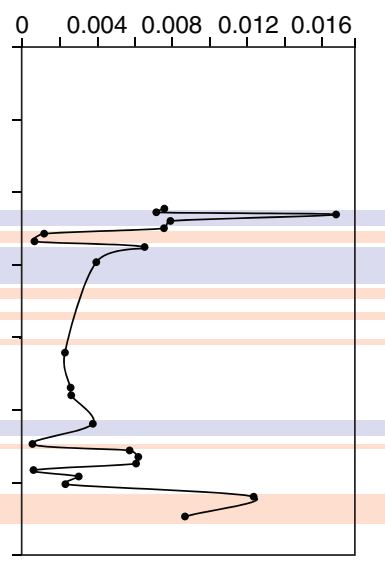

Dolomite + Ankerite $2.9 \AA$

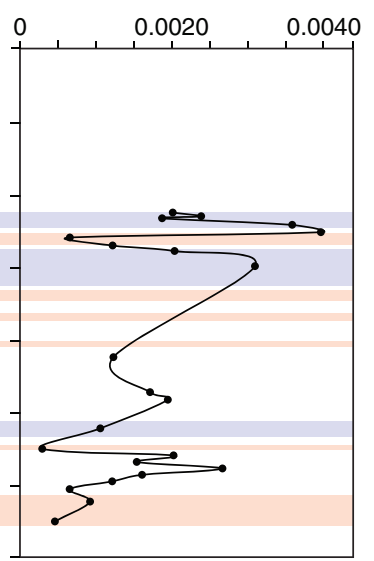

Amphibole $8.45 \AA$

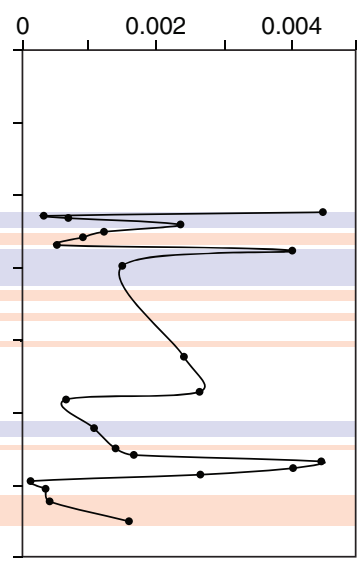

Apatite $2.801 \AA$

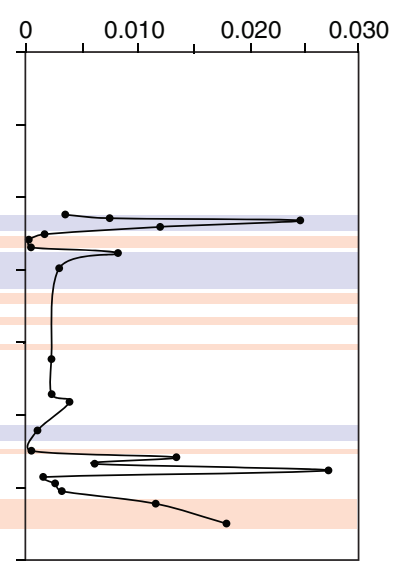


Figure F34. Composition-depth profiles of mineral content in sediment, Hole M0028A, as the ratio of intensity of the specified XRD peak(s) to total intensity of all peaks. Horizontal color bands denote discrete freshwater (blue) and salty (pink) layers of interstitial water.

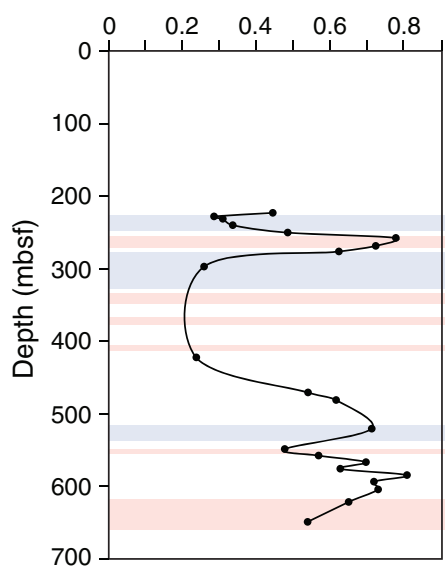

Goethite $4.17 \AA$

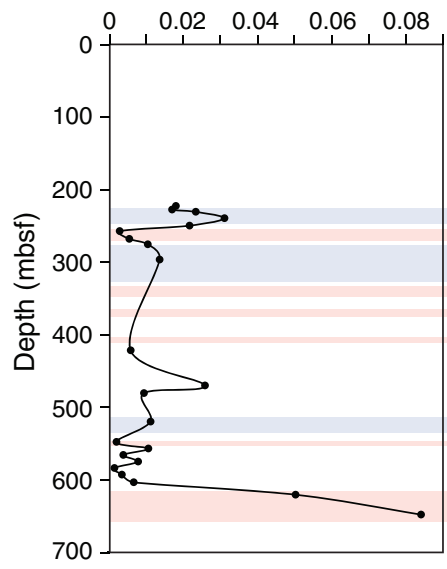

Clay 4.55-4.4

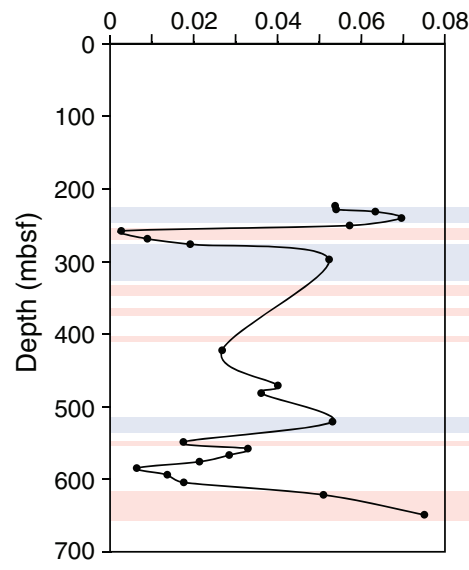

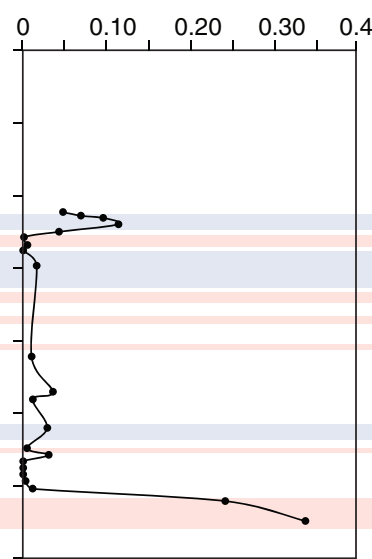

Magnetite $2.53 \AA$

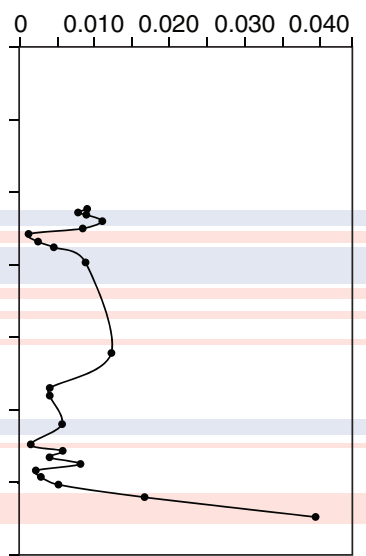

Mica + Illite $10 \AA$

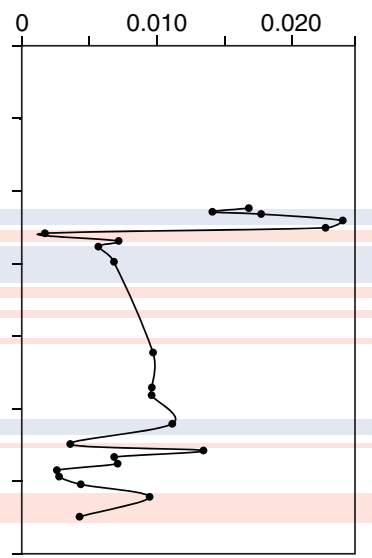

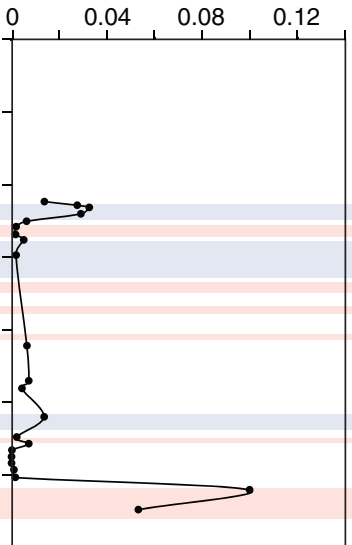

Glauconite $2.392 \AA$

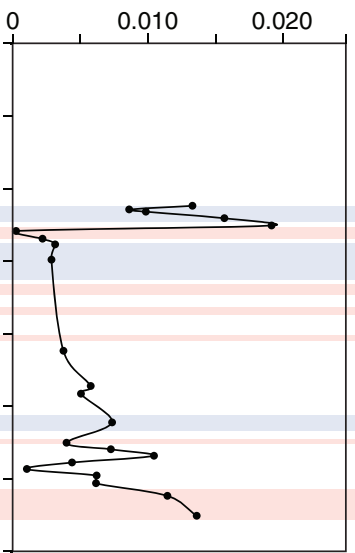

Mixed-layer clay 13.9-10.2 ̊

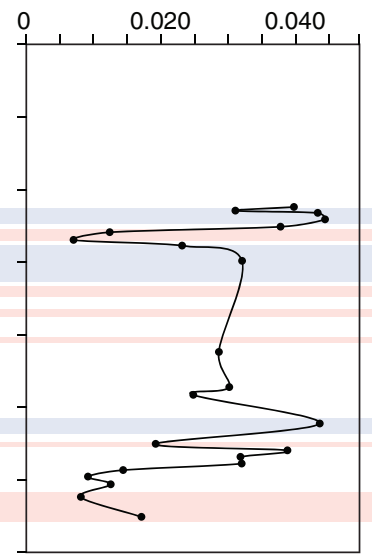

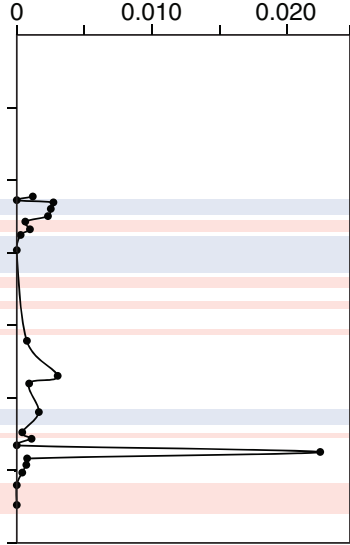

Glauconite $3.63 \AA$

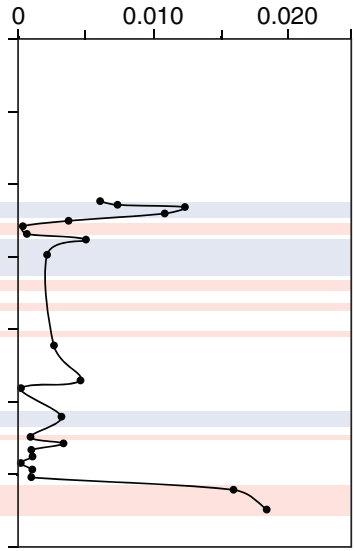

Smectite $17 \AA, 14 \AA$, $5 \AA$

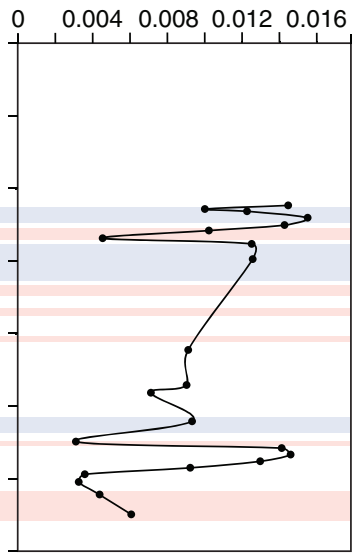


Figure F35. Overview of data acquired from multisensor core logger (MSCL) and sample measurements, Hole M0028A. From MSCL: natural gamma radiation (NGR), $P$-wave velocity, discrete $P$-wave, gamma density, magnetic susceptibility, noncontact electrical resistivity. From sample measurements: water content, wet bulk density, grain density, porosity, void ratio, and thermal conductivity.

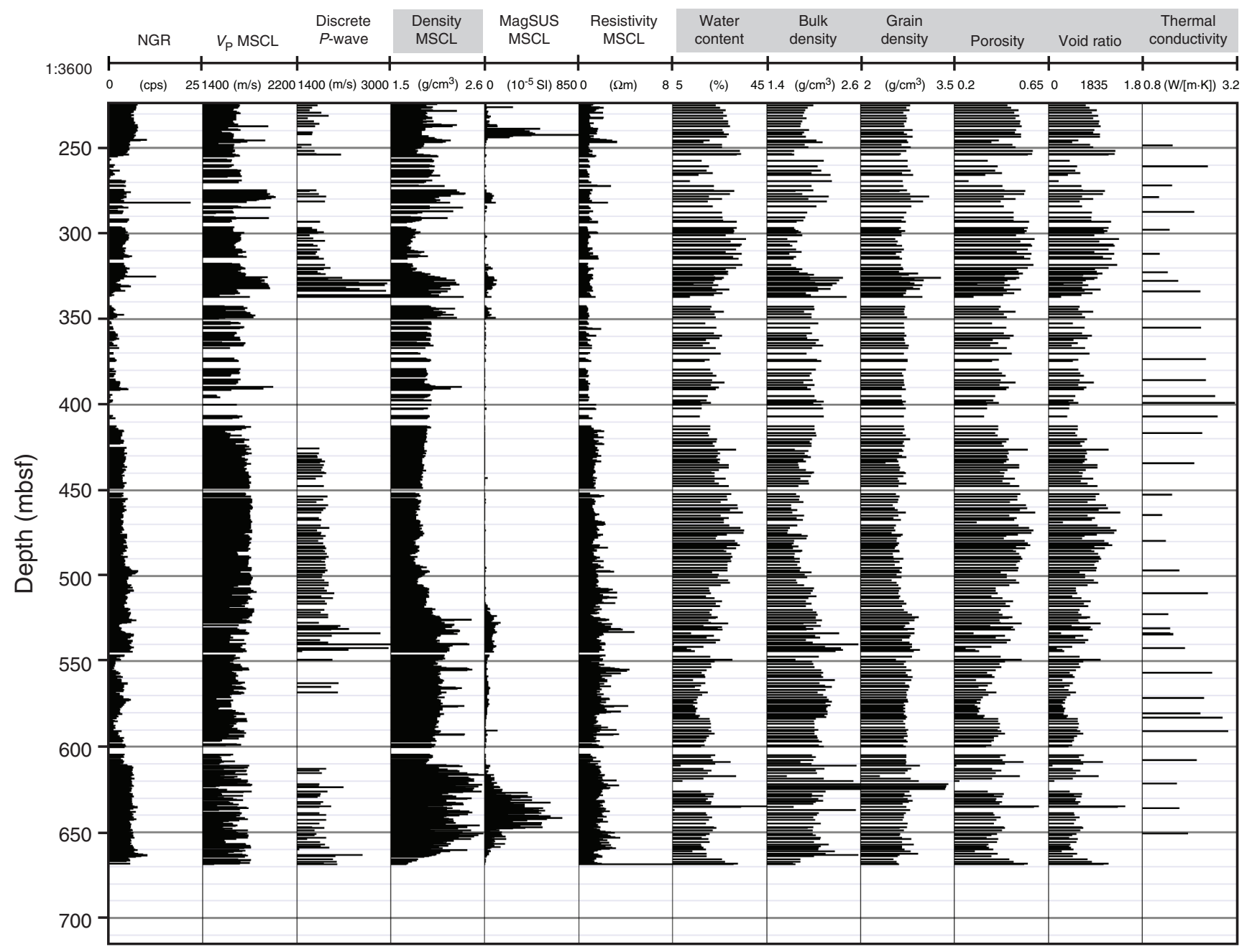


Figure F36. Detailed composite of selected downhole log data, petrophysical measurements, and derived calculations, Hole M0028A. Normalized amplitude acoustic image (ABI40 Ampl); acoustic caliper (AcCal); total gamma ray through pipe (ASGRcgs) and on cores (NGR core); potassium, uranium, and thorium contents (ASGRcgs K, U, and Th, respectively); U-Th/3 ratios; clay volume estimate; magnetic susceptibility from cores on the multisensor core logger (MagSus MSCL) and downhole logging (EM51); $P$-wave velocities on core $\left(V_{\mathrm{p}} \mathrm{MSCL}\right)$ and from log $\left(V_{\mathrm{p}} 2 \mathrm{PSA}\right)$; density from whole core (Density MSCL) and filtered signal; porosity from discrete measurements (porosity) and filtered signal; and impedance calculated from MSCL $P$-wave data (impedance MSCL) and sonic $P$-wave log (impedance $2 \mathrm{PSA}$ ). Stratigraphic surfaces are added to the left: $\mathrm{SB}=$ sequence boundary, FS = flooding surface, HFS = maximum flooding surface, TS = transgressive surface. Petrophysical boundaries are shown in pink. See text for discussion, Table T12 for boundary descriptions, and Figure F4 in the "Methods" chapter for lithology legend. A. 596-666 m WSF. (Continued on next four pages.)

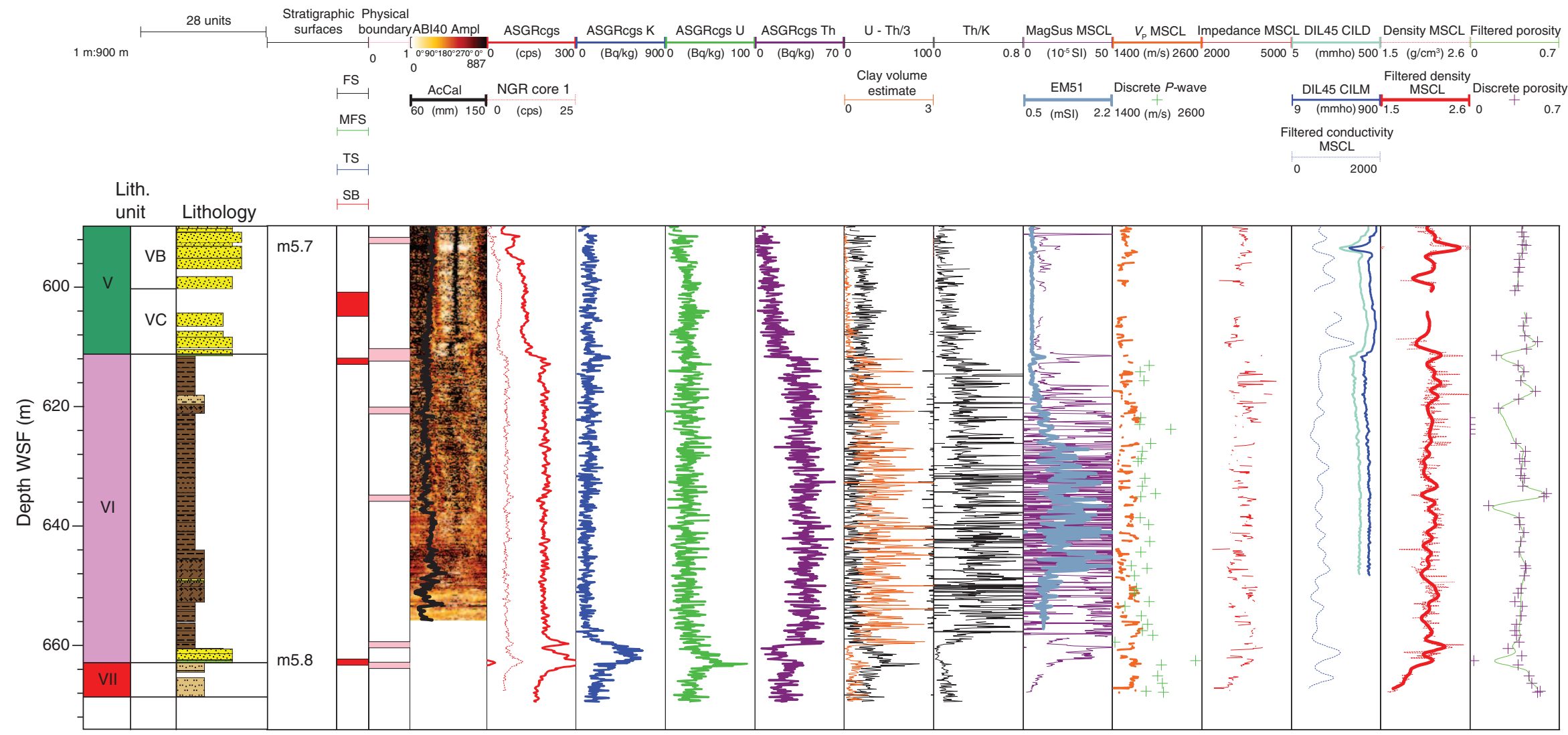



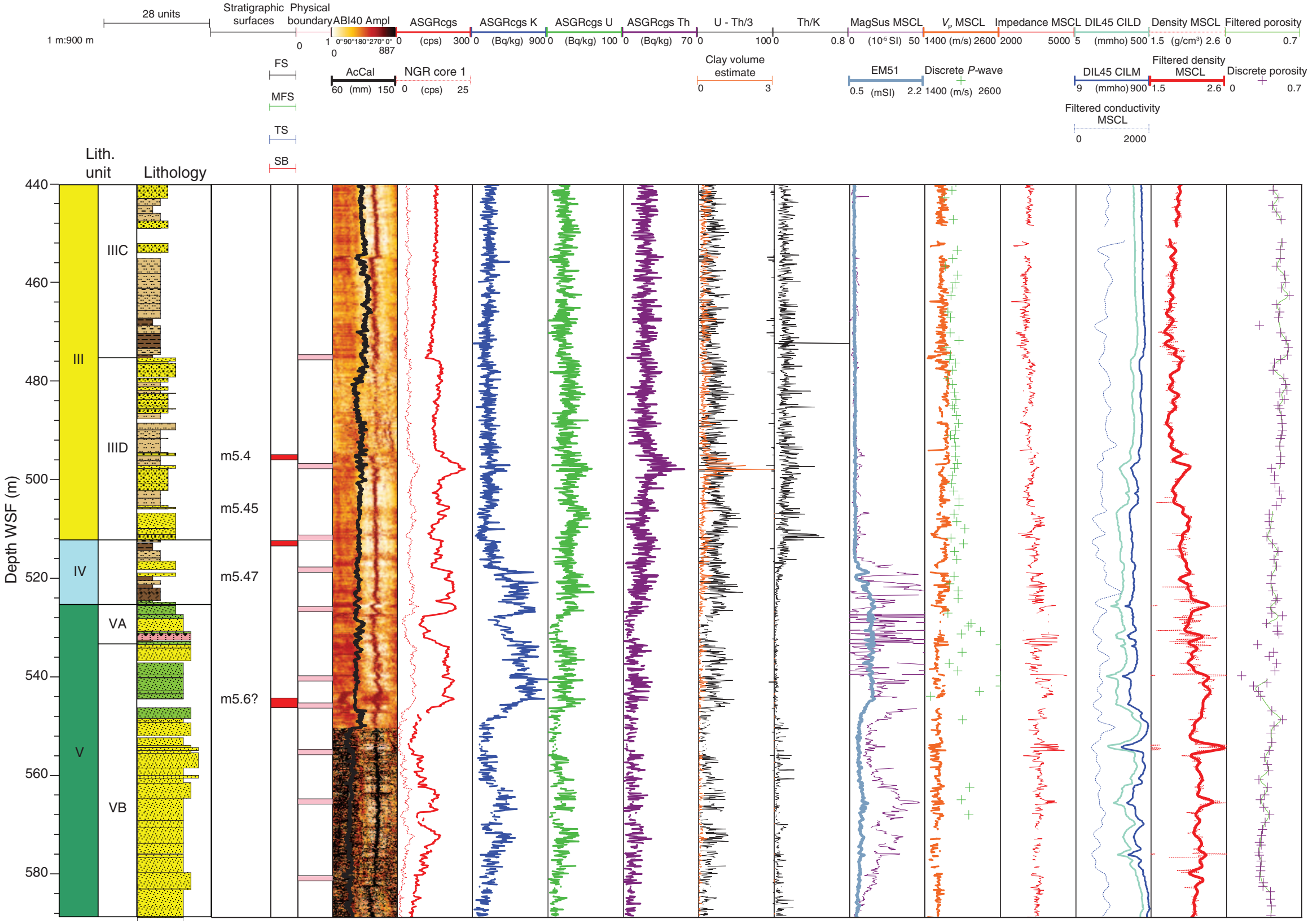
Figure F36 (continued). C. 298-440 m WSF. (Continued on next page.)
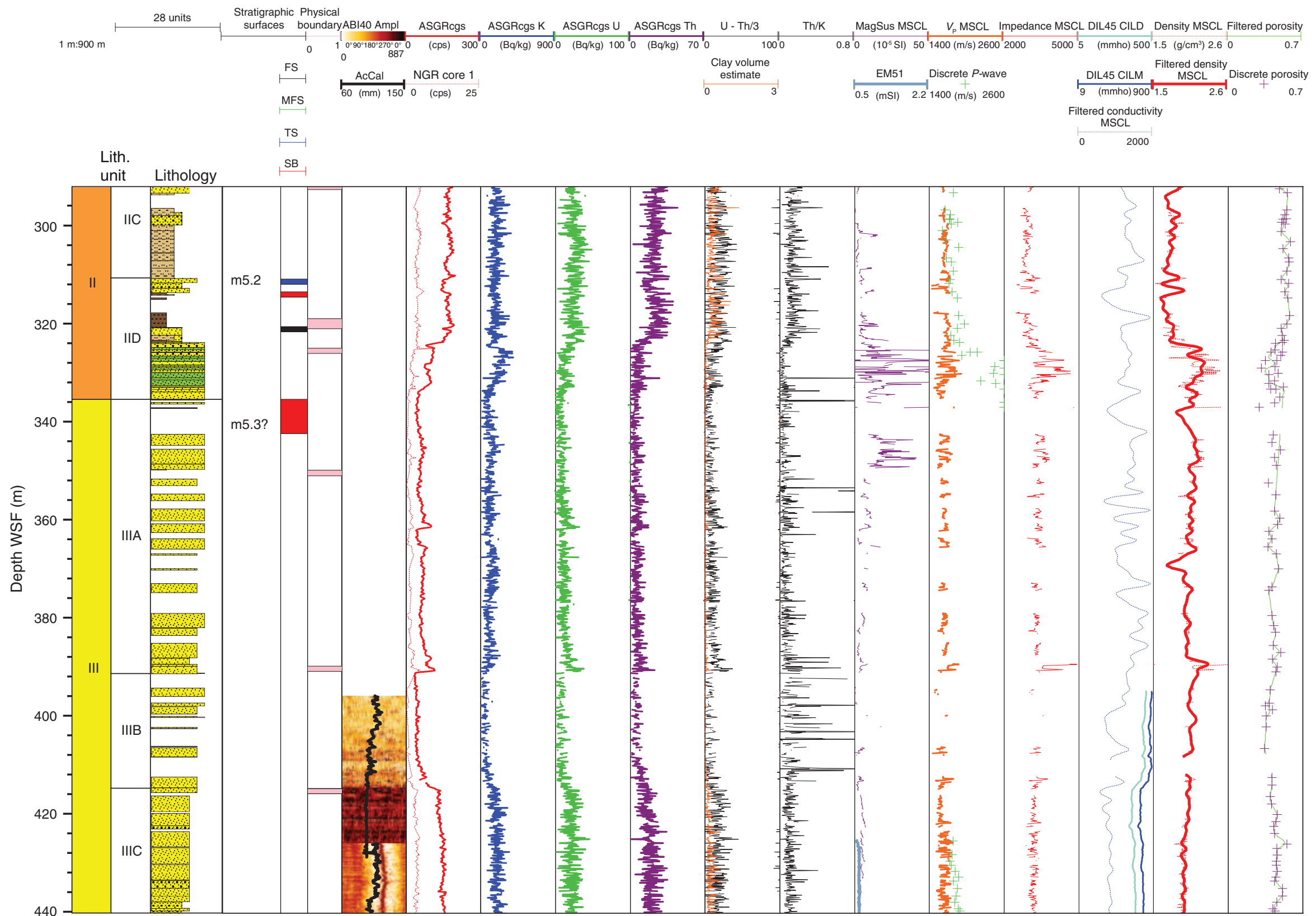


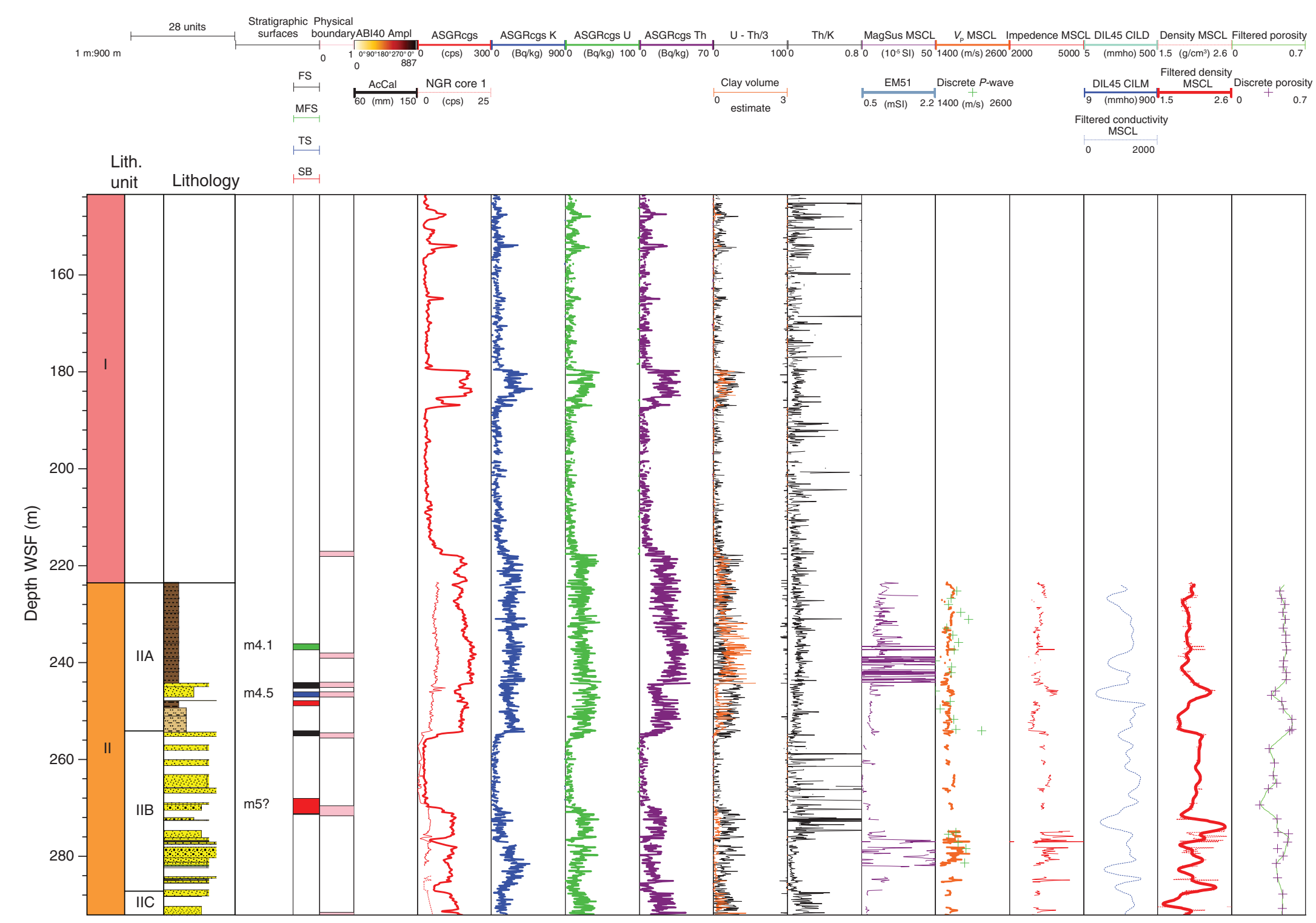


Figure F36 (continued). E. 0-140 m WSF.
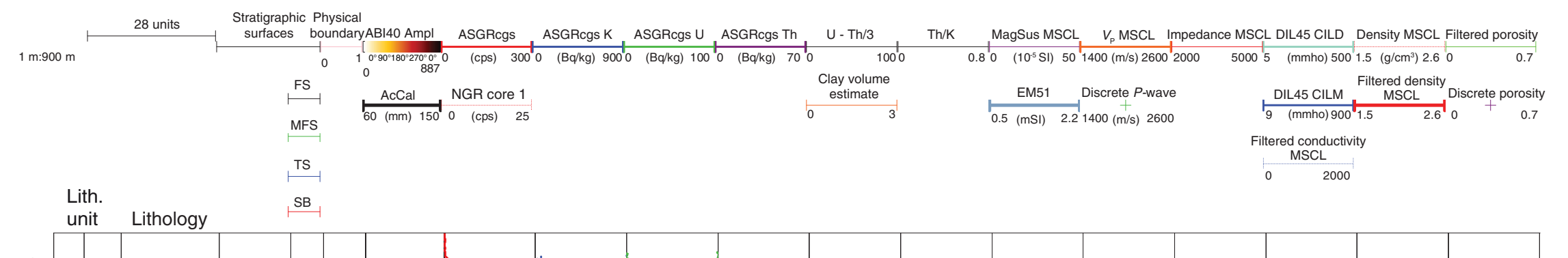

$\theta$

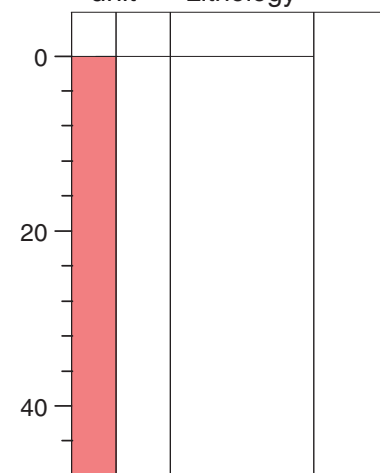

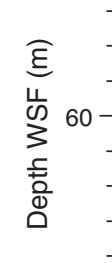

80

140-
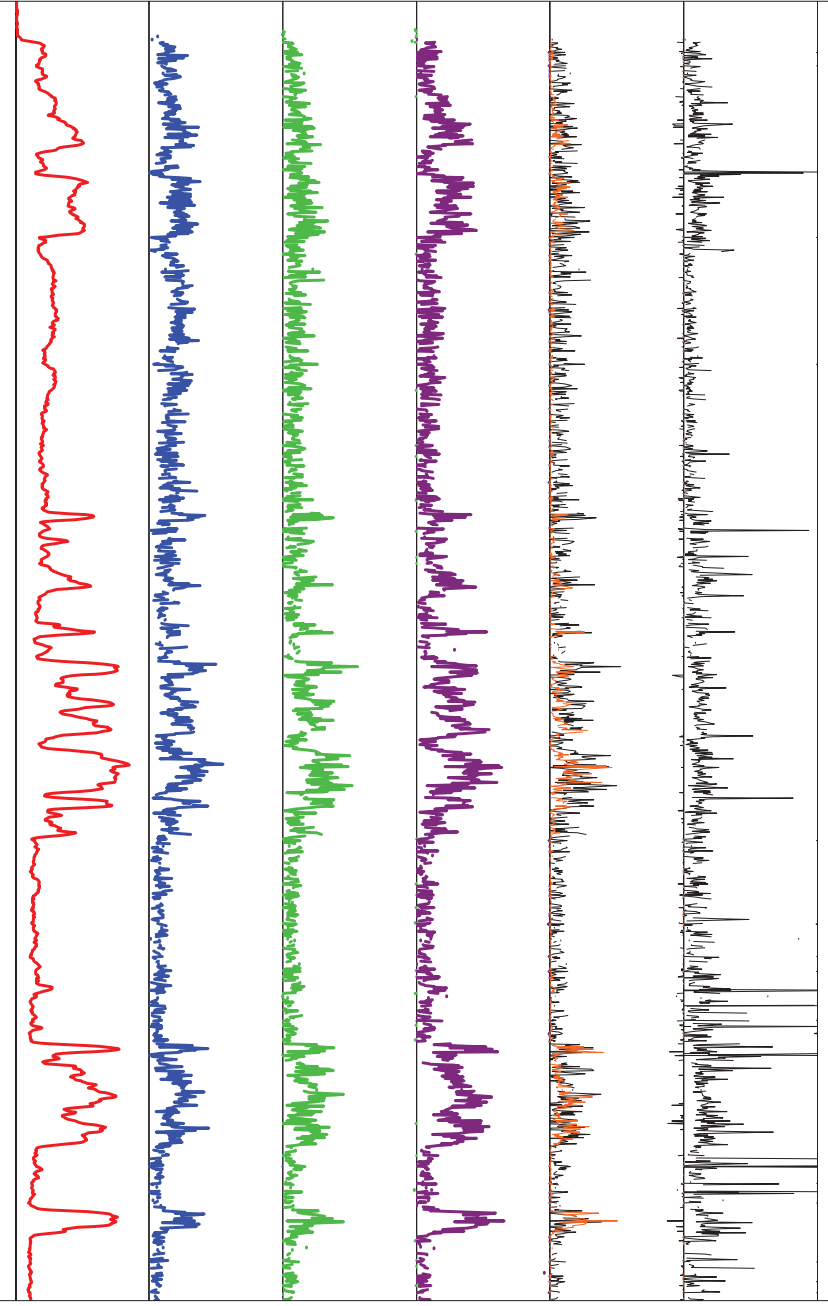
Figure F37. Gamma density, wet bulk density, porosity, and resistivity compared with lithology in Hole M0028A. A. Gamma density from the MSCL (black line) and wet bulk density from section samples (red crosses). B. Porosity from section samples (red crosses) and high-pass filtered porosity (black line). Mean porosity reduction of sands (blue line) and clay (green line) from global averages. C. Resistivity from MSCL. Black line $=$ unfiltered, red line $=$ filtered $($ see text), vertical black line at $1.3 \Omega \mathrm{m}=$ average clay-silt resistivity with low-chlorinity pore water. Note how porosity reduction in clay and silt-rich intervals follows reduction of global averages. See Figure F4 in the "Methods" chapter for lithology legend.

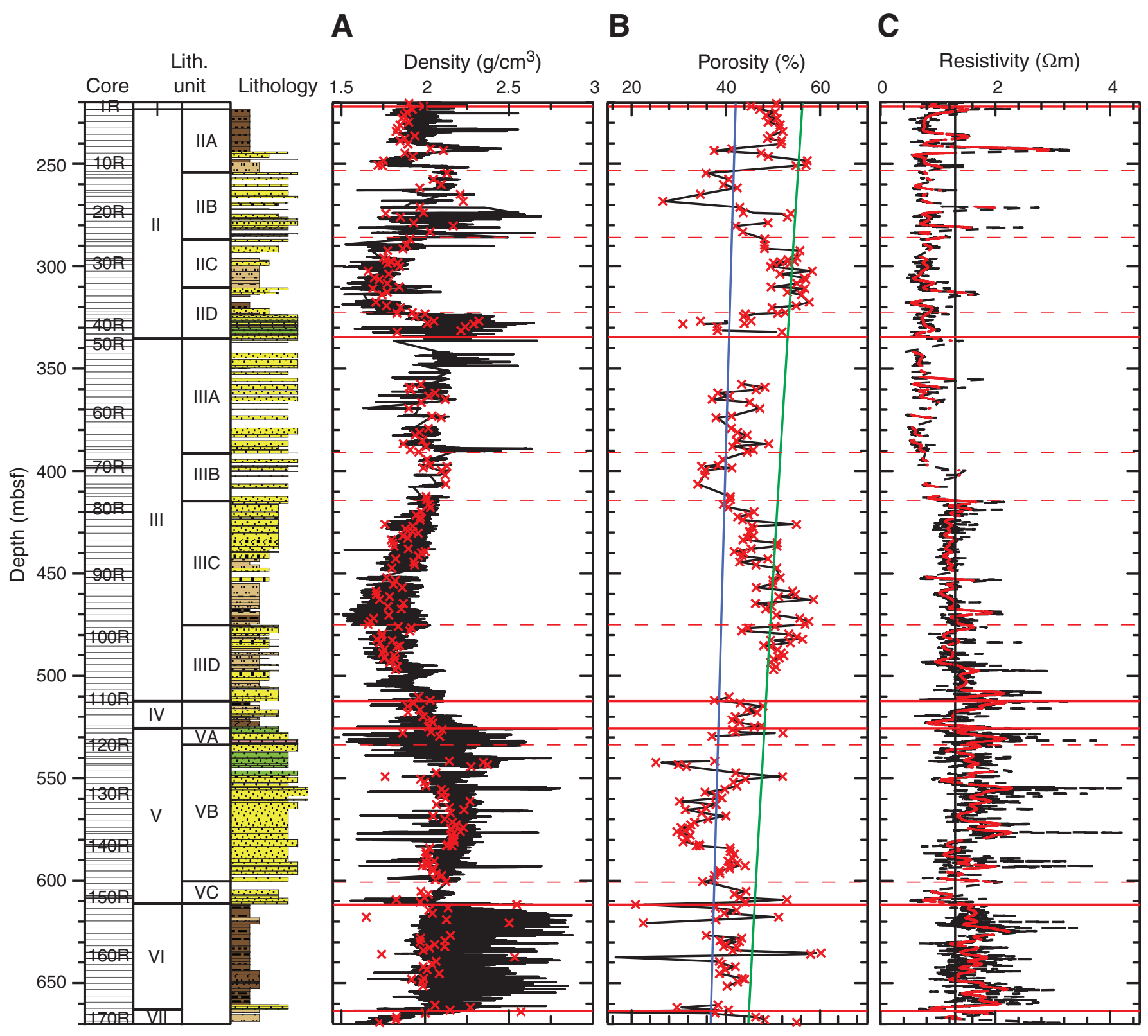


Figure F38. Cross-plot of gamma density and wet bulk density, Hole M0028A. GRA density is consistently higher than calculated wet bulk density from core samples. MSCL $=$ multisensor core logger.

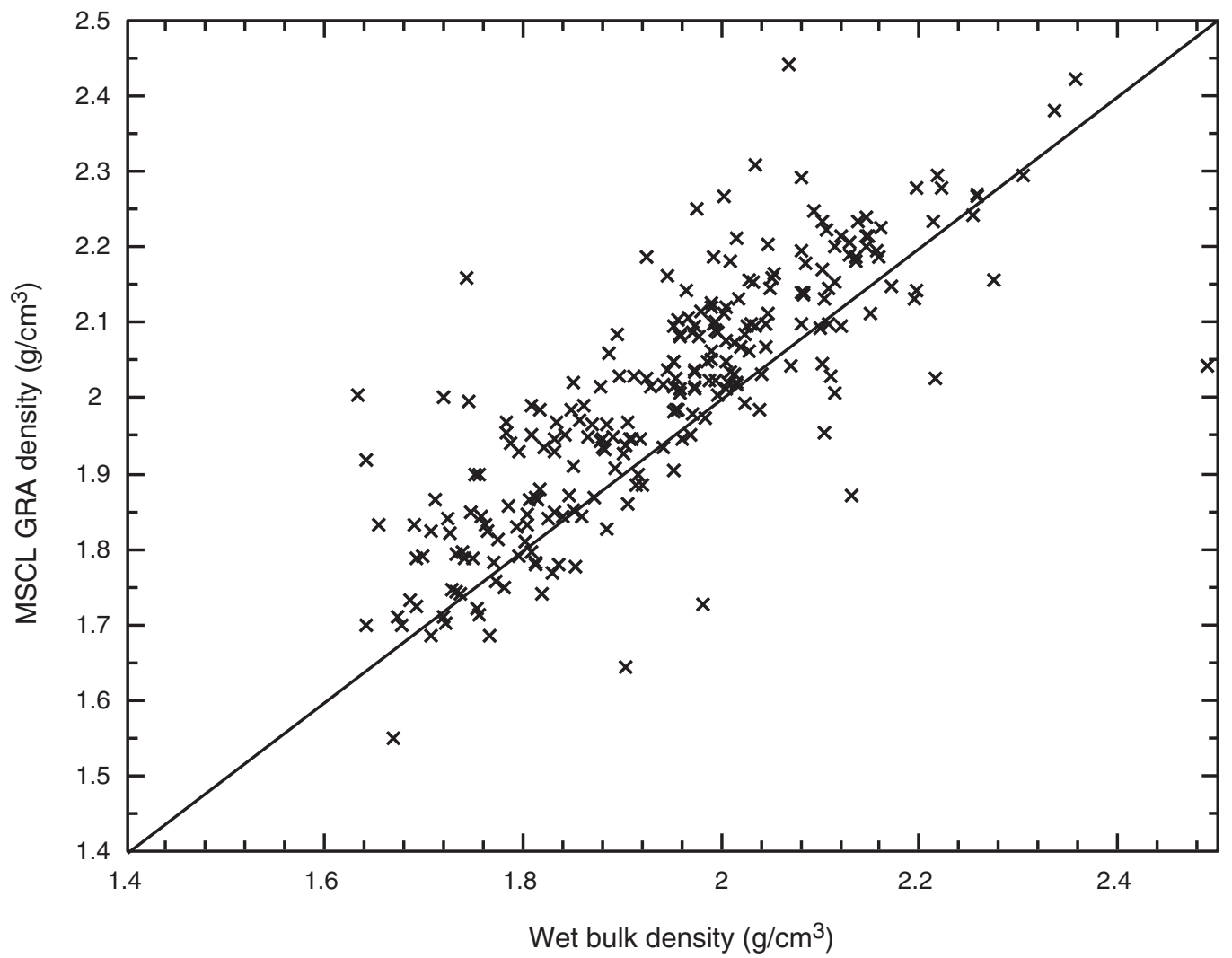


Figure F39. Cross-plot of wet bulk density and porosity from section samples, Hole M0028A. Diagonal line = mixing line between rock (zero porosity and density of $\left.2.7 \mathrm{~g} / \mathrm{cm}^{3}\right)$ and saltwater $(100 \%$ porosity and density of $1.024 \mathrm{~g} / \mathrm{cm}^{3}$ ). Note how glauconite lithologies consistently fall to the right of the mixing line with greater density, probably because glauconite has a density up to $2.9 \mathrm{~g} / \mathrm{cm}^{3}$.

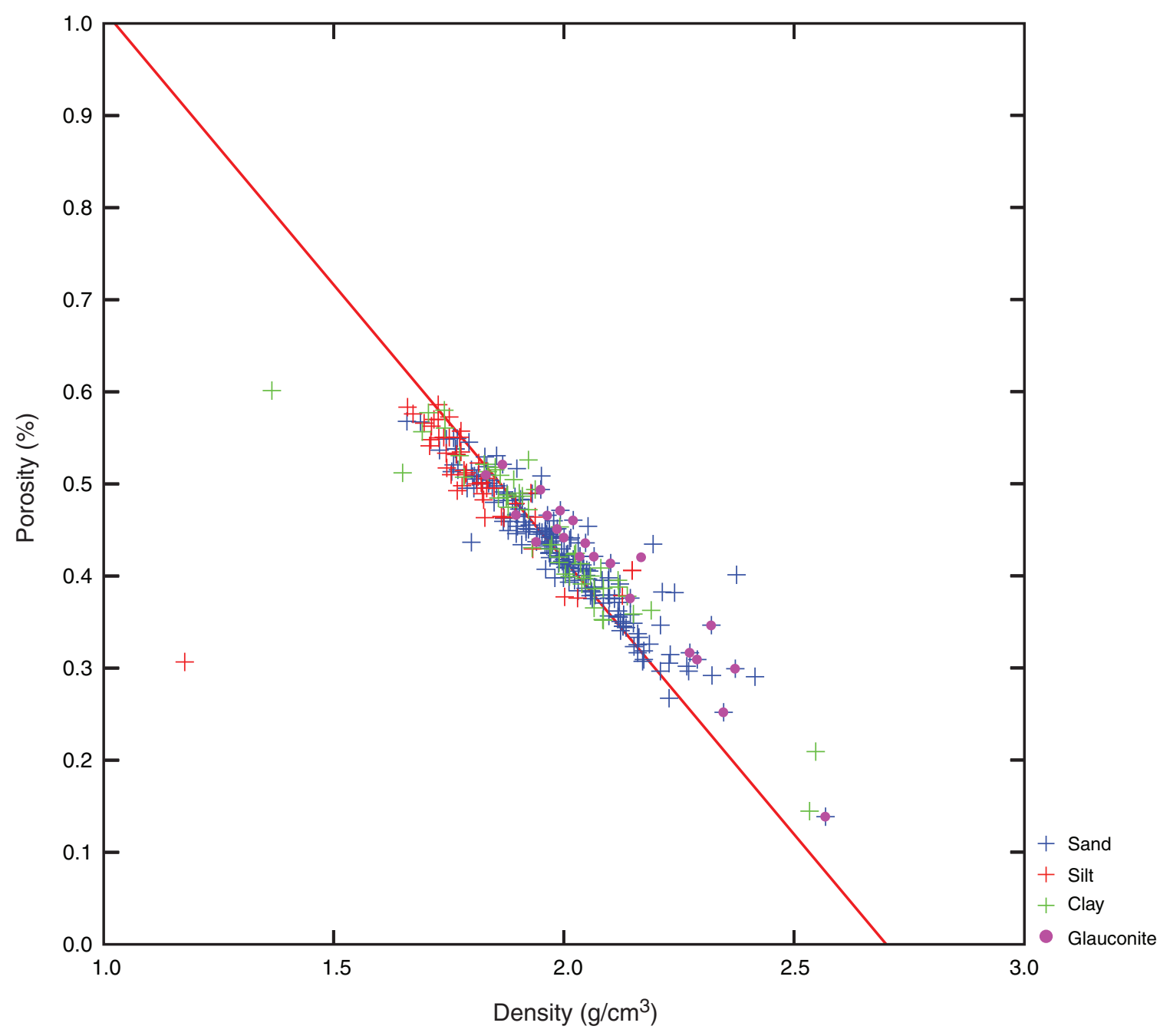


Figure F40. High-pass filtered porosity, density, and resistivity vs. depth compared with lithology in Hole M0028A. Porosity and density: bulk wet density from samples (thick black line) overlain on gamma density (thin black line). Porosity (red line) increases to left. Resistivity: black line = original data with Section 3 s removed (see text), red line $=$ high-pass filtered record. Overall packages with increasing density and decreasing porosity (diagonal arrows) have a tendency to end with a sharp decrease in density and increase in porosity (horizontal arrows). These sharp shifts to the left correspond to grain size decreases as determined from lithology and may represent thin transgressive packages or flooding surfaces. See Figure F1 for lithology legend. A. 220-350 mbsf. (Continued on next two pages.)

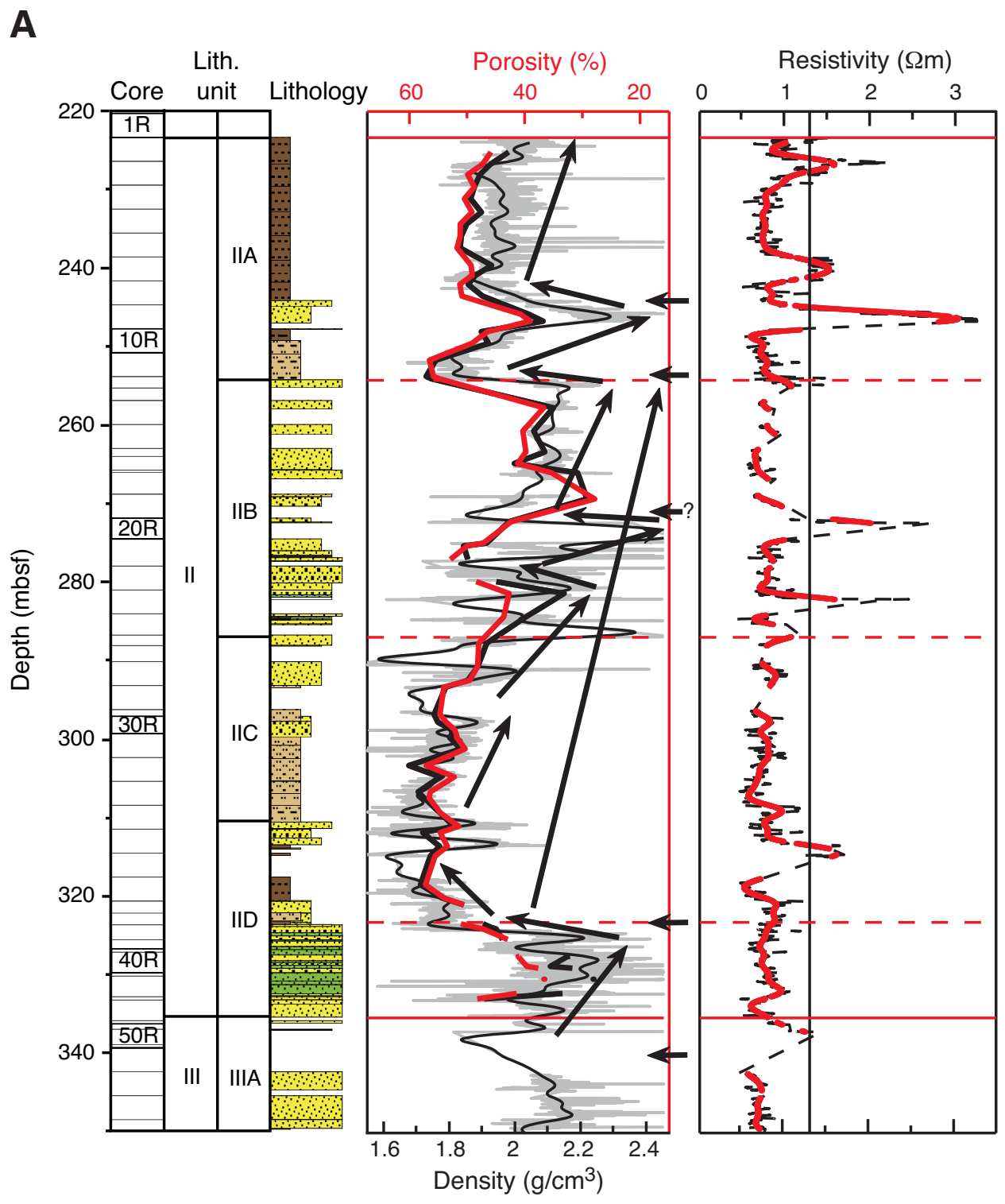


Figure F40 (continued). B. 320-500 mbsf. (Continued on next page.)

B

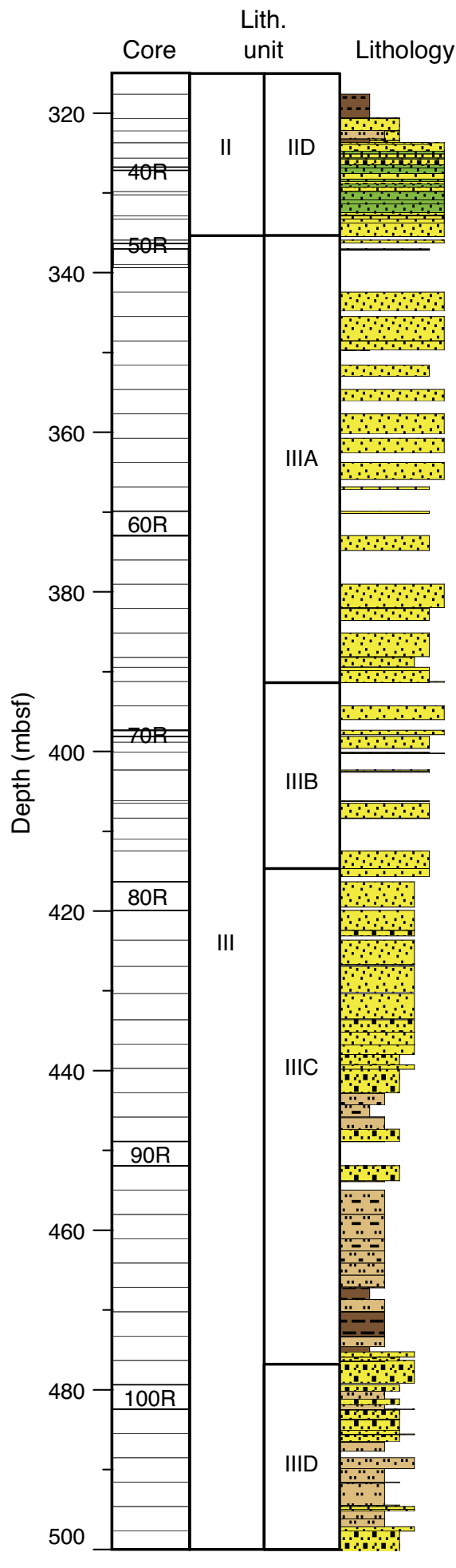

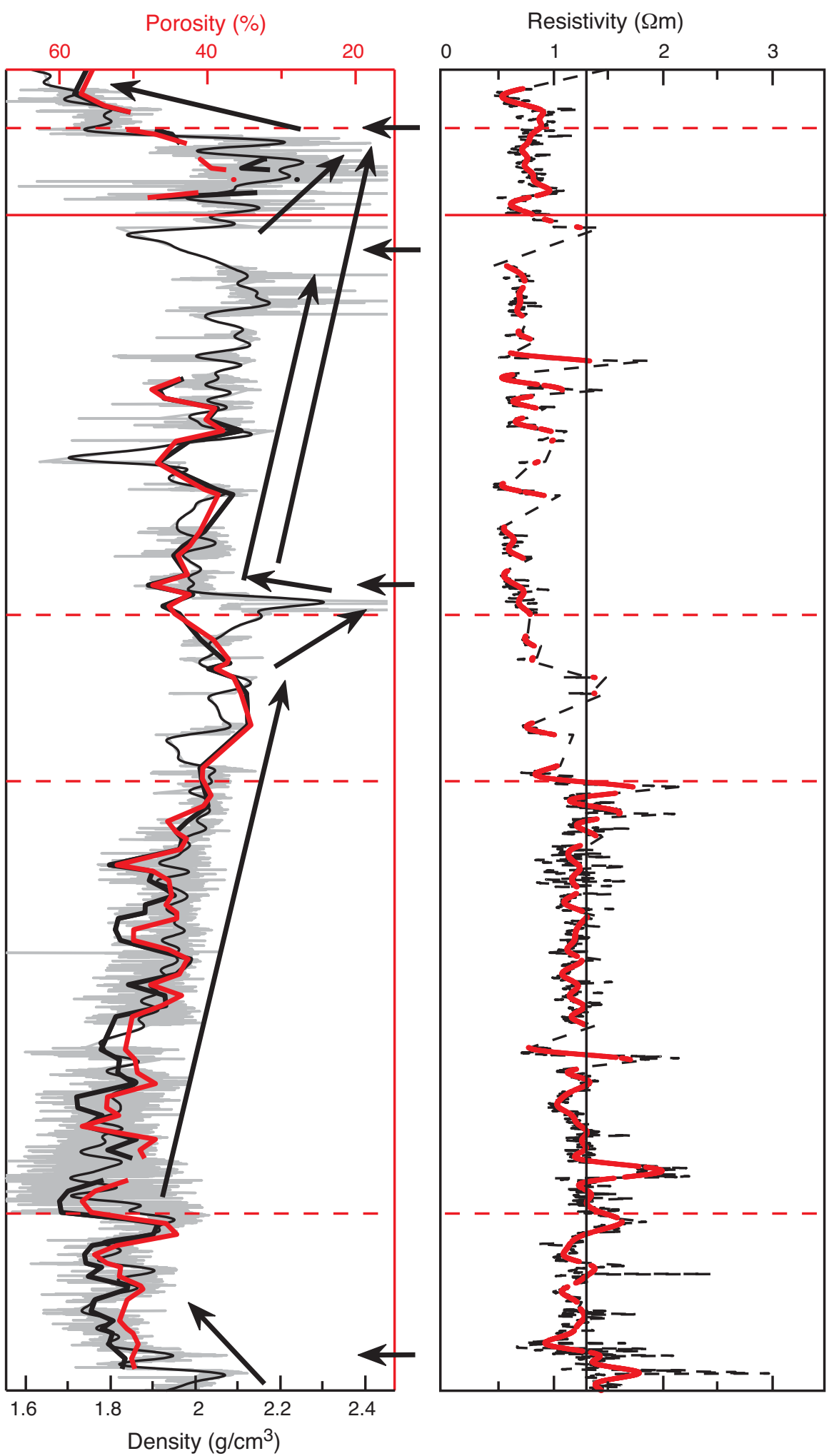


Figure F40 (continued). C. 500-670 mbsf.

C

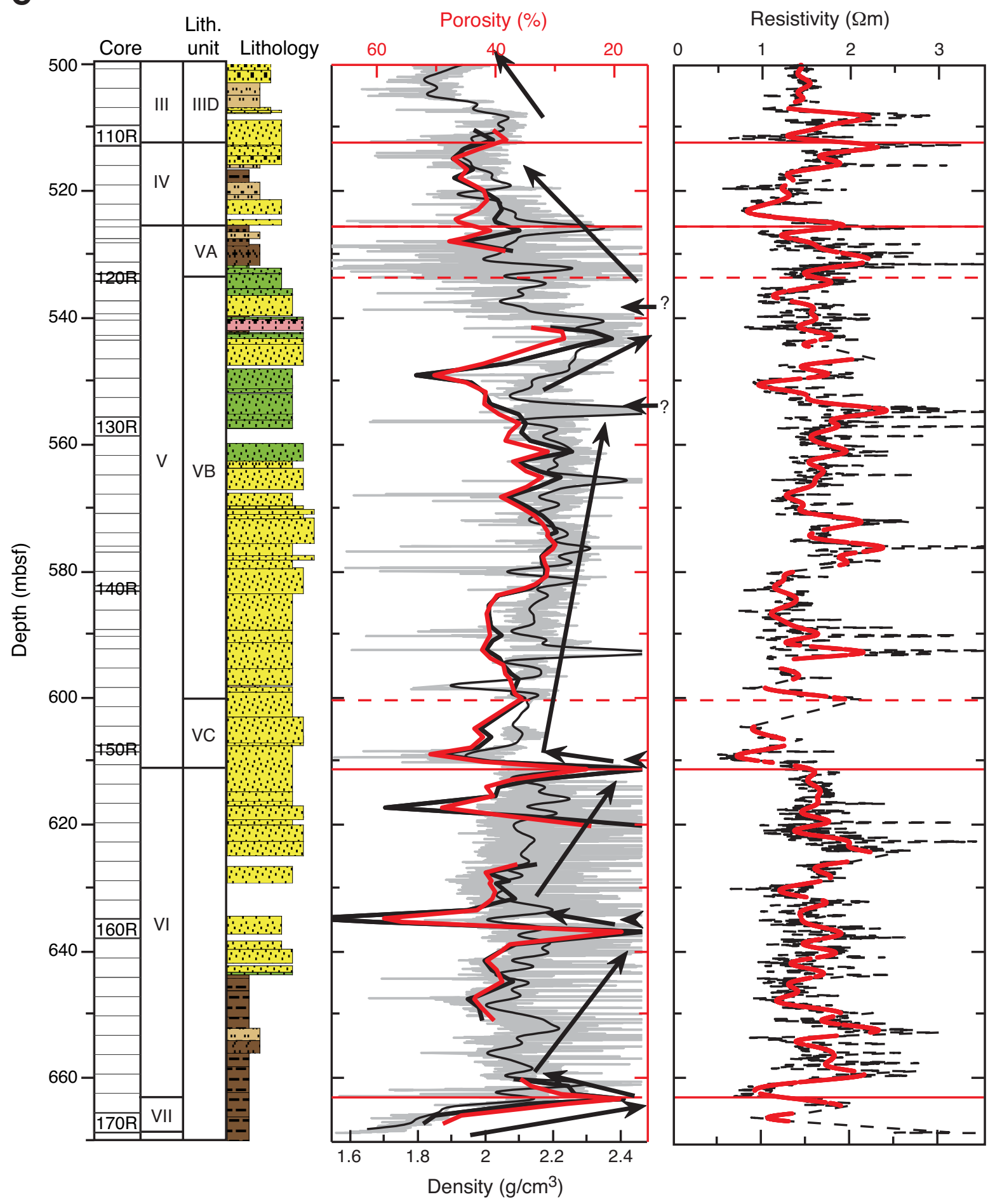


Figure F41. Total gamma ray (ASGRcgs), $P$-wave MSCL velocities, electrical conductivities (DIL45 and MSCL), chlorinity, and thermal conductivity, Hole M0028A. Cemented levels observed by sedimentologists are plotted as pink lines/bars across the $P$-wave and conductivity logs, which are anticipated to show an increase and decrease, respectively, at most of these horizons. Pink and blue shading shows intervals of high salinity and freshwater, respectively (see "Geochemistry"). See Figure F1 for lithology legend.

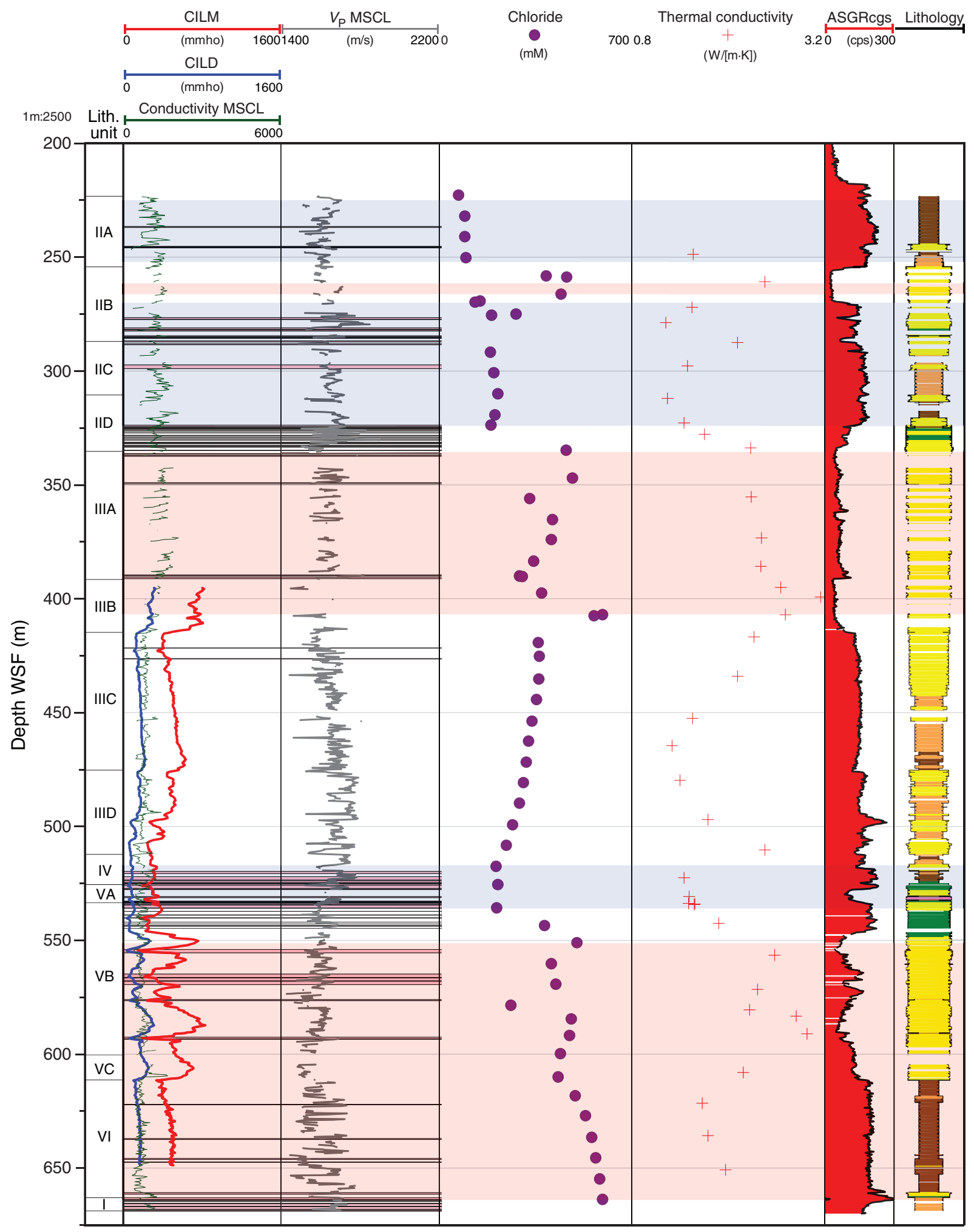


Figure F42. Estimated glauconite content compared with spectral gamma ray counts and magnetic susceptibility from 500 to 630 mbsf and m WSF, Hole M0028A. Glauconite estimate from sedimentological description. Magnetic susceptibility (MagSUS) from the multisensor core logger (MSCL) corresponds to glauconite-rich layers. Intervals where magnetic susceptibility is not associated with an increase in $\mathrm{K}$ or K/Th are those in which glauconite is less significant. TGR = total gamma ray. See Figure F4 in the "Methods" chapter for lithology legend.

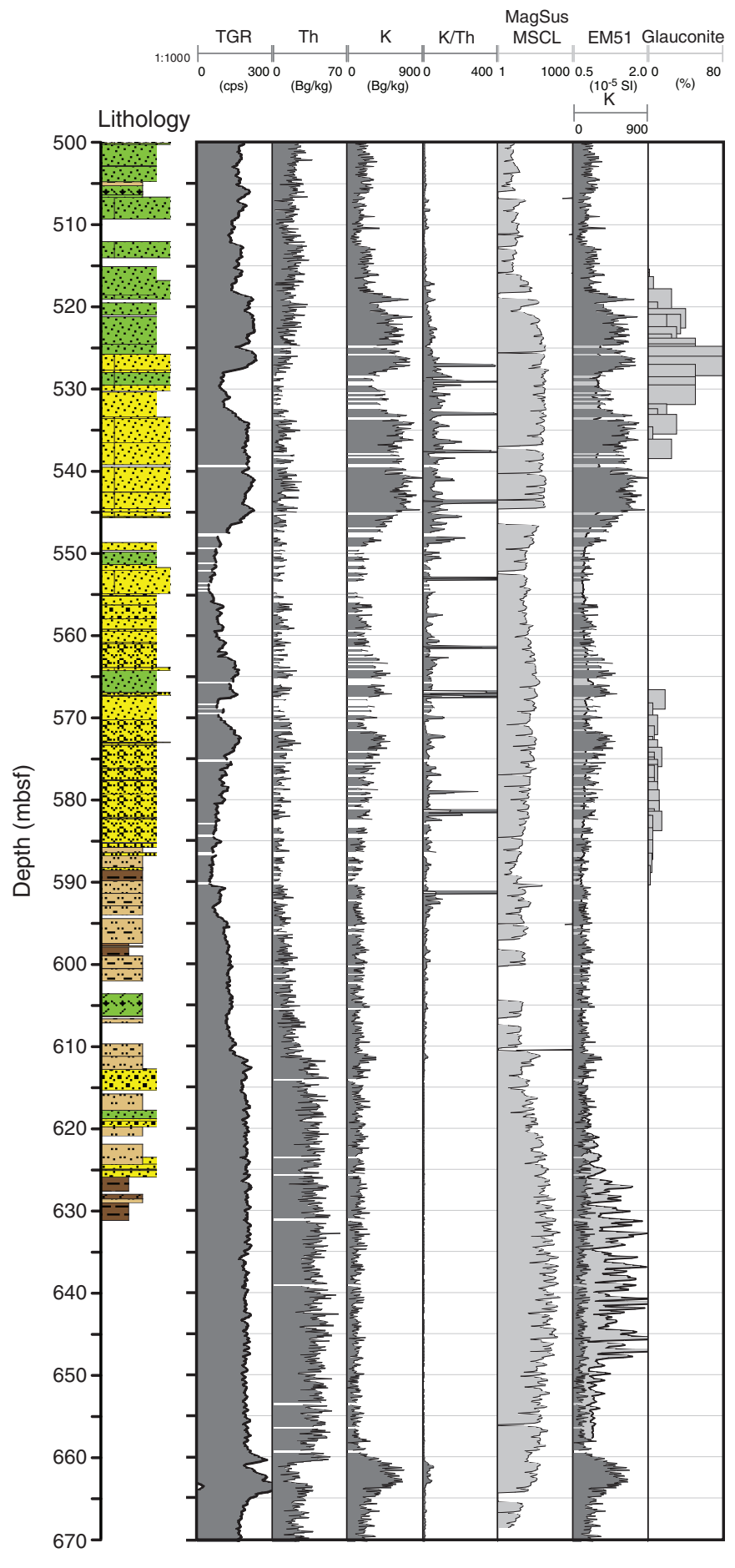


Figure F43. Example of linear correlation between density (red curve) and magnetic susceptibility (MS; blue curve), Sections 313-M0028A-22R-1 and 22R-2. Linear correlation is probably caused by the concentration of mature glauconite (density of $2.9 \mathrm{~g} / \mathrm{cm}^{3}$ and high iron content) in the sediments.
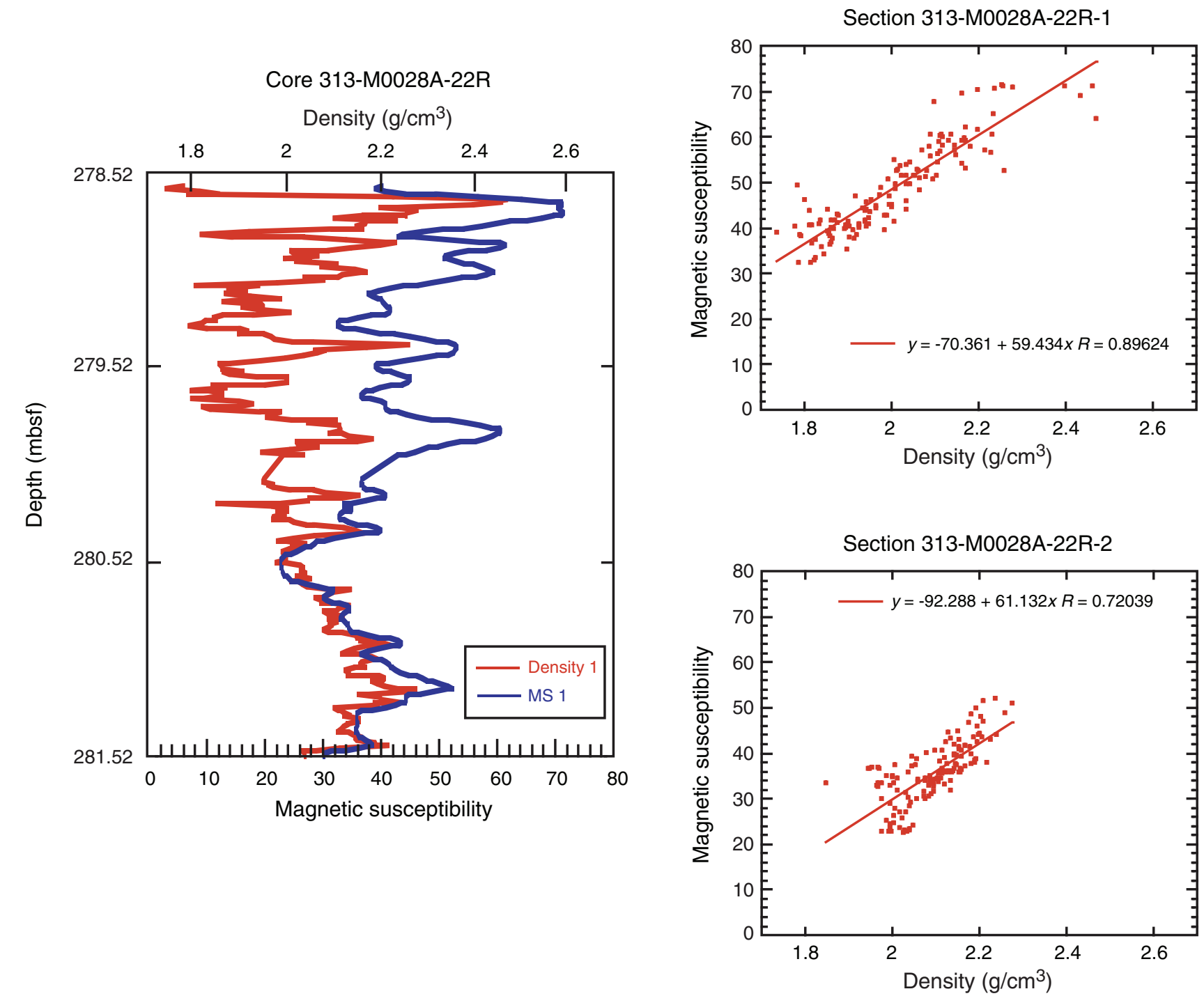
Figure F44. Inclination and magnetic moment data for Hole M0028A for initial natural remanent magnetization (NRM; black), and after 15 and $30 \mathrm{mT}$ AF demagnetization (blue and red, respectively). MSCL magnetic susceptibility (MS) is also shown for reference.

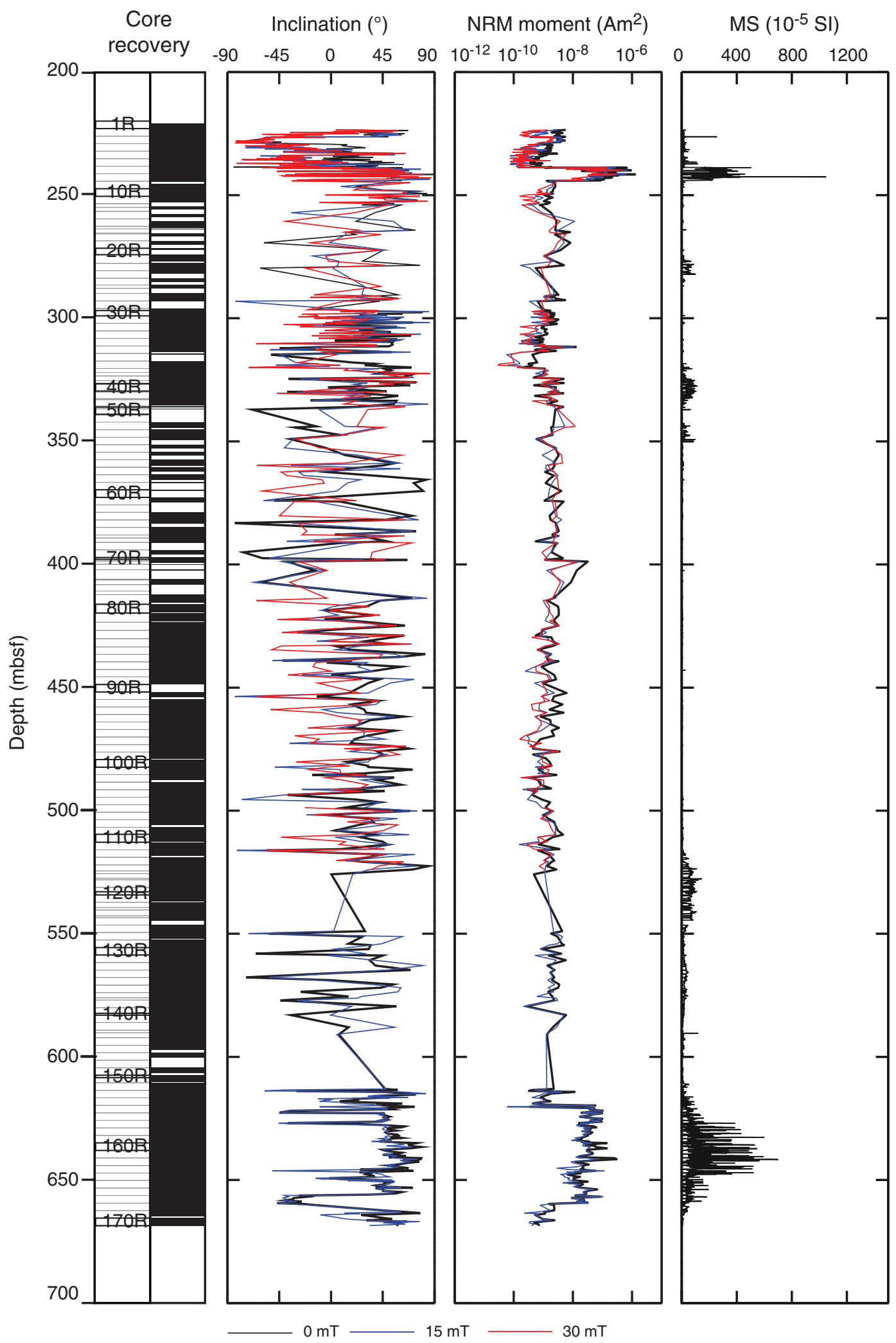


Figure F45. Preliminary magnetostratigraphic interpretation, Cores 313-M0028A-152R through 170R. Inclination data of initial NRM (black) and at $15 \mathrm{mT}$ (blue). Magnetic polarity timescale from Cande and Kent (1995). Solid lines = preliminary tie points.

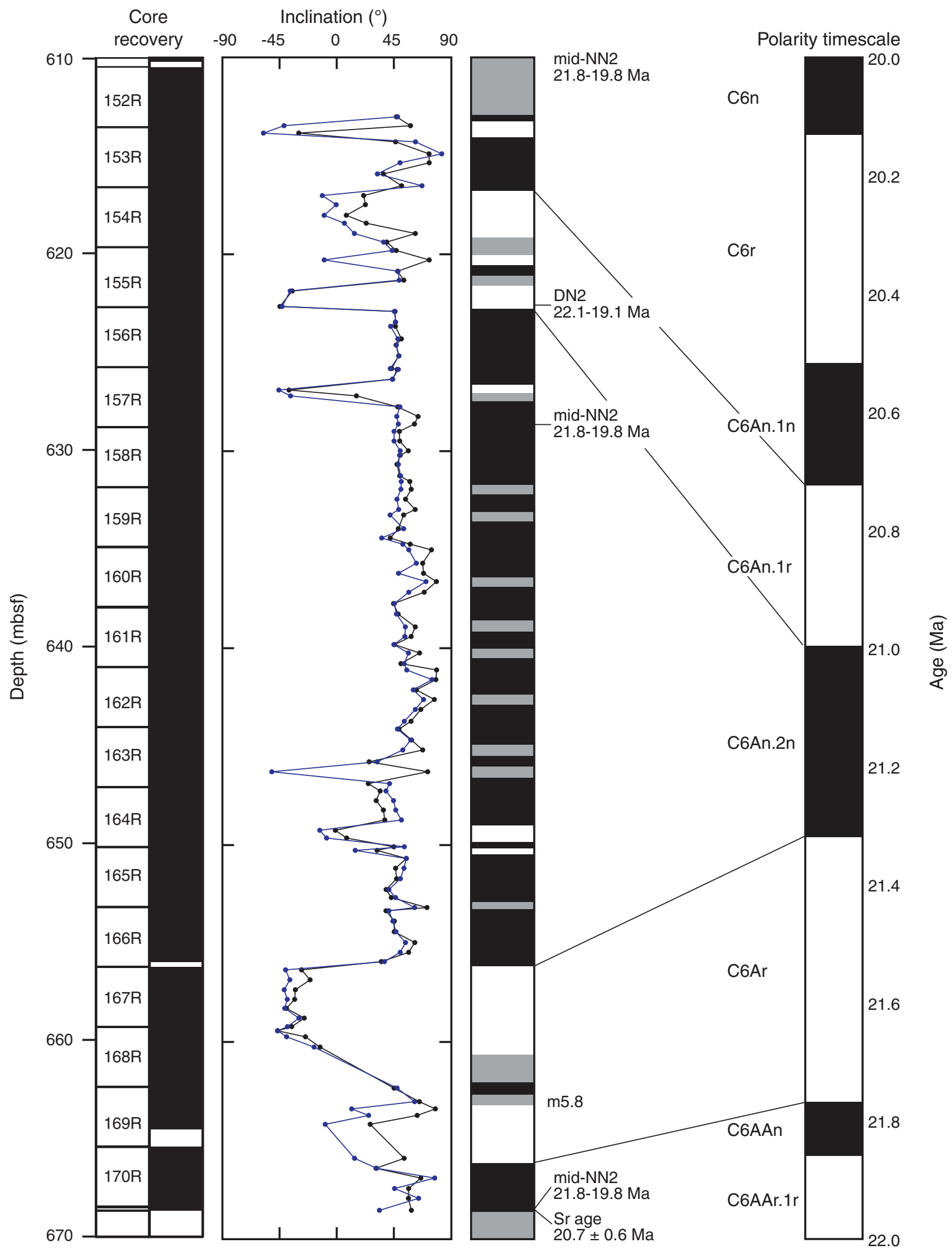


Figure F46. Magnetic mineralogy observed in four thin sections. A. Fine opaque particles in siltstone containing unidentified ferrimagnetic grains and organic fragments. Green mineral left of center is glauconite. B. Framboidal iron sulfate magnetic minerals (upper center right) formed in a pore possibly carrying a secondary magnetization. C. Series of fine magnetic minerals situated along glauconite pellets show an authigenic origin. D. Subangular magnetite grain (center, opaque) showing detrital origin.

\section{A}

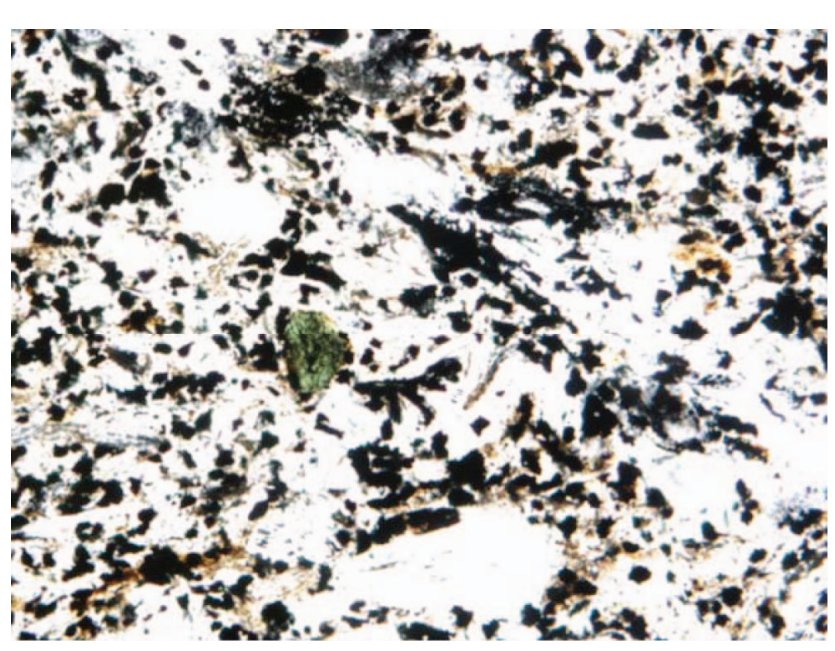

C

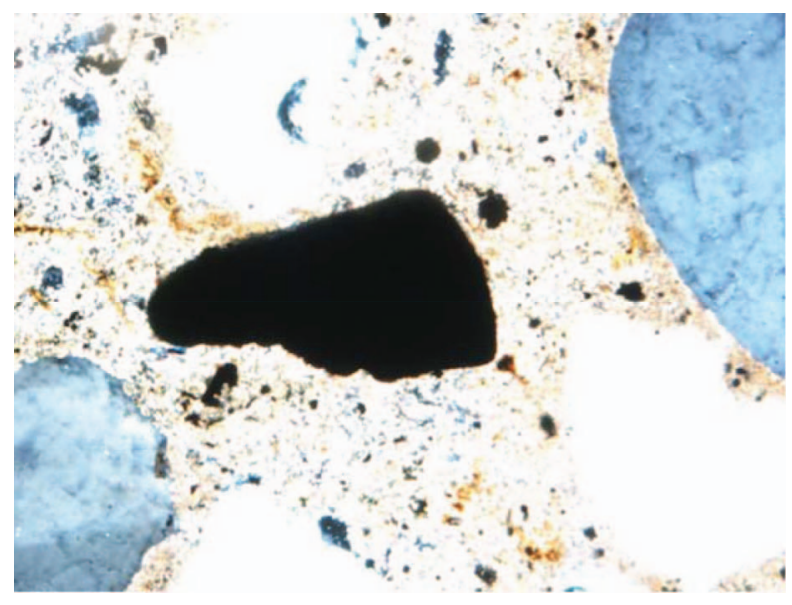

B

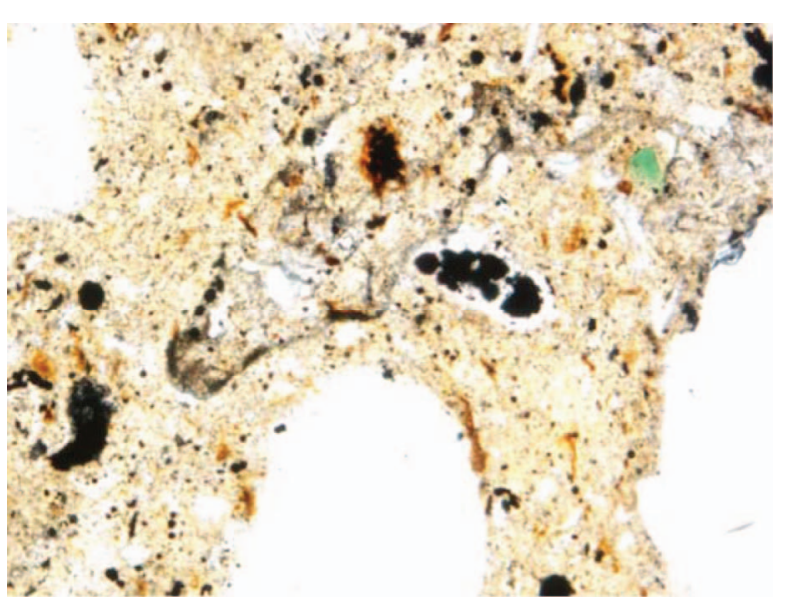

D

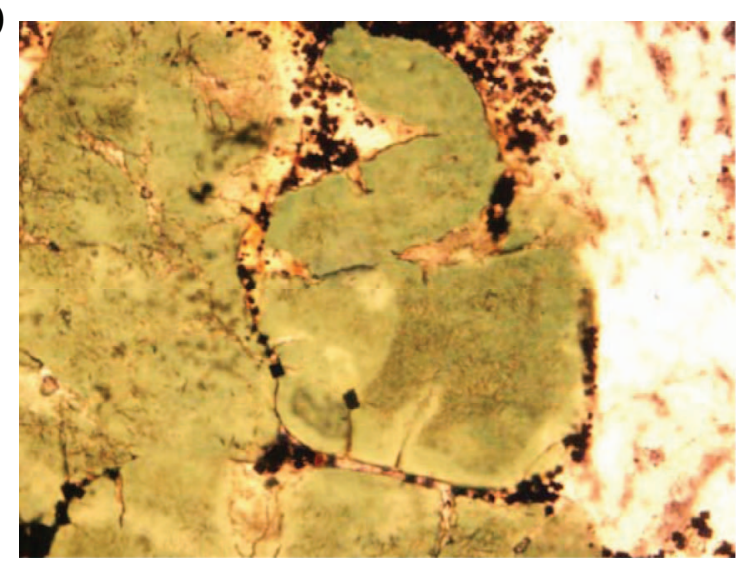


Figure F47. Preliminary magnetostratigraphic interpretation, Cores 313-M0028A-2R through 12R. Inclination data of initial NRM (black) and at $30 \mathrm{mT}$ (blue) and of ChRM (red) derived by PCA analyses where applicable. Magnetic polarity timescale from Cande and Kent (1995). Preliminary tie points: solid line = interpretation A, dashed line $=$ interpretation $\mathrm{B}$.

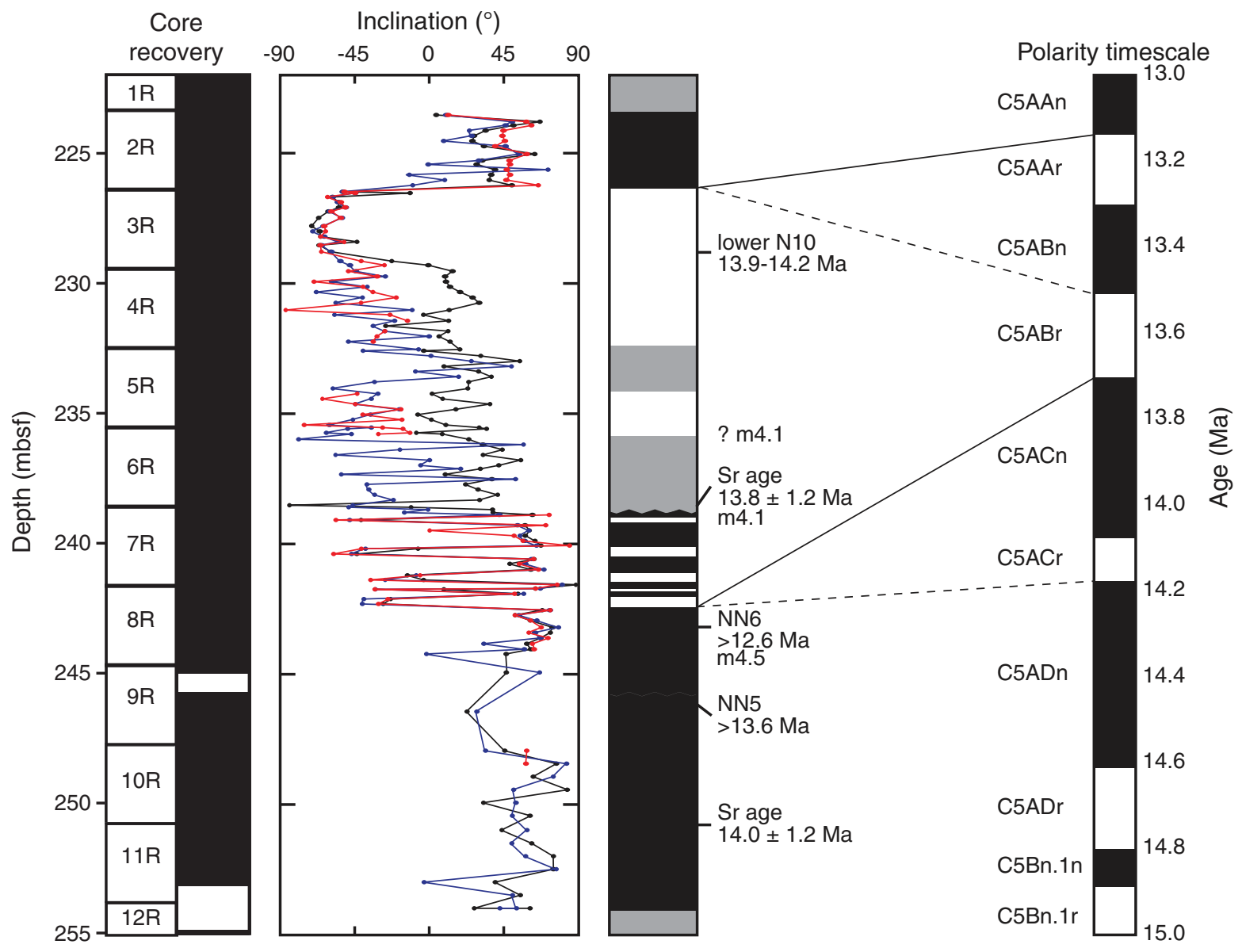


Figure F48. Composite of downhole logging data, Hole M0028A. Normalized amplitude and traveltime acoustic images (ABI40 Ampl and ABI40 TT), hole diameter (AcCal), total and spectral gamma ray through pipe (AGSRcgs), conductivity (DIL45), and magnetic susceptibility (EM51). See Figure F4 in the "Methods" chapter for lithology legend.
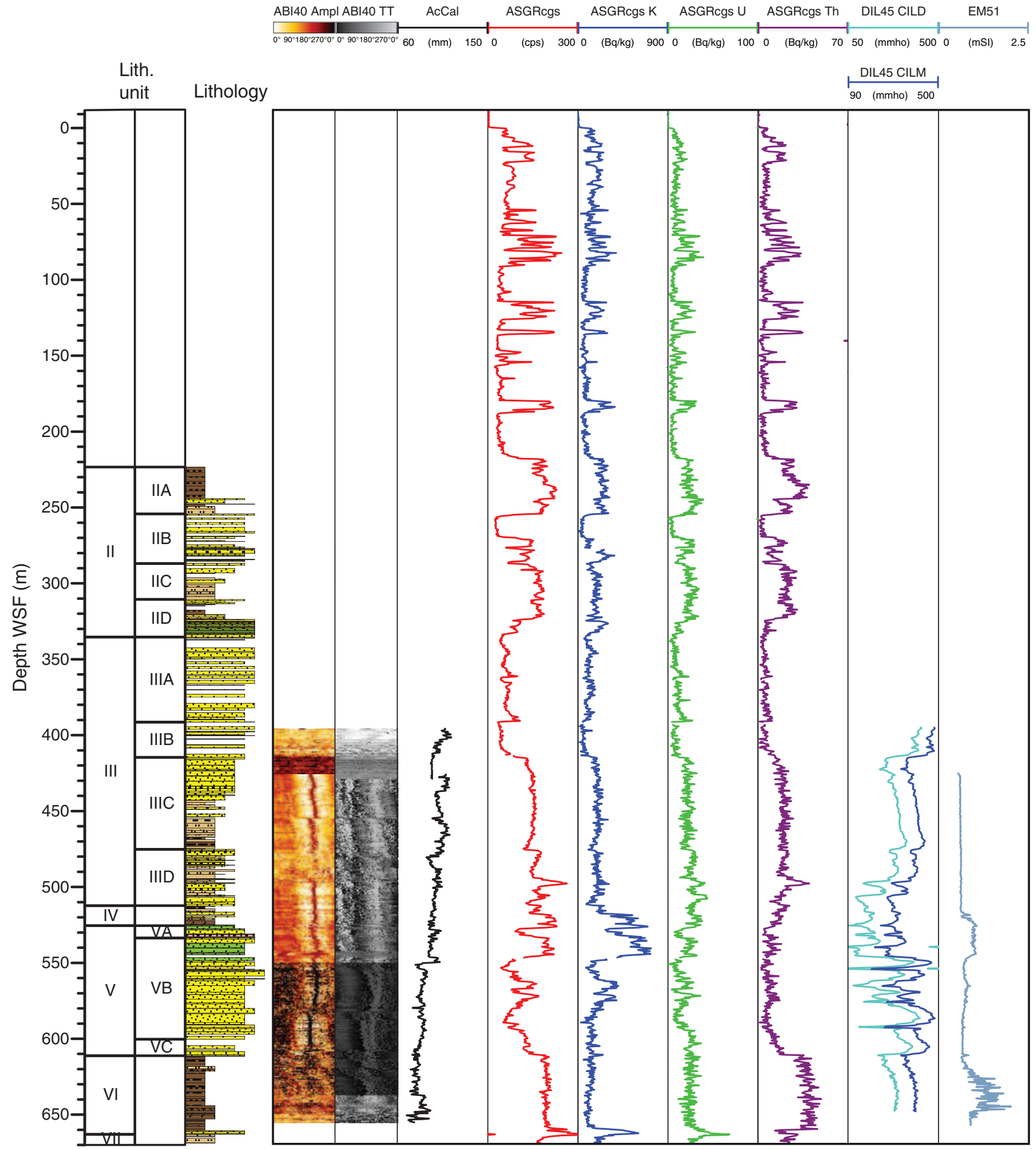
Figure F49. U/K and Th/K ratios on logarithmic scale vs. depth, Hole M0028A. Cemented levels, organic matter, and glauconite-rich levels observed by sedimentologists are indicated.

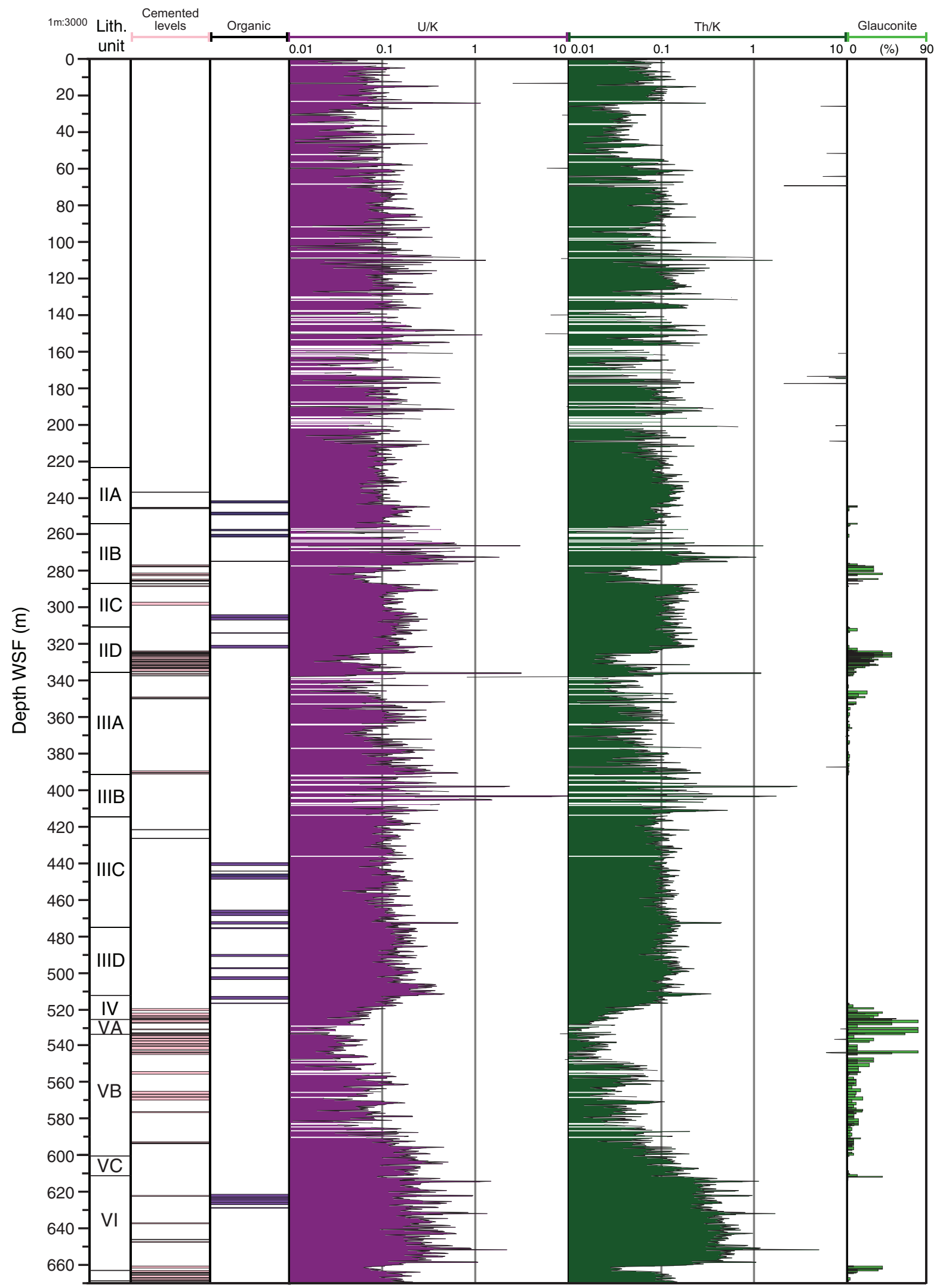


Figure F50. Total gamma ray (TGR), U/K and Th/K ratios, and lithological interpretation from the upper part of Hole M0028A where there was no core recovery.

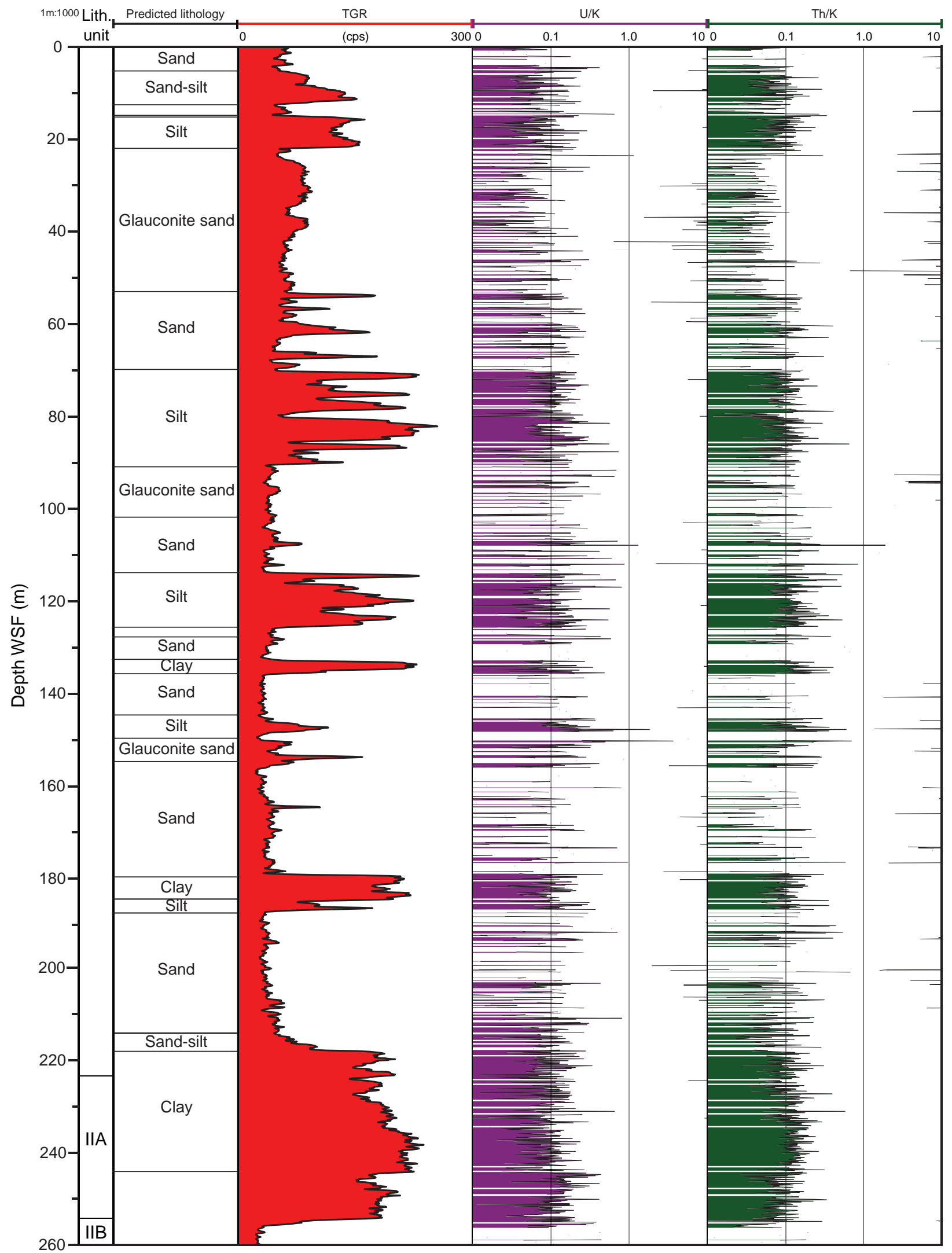


Figure F51. Composite of line scan images of Section 313-M0028A-80R-2 with petrophysical and downhole logging data. High-resolution normalized amplitude and traveltime acoustic images (ABI40 Ampl and ABI40 TT); hole diameter (AcCal); whole-core natural gamma radiation (NGR); and density, resistivity, and magnetic susceptibility (MagSus) from multisensor core logger (MSCL). Core depth and whole-core measurement have been shifted down by $4 \mathrm{~cm}$ to match wireline images. At 418.4, 418.8, and $419.13 \mathrm{~m}$ WSF, some changes in image amplitude signal (lower amplitude) mark the presence of normal graded storm sandy beds also visible in cores. These beds are also evidenced on the traveltime image and caliper by a decrease in borehole diameter, total gamma ray measured on core, and, locally, density and resistivity.

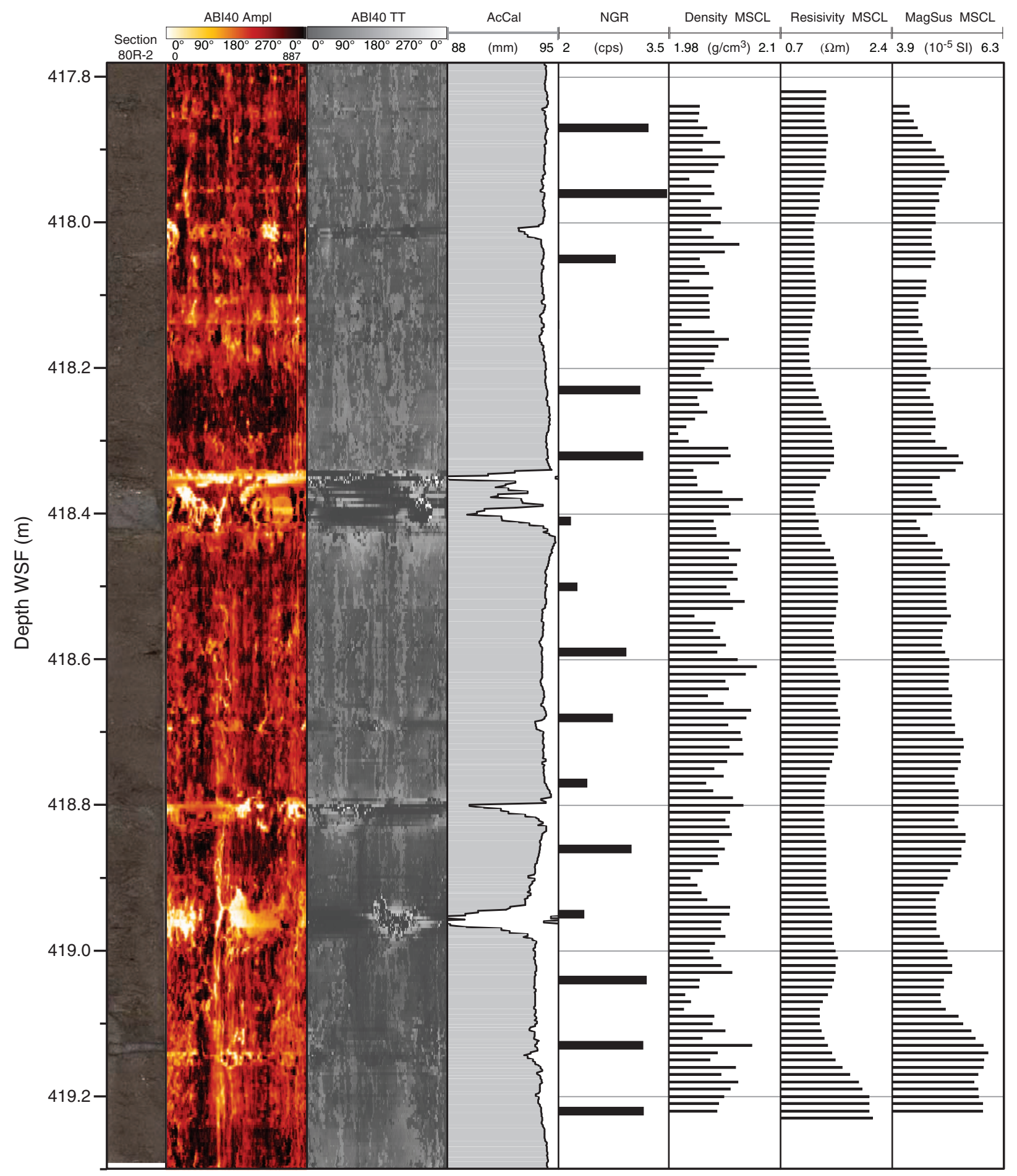


Figure F52. VSP two-way traveltime vs. depth, Hole M0028A.

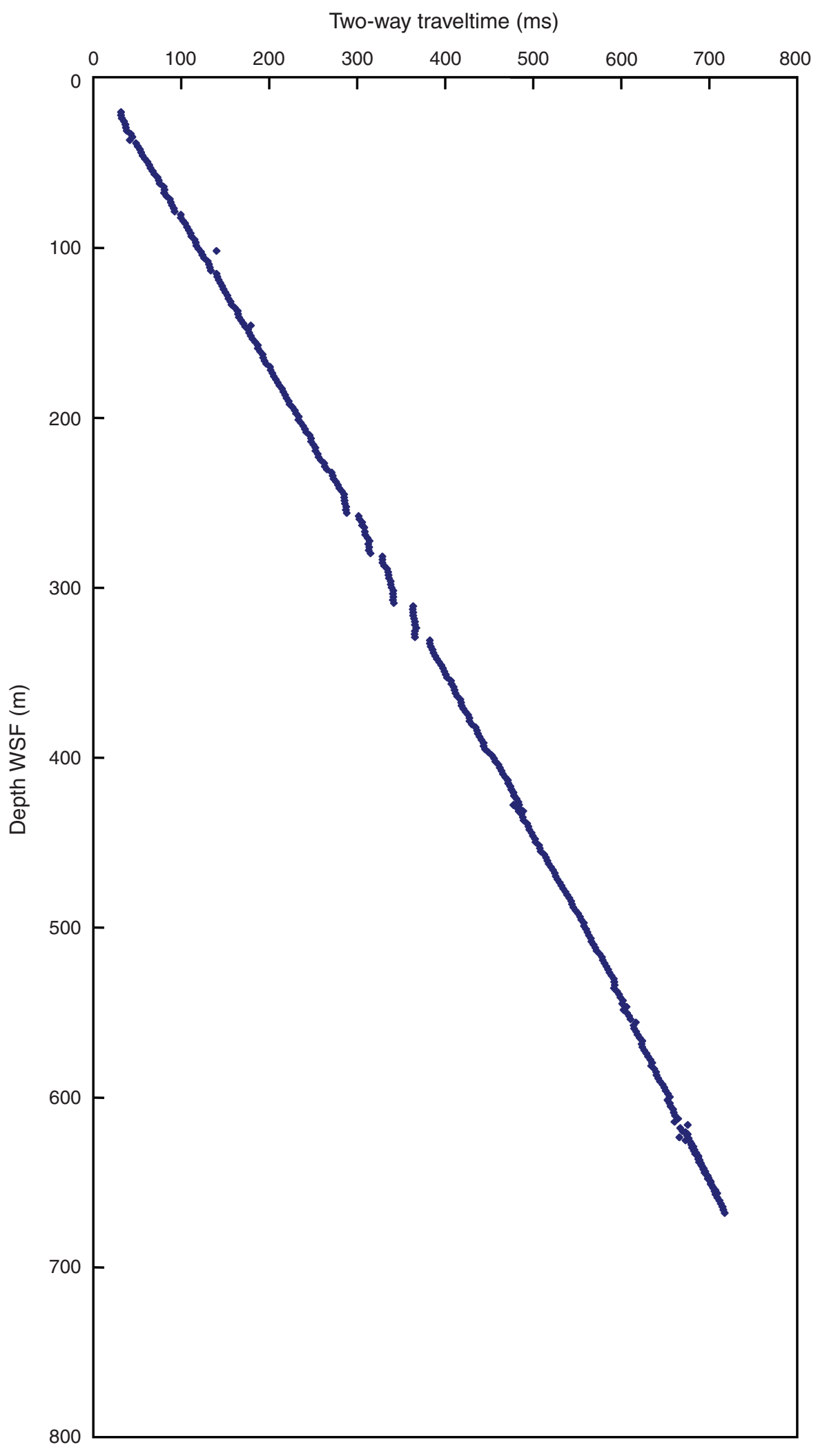


Figure F53. Petrophysical and downhole logging data at the m5.8 boundary in Hole M0028A (Cores 313M0028A-167R through 169R). Total and spectral gamma ray through pipe (AGSR), along with natural gamma ray (NGR), density, $P$-wave, resistivity, and magnetic susceptibility from multisensor core logger (MSCL) measurements on cores. Dotted yellow line = base of the tan-colored sand clays described in "Sedimentology;" marks abrupt downward increase in impedance suggesting possible seismic reflector. Wavy yellow line $=$ depth of m5.8 sequence boundary in both cores and petrophysical data (see "Lithostratigraphy"). (Figure on next page.) 
Figure F53 (continued). (Caption on previous page.)

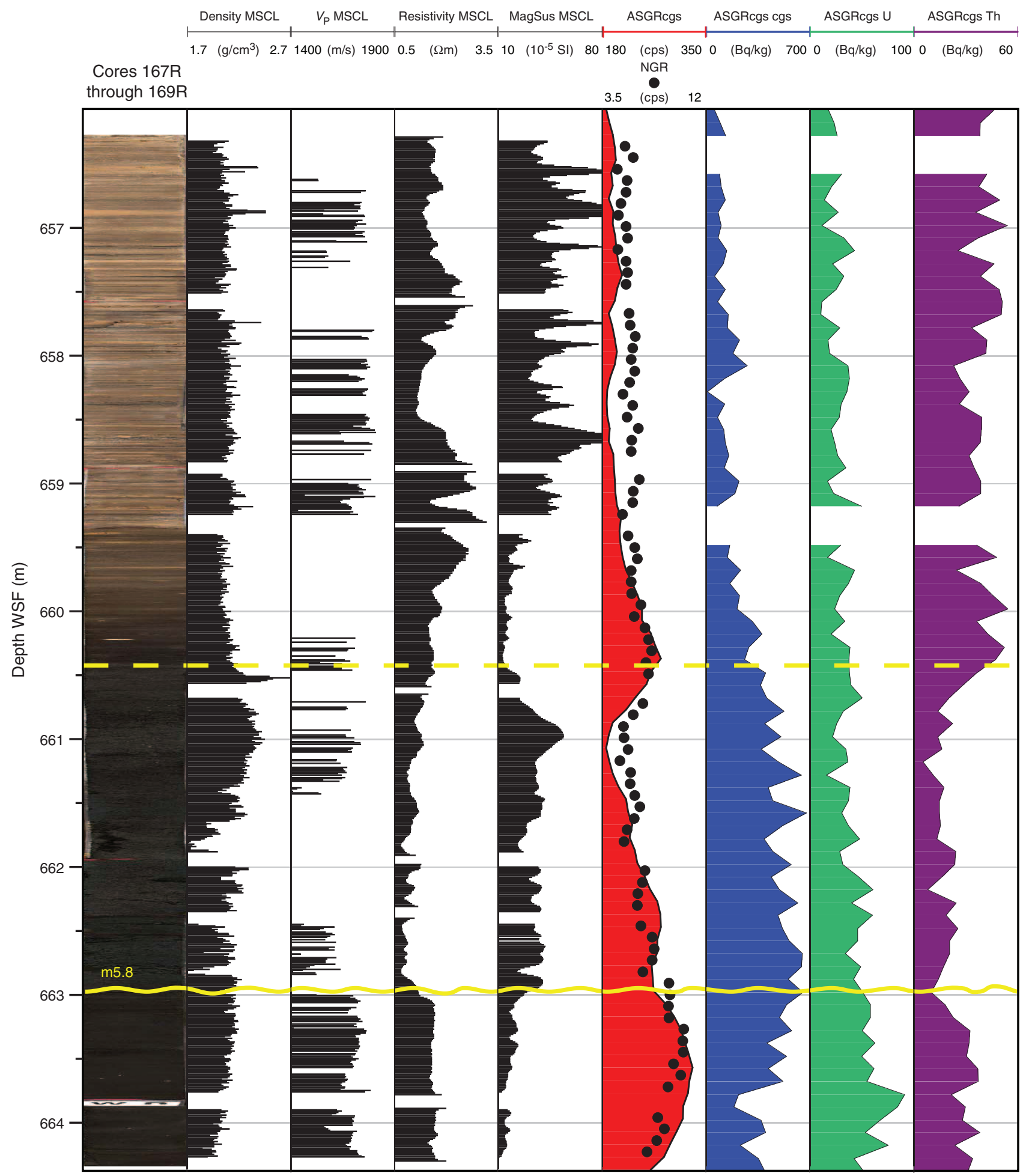


Figure F54. Interpretation of seismic surfaces on strike line CH0698 profile 218. CDP = common depth point.

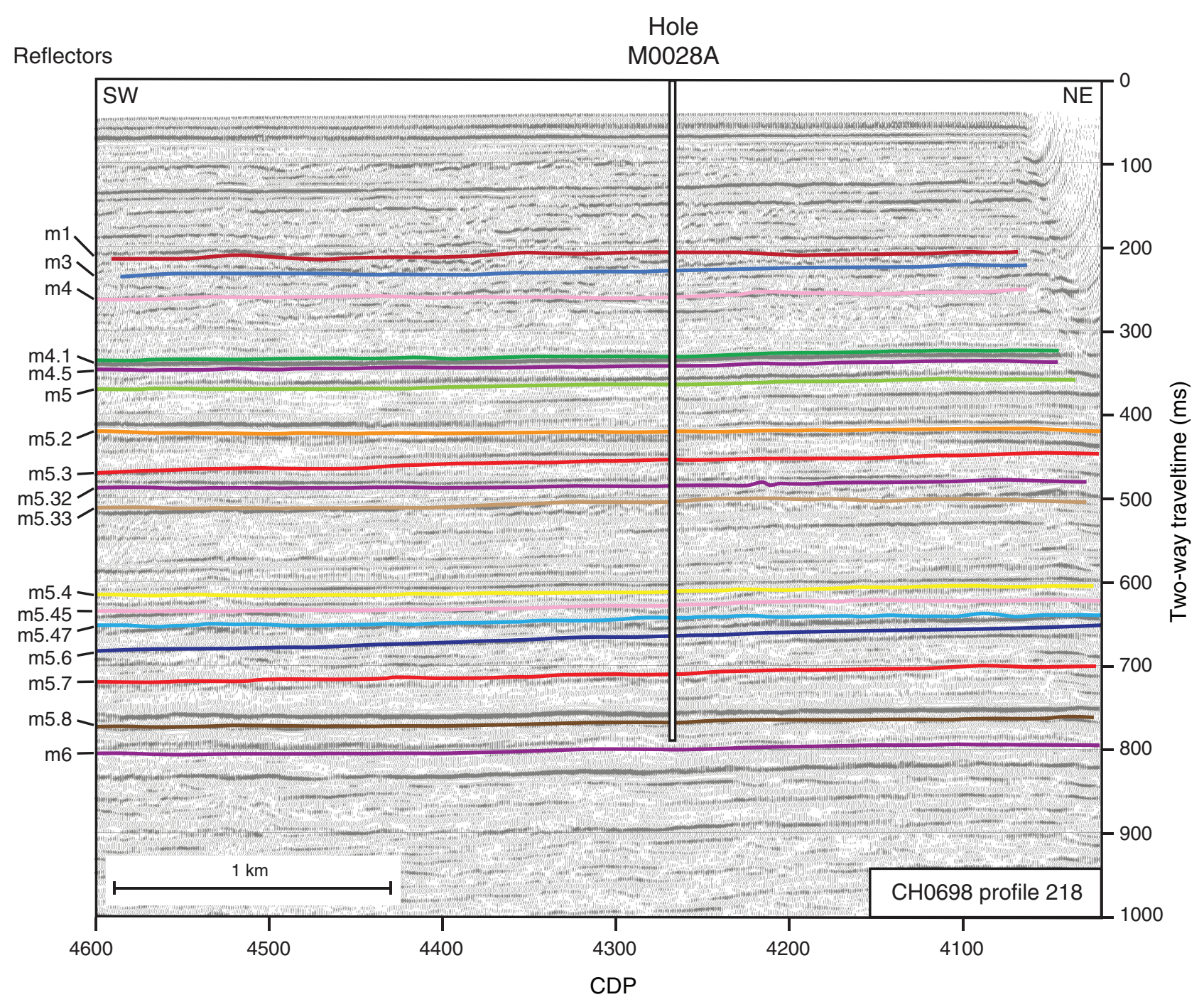


Figure F55. Interpretation of seismic surfaces on dip line Oc270 profile 529. CDP = common depth point.

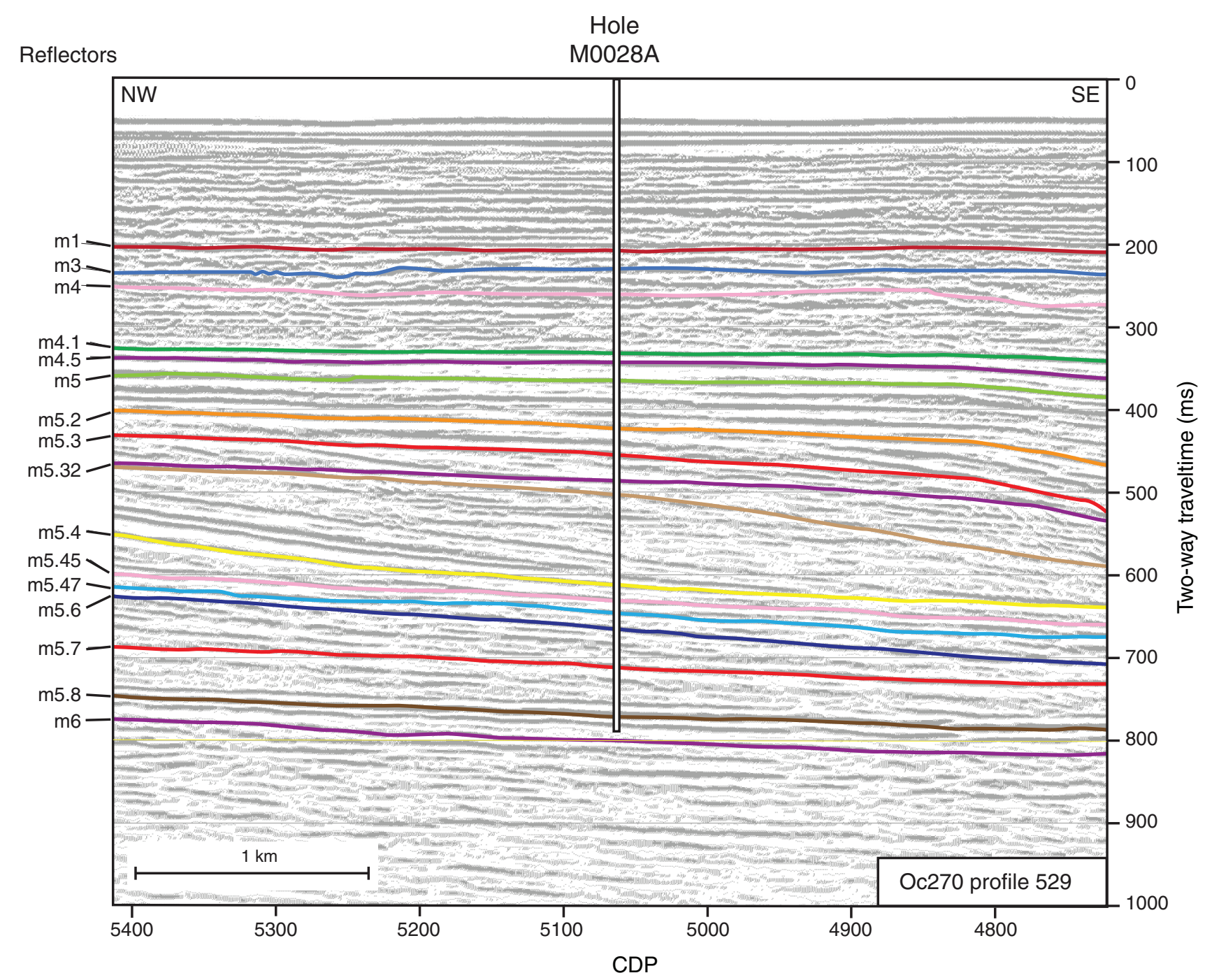


Figure F56. Summary of lithology, lithostratigraphy, well (total gamma ray [TGR], K, U, and Th), and multisensor core logger (MSCL) data (natural gamma radiation [NGR] and bulk density); acoustic impedance calculated using MSCL bulk densities; depositional environments and correlating core surfaces; and predicted depth ranges based on Hole M0028A velocity between 220 and 350 mbsf. OFF $=$ offshore, SF $=$ shoreface, SOT $=$ shoreface-offshore transition. Blue dots = NGR, red line = TGR. See Figure F1 for lithology legend.

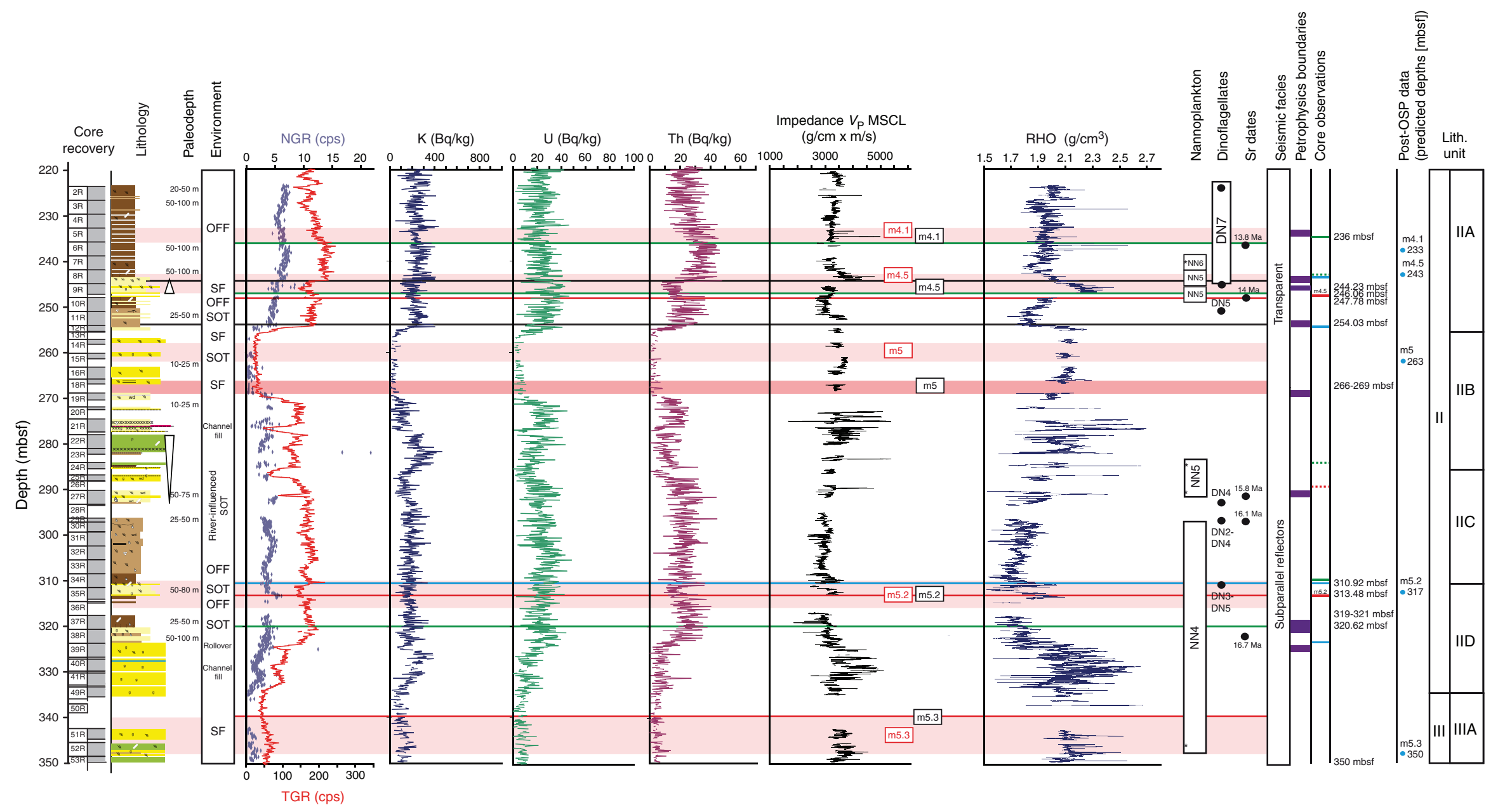


Figure F57. Correlation of core image with interpretation of deposition and age along with density, 236.0237.4 mbsf.

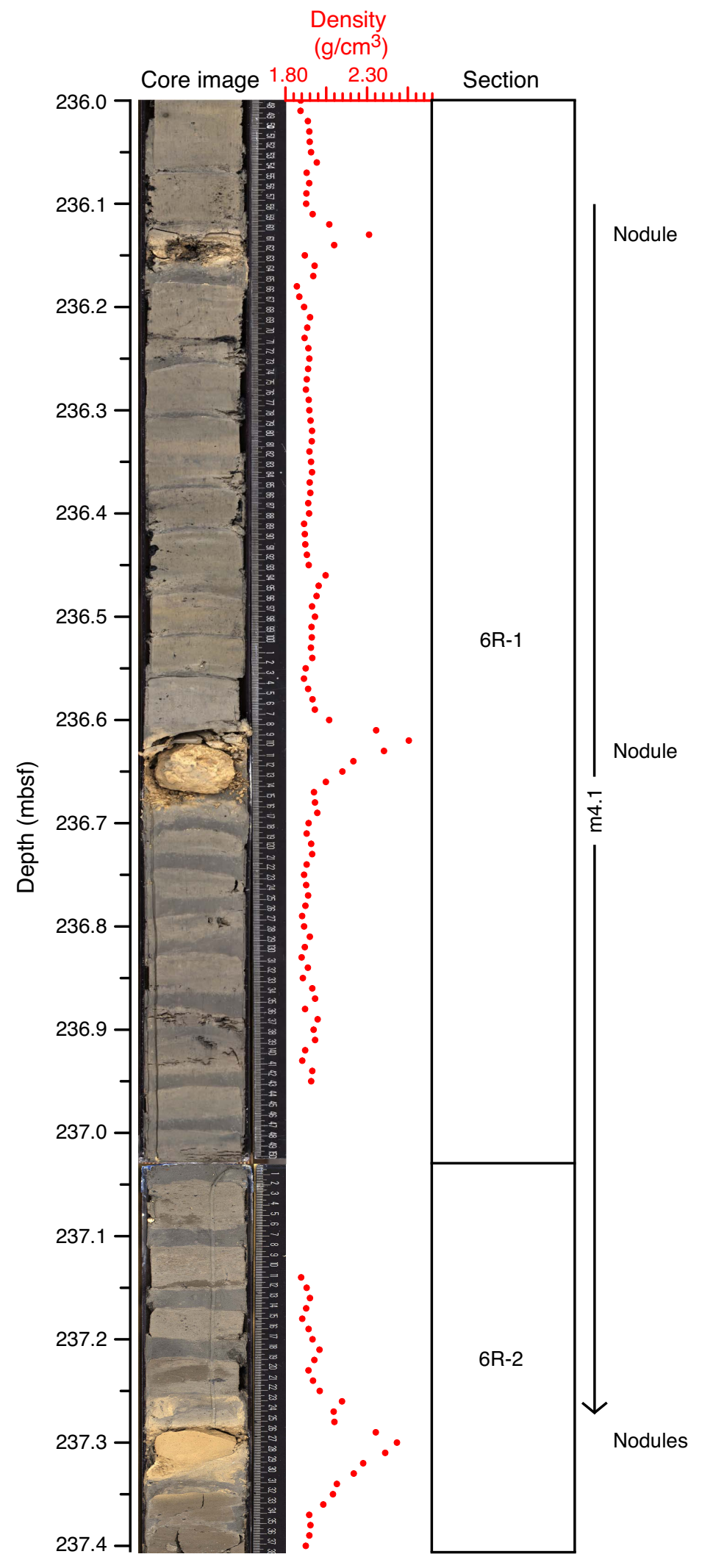


Figure F58. Correlation of core image with interpretation of deposition and age along with density, 245.6246.5 mbsf. TS = transgressive surface.

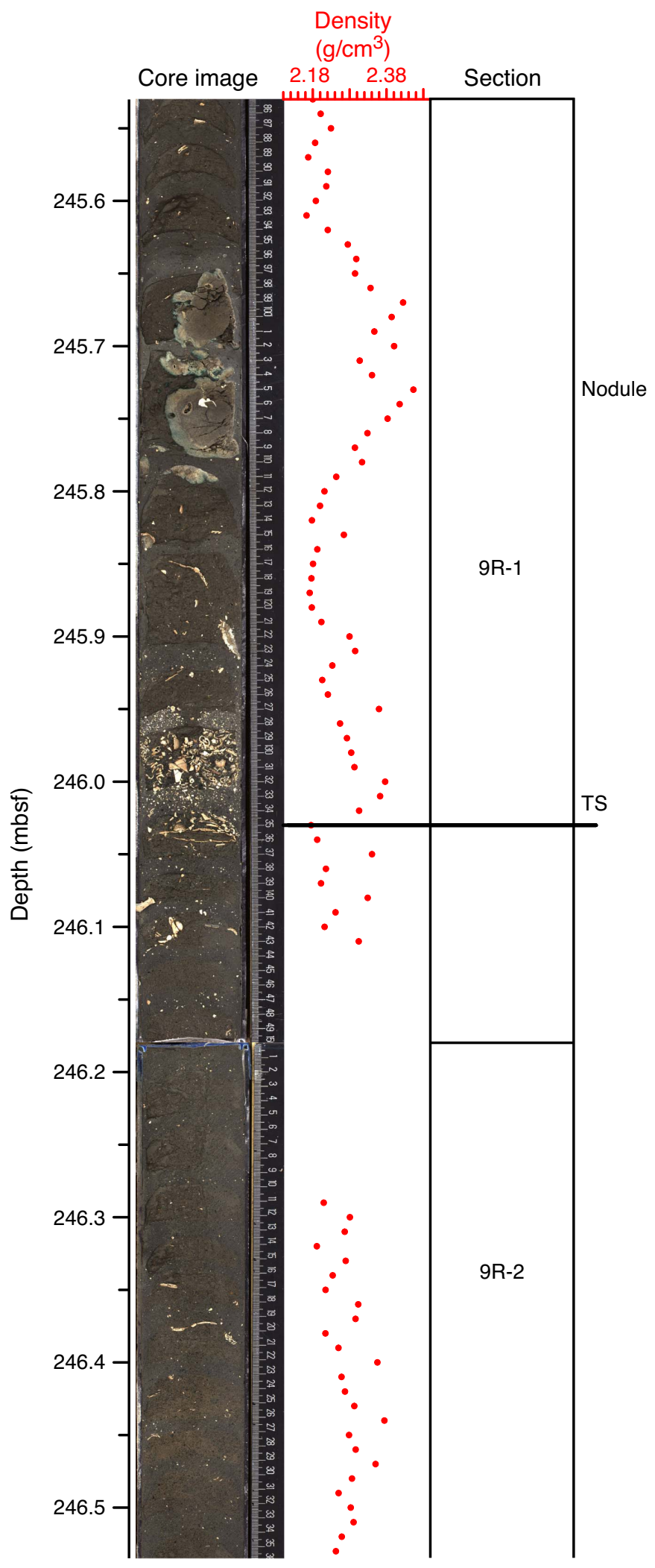


Figure F59. Correlation of core image with interpretation of deposition and age along with density, 313.0314.0 mbsf.

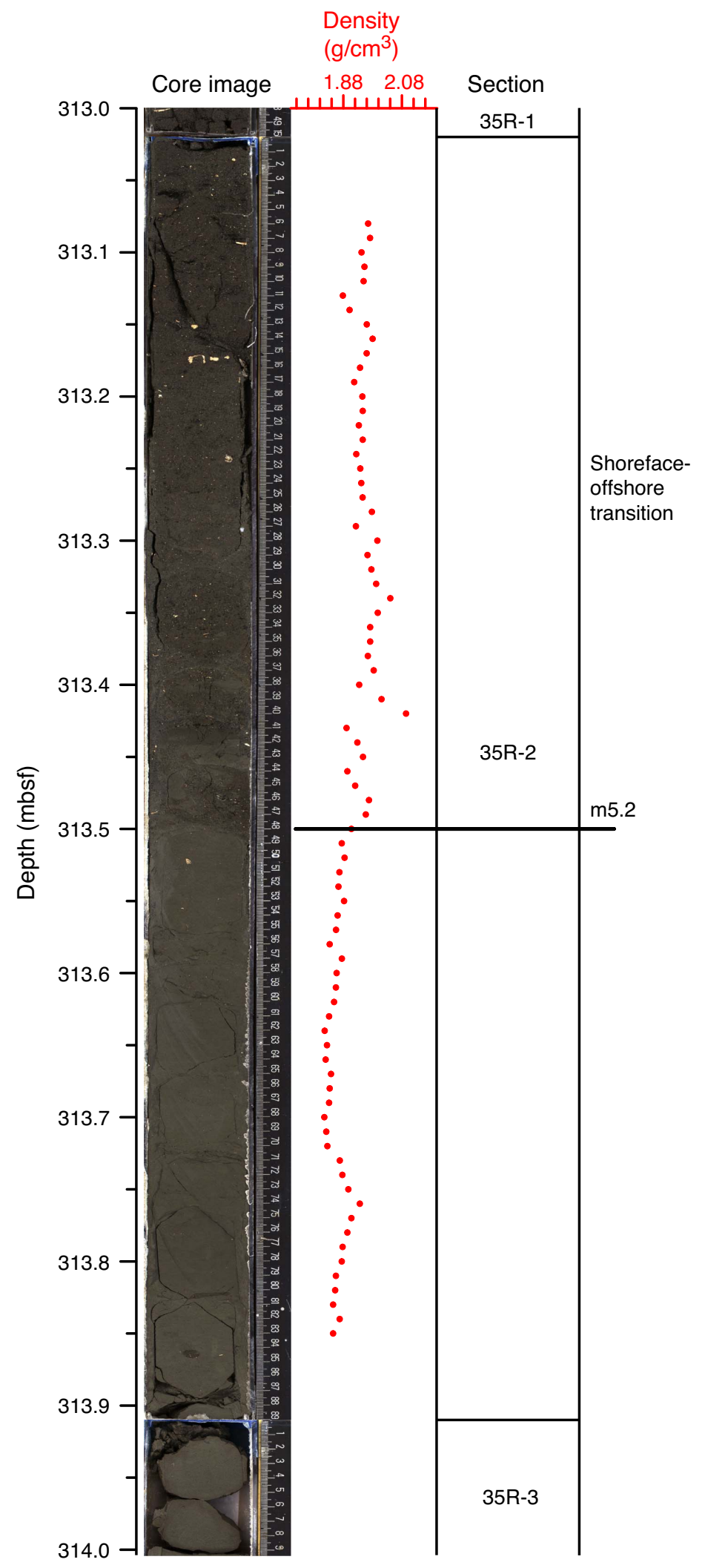


Figure F60. Correlation of core image with interpretation of deposition and age, 320.2-321.1 mbsf. MFS = maximum flooding surface.

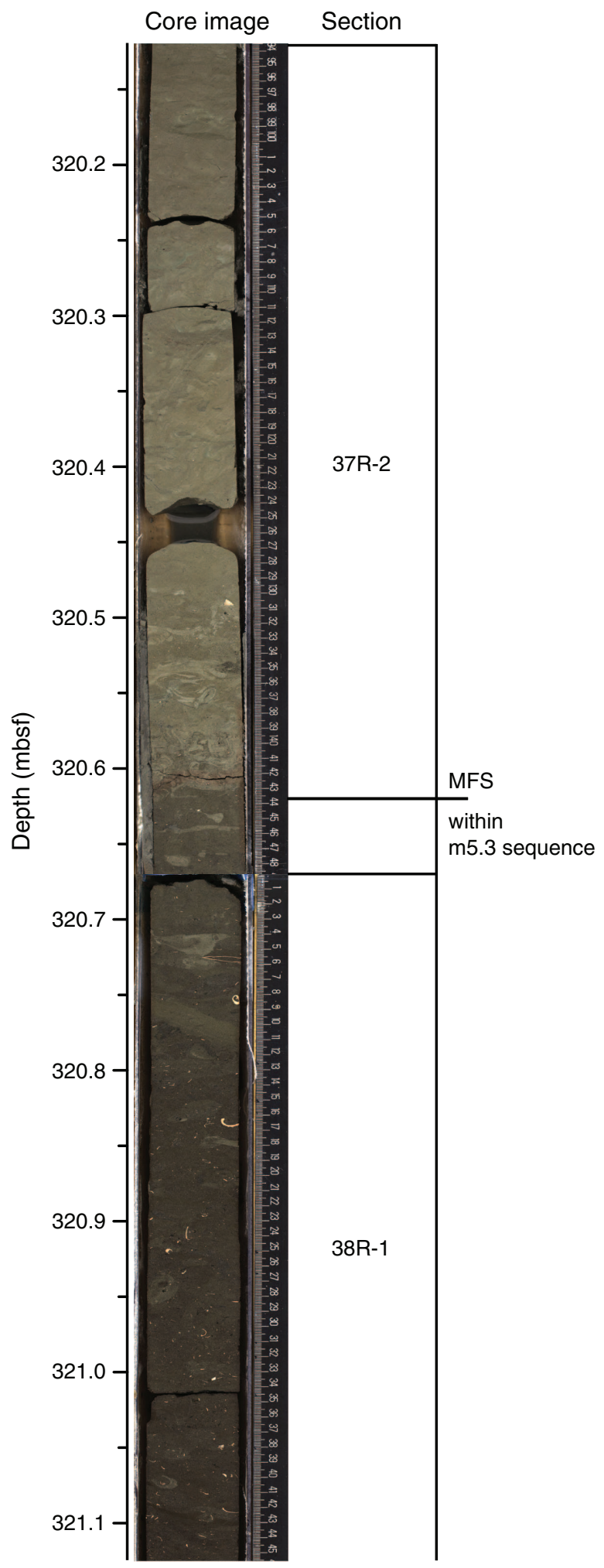


Figure F61. Correlation of core image with interpretation of deposition and age along with density, 494.7495.7 mbsf.

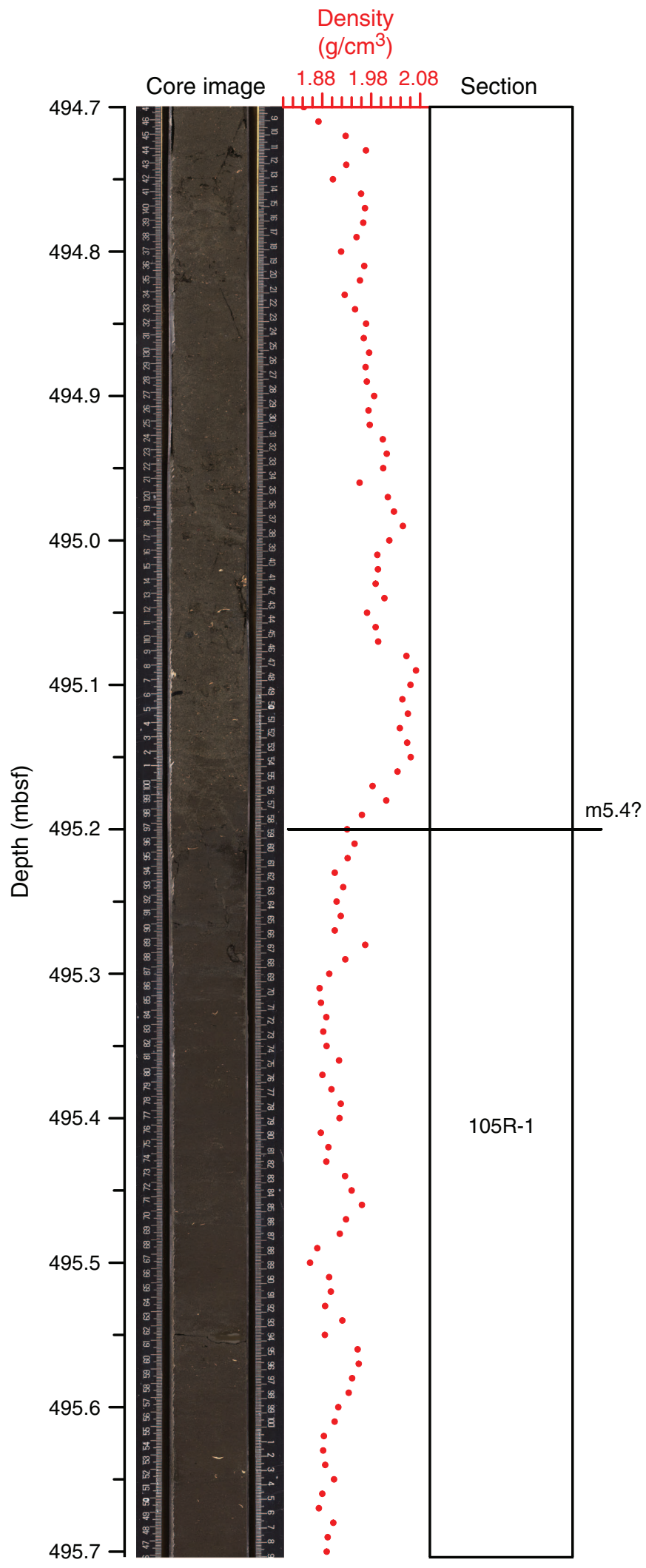


Figure F62. Correlation of core image with interpretation of deposition and age along with density, 511.9512.8 mbsf.

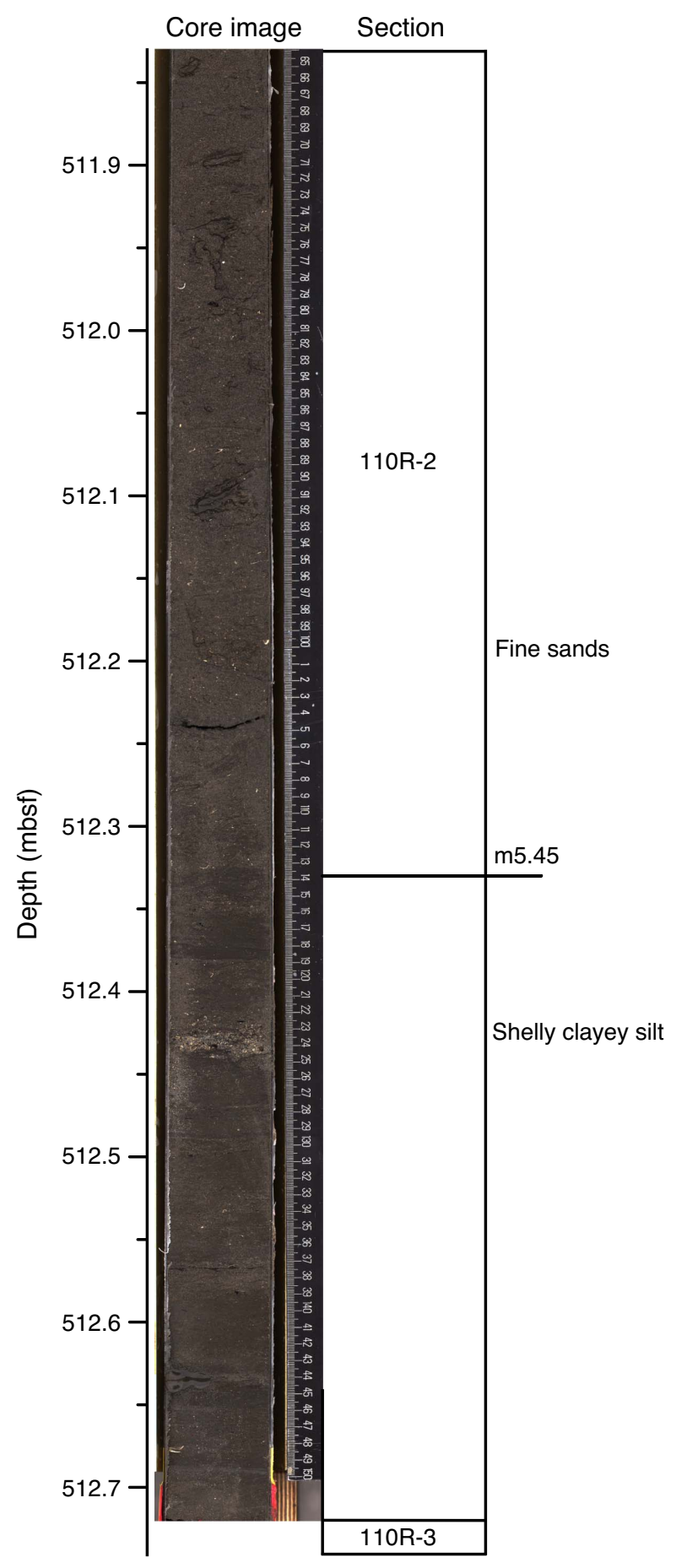


Figure F63. Correlation of core image with interpretation of deposition and age along with density, 519.2520.1 mbsf.

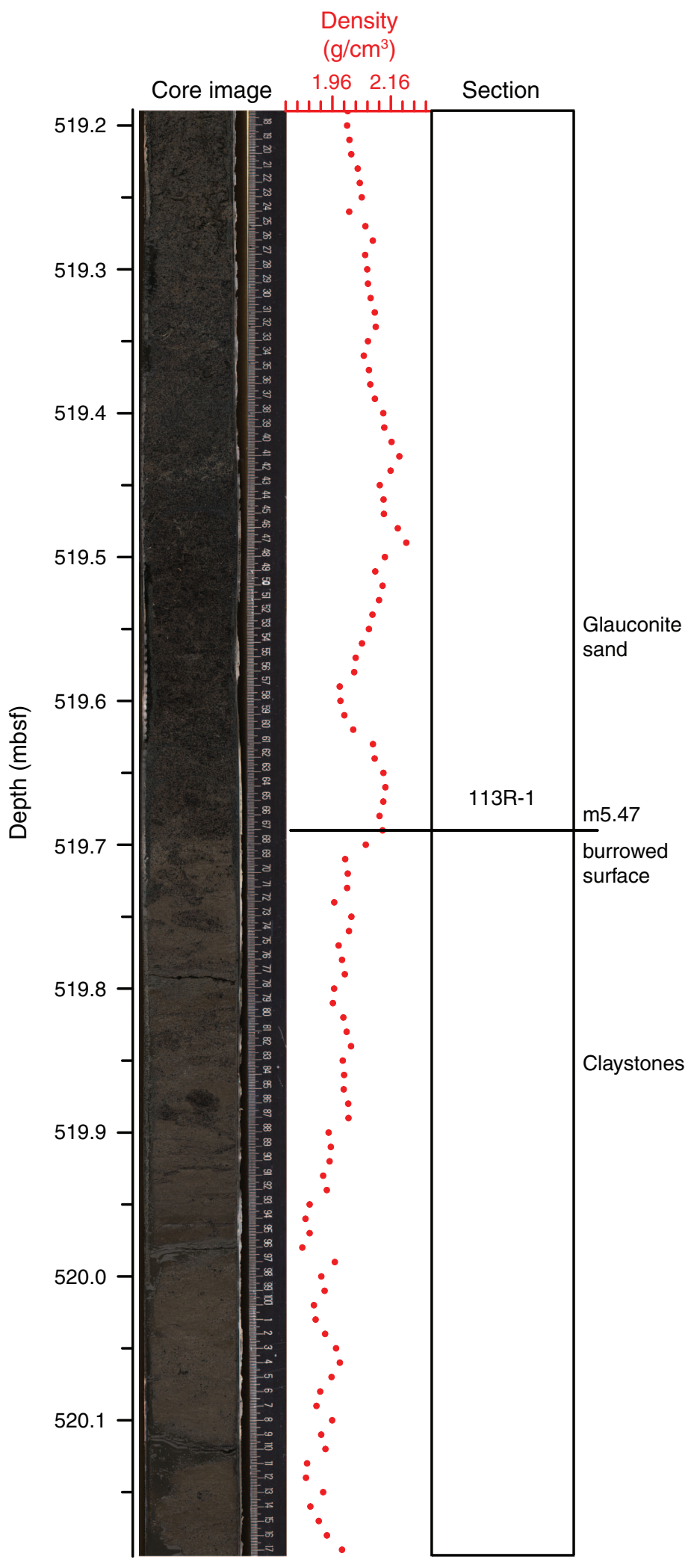


Figure F64. Correlation of core image with interpretation of deposition and age along with density, 611.1612.1 mbsf.

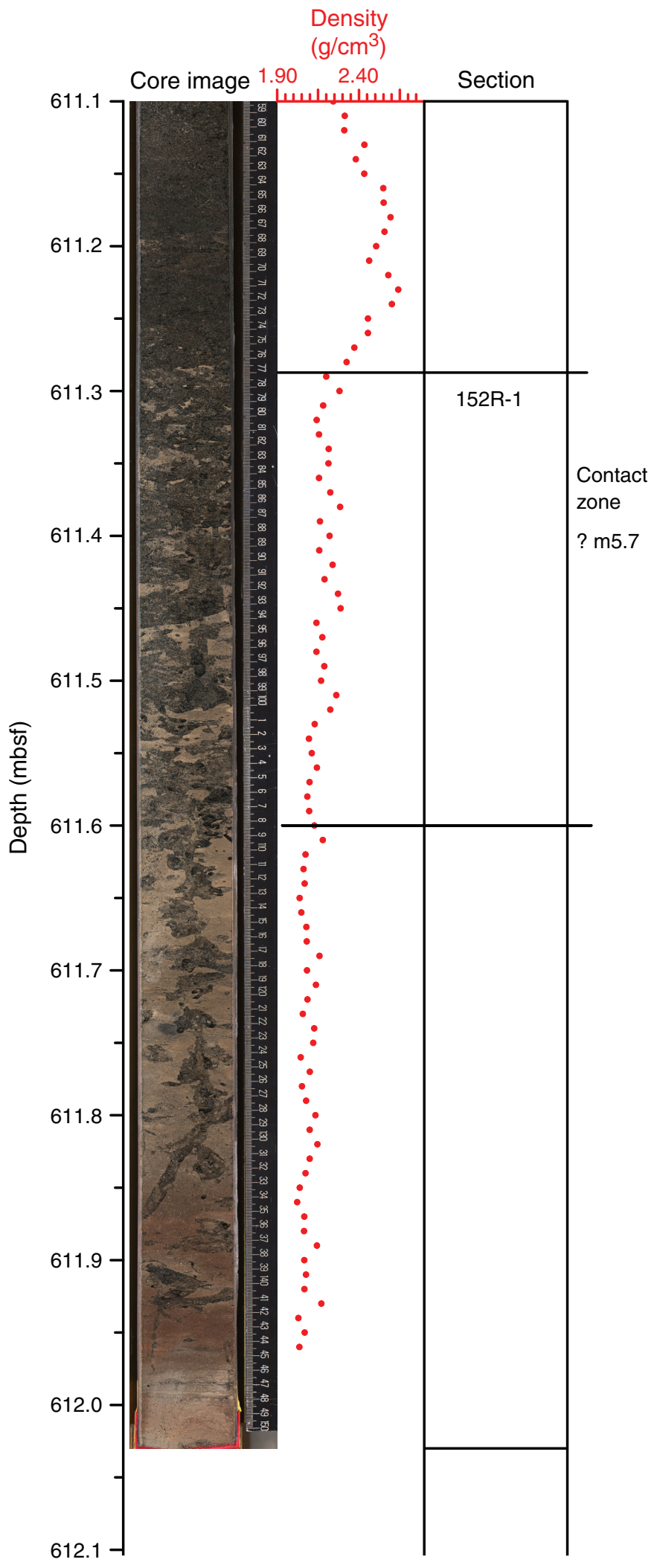


Figure F65. Summary of lithology, lithostratigraphy, well (total gamma ray [TGR], K, U, and Th), and multisensor core logger (MSCL) data (natural gamma radiation [NGR] and bulk density); depositional environments and correlating core surfaces; acoustic impedance calculated using MSCL bulk densities; and predicted depth ranges based on Hole M0028A velocity between 350 and 500 mbsf. SF $=$ shoreface, SOT = shoreface-offshore transition, OFF = offshore. Blue dots = NGR, red line = TGR. See Figure F1 for lithology legend.

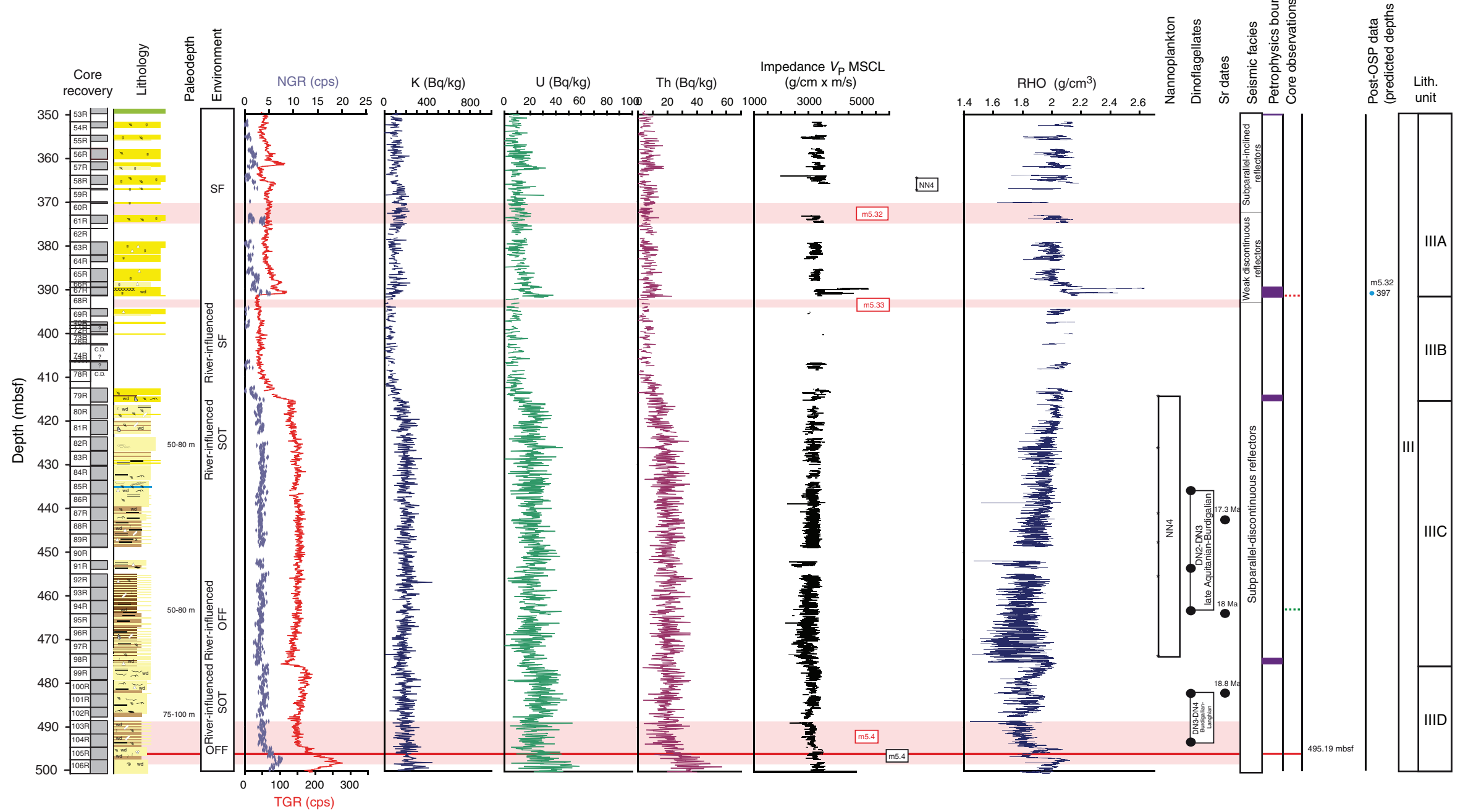


Figure F66. Summary of lithology, lithostratigraphy, well (total gamma ray [TGR], K, U, and Th), and multisensor core logger (MSCL) data (natural gamma radiation [NGR] and bulk density); depositional environments and correlating core surfaces; acoustic impedance calculated using MSCL bulk densities; and predicted depth ranges based on Hole M0028A velocity between 490 and 610 mbsf. Blue dots $=$ NGR, red line = TGR. See Figure F1 for lithology legend.

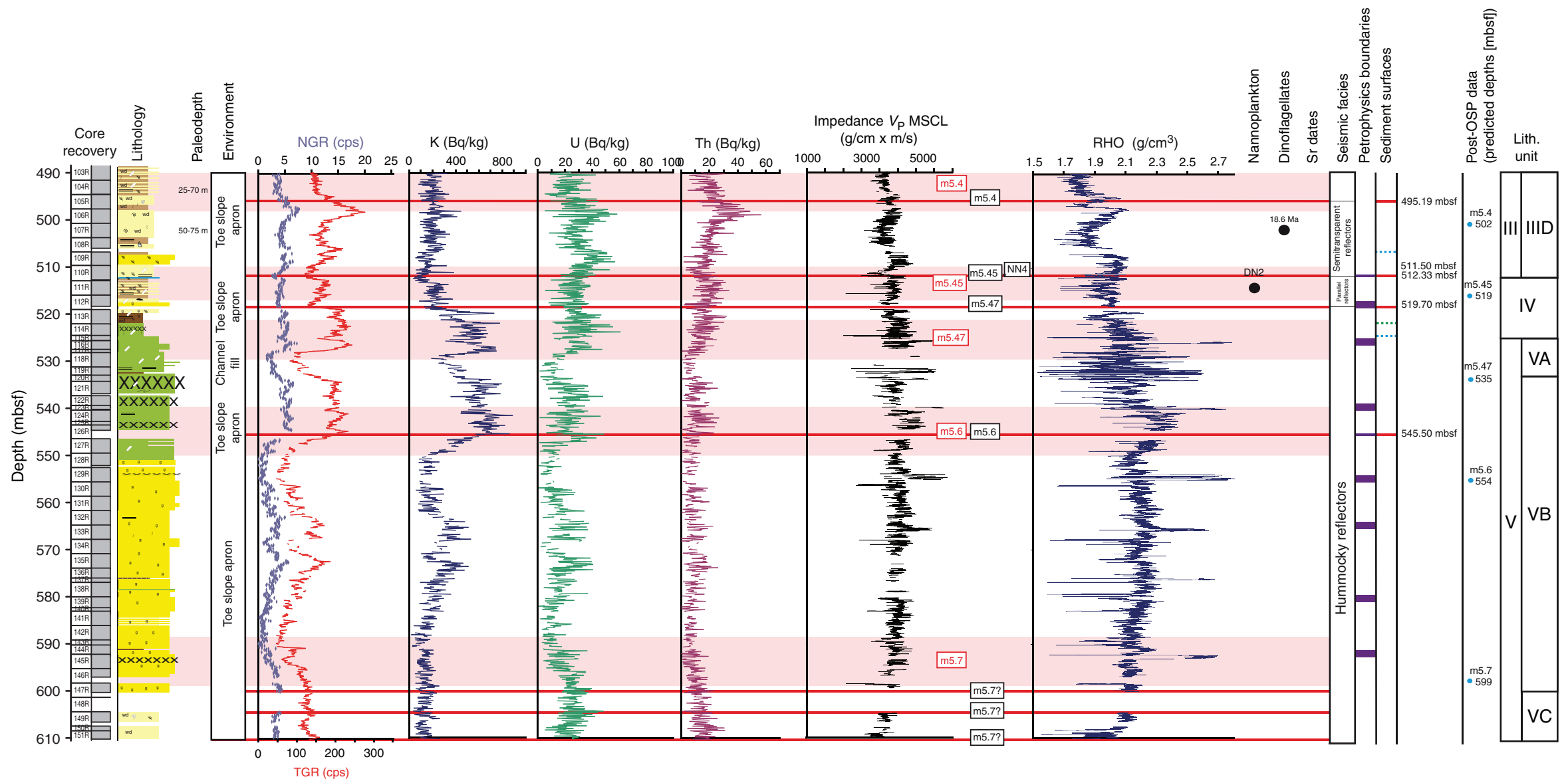


Figure F67. Summary of lithology, lithostratigraphy, well (total gamma ray [TGR], K, U, and Th), and multisensor core logger (MSCL) data (natural gamma radiation [NGR] and bulk density); depositional environments and correlating core surfaces; acoustic impedance calculated using MSCL bulk densities; and predicted depth ranges based on Hole M0028A velocity between 600 and 670 mbsf. Blue dots = NGR, red line = TGR. See Figure F1 for lithology legend.
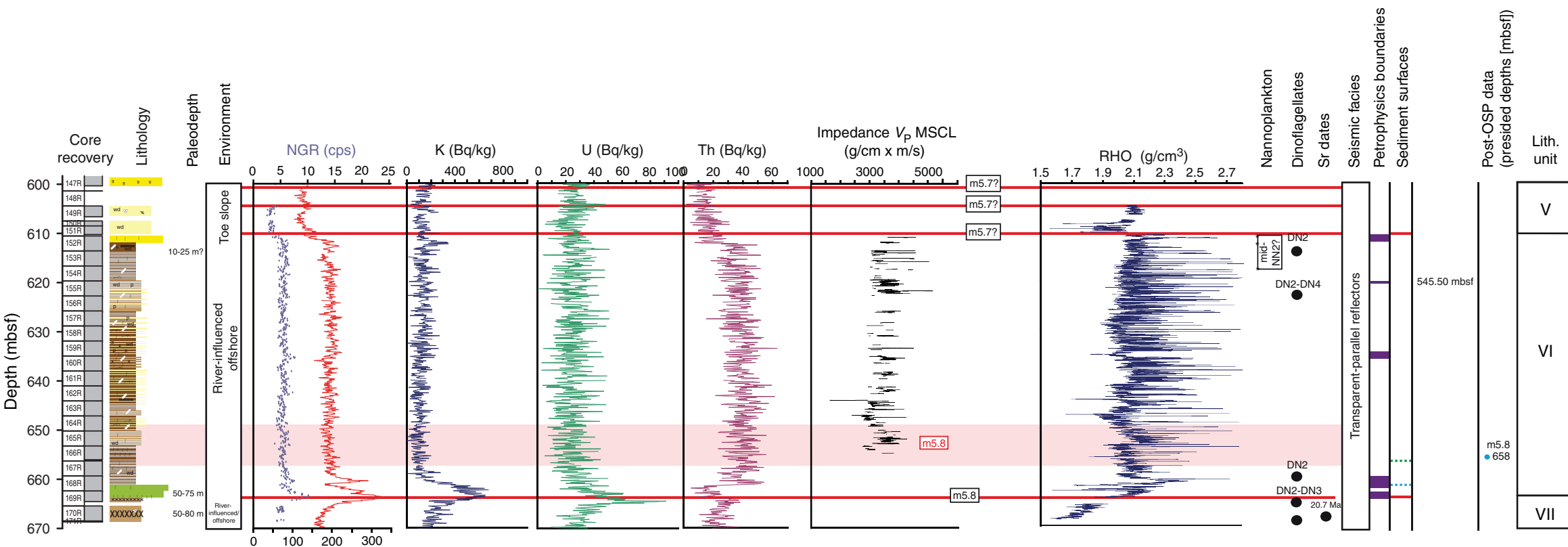

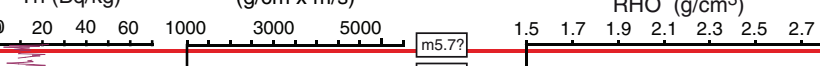

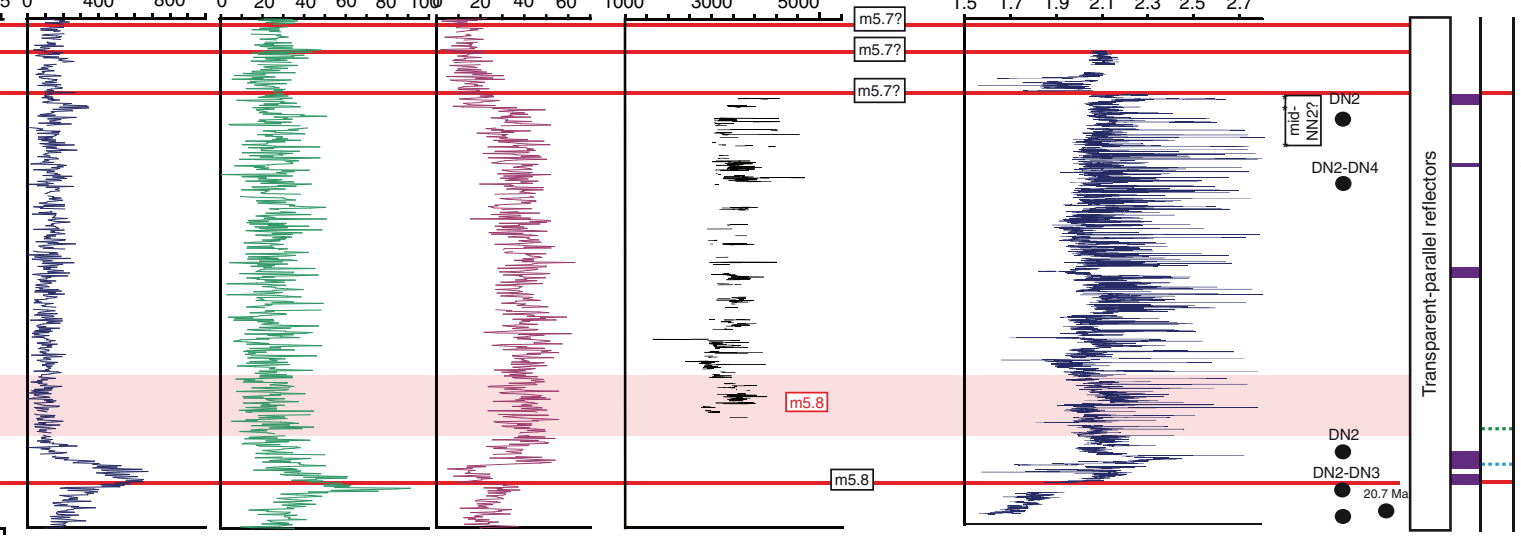

TGR (cps) 
Figure F68. Synthesis of Hole M0028A, including lithology; lithostratigraphy; lithology, lithostratigraphy, well (total gamma ray [TGR], K, U, and Th), and multisensor core logger (MSCL) data (natural gamma radiation [NGR]); acoustic impedance from MSCL bulk density; depositional environments and correlating surfaces; and predicted depth ranges based on velocity. See Figure F1 for lithology legend.

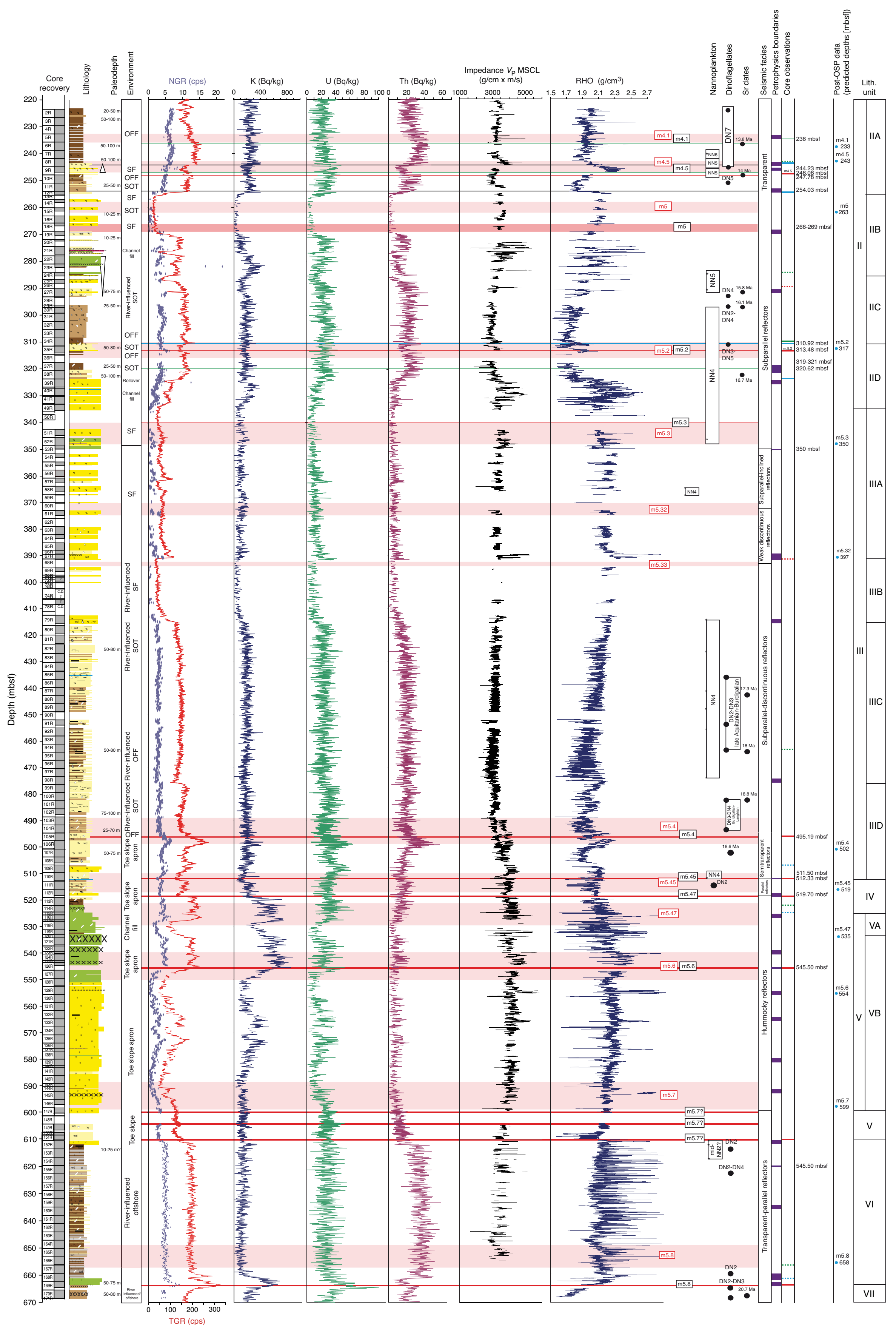


Table T1. Coring summary, Hole M0028A. (See table note.) (Continued on next two pages.)

\section{Hole M0028A}

Latitude: $39^{\circ} 33.942790^{\prime} \mathrm{N}$

Longitude: $73^{\circ} 29.834810^{\prime} \mathrm{W}$

Seafloor (drill pipe measurement from rig floor, mbrf): 48.77

Distance between rig floor and sea level $(\mathrm{m}): 13.72$

Water depth (drill pipe measurement from sea level, $\mathrm{m}$ ): 35.05

Total penetration (mbsf): 668.66

Total drilled interval (m): 476.97

\begin{tabular}{|c|c|c|c|c|c|c|c|c|}
\hline \multirow[b]{2}{*}{ Core } & \multirow{2}{*}{$\begin{array}{l}\text { Date } \\
(2009)\end{array}$} & \multirow{2}{*}{$\begin{array}{l}\text { Time } \\
\text { (UTC) }\end{array}$} & \multicolumn{2}{|c|}{ Depth (mbsf) } & \multicolumn{2}{|c|}{ Length $(\mathrm{m})$} & \multirow{2}{*}{$\begin{array}{l}\text { Recovery } \\
\quad(\%)\end{array}$} & \multirow[b]{2}{*}{ Comments } \\
\hline & & & Top & Bottom & Cored & Recovered & & \\
\hline \multicolumn{9}{|c|}{ 313-M0028A- } \\
\hline \multicolumn{9}{|c|}{$\star \star * * * *$ Drilled from 0.0 to $220.38 \mathrm{mbsf}^{\star * * * *}$} \\
\hline $1 R$ & 26 May & 1515 & 220.28 & 223.33 & 3.05 & 0.00 & 0.0 & \\
\hline $2 \mathrm{R}$ & 26 May & 1630 & 223.33 & 226.38 & 3.05 & 3.45 & 113.1 & \\
\hline $3 R$ & 26 May & 1730 & 226.38 & 229.43 & 3.05 & 3.19 & 104.6 & \multirow[t]{2}{*}{ Basket catcher pulled into core } \\
\hline $4 \mathrm{R}$ & 26 May & 1900 & 229.43 & 232.48 & 3.05 & 3.37 & 110.5 & \\
\hline $5 R$ & 26 May & 1950 & 232.48 & 235.53 & 3.05 & 3.39 & 111.2 & \multirow[t]{2}{*}{ Basket catcher pulled into core } \\
\hline $6 \mathrm{R}$ & 26 May & 2045 & 235.53 & 238.58 & 3.05 & 3.47 & 113.8 & \\
\hline $7 R$ & 26 May & 2150 & 238.58 & 241.63 & 3.05 & 3.21 & 105.3 & \multirow{2}{*}{$\begin{array}{l}\text { Basket catcher pulled into core } \\
\text { Core spring missing }\end{array}$} \\
\hline $8 \mathrm{R}$ & 26 May & 2300 & 241.63 & 244.68 & 3.05 & 3.21 & 105.3 & \\
\hline $9 \mathrm{R}$ & 26 May & 2350 & 244.68 & 247.73 & 3.05 & 2.32 & 76.1 & \\
\hline $10 \mathrm{R}$ & 27 May & 0045 & 247.73 & 250.78 & 3.05 & 3.21 & 105.3 & \\
\hline $11 R$ & 27 May & 0140 & 250.78 & 253.83 & 3.05 & 3.42 & 112.1 & \\
\hline $12 \mathrm{R}$ & 27 May & 0255 & 253.83 & 255.28 & 1.45 & 1.34 & 92.4 & \\
\hline $13 R$ & 27 May & 0345 & 255.28 & 256.88 & 1.60 & 0.00 & 0.0 & \\
\hline $14 R$ & 27 May & 0440 & 256.88 & 259.93 & 3.05 & 1.09 & 35.7 & \\
\hline $15 R$ & 27 May & 0555 & 259.93 & 262.98 & 3.05 & 1.22 & 40.0 & \\
\hline $16 \mathrm{R}$ & 27 May & 0830 & 262.98 & 266.03 & 3.05 & 2.63 & 86.2 & \\
\hline $17 R$ & 29 May & 2100 & 264.00 & 265.77 & 1.77 & 0.17 & 9.6 & \\
\hline $18 \mathrm{R}$ & 29 May & 2145 & 265.77 & 268.82 & 3.05 & 1.07 & 35.1 & \\
\hline $19 R$ & 30 May & 0115 & 268.82 & 271.87 & 3.05 & 1.53 & 50.2 & \\
\hline $20 R$ & 30 May & 0250 & 271.87 & 274.52 & 2.65 & 0.60 & 22.6 & \\
\hline $21 R$ & 30 May & 0355 & 274.52 & 277.97 & 3.45 & 2.85 & 82.6 & \multirow{7}{*}{ Strong backflow through pipe } \\
\hline $22 \mathrm{R}$ & 30 May & 0500 & 277.97 & 281.02 & 3.05 & 3.06 & 100.3 & \\
\hline $23 R$ & 30 May & 0550 & 281.02 & 284.07 & 3.05 & 1.23 & 40.3 & \\
\hline $24 R$ & 30 May & 0725 & 284.07 & 286.78 & 2.71 & 1.37 & 50.6 & \\
\hline $25 R$ & 30 May & 1130 & 286.78 & 288.12 & 1.34 & 1.40 & 104.5 & \\
\hline $26 \mathrm{R}$ & 30 May & 1230 & 288.12 & 290.17 & 2.05 & 0.00 & 0.0 & \\
\hline $27 R$ & 30 May & 1350 & 290.17 & 293.22 & 3.05 & 3.37 & 110.5 & \\
\hline $28 \mathrm{R}$ & 30 May & 1500 & 293.22 & 296.27 & 3.05 & 0.00 & 0.0 & \multirow{5}{*}{$\begin{array}{l}\text { Core slipped on retrieval } \\
\text { Picked up previous core with a short run }\end{array}$} \\
\hline $29 R$ & 30 May & 1545 & 296.27 & 297.13 & 0.86 & 3.47 & 403.5 & \\
\hline $30 R$ & 30 May & 1630 & 297.13 & 299.32 & 2.19 & 2.10 & 95.9 & \\
\hline $31 R$ & 30 May & 1740 & 299.32 & 302.37 & 3.05 & 3.20 & 104.9 & \\
\hline $32 \mathrm{R}$ & 30 May & 1900 & 302.37 & 305.42 & 3.05 & 2.98 & 97.7 & \\
\hline $33 R$ & 30 May & 2000 & 305.42 & 308.47 & 3.05 & 3.08 & 101.0 & Basket catcher twisted \\
\hline $34 \mathrm{R}$ & 30 May & 2130 & 308.47 & 311.52 & 3.05 & 2.98 & 97.7 & Basket catcher twisted, top $1 \mathrm{~m}$ of liner creased \\
\hline $35 R$ & 30 May & 2300 & 311.52 & 314.57 & 3.05 & 2.54 & 83.3 & \\
\hline $36 \mathrm{R}$ & 31 May & 0030 & 314.57 & 317.62 & 3.05 & 0.33 & 10.8 & \\
\hline $37 R$ & 31 May & 0140 & 317.62 & 320.67 & 3.05 & 3.09 & 101.3 & \\
\hline $38 \mathrm{R}$ & 31 May & 0350 & 320.67 & 323.72 & 3.05 & 3.27 & 107.2 & \\
\hline $39 R$ & 31 May & 0520 & 323.72 & 326.77 & 3.05 & 3.18 & 104.3 & \\
\hline $40 R$ & 31 May & 0730 & 326.77 & 329.82 & 3.05 & 3.05 & 100.0 & \\
\hline $41 \mathrm{R}$ & 31 May & 0835 & 329.82 & 332.87 & 3.05 & 2.69 & 88.2 & \\
\hline $42 \mathrm{R}$ & 31 May & 0930 & 332.87 & 335.92 & 3.05 & 0.92 & 30.2 & \\
\hline $43 R$ & 31 May & 1025 & 335.92 & 337.01 & 1.09 & 0.35 & 32.1 & \\
\hline $44 \mathrm{R}$ & 31 May & 1205 & 337.01 & 338.97 & 1.96 & 0.20 & 10.2 & BHA and reaming shell broken off and left downhole \\
\hline $45 \mathrm{R}$ & 3 June & 0215 & 322.22 & 325.62 & 3.40 & 3.41 & 100.3 & No evidence of broken $\mathrm{BHA} /$ reaming shell on reentry \\
\hline $46 \mathrm{R}$ & 3 June & 0335 & 325.62 & 327.19 & 1.57 & 1.45 & 92.4 & No evidence of broken $\mathrm{BHA} /$ reaming shell \\
\hline $47 R$ & 3 June & 0505 & 327.19 & 330.24 & 3.05 & 3.06 & 100.3 & No evidence of broken $\mathrm{BHA} /$ reaming shell \\
\hline $48 \mathrm{R}$ & 3 June & 0640 & 330.24 & 333.29 & 3.05 & 3.10 & 101.6 & \\
\hline $49 \mathrm{R}$ & 3 June & 0800 & 333.29 & 336.34 & 3.05 & 2.19 & 71.8 & \\
\hline $50 R$ & 3 June & 0930 & 336.34 & 339.39 & 3.05 & 0.00 & 0.0 & No basket catcher in, core slipped on retrieval, hole caving \\
\hline & & & & Drilled fro & 39.39 to & 42.44 mbsf* & ***** & \\
\hline $51 \mathrm{R}$ & 3 June & 1430 & 342.44 & 345.49 & 3.05 & 2.32 & 76.1 & Hole caving $-6 \mathrm{~m}$ lost on barrel trip \\
\hline $52 \mathrm{R}$ & 3 June & 1710 & 345.49 & 348.54 & 3.05 & 3.03 & 99.3 & $\begin{array}{l}\text { Hole caving - } 6 \mathrm{~m} \text { lost on barrel trip-unknown infill amount in } \\
\text { this section }\end{array}$ \\
\hline $53 R$ & 3 June & 2030 & 348.54 & 351.59 & 3.05 & 1.21 & 39.7 & \\
\hline $54 \mathrm{R}$ & 3 June & 2200 & 351.59 & 354.64 & 3.05 & 1.38 & 45.3 & \\
\hline $55 \mathrm{R}$ & 4 June & 0010 & 354.64 & 357.69 & 3.05 & 1.40 & 45.9 & \\
\hline $56 \mathrm{R}$ & 4 June & 0135 & 357.69 & 360.74 & 3.05 & 2.44 & 80.0 & \\
\hline
\end{tabular}


Table T1 (continued). (Continued on page.)

\begin{tabular}{|c|c|c|c|c|c|c|c|c|}
\hline \multirow[b]{2}{*}{ Core } & \multirow{2}{*}{$\begin{array}{l}\text { Date } \\
(2009)\end{array}$} & \multirow{2}{*}{$\begin{array}{l}\text { Time } \\
\text { (UTC) }\end{array}$} & \multicolumn{2}{|c|}{ Depth (mbsf) } & \multicolumn{2}{|c|}{ Length (m) } & \multirow{2}{*}{$\begin{array}{l}\text { Recovery } \\
\text { (\%) }\end{array}$} & \multirow[b]{2}{*}{ Comments } \\
\hline & & & Top & Bottom & Cored & Recovered & & \\
\hline $57 \mathrm{R}$ & 4 June & 0250 & 360.74 & 363.79 & 3.05 & 1.81 & 59.3 & \\
\hline $58 \mathrm{R}$ & 4 June & 0420 & 363.79 & 366.84 & 3.05 & 2.12 & 69.5 & \\
\hline $59 \mathrm{R}$ & 4 June & 0550 & 366.84 & 369.89 & 3.05 & 0.31 & 10.2 & \\
\hline $60 \mathrm{R}$ & 4 June & 0805 & 369.89 & 372.94 & 3.05 & 0.32 & 10.5 & \\
\hline $61 R$ & 4 June & 1020 & 372.94 & 375.99 & 3.05 & 1.87 & 61.3 & \\
\hline $62 \mathrm{R}$ & 4 June & 1150 & 375.99 & 379.04 & 3.05 & 0.00 & 0.0 & \\
\hline $63 R$ & 4 June & 1335 & 379.04 & 382.09 & 3.05 & 2.95 & 96.7 & \\
\hline $64 \mathrm{R}$ & 4 June & 1515 & 382.09 & 385.14 & 3.05 & 1.50 & 49.2 & \\
\hline $65 R$ & 4 June & 1650 & 385.14 & 388.19 & 3.05 & 2.98 & 97.7 & \\
\hline $66 \mathrm{R}$ & 4 June & 1800 & 388.19 & 389.46 & 1.27 & 1.17 & 92.1 & Hole collapsed \\
\hline $67 R$ & 4 June & 1940 & 389.46 & 391.24 & 1.78 & 1.94 & 109.0 & \\
\hline $68 \mathrm{R}$ & 4 June & 2120 & 391.24 & 394.29 & 3.05 & 0.09 & 3.0 & \\
\hline $69 R$ & 4 June & 2300 & 394.29 & 397.34 & 3.05 & 1.71 & 56.1 & \\
\hline $70 \mathrm{R}$ & 5 June & 0045 & 397.34 & 398.11 & 0.77 & 0.57 & 74.0 & \\
\hline $71 \mathrm{R}$ & 6 June & 0500 & 398.11 & 398.84 & 0.73 & 0.01 & 1.4 & PQ stuck, run from now with HQ system \\
\hline $72 \mathrm{R}$ & 6 June & 0700 & 398.84 & 400.07 & 1.23 & 0.01 & 0.8 & \\
\hline $73 R$ & 6 June & 0840 & 400.07 & 402.32 & 2.25 & 0.23 & 10.2 & \\
\hline $74 \mathrm{R}$ & 6 June & 1320 & 402.32 & 408.34 & 6.02 & 0.29 & 4.8 & Pulled HQ pipe back into PQ as hole caving, reaming \\
\hline $75 \mathrm{R}$ & 6 June & 1620 & 408.34 & 410.97 & 2.63 & 0.09 & 3.4 & \\
\hline $76 \mathrm{R}$ & 7 June & 2300 & 398.11 & 406.18 & 8.07 & 1.50 & 18.6 & Drilling through cavings \\
\hline $77 R$ & 8 June & 0030 & 406.18 & 406.48 & 0.30 & 0.10 & 33.3 & Drilling through cavings \\
\hline $78 \mathrm{R}$ & 8 June & 0220 & 406.48 & 412.47 & 5.99 & 1.86 & 31.1 & Drilling through cavings \\
\hline $79 R$ & 8 June & 0400 & 412.47 & 416.32 & 3.85 & 3.20 & 83.1 & \\
\hline $80 \mathrm{R}$ & 8 June & 0530 & 416.32 & 419.91 & 3.59 & 3.18 & 88.6 & \\
\hline $81 \mathrm{R}$ & 8 June & 0745 & 419.91 & 423.63 & 3.72 & 3.19 & 85.8 & \\
\hline $82 \mathrm{R}$ & 8 June & 0927 & 423.63 & 426.92 & 3.29 & 3.13 & 95.1 & \\
\hline $83 R$ & 8 June & 1115 & 426.92 & 430.34 & 3.42 & 3.21 & 93.9 & \\
\hline $84 \mathrm{R}$ & 8 June & 1240 & 430.34 & 433.62 & 3.28 & 3.17 & 96.7 & \\
\hline $85 \mathrm{R}$ & 8 June & 1355 & 433.62 & 436.67 & 3.05 & 3.14 & 103.0 & \\
\hline $86 \mathrm{R}$ & 8 June & 1525 & 436.67 & 439.72 & 3.05 & 3.16 & 103.6 & \\
\hline $87 R$ & 8 June & 1650 & 439.72 & 442.77 & 3.05 & 3.13 & 102.6 & \\
\hline $88 \mathrm{R}$ & 8 June & 1815 & 442.77 & 445.82 & 3.05 & 3.13 & 102.6 & \\
\hline $89 R$ & 8 June & 2000 & 445.82 & 448.87 & 3.05 & 3.10 & 101.6 & \\
\hline $90 R$ & 8 June & 2130 & 448.87 & 451.92 & 3.05 & 0.00 & 0.0 & Core slipped on retrieval \\
\hline $91 \mathrm{R}$ & 8 June & 2305 & 451.92 & 454.97 & 3.05 & 1.99 & 65.3 & Drilling out slipped core \\
\hline $92 \mathrm{R}$ & 9 June & 0015 & 454.97 & 458.02 & 3.05 & 3.05 & 100.0 & \\
\hline $93 R$ & 9 June & 0120 & 458.02 & 461.07 & 3.05 & 3.05 & 100.0 & \\
\hline $94 \mathrm{R}$ & 9 June & 0225 & 461.07 & 464.12 & 3.05 & 3.05 & 100.0 & \\
\hline $95 \mathrm{R}$ & 9 June & 0350 & 464.12 & 467.17 & 3.05 & 3.10 & 101.6 & \\
\hline $96 \mathrm{R}$ & 9 June & 0455 & 467.17 & 470.22 & 3.05 & 3.08 & 101.0 & \\
\hline 97R & 9 June & 0555 & 470.22 & 473.27 & 3.05 & 3.15 & 103.3 & \\
\hline $98 \mathrm{R}$ & 9 June & 0735 & 473.27 & 476.32 & 3.05 & 3.20 & 104.9 & \\
\hline $99 R$ & 9 June & 0850 & 476.32 & 479.37 & 3.05 & 2.84 & 93.1 & \\
\hline $100 \mathrm{R}$ & 9 June & 1020 & 479.37 & 482.42 & 3.05 & 3.18 & 104.3 & \\
\hline $101 \mathrm{R}$ & 9 June & 1330 & 482.42 & 485.47 & 3.05 & 3.22 & 105.6 & \\
\hline $102 \mathrm{R}$ & 9 June & 1440 & 485.47 & 488.52 & 3.05 & 2.23 & 73.1 & \\
\hline $103 R$ & 9 June & 1610 & 488.52 & 491.57 & 3.05 & 3.20 & 104.9 & \\
\hline $104 \mathrm{R}$ & 9 June & 1735 & 491.57 & 494.62 & 3.05 & 2.99 & 98.0 & \\
\hline $105 R$ & 9 June & 1935 & 494.62 & 497.67 & 3.05 & 3.19 & 104.6 & \\
\hline $106 \mathrm{R}$ & 9 June & 2050 & 497.67 & 500.72 & 3.05 & 3.10 & 101.6 & \\
\hline $107 R$ & 9 June & 2150 & 500.72 & 503.77 & 3.05 & 3.09 & 101.3 & \\
\hline $108 \mathrm{R}$ & 9 June & 2305 & 503.77 & 506.82 & 3.05 & 2.26 & 74.1 & $\sim 80 \mathrm{~cm}$ core slipped on retrieval \\
\hline $109 \mathrm{R}$ & 10 June & 0005 & 506.82 & 509.67 & 2.85 & 3.20 & 112.3 & $\begin{array}{l}\text { Shorter core run as blocking off because of slipped material } \\
\text { from previous run }\end{array}$ \\
\hline $110 \mathrm{R}$ & 10 June & 0210 & 509.67 & 512.92 & 3.25 & 3.07 & 94.5 & \\
\hline $111 \mathrm{R}$ & 10 June & 0320 & 512.92 & 515.97 & 3.05 & 3.04 & 99.7 & \\
\hline $112 \mathrm{R}$ & 10 June & 0430 & 515.97 & 519.02 & 3.05 & 2.37 & 77.7 & \\
\hline $113 R$ & 10 June & 0535 & 519.02 & 522.07 & 3.05 & 3.20 & 104.9 & \\
\hline $114 \mathrm{R}$ & 10 June & 0805 & 522.07 & 524.52 & 2.45 & 2.58 & 105.3 & \\
\hline $115 \mathrm{R}$ & 10 June & 0930 & 524.52 & 525.65 & 1.13 & 1.07 & 94.7 & \\
\hline $116 \mathrm{R}$ & 10 June & 1100 & 525.65 & 527.5 & 1.85 & 1.85 & 100.0 & Sample stuck in core spring \\
\hline $117 \mathrm{R}$ & 10 June & 1250 & 527.50 & 528.17 & 0.67 & 0.83 & 123.9 & \\
\hline $118 \mathrm{R}$ & 11 June & 0250 & 528.17 & 531.22 & 3.05 & 3.12 & 102.3 & \\
\hline $119 \mathrm{R}$ & 11 June & 0400 & 531.22 & 532.96 & 1.74 & 1.85 & 106.3 & \\
\hline $120 \mathrm{R}$ & 11 June & 0520 & 532.96 & 534.27 & 1.31 & 1.36 & 103.8 & \\
\hline $121 \mathrm{R}$ & 11 June & 0700 & 534.27 & 537.32 & 3.05 & 2.64 & 86.6 & \\
\hline $122 \mathrm{R}$ & 11 June & 0850 & 537.32 & 539.37 & 2.05 & 2.47 & 120.5 & \\
\hline $123 \mathrm{R}$ & 11 June & 1050 & 539.37 & 540.37 & 1.00 & 0.85 & 85.0 & \\
\hline $124 \mathrm{R}$ & 11 June & 1300 & 540.37 & 542.78 & 2.41 & 2.47 & 102.5 & \\
\hline
\end{tabular}


Table T1 (continued).

\begin{tabular}{|c|c|c|c|c|c|c|c|c|}
\hline \multirow[b]{2}{*}{ Core } & \multirow{2}{*}{$\begin{array}{l}\text { Date } \\
(2009)\end{array}$} & \multirow{2}{*}{$\begin{array}{l}\text { Time } \\
\text { (UTC) }\end{array}$} & \multicolumn{2}{|c|}{ Depth (mbsf) } & \multicolumn{2}{|c|}{ Length (m) } & \multirow{2}{*}{$\begin{array}{l}\text { Recovery } \\
\quad(\%)\end{array}$} & \multirow[b]{2}{*}{ Comments } \\
\hline & & & Top & Bottom & Cored & Recovered & & \\
\hline $125 \mathrm{R}$ & 11 June & 1445 & 542.78 & 543.54 & 0.76 & 0.82 & 107.9 & \\
\hline $126 \mathrm{R}$ & 11 June & 1700 & 543.54 & 546.47 & 2.93 & 1.13 & 38.6 & \\
\hline $127 \mathrm{R}$ & 11 June & 1905 & 546.47 & 549.52 & 3.05 & 3.03 & 99.3 & \\
\hline $128 \mathrm{R}$ & 11 June & 2010 & 549.52 & 552.57 & 3.05 & 2.64 & 86.6 & \\
\hline $129 \mathrm{R}$ & 11 June & 2135 & 552.57 & 555.62 & 3.05 & 3.15 & 103.3 & \\
\hline $130 \mathrm{R}$ & 11 June & 2250 & 555.62 & 558.67 & 3.05 & 3.11 & 102.0 & \\
\hline $131 \mathrm{R}$ & 11 June & 2355 & 558.67 & 561.72 & 3.05 & 3.14 & 103.0 & \\
\hline $132 R$ & 12 June & 0105 & 561.72 & 564.77 & 3.05 & 3.16 & 103.6 & \\
\hline $133 R$ & 12 June & 0240 & 564.77 & 567.82 & 3.05 & 3.08 & 101.0 & \\
\hline $134 \mathrm{R}$ & 12 June & 0505 & 567.82 & 570.87 & 3.05 & 3.06 & 100.3 & \\
\hline $135 \mathrm{R}$ & 12 June & 0745 & 570.87 & 573.92 & 3.05 & 3.20 & 104.9 & \\
\hline $136 \mathrm{R}$ & 12 June & 0935 & 573.92 & 576.02 & 2.10 & 2.21 & 105.2 & \\
\hline $137 R$ & 12 June & 1240 & 576.02 & 576.97 & 0.95 & 0.93 & 97.9 & \\
\hline $138 \mathrm{R}$ & 12 June & 1440 & 576.97 & 580.02 & 3.05 & 3.08 & 101.0 & \\
\hline $139 R$ & 12 June & 1615 & 580.02 & 582.33 & 2.31 & 3.14 & 135.9 & $2 \mathrm{~m}$ reaming before coring, $\sim 95 \mathrm{~cm}$ if fill at top of core \\
\hline $140 \mathrm{R}$ & 12 June & 1750 & 582.33 & 583.07 & 0.74 & 1.23 & 166.2 & Reaming before coring, possible infill at top of core \\
\hline $141 \mathrm{R}$ & 12 June & 2015 & 583.07 & 586.12 & 3.05 & 3.08 & 101.0 & \\
\hline $142 \mathrm{R}$ & 12 June & 2345 & 586.12 & 589.17 & 3.05 & 3.10 & 101.6 & \\
\hline $143 R$ & 13 June & 0200 & 589.17 & 590.25 & 1.08 & 1.16 & 107.4 & \\
\hline $144 \mathrm{R}$ & 14 June & 0740 & 590.25 & 592.22 & 1.97 & 2.34 & 118.8 & \\
\hline $145 \mathrm{R}$ & 14 June & 0930 & 592.22 & 595.27 & 3.05 & 3.02 & 99.0 & \\
\hline $146 \mathrm{R}$ & 14 June & 1105 & 595.27 & 598.32 & 3.05 & 1.79 & 58.7 & \\
\hline 147R & 14 June & 1300 & 598.32 & 601.37 & 3.05 & 2.01 & 65.9 & \\
\hline $148 \mathrm{R}$ & 14 June & 1440 & 601.37 & 604.42 & 3.05 & 0.00 & 0.0 & \\
\hline $149 \mathrm{R}$ & 14 June & 1615 & 604.42 & 607.47 & 3.05 & 2.20 & 72.1 & \\
\hline $150 \mathrm{R}$ & 14 June & 1735 & 607.47 & 608.47 & 1.00 & 1.03 & 103.0 & \\
\hline $151 \mathrm{R}$ & 14 June & 1950 & 608.47 & 610.52 & 2.05 & 1.76 & 85.9 & Reamed out bottom $5 \mathrm{~m}$ of hole prior to coring \\
\hline $152 \mathrm{R}$ & 14 June & 2120 & 610.52 & 613.57 & 3.05 & 3.04 & 99.7 & \\
\hline $153 R$ & 14 June & 2355 & 613.57 & 616.62 & 3.05 & 3.21 & 105.3 & \\
\hline $154 \mathrm{R}$ & 15 June & 0145 & 616.62 & 619.67 & 3.05 & 3.05 & 100.0 & \\
\hline $155 \mathrm{R}$ & 15 June & 0315 & 619.67 & 622.72 & 3.05 & 3.21 & 105.3 & \\
\hline $156 \mathrm{R}$ & 15 June & 0450 & 622.72 & 625.77 & 3.05 & 3.32 & 108.9 & \\
\hline $157 R$ & 15 June & 0645 & 625.77 & 628.82 & 3.05 & 3.26 & 106.9 & \\
\hline $158 \mathrm{R}$ & 15 June & 0820 & 628.82 & 631.87 & 3.05 & 3.15 & 103.3 & \\
\hline $159 R$ & 15 June & 1000 & 631.87 & 634.92 & 3.05 & 3.14 & 103.0 & \\
\hline $160 \mathrm{R}$ & 15 June & 1130 & 634.92 & 637.97 & 3.05 & 3.21 & 105.3 & \\
\hline $161 R$ & 15 June & 1250 & 637.97 & 641.02 & 3.05 & 3.06 & 100.3 & \\
\hline $162 \mathrm{R}$ & 15 June & 1410 & 641.02 & 644.07 & 3.05 & 3.10 & 101.6 & \\
\hline $163 R$ & 15 June & 1530 & 644.07 & 647.12 & 3.05 & 3.28 & 107.5 & \\
\hline $164 \mathrm{R}$ & 15 June & 1740 & 647.12 & 650.17 & 3.05 & 3.10 & 101.6 & \\
\hline $165 R$ & 15 June & 1935 & 650.17 & 653.22 & 3.05 & 3.23 & 105.9 & \\
\hline $166 \mathrm{R}$ & 15 June & 2105 & 653.22 & 656.27 & 3.05 & 2.81 & 92.1 & Bottom of core slipped on retrieval \\
\hline $167 R$ & 15 June & 2240 & 656.27 & 659.32 & 3.05 & 3.24 & 106.2 & Possibly drilling out core from previous run \\
\hline $168 \mathrm{R}$ & 16 June & 0010 & 659.32 & 662.37 & 3.05 & 3.22 & 105.6 & \\
\hline $169 \mathrm{R}$ & 16 June & 0120 & 662.37 & 665.42 & 3.05 & 2.15 & 70.5 & $\begin{array}{l}\text { Bottom section of core slipped on retrieval, } \sim 15 \mathrm{~cm} \text { of core } \\
\text { projecting beyond core catcher }\end{array}$ \\
\hline 170R & 16 June & 0240 & 665.42 & 668.47 & 3.05 & 3.23 & 105.9 & \\
\hline $171 \mathrm{R}$ & 16 June & 1105 & 668.47 & 668.66 & 0.19 & 0.19 & 100.0 & Small core drilled out during preparation for logging \\
\hline
\end{tabular}

Note: $\mathrm{BHA}=$ bottom-hole assembly. 
Table T2. Summary of lithostratigraphic units, Hole M0028A.

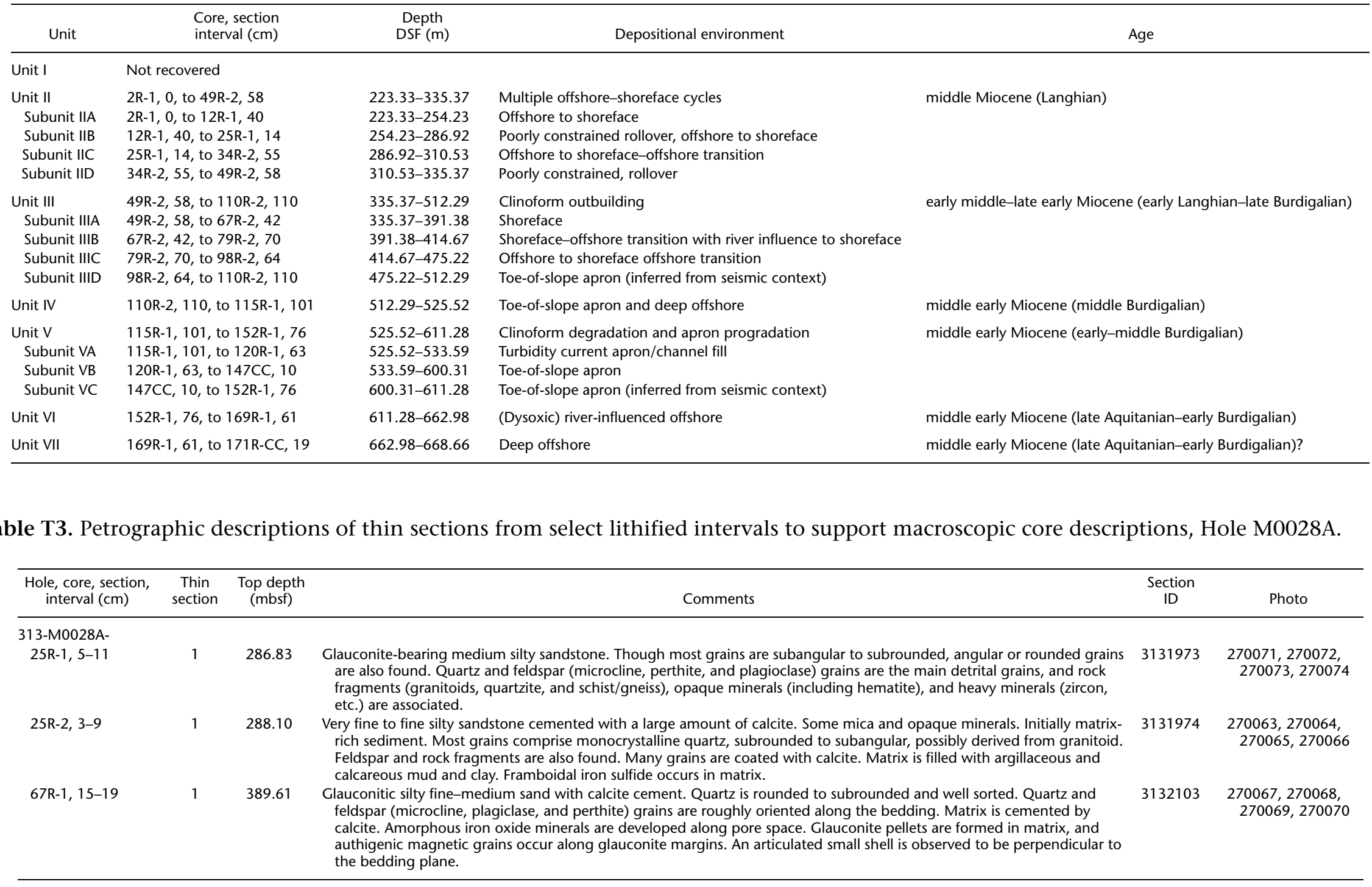

Table T4. Distribution of calcareous nannofossils, Hole M0028A. This table is available in an oversized format. 
Table T5. Planktonic foraminifer occurrences and zonations, Hole M0028A. (See table notes.)

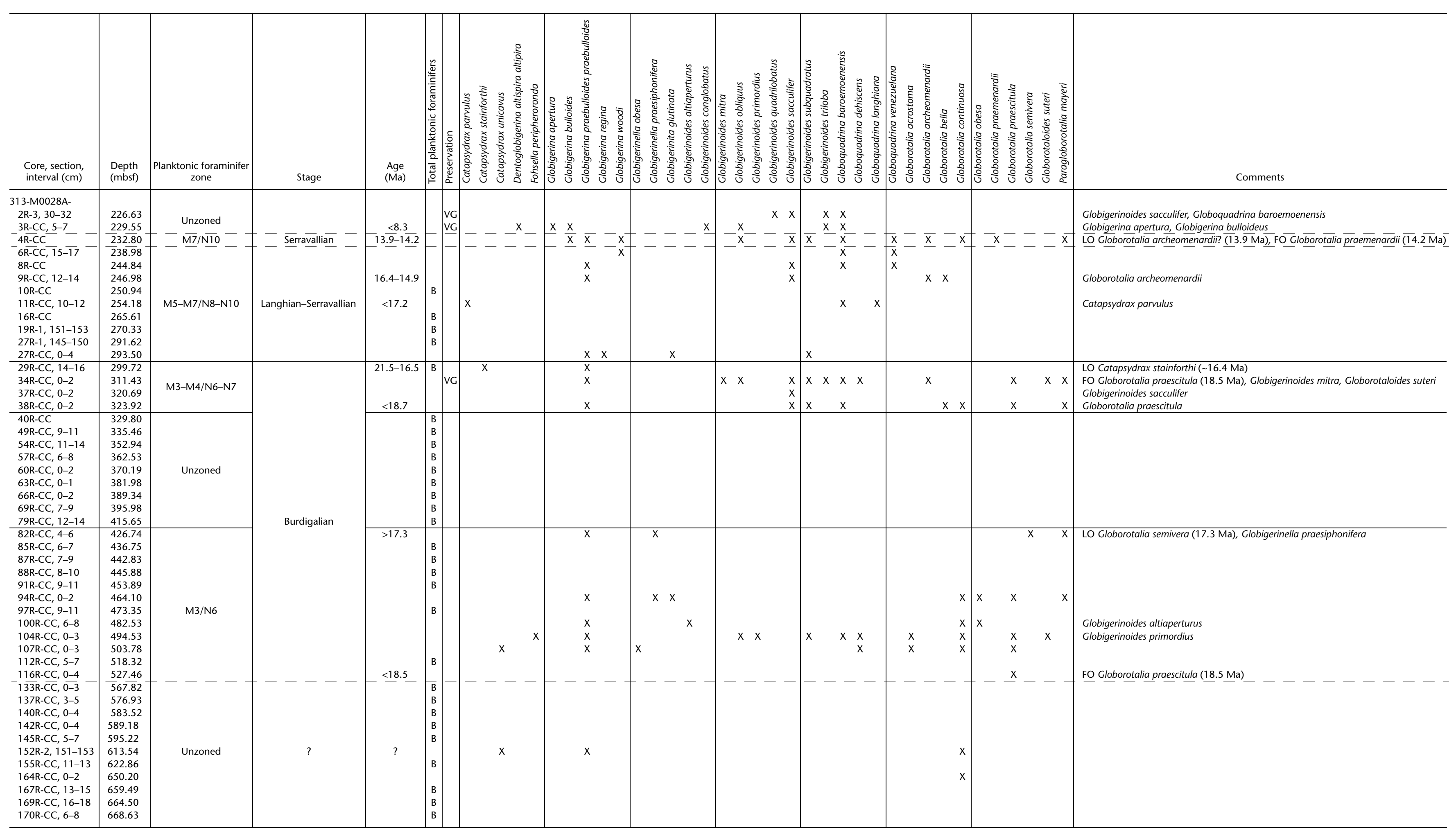

Notes: $\mathrm{FO}=$ first occurrence, $\mathrm{LO}=$ last occurrence. $\mathrm{B}=$ barren. Preservation: $\mathrm{VG}=$ very good 
Table T7. Benthic foraminifer occurrences and paleobathymetric interpretations, Hole M0028A. (See table notes.) (Continued on next page.)

\begin{tabular}{|c|c|c|c|c|c|}
\hline $\begin{array}{l}\text { Core, section, } \\
\text { interval }(\mathrm{cm})\end{array}$ & $\begin{array}{l}\text { Depth } \\
\text { (mbsf) }\end{array}$ & Benthic foraminifer taxa & Preservation & Comments & $\begin{array}{l}\text { Paleodepth estimate } \\
\text { (m) }\end{array}$ \\
\hline \multicolumn{6}{|l|}{ 313-M0028A- } \\
\hline $2 \mathrm{R}-3,30-32$ & 226.63 & A: Nonionella pizarrensis; C: Hanzawaia concentrica, R: Lenticulina & & Very fine grained residue, small sample & $25-50$ \\
\hline $3 \mathrm{R}-\mathrm{CC}, 5-7$ & 229.55 & $\begin{array}{l}\text { A: Nonionella pizarrensis, Uvigerina juncea; C: Bolivina, Buliminella gracilis, Hanzawaia concentrica; F: } \\
\text { Bolivinella elegans, agglutinants }\end{array}$ & VG-E & $\begin{array}{l}\text { Small sample, abundant planktonics and } \\
\text { benthics }\end{array}$ & $50-100$ \\
\hline $4 \mathrm{R}-\mathrm{CC}$ & 232.80 & $\begin{array}{l}\text { A: Nonionella pizarrensis, Uvigerina juncea; C: Lenticulina, Buliminella gracilis (and Buliminella curta); } \\
\text { F-C: Hanzawaia concentrica; F: Bolivina; R: Cibicidoides primulus, Cibicidoides pachyderma, miliolid }\end{array}$ & G-E & Abundant foraminifers & $50-100$ \\
\hline $6 \mathrm{R}-\mathrm{CC}, 15-17$ & 238.98 & $\begin{array}{l}\text { Nonionella pizarrensis (10); Hanzawaia concentrica (5); Lenticulina (3); Bolivina brevior (1); Bolivina cf. } \\
\text { alazanensis (3); Buliminella gracilis (9); Uvigerina juncea (8) }\end{array}$ & VG-E & & $50-100$ \\
\hline $8 \mathrm{R}-\mathrm{CC}$ & 244.84 & $\begin{array}{l}\text { Lenticulina spp., Lenticulina americana, Bolivina alazanensis, Bolivina brevior, Uvigerina juncea, } \\
\text { Buliminella gracilis, Buliminella curta, Nonionella pizarrensis }\end{array}$ & G-E & Abundant foraminifers & $50-100$ \\
\hline 9R-CC, 12-14 & 246.98 & $\begin{array}{l}\text { A: Hanzawaia concentrica, Nonionella pizarrensis; F: Buliminella gracilis; R: Lenticulina, Dentalina, } \\
\text { Textularia, Uvigerina juncea }\end{array}$ & P-VG & & 25-50 (?60ish) \\
\hline 10R-CC & 250.94 & Barren & & & ? \\
\hline 11R-CC, 10-12 & 254.18 & None $>150 \mu \mathrm{m}$; pan-rare Buliminella gracilis, Lenticulina, Bolivina & & & $? ? 50-75$ \\
\hline $16 \mathrm{R}-\mathrm{CC}$ & 265.61 & Hanzawaia concentrica (3); Lenticulina (1) & & Rare foraminifers & $10-25$ \\
\hline 19R-1, 151-153 & 270.33 & A: Hanzawaia concentrica, Lenticulina; F: Dentalina & & & $10-25$ \\
\hline $27 \mathrm{R}-1,145-150$ & 291.62 & Barren & & & $?$ \\
\hline $27 \mathrm{R}-\mathrm{CC}, 0-4$ & 295.50 & $\begin{array}{l}\text { Buliminella gracilis (6); Nonionella pizarrensis (6); Hanzawaia concentrica (6); Pararotalia (1); Bolivina } \\
\text { paula (1); Cibicidoides aff. mundulus (1) }\end{array}$ & VG-E & & $50-75$ \\
\hline 29R-CC, 14-16 & 299.72 & $\begin{array}{l}\text { Hanzawaia concentrica (4); Lenticulina (1); Pararotalia (1); Cassidulinoides (1); Bolivina paula (1); } \\
\text { Nonionella pizarrensis (4); Buliminella ( gracilis with spines) (1) }\end{array}$ & VG-E & & $25-50$ \\
\hline $34 \mathrm{R}-\mathrm{CC}, 0-2$ & 311.43 & $\begin{array}{l}\text { A: Lenticulina americana, Lenticulina spp., Nonionella pizarrensis; C: Hanzawaia concentrica, } \\
\text { Hanzawaia spp., Buliminella gracilis/Buliminella curta; } \mathrm{F} \text { : Uvigerina cf. juncea, Bolivina paula; } \mathrm{R} \text { : } \\
\text { Cibicidoides pachyderma, polymorph, Rectuvigerina lamelata, agglutinants, Bulimina mexicana, } \\
\text { Cassidulinoides }\end{array}$ & VG-E & Abundant foraminifers & $50-80$ \\
\hline $37 R-C C, 0-2$ & 320.69 & Lenticulina-Nonionella pizarrensis-Hanzawaia concentrica, rare Cancris sagra, Uvigerina, Fissurina & P-VG & & $25-50$ \\
\hline $38 \mathrm{R}-\mathrm{CC}, 0-2$ & 323.92 & $\begin{array}{l}\text { A: Lenticulina, Hanzawaia; C: Nonionella pizarrensis, Uvigerina juncea; F: Nonion, Cibicidoides, Bolivina } \\
\text { marginata; R: polymorph, agglutinants, Rectuvigerina lamelata }\end{array}$ & P-VG & & $50-100$ \\
\hline 40R-CC & 329.80 & Barren & & & ? \\
\hline 49R-CC, 9-11 & 335.46 & Barren & & & $?$ \\
\hline 54R-CC, 11-14 & 352.94 & 1 broken Lenticulina & $\mathrm{P}$ & & ? \\
\hline $57 \mathrm{R}-\mathrm{CC}, 6-8$ & 362.53 & Barren & & & $?$ \\
\hline $60 \mathrm{R}-\mathrm{CC}, 0-2$ & 370.19 & Barren & & & $?$ \\
\hline $63 \mathrm{R}-\mathrm{CC}, 0-1$ & 381.98 & Barren & & & $?$ \\
\hline $66 \mathrm{R}-\mathrm{CC}, 0-2$ & 389.34 & 1 Cibicidoides, 1 Lenticulina fragment & $\mathrm{P}$ & & $?$ \\
\hline 69R-CC, 7-9 & 395.98 & Barren & & & $?$ \\
\hline 79R-CC, 12-14 & 415.65 & Barren & & & $?$ \\
\hline $82 \mathrm{R}-\mathrm{CC}, 4-6$ & 426.74 & $\begin{array}{l}\text { Buliminella gracilis (4); Lenticulina (2); polymorph (1); Cibicidoides (1); Hanzawaia concentrica (4); } \\
\text { Nonionella pizarrensis (6); Textularia (3) }\end{array}$ & VG-E & Rare foraminifers & $50-75$ \\
\hline $85 \mathrm{R}-\mathrm{CC}, 6-7$ & 436.75 & Barren & & & $?$ \\
\hline 87R-CC, 7-9 & 442.83 & Barren & & & $?$ \\
\hline $88 \mathrm{R}-\mathrm{CC}, 8-10$ & 445.88 & Barren & & & ? \\
\hline 91R-CC, 9-11 & 453.89 & Barren & & & $?$ \\
\hline $94 \mathrm{R}-\mathrm{CC}, 0-2$ & 464.10 & $\begin{array}{l}\text { Hanzawaia concentrica (8); Hanzawaia (2); Nonionella pizarrensis (3); Textularia (1); Buliminella } \\
\text { gracilis (6); Uvigerina juncea (3) }\end{array}$ & G-E & & $50-80$ \\
\hline 97R-CC, 9-11 & 473.35 & Lenticulina (1); Hanzawaia concentrica (1) & & & ??10-25?? \\
\hline 100R-CC, 6-8 & 482.53 & $\begin{array}{l}\text { A: Uvigerina juncea, Lenticulina; C: Bolivina floridana; R: Cibicidoides pachyderma, Nonionella } \\
\text { pizarrensis, Hanzawaia }\end{array}$ & & & $75-100$ \\
\hline
\end{tabular}


Table T7 (continued).

\begin{tabular}{|c|c|c|c|c|c|}
\hline $\begin{array}{l}\text { Core, section, } \\
\text { interval }(\mathrm{cm})\end{array}$ & $\begin{array}{l}\text { Depth } \\
\text { (mbsf) }\end{array}$ & Benthic foraminifer taxa & Preservation & Comments & $\begin{array}{c}\text { Paleodepth estimate } \\
(\mathrm{m})\end{array}$ \\
\hline $102 R-C C, 0-2$ & 487.68 & Barren & & & ? \\
\hline 104R-CC, 0-3 & 494.53 & $\begin{array}{l}\text { A: Lenticulina americana, Lenticulina spp., Hanzawaia concentrica, Hanzawaia spp., Nonionella } \\
\text { pizarrensis; R: Textularia, Pullenia salisburyi, Uvigerina }\end{array}$ & P-VG & & $25-70$ \\
\hline 107R-CC, 0-3 & 503.78 & $\begin{array}{l}\text { Buliminella gracilis (1); Hanzawaia concentrica (2); Lenticulina (2); Bolivina paula (3); Textularia (1); } \\
\text { Nonionella pizarrensis (1); Cassidulinoides (4) }\end{array}$ & $P-V G$ & & $50-75$ \\
\hline $110 \mathrm{R}-\mathrm{CC}, 0-2$ & 512.72 & Barren & & & ? \\
\hline $116 \mathrm{R}-\mathrm{CC}, 0-4$ & 527.46 & Cassidulinoides (1) & $\mathrm{E}$ & & $?$ \\
\hline $122 \mathrm{R}-\mathrm{CC}, 0-3$ & 539.76 & Barren & & & ? \\
\hline $133 \mathrm{R}-\mathrm{CC}, 0-3$ & 567.82 & Barren & & & ? \\
\hline 137R-CC, 3-5 & 576.93 & Barren & & & $?$ \\
\hline $140 \mathrm{R}-\mathrm{CC}, 0-3$ & 583.52 & Barren & & & ? \\
\hline $142 \mathrm{R}-\mathrm{CC}, 0-4$ & 589.18 & Barren & & & ? \\
\hline $145 \mathrm{R}-\mathrm{CC}, 5-7$ & 595.22 & Barren & & & $?$ \\
\hline 149R-CC, 7-9 & 606.60 & Barren & & & $?$ \\
\hline 152R-CC, 151-153 & 613.54 & Hanzawaia concentrica (1); Hanzawaia hughesi (1); Plectofrondicularia morneyae (1); Stilostomella (1) & P-VG & Rare foraminifers & ?10-25? \\
\hline 155R-CC, 11-13 & 622.86 & Barren & & Few benthics may have gone to $\mathrm{Sr}$ (not run) & ? \\
\hline 158R-CC, 4-6 & 631.95 & Barren & & & ? \\
\hline $161 \mathrm{R}-\mathrm{CC}, 7-9$ & 641.01 & Barren & & & ? \\
\hline $164 \mathrm{R}-\mathrm{CC}, 0-2$ & 650.20 & Barren & & & ? \\
\hline 167R-CC, 13-15 & 659.49 & Barren & & & ? \\
\hline 169R-CC, 16-18 & 664.50 & Plectofrondicularia morneyae (1); Stilostomella (2); Buliminella grata (6) & P-VG & Rare foraminifers & $50-75$ \\
\hline 170R-CC, 6-8 & 668.63 & $\begin{array}{l}\text { Nonionella pizarrensis (6); Uvigerina juncea (3); Buliminella gracilis (1); Lenticulina (1); marginulinid } \\
\text { (1), Stilostomella (1); Sphaeroidina bulloides (1); ?Ceratobulimina (broken) (1); Plectofrondicularia } \\
\text { morneyae (5); Bolivina alazanensis (5) }\end{array}$ & $\mathrm{E}$ & & $50-80$ \\
\hline
\end{tabular}

Notes: Abundance: $A=$ abundant, $C=$ common, $F=$ few,$R=$ rare, $P=$ present. Preservation: $E=$ excellent, $V G=$ very good, $G=$ good, $P=$ poor. 
Table T8. Palynomorph data and remarks on dominant tree taxa, Hole M0028A. (See table notes.)

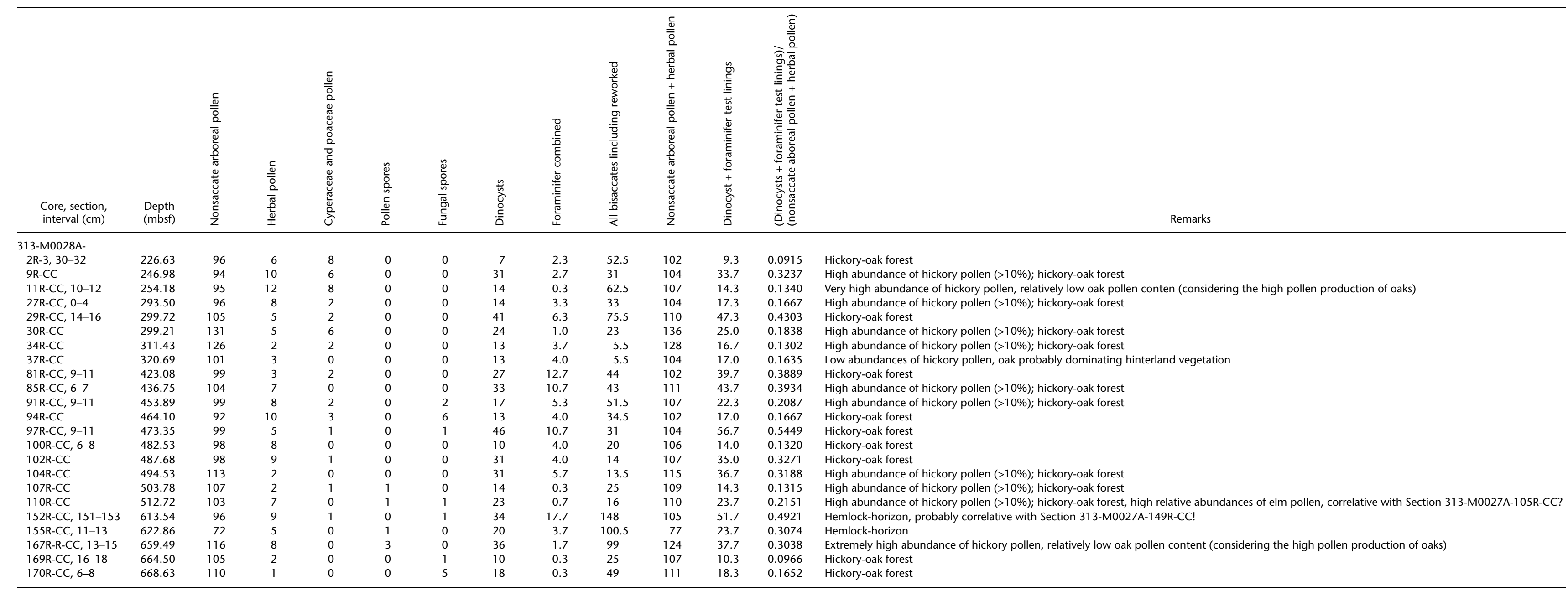

Notes: Remarks concerning nonsaccate pollen like "high percentages" are always in relation to the production and transport potential of the different pollen types. 
Table T9. Composition of interstitial water, Hole M0028A. This table is available in an oversized format.

Table T10. Total carbon, total organic carbon, total inorganic carbon, and total sulfur in sediment, Hole M0028A.

\begin{tabular}{|c|c|c|c|c|c|}
\hline \multirow{2}{*}{$\begin{array}{l}\text { Core, section, } \\
\text { interval }(\mathrm{cm})\end{array}$} & \multirow{2}{*}{$\begin{array}{l}\text { Depth } \\
\text { (mbsf) }\end{array}$} & \multicolumn{3}{|c|}{ Carbon (wt\%) } & \multirow{2}{*}{$\begin{array}{l}\text { Total sulfur } \\
\quad(w t \%)\end{array}$} \\
\hline & & Total & Organic & Inorganic & \\
\hline \multicolumn{6}{|l|}{ 313-M0027A- } \\
\hline $2 \mathrm{R}-1,0.0-1.0$ & 223.34 & 2.10 & 1.56 & 0.54 & 2.07 \\
\hline $3 \mathrm{R}-2,71.0-72.0$ & 228.42 & 1.73 & 1.51 & 0.21 & 2.76 \\
\hline $4 \mathrm{R}-2,54.0-55.0$ & 231.48 & 2.10 & 1.33 & 0.77 & 1.36 \\
\hline 7R-2, 38.0-39.0 & 240.47 & 1.11 & 0.93 & 0.17 & 0.54 \\
\hline 10R-2, 141.0-142.0 & 250.65 & 2.31 & 2.08 & 0.23 & 3.09 \\
\hline $14 \mathrm{R}-1,108.0-109.0$ & 257.97 & 0.23 & 0.13 & 0.09 & 0.22 \\
\hline $19 \mathrm{R}-1,0.0-1.0$ & 268.83 & 1.07 & 0.61 & 0.46 & 1.25 \\
\hline $21 \mathrm{R}-2,44.0-45.0$ & 276.47 & 0.87 & 0.47 & 0.40 & 1.63 \\
\hline $29 \mathrm{R}-1,110.0-111.0$ & 297.38 & 2.00 & 1.66 & 0.34 & 2.05 \\
\hline $81 \mathrm{R}-3,20.0-21.0$ & 422.62 & 1.47 & 1.27 & 0.20 & 1.44 \\
\hline 97R-1, 76.0-77.0 & 470.99 & 3.16 & 2.90 & 0.26 & 2.16 \\
\hline $100 \mathrm{R}-2,70.0-71.0$ & 481.43 & 2.21 & 1.91 & 0.31 & 2.13 \\
\hline $113 R-2,30.0-31.0$ & 520.87 & 1.20 & 1.02 & 0.18 & 2.01 \\
\hline $127 \mathrm{R}-2,90.0-91.0$ & 548.88 & 0.63 & 0.58 & 0.05 & 1.01 \\
\hline 130R-2, 75.0-76.0 & 557.88 & 1.79 & 1.76 & 0.03 & 1.42 \\
\hline $133 R-2,58.0-59.0$ & 566.88 & 0.74 & 0.63 & 0.11 & 0.98 \\
\hline $136 \mathrm{R}-2,45.0-46.0$ & 575.88 & 0.45 & 0.42 & 0.03 & 0.78 \\
\hline $141 \mathrm{R}-2,26.0-27.0$ & 584.88 & 0.25 & 0.15 & 0.09 & 0.37 \\
\hline $145 \mathrm{R}-3,2.0-3.0$ & 593.88 & 0.40 & 0.37 & 0.03 & 0.43 \\
\hline 149R-1, 0.0-1.0 & 604.43 & 0.74 & 0.64 & 0.09 & 0.64 \\
\hline $152 \mathrm{R}-1,134.0-135.0$ & 611.87 & 1.08 & 0.66 & 0.42 & 0.80 \\
\hline $155 \mathrm{R}-1,47.0-48.0$ & 620.15 & 0.98 & 0.67 & 0.31 & 0.26 \\
\hline $161 \mathrm{R}-1,17.0-18.0$ & 638.15 & 1.39 & 0.66 & 0.73 & 0.13 \\
\hline $164 \mathrm{R}-2,67.0-72.0$ & 649.12 & 1.01 & 0.64 & 0.37 & 0.06 \\
\hline
\end{tabular}


Table T11. Summary of sediment mineralogy from X-ray diffraction, Hole M0028A. (See table notes.)

\begin{tabular}{lrr}
\hline \multicolumn{1}{c}{ Intensity ratios } & Mean & Max \\
\hline Clay minerals & 15.0 & 64.1 \\
Kaolinite & 8.9 & 53.9 \\
Micas and Illite & 2.0 & 4.2 \\
Mixed layered clays & 3.0 & 4.4 \\
Smectite & 1.1 & 1.5 \\
Carbonates & 4.7 & 18.1 \\
Mg-rich calcite & 0.7 & 4.4 \\
Calcite & 1.2 & 4.4 \\
Siderite & 0.6 & 1.7 \\
Rhodochrosite & 0.9 & 4.9 \\
Dolomite and ankerite & 0.2 & 0.4 \\
Aragonite & 1.1 & 2.3 \\
Detrital minerals & 72.8 & 116.2 \\
Quartz & 63.8 & 81.0 \\
Plagioclase & 1.5 & 2.7 \\
Chlorite & 3.1 & 19.4 \\
K-feldspar & 1.2 & 2.4 \\
Pyroxene & 1.4 & 4.2 \\
Zeolites & 0.7 & 2.2 \\
Gibbsite & 0.5 & 2.6 \\
Epidote & 0.5 & 1.3 \\
Amphibole & 0.2 & 0.4 \\
Authigenic minerals & 7.5 & 24.0 \\
Pyrite & 2.1 & 4.4 \\
Glauconite & 1.4 & 3.8 \\
Goethite & 1.9 & 8.4 \\
Apatite & 0.8 & 2.7 \\
Magnetite & 0.9 & 4.0 \\
Barite & 0.4 & 0.7 \\
Total: & 100.0 & 222.3 \\
\hline
\end{tabular}

Notes: The original sum for the mean of all measured peak intensity ratios was $92.3 \%$. After elimination of all clay minerals (4.55-4.4 $\AA$, $3.6 \%$ ), gypsum $(0.8 \%)$, and halite $(0.9 \%)$, this sum became $86.9 \%$, which was then renormalized to $100 \%$ above. 


\begin{tabular}{|c|c|c|c|c|c|c|c|c|c|c|c|c|c|c|}
\hline $\begin{array}{l}\text { Depth } \\
\text { (mbsf) }\end{array}$ & Top & Bottom & $\begin{array}{c}\text { Total } \\
\text { gamma ray }\end{array}$ & $\mathrm{Th} / \mathrm{K}$ & u & Th & Conductivity & Sonic & $v_{\mathrm{p}}$ & Density & Resistivity & $\begin{array}{c}\text { Magnetic } \\
\text { susceptibility }\end{array}$ & Surface correspondence & Comments/Interpretation \\
\hline 217.0 & - & - & Increase & & & & & & & & & & Unit $\mathrm{I} / \mathrm{ll}$ boundary $6 \mathrm{~m}$ below & Located where no core recovery \\
\hline 238.0 & - & - & & & & & & & & Increase & & Increase & $\mathrm{m} 4.1$ surface $1 \mathrm{~m}$ above & \\
\hline 244.0 & - & - & & & & & & & Decrease & & & Decrease & & \\
\hline \multirow[t]{3}{*}{246.0} & - & - & & & & & Low & & & Increase & & & $\mathrm{m} 4.5 \mathrm{TS}$ with erosional surface $1.8 \mathrm{~m}$ below & \\
\hline & 254.5 & 255 & Decrease & & & & & & Increase & Increase & & Small peak & FS & \\
\hline & 269.5 & 271 & Increase & & & & & & & & & & m5 within interval & \\
\hline 291.5 & - & - & Hole & & & & & & Peak & Peak & & & No corresponding surface & \\
\hline 319.0 & 321 & - & & Small peak & & & High & & & & & Small peak & FS & \\
\hline 325.0 & - & - & Decrease & & & & & & & Density & & & Impedance contrast picked $1.5 \mathrm{~m}$ above & Cemented layers \\
\hline 350.0 & - & - & & & & & & & & Small low & & Decrease & Lithological change & \\
\hline 390.0 & - & - & & & & & & & Increase & Increase & & & No corresponding surface & Cemented layers \\
\hline 391.0 & - & - & Decrease & & & & & & & & & & Subunit IIIA/B boundary & Cemented layers \\
\hline \multirow{3}{*}{475.0} & - & - & Increase & & & & Decrease & & & & & & Subunit IIIB/C boundary & Acoustic amplitude increase \\
\hline & - & - & Increase & & & & Decrease & & Increase & & & & Subunit IIIC/D boundary & \\
\hline & 497 & 498 & Increase & & & & Decrease & & Increase & Increase & & & $\mathrm{m} 5.4$ surface $2 \mathrm{~m}$ above & \\
\hline 511.5 & - & - & & Peak & & & & & Small low & & & & SB $0.8 \mathrm{~m}$ below, $\mathrm{m} 5.45$ surface $6 \mathrm{~m}$ above & \\
\hline 518.0 & - & - & Increase & & & & & & Increase & & & Increase & $\mathrm{m} 5.47$ surface $1.6 \mathrm{~m}$ below & Petrophysics boundary picked at start of changes, stratigraphic surface at peak \\
\hline 526.0 & - & - & & & & & Hole & & Hole & Increase & & & $\mathrm{m} 5.47$ surface $6 \mathrm{~m}$ above & \\
\hline 540.0 & - & - & & & & & & & Increase & Density & & & No corresponding surface & Cemented layers \\
\hline 545.5 & - & - & Decrease & & Decrease & & & & & & & & In middle of $\mathrm{m} 5.6$ surface error bars & \\
\hline 555.0 & - & - & & & & & Hole & & Peak & Peak & & & No corresponding surface & Cemented layers \\
\hline 565.0 & - & - & & & & & & & Peak & Peak & & & No corresponding surface & Cemented layers \\
\hline 580.5 & - & - & & & & & & & Increase & Increase & & & No corresponding surface & Grain size increase \\
\hline 592.0 & - & - & & & & & Hole & & & Peak & & & $\mathrm{m} 5.7$ surface & Cemented layers \\
\hline 611.0 & - & - & Increase & & & & Decrease & & Increase & Increase & & & Unit $V / V I$ boundary and $S B$ & \\
\hline 620.0 & - & - & & & & & & & & & & Start of increase & Lithological change & Cemented layer $2 \mathrm{~m}$ below, porosity low \\
\hline \multirow{3}{*}{$\begin{array}{l}635.0 \\
663.8\end{array}$} & - & - & & & & & & & & Hole & & & No corresponding surface & Cemented layer $2 \mathrm{~m}$ below, porosity high \\
\hline & 660 & 661 & Increase & Decrease & & & & & Hole & Decrease & & & $\mathrm{m} 5.8$ surface $3 \mathrm{~m}$ below & Cemented layers \\
\hline & - & - & & & Peak & & & & & & & & $\begin{array}{c}\mathrm{m} 5.8 \text { surface }<1 \mathrm{~m} \text { above, Unit VI/VII } \\
\text { boundary }\end{array}$ & Cemented layers \\
\hline
\end{tabular}

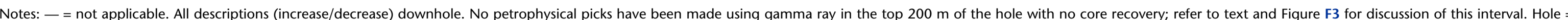
sharp confined low in measurement, peak = sharp confined high in measurement. $\mathrm{FS}=$ flooding surface, $\mathrm{TS}=$ transgressive surface, $\mathrm{SB}=$ surface boundary. 
Table T13. Preliminary magnetostratigraphic age-depth tie points, Hole M0028A. (See table notes.)

\begin{tabular}{cllcc}
\hline $\begin{array}{c}\text { Depth } \\
\text { (mbsf) }\end{array}$ & \multicolumn{1}{c}{$\begin{array}{c}\text { Interpretation } \\
\text { A }\end{array}$} & $\begin{array}{c}\text { Age } \\
(\mathrm{Ma})\end{array}$ & $\begin{array}{c}\text { Interpretation } \\
\text { B }\end{array}$ & $\begin{array}{c}\text { Age } \\
(\mathrm{Ma})\end{array}$ \\
\hline $226.53-226.23$ & C5AAr-C5AAn & 13.139 & C5ABr-C5ABn & 13.510 \\
$242.59-242.30$ & C5ACn-C5ABr & 13.703 & C5ADn-C5ACr & 14.178 \\
$617.02-616.52$ & C6An.1r-C6An.1n & 20.725 & - & - \\
$622.90-622.65$ & C6An.2n-C6An.1r & 20.996 & - & - \\
$656.34-655.92$ & C6Ar-C6An.2n & 21.32 & - & - \\
$666.41-665.91$ & C6AAn-C6Ar & 21.768 & - & - \\
\hline
\end{tabular}

Notes: All ages according to Cande and Kent (1995). $-=$ no alternative interpretation. 
Table T14. Correlations of seismic sequence boundaries to core surfaces, Hole M0028A. (See table notes.)

\begin{tabular}{|c|c|c|c|c|c|c|c|c|c|c|}
\hline \multirow{2}{*}{$\begin{array}{l}\text { Predicted age } \\
\text { BKSA95 (Ma) }\end{array}$} & \multirow{2}{*}{$\begin{array}{c}\text { Seismic } \\
\text { sequence } \\
\text { boundaries }\end{array}$} & \multirow{2}{*}{$\begin{array}{c}\text { Seismic } \\
\text { picks } \\
(\mathrm{ms})\end{array}$} & \multicolumn{2}{|c|}{ Predicted depth (mbsf) } & \multirow{2}{*}{$\begin{array}{l}\text { Predicted } \\
\text { core }\end{array}$} & \multirow{2}{*}{$\begin{array}{c}\text { Actual depth } \\
\text { (mbsf) }\end{array}$} & \multirow{2}{*}{$\begin{array}{l}\text { Actual core, section, } \\
\text { interval (cm) }\end{array}$} & \multirow[b]{2}{*}{ Remarks } & \multicolumn{2}{|c|}{$\begin{array}{l}\text { Age derived from } \\
\text { age-depth plot (Ma) }\end{array}$} \\
\hline & & & Monteverde & $\begin{array}{l}\text { Selmisc and velocity } \\
\text { function core }\end{array}$ & & & & & & \\
\hline \multirow{5}{*}{$? 14.1$} & & & & & 313-M0028A- & & 313-M0028A- & & & \\
\hline & $\begin{array}{l}\mathrm{m} 4 \\
\mathrm{~m} 4.1\end{array}$ & $\begin{array}{l}215 \\
284\end{array}$ & $\begin{array}{l}174 \\
234\end{array}$ & $\begin{array}{c}171 \\
231-232\end{array}$ & $\begin{array}{l}\text { Not cored } \\
5 \mathrm{R}\end{array}$ & $\underset{236.1 / 236.6 / 236.3}{N}$ & & & & \\
\hline & NR & NR & NR & $\mathrm{NR}$ & NR & 244.16 & $\begin{array}{l}6 \mathrm{R}-1,1,1,1 \\
8 \mathrm{R}-2,103\end{array}$ & FS clays/shoreface; minor density increase & & \\
\hline & m4.5 & 295 & 244 & 241-243 & 8 & 246.04 & $9 \mathrm{R}-1,135$ & TS base shells; ? due to disturbance; start density maximum & $13.8-14.0$ & $12.8-14.8$ \\
\hline & $\mathrm{m} 4.5$ & NR & NR & NR & NR & 247.78 & $100-1,5$ & SB minor erosional surface; sand/clay SOT/off; impedance contrast & & \\
\hline & $\begin{array}{l}\mathrm{NR} \\
\mathrm{m} 5\end{array}$ & $\begin{array}{l}\text { NR } \\
317\end{array}$ & 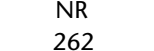 & $\begin{array}{c}\text { NR } \\
258-263\end{array}$ & $\begin{array}{l}\text { NR } \\
16\end{array}$ & $\begin{array}{l}264.03 \\
268-271\end{array}$ & $\begin{array}{l}12 \mathrm{R}-1,19.5 \mathrm{~cm} \\
\text { Not cored }\end{array}$ & $\begin{array}{l}\text { FS Cl clyyey sitt vorer sands, moderate impedance contrast } \\
\text { SB; base log sands; } 271 \text { mod }\end{array}$ & & \\
\hline \multirow{4}{*}{$\begin{array}{l}17.8-15.8 \\
16.0-16.5\end{array}$} & $\begin{array}{l}\mathrm{ms} \\
\mathrm{m} 5.2\end{array}$ & 375 & 316 & 310-313 & $34 \mathrm{R}-35 \mathrm{R}$ & ${ }_{310.92}^{20871}$ & $34 \mathrm{R}-2,95$ & $\begin{array}{l}\mathrm{T} \text {; ; sharp erosional surface; muds/shelly sands; thin impe } \\
\mathrm{T}\end{array}$ & 16.0 & 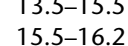 \\
\hline & & $\mathrm{NR}$ & NR & $\mathrm{NR}$ & NR & & $35 \mathrm{R}-2,48$ & SB erosional contact with fine-medium sand ov & & \\
\hline & $\mathrm{NR}$ & NR & NR & NR & NR & 320.62 & 37R-1, 143 & FS clay/very fine sand; heavily burrowed & & \\
\hline & & NR & NR & NR & NR & 323.5 & $38 \mathrm{R}-2,33$ & Top glauconitic sandstones and gravels; impedance contrast yields strong intra-sequence reflection & & \\
\hline \multirow[t]{3}{*}{17.2} & $\mathrm{~m} 5.3$ & 409 & 347 & $\stackrel{340-348}{3 R}$ & $51-52 \mathrm{R}$ & $\begin{array}{l}335.48-342.44 \\
349 \\
342-35.59\end{array}$ & $\begin{array}{l}\text { Not cored } \\
\text { Between } 53 \mathrm{~B} \text { and } 54 \mathrm{R}\end{array}$ & $\begin{array}{l}\text { SB disturbed; gravely glass/shelly glauconitic sandstone } \\
\text { Clauconitic sandstonel/auratz ands }\end{array}$ & $\sim 16.6$ & 16.4-16.8 \\
\hline & m5.32 & $\begin{array}{l}\mathrm{NR} \\
\mathrm{NR}\end{array}$ & $\begin{array}{l}\text { NR } \\
\text { NR }\end{array}$ & $\begin{array}{c}\text { NR } \\
370-375\end{array}$ & $\begin{array}{l}\mathrm{NR} \\
\mathrm{NR}\end{array}$ & $\underset{N R}{349.72-351.59}$ & $\begin{array}{l}\text { Between 53R and 54R } \\
\text { NR }\end{array}$ & $\begin{array}{l}\text { Glauconoitic sandstone/quartz sands } \\
\text { No expression }\end{array}$ & & \\
\hline & $\mathrm{m} 5.33$ & 458 & 39 & & & NR & & No expression & & \\
\hline & m5.4 & 565 & 49 & & 10 & & 105 & SB base thin sand be & T10 & $17.3-18.3$ \\
\hline \multirow{3}{*}{19.5} & $? \mathrm{~m}$ & 582 & & 10-517 & & 505.93 & & Clay, coring gap, gra & ?18.2 & $17.0-18.4$ \\
\hline & & & 514 & 7 & 110-112R & 508.36 & 109R-1, 82 & Base graded bed & & \\
\hline & ?m5.45 & 38. & 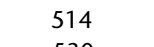 & 要 & 110 & 512.33 & 110R- & SB favored: base of sands/top of clay & & \\
\hline & & & & & & & & & ?18.3 & 17.0-18.4 \\
\hline \multirow{3}{*}{20.4} & $\begin{array}{l}m 5.6 \\
2 m 57\end{array}$ & 617 & 545 & $\begin{array}{l}540-550 \\
589-599\end{array}$ & 124-127R & $\begin{array}{l}544.55-546.47 \\
592.37\end{array}$ & $1265 / 278$ & SB coring gap & 318.6 & 18.6-19.6 \\
\hline & ?m5.7 & 662 & 595 & $\begin{array}{l}589-599 \\
58-599\end{array}$ & $\begin{array}{l}143-14 / \mathrm{R} \\
143-147 \mathrm{R}\end{array}$ & $600.3 / 604.42$ & 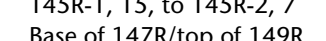 & 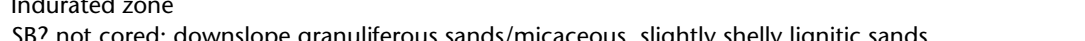 & & \\
\hline & $? \mathrm{~m} 5.7$ & 662 & 595 & $589-599$ & $143-147 \mathrm{R}$ & 60 & $152 \mathrm{R}-1,108$ & Major surface: medium sand, surface (SB or MFSS) & & \\
\hline 21.5-22.0 & $\mathrm{m} 5.8$ & 721 & 657 & 649-651 & 164-165R & 662.98 & 169R-1, , & SB major surface; glauconite sand over siltstone; density contrast starts 660 at increase glauconite & 21.3 & $20.0-21.5$ \\
\hline
\end{tabular}

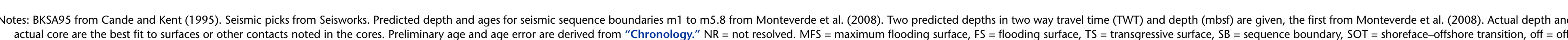
shore. 